\title{
THE TRANSGENDER EXIGENCY
}

DEFINING SEX AND GENDER IN THE 2IST CENTURY 
“Above all, this book provides a very basic service to our society's vexed debates about transgender: it gives the empiricals. I have not come across a book that lays out the relevant factual background better than this one does. Through careful and detailed discussion of the particularities involved, Schiappa develops a pragmatic, moderate, and sensible approach to the main issues, culminating in his very helpful proposal to apply four different levels of gatekeeping to transgender people in different kinds of context. This moderate and context-nuanced approach is a sensible corrective to the ideological extremism that all too often comes from both sides."

—Professor Sophie Grace Chappell, Open University

"Definitions matter: American, socialist, patriot, Trumpian ... and woman. Schiappa does not think it is obvious that the state should be involved in all defining, though clearly it should in some. His warm, scholarly, humane, and readable book brings the discussion of trans rights and responsibilities to a higher level. But perhaps more significantly, it raises, too, the level of the discussion about definition itself. The next time you reach for a definition to make an argument, think Schiappa, and pause. A long time. So you don't start throwing rocks."

—Deirdre N. McCloskey, Distinguished Professor of Economics, History, English, and Communication University of Illinois at Chicago 
$\because$ Taylor \& Francis

Taylor \& Francis Group

http://taylorandfrancis.com 


\section{THE TRANSGENDER EXIGENCY}

At no other point in human history have the definitions of "woman" and "man," "male" and "female," "masculine" and "feminine," been more contentious than now. This book advances a pragmatic approach to the act of defining that acknowledges the important ethical dimensions of our definitional practices.

Increased transgender rights and visibility has been met with increased opposition, controversy, and even violence. Who should have the power to define the meanings of sex and gender? What values and interests are advanced by competing definitions? Should an all-boys' college or high school allow transgender boys to apply? Should transgender women be allowed to use the women's bathroom? How has growing recognition of intersex conditions challenged our definitions of sex/gender? In this timely intervention, Edward Schiappa examines the key sites of debate including schools, bathrooms, the military, sports, prisons, and feminism, drawing attention to the political, practical, and ethical dimensions of the act of defining itself.

This is an important text for students and scholars in gender studies, philosophy, communication, and sociology.

Edward Schiappa is the John E. Burchard Professor of Humanities at the Massachusetts Institute of Technology. His work in rhetorical theory and media studies has been published in journals in Classics, Psychology, Philosophy, English, Law, and Communication Studies. He is the author of a number of books, including Defining Reality: Definitions and the Politics of Meaning and Beyond Representational Correctness: Rethinking Criticism of Popular Media. 
$\because$ Taylor \& Francis

Taylor \& Francis Group

http://taylorandfrancis.com 


\section{THE TRANSGENDER EXIGENCY}

\section{Defining Sex and Gender in the 21 st Century}

Edward Schiappa

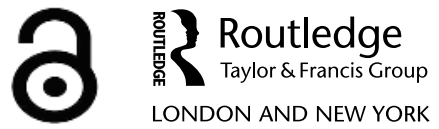


Cover image: Getty Images.

First published 2022

by Routledge

4 Park Square, Milton Park, Abingdon, Oxon OX14 4RN

and by Routledge

605 Third Avenue, New York, NY 10158

Routledge is an imprint of the Taylor E Francis Group, an informa business

(C) 2022 Edward Schiappa

The right of Edward Schiappa to be identified as author of this work has been asserted in accordance with sections 77 and 78 of the Copyright, Designs and Patents Act 1988.

The Open Access version of this book, available at www.taylorfrancis. com, has been made available under a Creative Commons AttributionNon Commercial-No Derivatives 4.0 license.

Trademark notice: Product or corporate names may be trademarks or registered trademarks, and are used only for identification and explanation without intent to infringe.

British Library Cataloguing-in-Publication Data

A catalogue record for this book is available from the British Library

Library of Congress Cataloging-in-Publication Data

Names: Schiappa, Edward, 1954- author.

Title: The transgender exigency : defining sex and gender in the 21st century / Edward Schiappa.

Description: Abingdon, Oxon ; New York, NY : Routledge, 2022. | Includes bibliographical references and index.

Identifiers: LCCN 2021043364 (print) | LC CN 2021043365 (ebook) | ISBN 9781032168364 (hbk) | ISBN 9781032168203 (pbk) | ISBN 9781003250494 (ebk) | ISBN 9781000538663 (adobe pdf) | ISBN 9781000538748 (epub)

Subjects: LCSH: Transgender people_Civil rights. Transgender people-Legal status, laws, etc. | Sex-History-21st century. | Gender identity-History-21st century.

Classification: LCC HQ77.9 .S37 2022 (print) | LCC HQ77.9 (ebook) |

DDC 306.76/8 — dc23/eng/20211013

LC record available at https://lccn.loc.gov/2021043364

LC ebook record available at https://lccn.loc.gov/2021043365

ISBN: 978-1-032-16836-4 (hbk)

ISBN: 978-1-032-16820-3 (pbk)

ISBN: 978-1-003-25049-4 (ebk)

DOI: $10.4324 / 9781003250494$

Typeset in Bembo

by Apex CoVantage, LLC 


\section{CONTENTS}

List of figures ix

Acknowledgments $x$

Preface: Stronger together xii

Introduction 1

\section{PART I}

Definitions and the Transgender Exigency

1 The role of regulatory definitions 9

2 A brief history of defining sex and gender 15

3 The Transgender Exigency 35

PART II

Definitional contexts $\quad 51$

4 Single-sex schools $\quad 55$

$\begin{array}{lll}5 \text { Bathrooms } & 73\end{array}$

6 The military $\quad 87$ 
viii Contents

$\begin{array}{llr}7 \text { Sports } & 107\end{array}$

8 Prisons 131

9 Feminisms 151

PART III

What now?

10 A pragmatic approach to defining sex/gender

References

191

Index

235 


\section{FIGURES}

0.1 The Transgender Umbrella 4

5.1 Tweet by Michael Hughes, used with permission 72

8.1 UK Evidence of Living in the Gender with which the Offender Identifies 


\section{ACKNOWLEDGMENTS}

I began to write this book in January 2020 and soon after went into isolation with my spouse to try to outlast the pandemic. All books depend on the support of family, colleagues, and helpful librarians, but such support was especially crucial in these challenging times.

Special thanks to an eclectic group friends and colleagues-whose responses varied from enthusiastic agreement to vigorous critique - who read the entire manuscript or large portions of it, including John Jackson, Minjie Li, John Nordin, Justin Reich, Nicholas-Brie Guarriello, Alex Byrne, Doriane Coleman, Karl Surkan, and the reviewers for Routledge. Thanks also to the anonymous reviewer who pushed me to reflect further on my subject position and to reckon as best I could with the principle "nothing about us without us."

I could not have finished the book in a timely manner without the aid of a terrific team of undergraduate research assistants. From Wellesley College I am indebted to Aliza Amin, Jessica Anthony, Eva Chang, Julia Cho, Maria Galebach, Isabella Garcia, Emily Huang, Alex Hussey, Ella Matticks, Grace (Yongxi) Pan, Yilia Qu, Gunjan Singh, Si Yan "Carrie" Wang, Sophie Wang, Sam Wolstenholme-Britt, and Chen Xu. From MIT I wish to thank Titash Biswas, Theresa Caso-McHugh, Sophie Cohen, Qiuyue Liu, Kathryn Mohr, Diane Mwizerwa, Harley Ride, Aiyedun Uzamere, and Nina Wang.

Each chapter incurred specific debts. For the chapter on schools, I want to acknowledge those willing to be interviewed, including Alexander Abbott, Paige Flanagan, Carrie Friend, Adam Howard, Justin Killian, Ninotska Love, Rick Melvoin, Eric Di Michele, Dawson Nash, Quinn Sipes, Larry Stimpert, Guy Terrell, and Michael Utzinger. The bathrooms chapter owes a special debt to Terry Kogan and to Kristie Seelman. The military chapter benefited from talking with Riley Dosh, Lt. General Robert Caslen (Ret.), Lt. General Michelle D. Johnson (Ret.), Dr. Aaron Belkin, and former Secretary of the Army Eric Fanning. I thank David 
Handelsman, Joanna Harper, Lindsay Pieper, and Eric Vilain for their assistance with the sports chapter. The prison chapter was aided by Jackie White Hughto, Valerie Jenness, and Jennifer Macy. And the chapter on feminisms received helpful feedback from Ásta, Sophie Grace Chappell, Sally Haslanger, Jennifer Saul, and Naomi Scheman.

Thanks also to the following for their assistance on specific aspects of the project: T.J. Billard, Katharine Dunn, Marla Eisenberg, Andrew R. Flores, Marshall Ganz, Anil Gupta, Hahrie Han, Rebecca Helm, Austin H. Johnson, John T. Kirby, Bonnie E. Litowitz, Tove Lundberg, Gabriella Lukacs, Deirdre McCloskey, Laura Miller, Patrick R. Miller, Hiromu Nagahara, Bruno Perreau, Paul Roquet, Quayshawn Spencer, Jami K. Taylor, and Stefan Th. Gries.

Gratitude and all my love to my partner Elizabeth Murray and daughters Lauren Murray and Jacqueline Schiappa.

The open access edition of this work was made possible by generous funding from the MIT libraries. 


\section{PREFACE: STRONGER TOGETHER}

This book brings together a long-time scholarly interest in definitions and the political work of categories with an on-going commitment to social justice. Especially in the wake of the calamitous Trump presidency, ${ }^{1}$ I felt it was high time to add the $\mathrm{T}$ to three decades of (intermittent) research and advocacy concerned with LGB issues. ${ }^{2}$

It is important to make clear that I do not pretend to speak for the transgender community. It was more than three decades ago that Linda Martin Alcoff described what she calls "The Problem of Speaking for Others" (1991). Alcoff's analysis remains a powerful scholarly intervention that reminds us of the inescapability and salience of our own position - in my case, a privileged white man. I am aware that I speak from a position of privilege, even if I cannot claim to be 100\% aware of all the ways my training and previous research limits my field of vision. Still, as Alcoff notes, if I were to remain silent and "retreat" from these issues, I would fail my political responsibility to speak out against oppression, a responsibility "incurred by the very fact of my privilege" $(1991,8)$.

I have read and consulted with many trans people throughout the research and writing of this book. In my concluding chapter, I discuss the importance of the theme "Nothing About Us Without Us" and involving trans people in efforts to resolve sex/gender definitional controversies. There is, of course, great variability in the viewpoints held by transgender people. Two noteworthy examples must suffice to make the point: Some transgender people describe their decision to transition as a matter of freedom and choice, and reject the "woman trapped in a man's body" (or vice versa) narrative (McCloskey 2007; Bettcher 2013, 2014), while others insist there was no choice at all and embrace some version of the "wrong body" narrative. ${ }^{3}$ Recently, some trans people support J.K. Rowling's and so-called "gender critical" scholars' right to speak (McCloskey 2020), while others actively work to "cancel" or "de-platform" such speakers (see Chapter 9). ${ }^{4}$ In any case: 
Though we must avoid essentializing a "transgender perspective," I acknowledge and respect the fact that experiencing life as transgender is profoundly different than my own life experience.

Thus, I offer this book as a contribution to a conversation, speaking with my cis and trans brothers and sisters. I strongly urge readers to take up related policyfocused work by such trans authors as Paisley Currah (2021, 2022), Heath Fogg Davis (2017), Dean Spade (2015), and Ann Travers (2018), as well as the important historical work by Susan Stryker (2017) and the extensive philosophical work by Talia Bettcher (see 2022, among others). It is important that we all listen to each other, and for us to all recognize the truth of the well-known saying that we are stronger together than apart. ${ }^{5}$

\section{Notes}

1 Paisley Curah aptly describes the Trump administration's efforts to reverse Obama-era policies on sex reclassification as violence that "is both epistemic and has real material effects" (in Fischel 2019, 97).

2 See Schiappa (2021) for a brief account of the origins of Schiappa (2008, 2012a, 2012b, 2019) and Schiappa, Gregg, and Hewes (2005, 2006).

3 Some trans activists and scholars argue that the "wrong body" narrative was imposed by the medical profession, while others feel that the it is a useful way to express their felt experience. As Jack Halberstam put it: "The term 'wrong body' was used often in the 1980s, even becoming the name of a BBC show about transsexuality, and offensive as the term might sound now, it at least harbored an explanation for how cross-gendered people might experience embodiment: I, at least, felt as if I was in the wrong body, and there seemed to be no way out" (2018, 1-2). Ulrica Engdahl provides a succinct summary of the critiques of the essentializing aspects of the "wrong body" narrative, while pointing the way to a theoretical account that avoids essentializing a gender binary while acknowledging the lived experience of some trans people: "Wrong body as lived body expresses the situatedness of trans body experience as wrong, hence relativizing it. Wrong body as trans embodiment expresses subjectively felt bodily meaning interacting with cultural interpretations of bodies, where the subjective and the cultural are not always congruent. This way the gender binary is replaced with gender variance as a frame for understanding gender, offering a more fluid understanding of the trans body" $(2014,269)$.

4 As Roger Brubaker puts it, "[W] hat does it mean to 'think with trans'? The sheer variety of transgender experience precludes a univocal answer" $(2016,10)$.

5 Taylor, Lewis, and Haider-Markel document how important it has been for the transgender rights movement to join itself with the "gay rights cause, creating a broader LGBT collective identity" (2018, 35). Van Dyke and Amos (2017) provide a recent summary of the considerable scholarly literature documenting how central coalition building with allies is for social movement success. See also Baumgartner et al. (2009) and Van Dyke and McCammon (2010). 
$\because$ Taylor \& Francis

Taylor \& Francis Group

http://taylorandfrancis.com 


\section{INTRODUCTION}

The argument of this book is that increased visibility and interest in transgender issues and politics have contributed to a definitional rupture with regard to sex and gender. By definitional rupture I mean a dispute or series of disputes that cannot be resolved simply or neutrally by reference to a dictionary or authoritative source, but only by considering the process of defining itself - how and why do we define words? Who should have the power to define? What values and interests are advanced by competing definitions?

Though cultural understandings of what it means to be a woman or a man have gone through times of reconsideration and debate, it is arguably the case that at no other point in recent history have the definitions of "woman" and "man," "male" and "female," "masculine" and "feminine," been more up for grabs than the present. To resolve these definitional controversies, we need to consider carefully the political, practical, and ethical dimensions of the act of defining.

Despite the fact that transgender history is far from new (Meyerowitz 2002; Stryker 2017), the visibility and salience of transgender issues has increased dramatically in the 21st century (Billard 2019, 165). The result is a clash over how one defines sex and gender. On one end of the spectrum, those who can be described as biological determinists argue that biological sex determines one's gender and thus both are evident at birth or earlier, and that one's medical designation should determine a host of legal and societal constraints based on one's assigned sex. On the other end of the spectrum, those who might be called autonomous nominalists or advocates of "self-identification" or "first-person authority" contend that gender identity is independent of biology and is a purely personal decision and, as such, should be respected and never regulated or discriminated against. ${ }^{2}$

These two opposing ways to define sex/gender have become highly politicized, first with the Trump administration and now with conservative state legislatures pushing a biological determinist approach wherever possible, while the Biden 
administration, the Democratic-controlled House of Representatives, and more liberal state legislatures have championed self-identification.

Though I have simplified the extreme positions, it is worth noting that advocates on either end of the spectrum might invoke the phrase "a boy is a boy" or "a girl is a girl." The biological determinist means that biology is destiny and thus immutable; whereas the nominalist is advocating that we respect a person's self-identification and not qualify it, for example, with the "trans" prefix. That people with such disparate starting points would make similar pronouncements while meaning very different things suggests a definitional rupture that cannot be resolved simply or neutrally but only by considering the process of defining itself.

If asked how I think sex and gender should be defined, my answer is that it depends on the context in which the question is posed. My goal in this book is not to offer a single, definitive answer, but rather to advocate a definitional process that takes seriously the political, practical, and ethical dimensions of the act of defining. In the final chapter, I describe the need for purpose-oriented definitions, and offer "levels of scrutiny" that are adapted from different levels of scrutiny found in U.S. constitutional law, in order to unpack the idea of context-specific standards or criteria for definitions of sex/gender. To preview the book's overall argument: The purposes of definition, and the values and interests that competing definitions or definitional criteria advance, vary considerably by context. While self-identification or first-person authority should be presumptive whenever and wherever possible, I conclude that there are rare contexts in which something more than a potentially ephemeral self-identification is justifiable. As will become clear, the further that definitional criteria move away from self-identification (such as requiring gender reassignment surgery), the more compelling the justification for segregation by sex needs to be.

\section{Defining "transgender"}

"Cisgender" refers to people whose sense of gender corresponds to their assigned sex at birth. "Transgender" describes people whose sense of gender does not correspond to their assigned sex at birth, and they wish to transition socially and sometimes medically to live and express their gender. ${ }^{3}$ As the National Center for Transgender Equality notes, "Gender expression is how a person presents their gender on the outside, often through behavior, clothing, hairstyle, voice or body characteristics" (2016b; see also Parsa \& Katz-Wise 2021).

We learn the meaning of words that denote categories by seeing or hearing other language-users (initially, parents and caregivers) demonstrate how to use the word with respect to clear examples, which can be described as prototypical exemplars. Thus, most people learn the word "transgender" in reference to people who have both socially and medically transitioned, such as Caitlyn Jenner, Renée Richards, or Chaz Bono. Social transitioning typically includes a change of name, pronouns, clothing, and hairstyle. Medical transitioning can include hormone treatments and 
surgery. In prototypical cases, the decision to transition is a response to a strongly felt discomfort with one's assigned gender, known as gender dysphoria. As we will see, some regulatory definitions of men and women require a diagnosis of gender dysphoria as a necessary attribute for a transgender person to "count" as a woman or man in a particular context (such as the U.S. military).

For the purposes of this book, I focus on the prototypical understanding of transgender as someone who a) experienced gender dysphoria and b) transitioned socially and often medically. That focus certainly is not intended to deny the word to people who do not share both attributes, but rather to identify and illumine the issues facing transgender people who navigate very specific contexts that have been segregated by sex, such as single-sex schools, bathrooms, sports, and prisons.

The transgender phenomenon is related but conceptually distinct from the larger cultural phenomenon of gender variance. Some people identify as gender nonconformist, genderqueer, nonbinary, or other terms that challenge the traditional binary language of gender. For the most part, I will not be focusing on gender variance. Again, this is not meant in any way to marginalize the experience of nonbinary people or gender nonconformists, but is designed to maintain focus specifically on the regulatory definitions based on the binary of male and female.

An example of how the vocabulary of describing gender is, itself, fluid is how the actor and comedian Eddie Izzard has self-identified over the years. As a standup comedian, Izzard often wore women's clothing and self-described (at the time) as a transvestite, straight, and (tongue in cheek) as a "male lesbian." In the Emmywinning show, Dress to Kill, Izzard talks about the category of transvestites to point out that it could include people ranging from "weirdo" transvestites to "executive" transvestites, and as a category distinct from drag queens (2002). Research I conducted with colleagues Peter Gregg and Dean Hewes found that watching Dress to Kill not only helped to educate viewers about the category of transvestites but also reduced negative attitudes held toward the group (Schiappa, Gregg, \& Hewes 2005).

Since that time, Izzard has self-identified as transgender (Ruby 2016). Izzard and others embrace what has been depicted as the Transgender Umbrella ${ }^{4}$ that subsumes a wide variety of categories including "any individual who crosses over or challenges their society's traditional gender roles and/or expressions" (Mays \& Hill 2014).

Initially, the labels "nonbinary" or "gender nonconformist" would be more precise (from my standpoint), since Izzard said "I identify somewhat boy-ish and somewhat girl-ish. I identify both but I fancy women" (Ruby 2016). More recently, however, Izzard has stated that she prefers "she/hers" pronouns and "at the moment, Izzard is self-identifying as a trans woman" (Hattenstone 2021). To be clear, Eddie Izzard can self-identify any way Eddie Izzard wants to self-identify. I make a distinction between transgender and nonbinary because it matters for how regulatory definitions function in sex-segregated contexts. Thus, when I use the word "transgender" in this book I am using it in the more limited, prototypical sense stipulated earlier. 


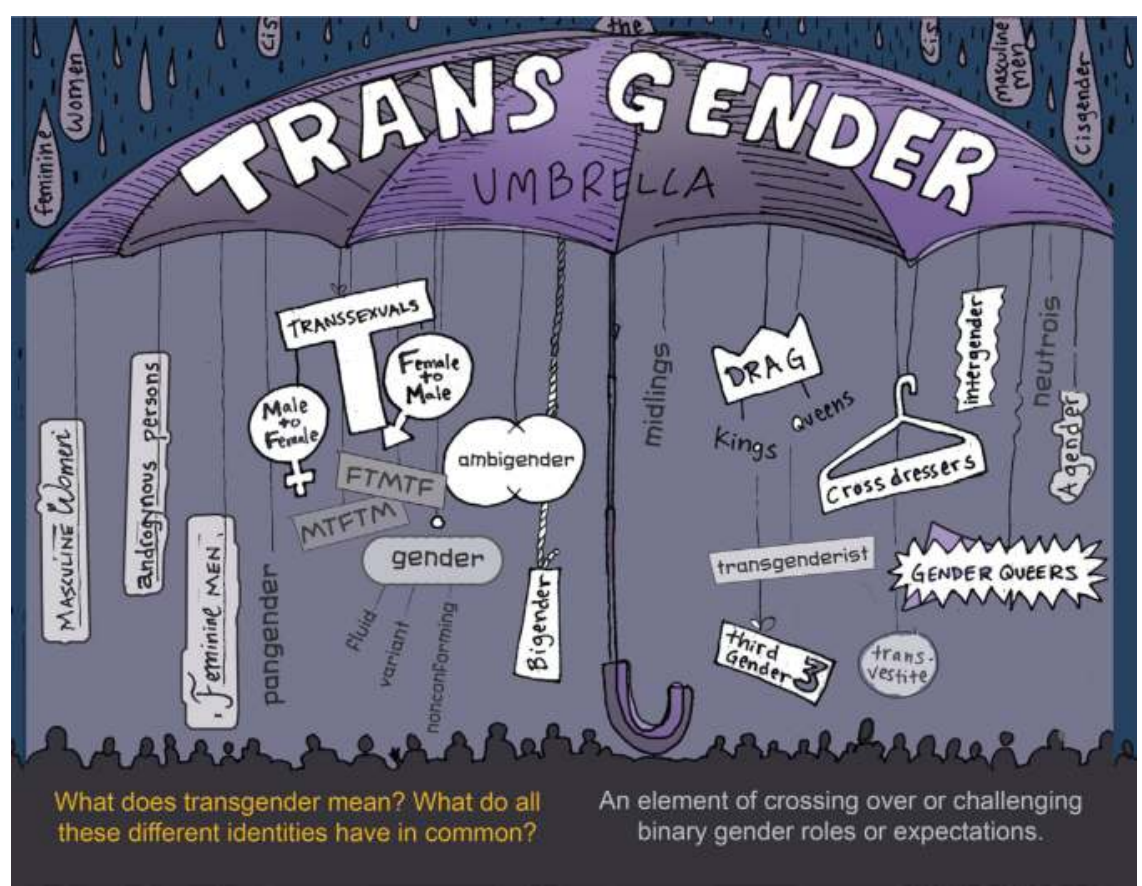

FIGURE 0.1 The Transgender Umbrella

Source: Graphic courtesy of the GENDER book (thegenderbook.com)

The objective of this book is a narrow one- to raise the question of how regulatory definitions of sex/gender should be thought about at a time I describe as the Transgender Exigency. There are other transgender issues that are important but go beyond the scope of this book, such as "At what age should children be able to make decisions about medical transitioning?" I set aside this particular question in part to keep the current project manageable, and in part because there are questions involving developmental psychology that I do not feel confident about handling. ${ }^{5}$ I also do not address the issues of "desistance" or "detransitioning"-when a person who has begun or even completed social and medical transitioning to a different gender and later changes their mind. Important issues, to be sure, but for now I want to maintain a specific focus on regulatory definitions.

In Chapter 3, I recount some of the awful statistics of how transgender people in the United States are frequently treated. As a nation, we need to do better. It is my hope that this book can contribute to the ongoing national dialogue to articulate and enhance the rights of transgender people.

\section{Notes}

1 Academic colleagues in philosophy tell me that my work here bears a relationship to work described as conceptual ethics and conceptual engineering. I agree that there is an affinity, 
but must set aside for another day the task of integrating the growing literature in that area with my previous and current work on definitional practices (Schiappa 2003). See: Burgess, Cappelen, and Plunkett (2020), Cappelen (2018), and Cull (2020).

2 Brubaker describes the two approaches as essentialist versus voluntarist (2016).

3 In Transgender: A Reference Handbook, Aaron Devor and Ardel Haefele-Thomas stipulate that "Transgender or trans are both umbrella terms used to describe a range of people who share the feature of not feeling that the sex and gender assignments made for them at birth were correct" $(2019,8)$. See also Rawson and Williams (2014).

4 There are a number of graphic representations of the Transgender Umbrella, the earliest of which can be found as Appendix E to the San Francisco Human Rights Commission's Investigation Into Discrimination Against Transgendered People (Green 1994, 68).

5 For a thoughtful history of transgender children, see Gill-Peterson (2018). Also, though I do not write here about age-related issues of transition, it is clear that legislation such as that passed by the Arkansas legislature to ban any and all medical treatment for those under the age of 18 is not supported by sound medical science, as noted by the American Medical Association (2021). 
$\because$ Taylor \& Francis

Taylor \& Francis Group

http://taylorandfrancis.com 


\section{PART I}

\section{Definitions and the \\ Transgender Exigency}


$\because$ Taylor \& Francis

Taylor \& Francis Group

http://taylorandfrancis.com 


\section{THE ROLE OF REGULATORY DEFINITIONS}

Think about the word “woman.” What does it mean? In the Merriam-Webster Dictionary the first definition listed for "woman" is "An adult female person." While this is a perfectly reasonable definition, the point I want to make initially is that if English is your first language, it is highly unlikely that you learned how to use the word "woman" by looking up its dictionary definition. More likely, you have no memory of learning the word, though obviously at some point you did.

Learning a word like "woman"- - a noun that refers to a category of peopletypically involves witnessing the word used by one's parents or acquaintances to refer to what are described as prototypical exemplars. That is, we learn categorydenoting words by seeing or hearing more experienced language-users employ the word with respect to clear examples. As we see or hear the word used to refer to examples, we acquire what are called "learned similarities" among them such that we can successfully generalize from those examples to use the word correctly. When we use the word incorrectly as a child, generally someone corrects us so we learn what does or does not count as a woman.

In fact, most of our vocabulary is learned without ever needing to refer to a dictionary. History illustrates the fact that languages can grow and flourish without collecting formal definitions into a dictionary. After all, the first dictionary of English was Cawdrey's Table Alphabetical in 1604, after William Shakespeare had written such masterpieces as Hamlet and Romeo and Juliet. Furthermore, scholars who study how children learn their first language document that formal dictionary definitions are rarely part of young children's language learning process. Learning to define a word, especially with the classic Aristotelian form ("An X is [a kind of] class name that has such-and-such attributes"), is an advanced linguistic skill developed through "time, practice, and exposure" (Gandía 2016, 4). ${ }^{1}$

Dictionary definitions represent the publisher's account of how words are most commonly used by a linguistic community. Dictionaries provide a descriptive 
account of definitions commonly referred to as lexical definitions. Such definitions obviously change to reflect new language use. In November 2020, for example, Oxford dictionaries updated their account of the word "woman" to correct outdated and sexist usage (Zdanowicz 2020).

A definitional "gap" occurs when someone hears or reads a word they don't recognize and need to look up the definition, such as someone hearing reference to a "shingle" haircut or hearing someone describe a political belief as "antediluvian." Such gaps are easy to fill under most circumstances. Even if several definitions of the same word are listed in a dictionary, an experienced language user normally can consider the context in which the word appears and correctly identify the relevant definition.

Even if children do not learn the meaning of most words by reference to a dictionary, dictionary definitions nonetheless serve a valuable archival function of identifying the most common uses of the words of a given language. They serve as a sort of collective memory to fill in the gap when we read or hear a word with which we are unfamiliar. Dictionaries are descriptive in the sense that they provide the predominant meaning of words, but also prescriptive in the sense that they convey what is taken as the "correct" usage and hence implies how we ought to use words.

Certain definitions describe a category of objects or actions that are considered important only or primarily within highly specific contexts to a particular group of language-users. Thus, in addition to conventional dictionaries, there are dictionaries that are designed for specialized language-users, such as legal dictionaries for the field of law and medical dictionaries for health care professionals. The larger and more complex a society becomes, the greater the need for such resources as specialized dictionaries to ensure that specialists talk the same talk, so to speak.

In this book, I am interested in a specific category of definitions that is a subset of what are known as stipulative definitions. A stipulative definition of a word does not depend on prior usage (though it may be informed by it); rather, a group of language-users agree that in a given context, the word $\mathrm{X}$ has a specified and agreed-upon meaning. For example, in poker the word "flush" is defined by Merriam-Webster as "a hand of playing cards all of the same suit," and the word has no necessary relationship to uses of the word "flush" in other contexts, such as plumbing.

The focus of this book is on what can be called regulatory definitions, understood as stipulative definitions that function to regulate some aspect of human behavior.

Regulatory definitions can be found in a wide array of contexts, from recreational games to laws governing matters of life and death. Learning to play a game typically involves learning the rules, and as games grow more sophisticated, such rules often require a set of specific definitions. The 2019 edition of Major League Baseball's Official Baseball Rules includes a section titled "Definitions of Terms" that includes all of the key words found in the rules, from "adjudged" to "wind-up position." Under normal circumstances, the umpires officiating a game have the power to decide what counts as a "balk," "spectator interference," and so forth. 
As I describe in an earlier book titled Defining Reality: Definitions and the Politics of Meaning, the legal definition of "death" changed in the 1970s and 1980s. Prior to the change, the standard definition used to declare a person "dead" was the cessation of cardio-respiratory activities. As technology changed such that patients could have their cardio-respiratory activities maintained with the aid of machines, the standard definition became one of the cessation of brain activities-so-called "brain death." The legal change was important because there were patients who could be considered alive under one definition but dead under another, and indeed there was a case brought against a doctor for murder for harvesting organs for transplant before the patient was considered dead by current law. Under normal circumstances, it is stipulated by law that an authorized medical professional and only an authorized medical professional has the power to pronounce a person dead.

The two examples I just described may seem quite different, but from the perspective of regulatory definitions, they share important elements. First, from the standpoint of linguistic behavior, regulatory definitions advance what I describe as "denotative conformity." That is, learning the definitional rule that "X counts as $\mathrm{Y}$ in context C"' improves the odds that we understand and describe aspects of our reality in a common manner. We want to be able to observe a phenomenon and agree that $\mathrm{X}$ is a $\mathrm{Y}$. We don't always achieve this goal, as anyone who has observed an argument between a baseball manager and an umpire can attest, but the goal of regulatory definitions is that we use language to describe a situation in a predictable and shared manner. Thus, one important goal of regulatory definitions is denotative conformity.

Second, we define words to serve one or more specific purpose and to promote certain values or interests for those involved. To play baseball, one has to know what counts as a balk, a walk, a run, etc., so the purpose of baseball's rules and definitions is to ensure all players know what is going on and how to play the game. In matters of life and death, there are serious consequences to declaring someone dead, from filing criminal charges of murder in some cases to being permitted to harvest organs to transplant in another. We need to know if a particular person counts as alive or dead to meet all sorts of needs and interests-religious, legal, medical, familial, etc.

Groups, organizations, or institutions have various motivations for advancing regulatory definitions. In games, a paramount value is fairness. And because we value life, it is understandable that we want to be very careful not to make mistakes in pronouncing someone dead prematurely. As we will see later in this book, the question of why an organization or institution is defining a word-what values and interests are being served by a particular definition-is crucial.

Third, regulatory definitions are formulated and authorized by recognized organizations or institutions, such as Major League Baseball or a state legislature. Outside of the purview of those organizations or institutions, the rules potentially have no authority. As this book proceeds, there will be ample examples of how one organization or legal jurisdiction may have one set of definitions (of "male" and "female," for example) that are different from another organization or legal 
jurisdiction. Regulatory definitions always depend on the backing of some sort of recognized entity that has been empowered to regulate a particular domain of human activity. Within the relevant contexts, specific individuals typically are empowered by the regulating entities to decide whether $\mathrm{X}$ counts as $\mathrm{Y}$ or not in any given instance, from an umpire declaring a balk to a medical professional declaring a patient dead.

I argue in this book that - in some contexts-definitions of female and male, women and men, should be treated as regulatory definitions crafted to further social and personal purposes, needs, and interests. They are formulated for the purpose of "determining gender" in specific contexts that are typically segregated by sex (Westbrook \& Schilt 2014). ${ }^{3}$ For the foreseeable future, it is neither necessary nor possible to devise a "one size fits all" definition that will meet all our needs at all times and in all contexts. This will strike some as counter-intuitive, because most of us grow up believing that one's identity as a man or woman is something stable, enduring, and "given" at birth. As we will see, as we move into the third decade of the 21 st century, the situation is more complicated than that.

We have many "social selves," as William James put it (1981, 294); some of those selves are recognized and acknowledged by institutions while others may be relevant only in informal social settings. The point with which I want to end this chapter is that the practice of having regulatory definitions that pertain to our personal identity is not new or unique to defining sex and gender. Each of us, as individuals, have many qualities and attributes that are used to define us in various social contexts. I am an educated, white, cisgender male well over the age of 21 who is a resident of the Commonwealth of Massachusetts. The attribute of my age is irrelevant in some contexts and highly salient in others. My age "entitles" me to certain privileges afforded by governmental agencies or institutions, such as the legal right to buy alcohol, to vote, and to obtain a driver's license. My eligibility for certain institutional benefits that are dependent on age, such as Social Security retirement and Medicare benefits, also is regulated by law. So, age is an identityattribute that is sometimes used to regulate aspects of human behavior and other times is irrelevant.

My status as a white cisgender male is supposed to be irrelevant to most institutional regulations, but I am not so naïve as to deny the unearned privileges historically associated with such an identity. Privilege, including unearned privilege, is negotiated socially, thus various social settings will result in differences in the opportunities or obstacles my social self will encounter. Since I present as a male, for example, my male-identity is accorded privilege in some settings (such as walking down the street at night relatively free of fear of abuse or assault) and disapproval or worse in others (such as in a battered women's shelter, a cloistered convent, or a women-only train car). ${ }^{4}$

One's sex and gender identity is irrelevant in some contexts and highly salient in others. The contexts in which sex and gender identity are subject to specific regulatory definitions adjudicated by specific institutions are relatively rare, but that does not make them unimportant. To understand the complexity of defining sex 
and gender in such contexts, the next chapter provides a brief review of how our understanding of them has changed in recent history.

\section{Notes}

1 I develop the point that children learn language without relying on dictionaries at length in Chapter 2 of Schiappa (2003). See also Litowtiz (1977) and Nippold (1988), Chapter 4.

2 After Searle (1995).

3 As Paisley Currah puts it, "The only thing we can say for sure about what sex means is what a particular state actor says it means" (in Fischel 2019, 100).

4 It should be noted that there are many more contexts that exclude women than exclude men, and that two of my examples of women-only spaces are the result of harassment and violence by men. See Chapter 9 . 


\section{Transgender voices}

"Gender, it turns out, is a language, and the more fluent I became in it, the more finding the words to express the messy humanity of myself and others like me became an urgent task -in part because it was becoming increasingly clear that, whether we asked for the job or not, trans people were going to play a key role in shaping the future of gender for everyone."

Thomas Page McBee (2021)

"I was born biologically female. I use testosterone to masculinize myself so I feel more like me. I had a legal sex change and now live as a male. All male pronouns. I am a transsexual and will never be biologically male. But I do live as a male. Simple."

Buck Angel (2019)

\section{"I can become a woman.}

I have always wanted to. I have learned by accident that I can . . .

I can be a woman, he said. And he wept in relief, as the car drove itself. I am a woman, he said. Yes!

She said again, I am a woman, and wept."

Deirdre Nansen McCloskey ${ }^{1}$

"I was not born in the wrong body. My body is perfect, and I love it. I see no contradiction between this and the fact that I take hormones to alter my appearance or that I am considering surgeries to change the shape of my body. When a cis woman receives surgery to change the shape of her breasts, we don't insist that she was born with the wrong breasts. When a child receives a surgery to snip a tied tongue, we don't find it necessary to say the child was born into a tongue that didn't match their 'real' tongue. The notion of being born into the 'wrong' body is, in my opinion, a convenient social lie that we have propounded to help the integration of transgender people into cisgender norms."

Naomi A. Jackson ${ }^{2}$ 


\section{2}

\section{A BRIEF HISTORY OF DEFINING SEX AND GENDER}

For the purposes of this book, our understanding of "sex" and "gender" in the United States can be described as having moved through three stages over the past seven decades. ${ }^{3}$ The first stage was dominated by a simple biological understanding of sex. Prior to the advent of psychologists investigating what we would now call gender dysphoria in the 1960s and feminist theory and research in the 1970s, the terms "sex" and "gender" were rarely in dialogue, and "gender" was scarcely used at all in English.

The online Merriam-Webster Dictionary's first definition of the noun "sex" is "either of the two major forms of individuals that occur in many species and that are distinguished respectively as female or male especially on the basis of their reproductive organs and structures." Prior to the past 50 years, the word "gender" was used in English primarily to refer to grammatical gender as found in various languages, such as Spanish, French, and German. "Gender" finds common etymological roots with words such as genre and genus, related to classification (Connell \& Pearse 2015,9). The most common gender divisions include masculine, feminine, and neuter. In most cases the gender assignment is arbitrary, and in fact a word such as "manliness" has feminine grammatical gender in some languages (Spanish hombría, masculinidad, German Männlichkeit, Polish męskość, among others).

Computer-assisted research by linguistics professor Stefan Th. Gries with law professors Brian Slocum and Lawrence Solan found that aside from references to grammatical gender, "in American English in the 1960s, gender was an extremely uncommon word" (Brief for Amici Curiae 2019, 23). Though the word "gender" certainly could be used correctly to refer to males and females, masculinity and femininity, it was relatively rare to do so prior to the 1970s.

Thus, the first stage can be described as treating the categories of "woman" and "man," "male" and female," as biological givens. Stereotypically, behaviors and 
traits thought of as "manly" or masculine would be assumed to be appropriate for men, and "womanly" or feminine for women. Such assumptions are described as the biological determinist or biological essentialist understanding of sex and gender, and it has been the dominant viewpoint toward the sexes for much of U.S. history, as subsequent chapters illustrate. Sociologists call this the "natural attitude" toward sex and gender (Garfinkel 1967; Kessler \& McKenna 1978); that is, the taken-for-granted belief that people can be classified biologically into one of only two "natural" categories, each of which is determined by the presence of particular genitals, and for which exceptions are temporary or pathological - that is, a sign of physical abnormality.

The second stage of defining "sex" and "gender" emerged from work in two areas-psychiatry and feminist scholarship. A thorough historical account of this period is beyond the scope of this book, ${ }^{4}$ but a few key moments deserve discussion.

The distinction between the words "sex" and "gender" in English first emerged in the 1950s and 1960s in the specialized literature of "psychiatrists and other medical personnel working with intersexed and transsexual patients" (Moi 1999, 21; see also Mikkola 2019). Psychiatrists and psychologists needed to describe and explain the phenomenon of a patient who felt trapped in the proverbial "wrong body," thus it became useful to distinguish a person's biological sex from their psychological orientation. In a 1955 publication, New Zealand psychologist John Money and his colleagues introduced the notion of "gender role" based on their study of "hermaphrodites" 5 to distinguish attitudes and behaviors that were conceptually distinct from biological sex characteristics. According to Money, "Gender role is appraised in relation to the following: general mannerisms, deportment and demeanor; play preferences and recreational interests; spontaneous topics of talk in unprompted conversation and casual comment; content of dreams, daydreams and fantasies; replies to oblique inquiries and projective tests; evidence of erotic practices, and, finally, the person's own replies to direct inquiry" $(1955,302) .{ }^{6}$ And in a 1963 paper presented to the International Psycho-Analytic Congress, American psychoanalyst Robert Stoller introduced the concept of "gender identity" to describe "the sense of knowing to which sex one belongs, that is, the awareness 'I am a male' or 'I am a female"" $(1964,220) .^{7}$

The 1980 edition of the American Psychiatric Association's Diagnostic and Statistical Manual of Mental Disorders (DSM-III) described the condition of a conflict between one's biological sex and one's gender identity as "gender identity disorder," but the latest edition (DSM-V 2013) refers to it as "gender dysphoria." While psychiatrists debate whether such feelings should be considered a "disorder," the point here is that efforts by Stoller and other psychologists led to treating "gender" as a psychological rather than a biological concept.

The belief that men and women have essentially different natures, rooted in biology, has dominated thinking about sex roles throughout much of human history. Thus, drawing a distinction between biological sex and psychological 
gender was an important step for feminists challenging the legacy of biological essentialism that has been used to justify discrimination against women (Bem 1993; Fausto-Sterling 1985). In a number of influential feminist texts in the second half of the 20th century, "sex" was defined as a biological category, whereas "gender" came to be understood as a culturally dependent social or psychological category. The classic formulation is found as early as 1972 in sociologist Ann Oakley's book, Sex, Gender, and Society: "'Sex' is a word that refers to the biological differences between male and female: the visible difference in genitalia, the related difference in procreative function. 'Gender' however is a matter of culture: it refers to the social classification into 'masculine' and 'feminine"," (1972, 16).

Sandra Lipsitz Bem's work as a psychologist is a useful illustration of the intellectual trend of treating sex and gender as distinct, especially because her work was influential in and beyond her home discipline of psychology.

Bem's feminism originated in the 1960s ("Early Career Awards" 1977). In 1970 she and her husband Daryl J. Bem published "Case Study of a Nonconscious Ideology: Training the Woman to Know Her Place” (Bem \& Bem 1970). The paper argued that girls are not encouraged to consider professional careers as they grow up and women face discrimination in the workplace. A revision of the paper was published the next year for the Pennsylvania Department of Public Instruction for distribution to all Pennsylvania high school guidance counselors. In 1973, Sandra and Daryl Bem coauthored research (originally conducted as part of legal testimony in sex discrimination cases) of how "sex-biased" job advertising leads to discrimination (Bem \& Bem 1973).

In 1974, Bem introduced her Sex-Role Inventory in "The Measurement of Psychological Androgyny." The inventory built on earlier work by psychologists to assess masculinity and femininity as personality traits for diagnostic purposes, ${ }^{8}$ but was distinctive because it "treats masculinity and femininity as two independent dimensions, thereby making it possible to characterize a person as masculine, feminine, or 'androgynous'" $(1974,155)$. The traits represented the dominant thinking about what counts as masculine and feminine at the time, based on subjects' perceptions of what attributes are desirable and appropriate for a man or a woman. The Bem Sex-Role Inventory, or BSRI, went on to become one of the more influential psychological measurement instruments of the past 50 years.

Bem's project and others like it were important because they signaled a break from the long legacy of biological essentialism. Challenging the belief that one's biological sex determines one's psychological make-up, Bem argued that the traits we normally associate with masculinity and femininity could be found in males and females alike, and that a given person might score high on the masculinity scale, or on the femininity scale, or both. These traits, Bem suggested, were a matter of socialization. The "sex-typed person" is "someone who has internalized society's sex-typed standards of desirable behavior for men and women" (155). 
The BSRI contains 60 items, categorized as follows:

Feminine Items

$\begin{array}{lll}\text { Affectionate } & \text { Sympathetic } & \text { Sensitive to the needs of others } \\ \text { Understanding } & \text { Compassionate } & \text { Eager to soothe hurt feelings } \\ \text { Warm } & \text { Tender } & \text { Loves children } \\ \text { Gentle } & \text { Yielding } & \text { Cheerful } \\ \text { Shy } & \text { Flatterable } & \text { Loyal } \\ \text { Soft-spoken } & \text { Gullible } & \text { Does not use harsh language } \\ \text { Childlike } & \text { Feminine } & \end{array}$

\section{Masculine Items}

$\begin{array}{lll}\text { Defends own beliefs } & \text { Independent } & \text { Assertive } \\ \text { Strong personality } & \text { Forceful } & \text { Has leadership abilities } \\ \text { Willing to take risks } & \text { Dominant } & \text { Willing to take a stand } \\ \text { Aggressive } & \text { Self-reliant } & \text { Athletic } \\ \text { Analytical } & \text { Self-sufficient } & \text { Makes decisions easily } \\ \text { Individualistic } & \text { Masculine } & \text { Competitive } \\ \text { Ambitious } & \text { Act as a leader } & \end{array}$

\section{Neutral Items}

$\begin{array}{lll}\text { Adaptable } & \text { Conceited } & \text { Conscientious } \\ \text { Conventional } & \text { Friendly } & \text { Happy } \\ \text { Helpful } & \text { Inefficient } & \text { Jealous } \\ \text { Likable } & \text { Moody } & \text { Reliable } \\ \text { Secretive } & \text { Sincere } & \text { Solemn } \\ \text { Tactful } & \text { Theatrical } & \text { Truthful } \\ \text { Unpredictable } & \text { Unsystematic } & \end{array}$

These items can be thought of as a catalogue of socially approved sex-specific traits for men and women in 1974. Interestingly enough, Bem did not use the word "gender" in the article. A few years later, however, Bem made another important contribution with the publication of "Gender Schema Theory: A Cognitive Account of Sex Typing" (1981). Bem defines "schema" as "a cognitive structure, a network of associations that organizes and guides an individual's perception" (355). Bem contends that the "sex typing" socialization process is how "a society transmutes male and female into masculine and feminine" (354). Gender schema "becomes a prescriptive standard or guide" that "prompts the individual to regulate his or her behavior so that it conforms to the culture's definitions of maleness and femaleness" (355). Offering empirical studies in support of her argument, Bem suggests that society "teaches" children a "substantive network of sex-related 
associations" that become cognitive schema through which the world is understood, and that "the dichotomy between male and female has extensive and intensive relevance to virtually every aspect of life" (362). Indeed, later research by social scientists found that by age five children already have developed clearly defined notions of what constitutes appropriate behavior for men and women (Lytton \& Romney 1991), and it should be no surprise that media portrayal of gender roles plays a significant gender socializing function (Ward \& Grower 2020).

Bem followed up the introduction of her theory with efforts to encourage parents to raise what she described as "gender-aschematic children"-also described at the time as "nonsexist" or "gender-liberated" child rearing (1983). Bem's goal was no less than to reduce the relevance of "gender" as a concept altogether: "[H]uman behaviors and personality attributes should no longer be linked to gender, and society should stop projecting gender into situations irrelevant to genitalia" $(1983,616){ }^{9}$

Bem was one of many feminists arguing that it is societal pressure, not biology, that shapes women's and men's understanding of gender roles. What is particularly noteworthy for our purposes is the fact that she attempted to specify the attributes defining masculine and feminine and to provide a simple paper and pencil test to operationalize and, in a sense, measure gender.

Various scholars documented the sort of normative messages that girls receive during socialization, such as "defer to men," "nurture others," and "be nice," among others (see, for example, Unger 1975; Gilbert \& Scher 1999). The sources of, and harm done by, gender typing and stereotypes became important topics especially to feminist psychologists (see, for example, Eagly \& Steffen 1984). The Bem Sex Role Inventory became the most widely shared measure of gender, particularly for femininity (Mahalik et al. 2005, 418).

Efforts to identify the beliefs and attitudes associated with masculinity followed, including the Macho Scale (Villemez \& Touhey 1977), a measure primarily of antifemininity and patriarchal beliefs; the Attitudes Toward Masculinity Transcendence Scale (Moreland \& Van Tuinen 1978); and the Brannon Masculinity Scale (Brannon \& Juni 1984) —an influential measure of masculinity ideology.

Such work illustrates the important intellectual trend of the 1970s and 1980s to separate the concepts of sex and gender. One indication of the growing awareness and importance of the idea of "gender" is that the use of the word grew significantly in publications from 1970 onward..$^{10}$ The word gender "was rapidly popularized in feminist political discourse as a tool to intervene in arguments against biology" (Fausto-Sterling 2016, 197). It did not take long for it to become standard in college textbooks in the humanities and social sciences to distinguish between sex as biological and gender as cultural/psychological.

For example, the glossary of a popular introductory textbook in sociology in 1981 noted: "Sex (male and female): Refers to the division of the human species into the biological categories of male and female" and "Gender: Refers to social conceptions about what personality trait and behavior are appropriate for members of each sex" (Robertson 1981, 629, 633). A textbook in psychology noted that "Femininity and masculinity are socially defined terms that are added to the 
biologically determined sex class of the individual. Gender defines the social and cultural meanings brought to each anatomical sex class; that is, children learn how to 'pass as' and 'act as' members of their assigned sexual categories" (Lindesmith, Strauss, \& Denzin 1999, 16).

Many authors and institutions continue to describe the difference between sex and gender as one of biology versus socialization. For example, in an essay on gender and sport, one finds "sex 'refers to a person's biological status' and can be identified by 'sex chromosomes, gonads, internal reproductive organs, and external genitalia' while gender refers to 'the attitudes, feelings, and behaviors that a given culture associates with a person's biological sex'” (Fisher, Knust, \& Johnson 2013, 21, quoting the American Psychological Association 2011).

In a 2018 article titled, "Sex and Gender: What is the Difference?" science writer Tim Newman wrote in Medical News Today: "In general terms, 'sex' refers to the biological differences between males and females, such as the genitalia and genetic differences. 'Gender' is more difficult to define, but it can refer to the role of a male or female in society, known as a gender role, or an individual's concept of themselves, or gender identity." Also in 2018, researchers with the World Health Organization noted that, "Gender refers to the roles, behaviours, activities, attributes and opportunities that any society considers appropriate for girls and boys, and women and men. Gender interacts with, but is different from, the binary categories of biological sex" (Manandhar et al. 2018).

The case for what has been described as the social construction of gender was strengthened by a burgeoning scholarly literature documenting the cultural variability of gender roles, both over time and across cultures. Such scholarship, too voluminous to summarize thoroughly here, includes historical and cross-cultural research that documents the fact that what is considered "normal" and "appropriate" for men and women is far from universal. For example, sociologist Raewyn Connell's influential book, Masculinities (1995, 2005), became a classic on the cultural specificity of gender role socialization that documents the notion of specific dominant or "hegemonic" understandings of masculinity.

Sometimes such historical or cultural gender variability seems trivial, such as the fact that knitting was once associated with men, especially sailors and fishermen, prior to the Victorian age; or the fact that over the past century, the genderappropriate color for boys or girls-blue or pink-has varied (Paoletti 2012; Del Giudice 2017). In other cases, the variability is quite consequential, such as the appropriateness or even legality of women holding a paying job, driving a car, or even being seen in public.

Anthropological and sociological scholarship on what has become known as third gender or third sex further illustrates the cultural variability of sex/gender. Gilbert H. Herdt's collection, Third Sex, Third Gender: Beyond Sexual Dimorphism in Culture and History (1994) was an important landmark in such scholarship. How "third genders" are understood varies, of course, from culture to culture, but several examples can illustrate their significance. Māh $\bar{u}$ translates to "in the middle" in Kanaka Maoli (Hawaiian) and Maohi (Tahitian) culture. The term is used to 
describe those fitting into an indeterminate, intermediate gender that has both feminine and masculine qualities who play important cultural roles, and the māhu phenomenon "defies reduction to any of the notions of gender familiar to us in the West" (Robertson 1989, 314). As a recent article on CNN reports, "Their gender identity has been accepted on the island [Tahiti] since time immemorial, and mahu traditionally play key social and spiritual roles, as guardians of cultural rituals and dances, or providers of care for children and elders" (Ponsford 2020). In the early 21 st century, the term mahuwahine was coined to refer specifically to what we would consider a male to female transgender identity (Ellingson \& Odo 2008).

In recent decades the term "Two Spirit" has been used to describe someone who fulfills nontraditional gender roles in Native American cultures and that Europeans actively discouraged (Brayboy 2018; Roscoe 1998). The label Two Spirit also has been criticized as eliding differences across groups. For example, for the Diné (Navaho) people of the southwestern United States, Nádleehi refers to a social category that we would describe as gender variable. Their role in the community is a fluid one, as Nádleehí may express their gender differently on different days, different situations or contexts, and when holding positions that are traditionally filled by men or women. In Diné culture, the role of Nádleehí is recognized, accepted, and honored by members of the community and is a status unique to the Diné people (Epple 1998; Roscoe 1998).

Although the traditional cultural term does not align perfectly with Western definitions, fa'afafine are people who identify as being nonbinary or having a third gender in Samoa, American Samoa, and the Samoan diaspora. Fa'afafine are considered male at birth, but have a strong affinity toward feminine activities and a feminine identity, and take part in daily work training given to women. The term translates as "in the manner of a woman." Fa'afafine have been part of Samoan culture for centuries, long before Western notions of "transgender" emerged (Dolgoy 2000).

There are a number of other examples throughout the world of what we would now describe as gender variance. Though it is possible to describe such gender nonconformists using contemporary language, such as transgender or nonbinary, doing so misses the cultural specificity of the phenomenon. Indeed, some scholars have suggested certain cultures have a fourth or even a fifth gender (Graham 2007; Trumbach 1994). The point is simply that since the emergence of scholarship in the 1970s and 1980s that treats gender as a matter not of biology but of socialization, examples across history and cultures continue to accumulate, often pointing to centuries-old traditions and practices. ${ }^{11}$

$$
* * *
$$

The second stage I have described has much to commend itself and it remains enormously influential. In many contexts, it has proven to be a useful framework to think about sex and gender. We are now in a third stage in which authors, in different ways and in different situations, sometime seek to collapse the categories of sex and gender. Because the motivations and purposes of those seeking to 
reconsider definitions of sex and gender are quite varied, a simple "this happened and then that happened" narrative would be misleading. Accordingly, I hope a more thematic approach can illustrate the complexity of the current definitional landscape. Specifically, I identify three strands of thinking that have emerged and proven influential.

The first strand of thought I want to identify can be described as the scientific argument for challenging the traditional sex categories of male and female. If one defines "sex" as biological and "gender" as psychological or cultural, then who has the right and the relevant expertise to define those terms? Because "gender" was introduced into the scholarly literature from the perspective of social scientists and humanists, and in light of the compelling evidence for the cultural and historical variability of gender norms that exists, it was not difficult for the idea that "gender is socially constructed" to become widely accepted. But what about "sex," understood as a biological category and hence the purview of natural science? This first strand accepts the epistemological authority of science; that is, the belief that scientific definitions are somehow more "real" or certain than other kinds of knowledge. Specifically: The scientific argument is that a nontrivial number of humans defy the traditional biological ways of defining male and female.

We typically view the number and type of sex-related genes and chromosomes as determining our sex ( $X X$ for women, $X Y$ for men), and we assume our genes determine external genitalia, internal reproductive anatomy (such as the uterus in females), sex hormone levels produced by the body (such as testosterone level), and the type of gonads (ovaries or testicles). But the situation is more complicated than that. ${ }^{12}$ The $S R Y$ (sex determining region $\mathrm{Y}$ ) gene is found on the $Y$ chromosome. The protein produced by this gene initiates processes that cause a fetus to grow male gonads and stop the development of female reproductive body parts (uterus and fallopian tubes). However, it is possible for a SRY gene to end up on an $X$ chromosome and thus for someone with XX chromosomes to grow male characteristics including testes. This is called the " $46, X X$ testicular disorder" and occurs in $0.005 \%$ of births ( 1 in 20,000). Alternatively, it is possible for a person with $X Y$ chromosomes to develop typical female external genitalia, a condition known as the Swyer Syndrome, which is estimated to occur in 1 in 80,000 births. Furthermore, as many as $0.005 \%$ of $X Y$ males (2 to 5 per 100,000) experience androgen insensitivity, where their bodies do not respond to certain male sex hormones, known as androgens, and have mostly female external sex characteristics or "signs of both males and female sexual development" (U.S. National Library of Medicine 2020). Other sorts of genetic variations are possible as well. In short, even if we define male and female strictly according to the science of genetics, not every human neatly falls into one or the other category.

Societies have long recognized the fact that some people are born, for example, with both male and female genitalia, and for centuries such individuals would be described as hermaphrodites. Today, a person whose body varies from the statistical norm for males and females in one or more of the areas described here may be categorized as "intersex" or having "Differences in Sex Development" (DSD). 
Just how many DSD people there are in the world is not known with precision. Because there is no systematic record kept of DSD births, some of the physical traits covered by broader definitions may not be discovered until puberty, attempts are made to conceive a child, or through genetic tests. Nonetheless, scientists have generated estimates based on the available data. Not surprisingly, how many DSD individuals there are depends on how one defines "intersex" or DSD. Using a narrow definition limited to cases where chromosomal sex is inconsistent with phenotypic sex (observable body parts), or in which the phenotype is not classifiable simply as either male or female, one estimate is as low as $0.018 \%$ (Sax 2002). Using a broader definition of any deviation from the prototypical male/female categories at the chromosomal, genital, gonadal, or hormonal level, biologist Anne FaustoSterling estimates the figure could be as high as $1.7 \%(2000) .{ }^{13}$ More recently, estimates of the number of people described as having DSD have a similarly broad range. Medical conditions "in which an individual's anatomical sex seems to be at odds with their chromosomal or gonadal sex" are quite rare-one in 4,500 or $0.02 \%$ (Ainsworth 2018), a figure similar to Sax's estimate. Some scientists feel that definition is too narrow. Eric Vilain, a clinician and former director of the Center for Gender-Based Biology at the University of California, Los Angeles, for example, points out that the "most inclusive definitions point to the figure of 1 in 100 people having some form of DSD" (Ainsworth 2018).

Fausto-Sterling has suggested, more as a thought experiment than as a serious policy proposal, that we imagine humans as divided into five sexes. Suggesting that the category of "intersex" was too broad, she suggested three subcategories be recognized: "the so-called true hermaphrodites, whom I call herms, who possess one testis and one ovary (the sperm- and egg-producing vessels, or gonads); the male pseudohermaphrodites (the 'merms'), who have testes and some aspects of the female genitalia but no ovaries; and the female pseudohermaphrodites (the 'ferms'), who have ovaries and some aspects of the male genitalia but lack testes" $(1993,21)$.

Fausto-Sterling criticized the Trump administration's Department of Health and Human Services efforts to define sex solely as male or female "based on immutable biological traits identifiable by or before birth" as based on "biological error" (2018). Noting that sexual development is "multilayered" and that the layers (such as chromosomal and hormonal) may be in conflict or resist simple binary division, she argued that the policy advocated by the Department of Health and Human Services "flies in the face of scientific consensus about sex and gender" (2018). Fausto-Sterling's work will be discussed again in this book, but for now the point is that she represents a biologist (whose Ph.D. is in Developmental Genetics) who is often cited as providing scientific reasons to challenge the dominance of the twosex system (Fausto-Sterling 2020a, 2020b).

The second strand, by contrast, does not defer to the authority of scientific definitions but instead stresses that scientific definitions are social constructions, devised by scientists to meet certain needs and interests and subject to change. Thus, like gender, "sex" is also a socially negotiable category. 
The claim that scientific definitions are more stable than nonscientific definitions typically depends on the idea that the referents of scientific analysis are objective and represent what are called "natural kinds." As philosopher Jerry Fodor summarizes the claim, "Science discovers essences, and doing science thereby links us to natural kinds as such" $(1998,158)$. The natural sciences, including biology, are assumed to be relatively immune to the challenges of redefinition. As historian and philosopher of science Thomas S. Kuhn puts it, "Their truths (and falsities) are thought to transcend the ravages of temporal, cultural, and linguistic change" (1989, 23).

The vocabulary of science provides what philosopher Saul Kripke called "rigid designators" that correspond to natural, not socially constructed, kinds. Kripke provides the example of gold - " $[\mathrm{P}]$ resent scientific theory is such that it is part of the nature of gold as we have it to be an element with atomic number 79" (1980, 125). Thus, "gold" is a "rigid designator, whose reference is fixed by its "definition"” (1980, 136). In this line of thinking, "male" and "female" are rigid designators that refer to natural (biological) not social categories, and it is consistent with normal scientific progress if a third category, such as "DSD," is added.

The history of science, however, challenges the idea that science produces permanently "rigid" designators. As Kuhn (1970) and other historians have demonstrated, scientific definitions are always understood in the context of a particular scientific theory, designed to meet specific needs and interests. Theories change. Kuhn notes that the concept of an atomic number, used to identify gold, relies on a particular atomic-molecular theory, and only while such a theory "endures do the names it categorizes designate rigidly" (1990, 315).

A well-known example from history is the case of phlogiston, which was once considered a physical substance that is contained within certain objects and released during combustion. It was as real and empirically verifiable and measurable as any other scientific concept of its time. Now, of course, the theory of phlogiston has been superseded by a theory of gases in which phlogiston is no longer considered real (White 1973). The term has changed its status from a hypothesized rigid designator to fiction.

Not all examples of conceptual evolution are as dramatic as the rise and fall of phlogiston, of course. But most philosophers of science today agree that all scientific terms are similarly dependent on a larger set of beliefs, or theory. Even elementary concepts such as "force," "species," "heat," "element," and "temperature" have evolved over time as scientists revise their theories (Kuhn 1990, 313). ${ }^{14}$ The controversy over whether to classify Pluto as a planet is the result of changing definitions promulgated by the International Astronomical Union. Once the IAU changed its definition of planets, it decided that Pluto did not meet all three of its definitional criteria and hence no longer counted as a planet. Even scientific definitions, then, may be described using the grammar of a regulatory definition: " $\mathrm{X}$ counts as $\mathrm{Y}$ in context $\mathrm{C}$ " if we think of a specific scientific theory as functioning as a historically situated context: "Gold counts as atomic number 79 in atomic/ molecular theory," or "Pluto does not count as a planet according to IAU's criteria." 
The point of this second strand, then, is to apply the lesson of the history of science to our understanding of the biological categories of the sexes. Scientific language evolves to meets the needs and interests of specific scientific communities, and the current ways of categorizing humans' biological sex is no less of a historically situated social construction than other scientific definitions. This is not to say that biological entities are not real, which is a common misinterpretation of describing a belief or practice as socially constructed. Rather, it is to call attention to the fact that emphasizing different definitional attributes (hormones versus chromosomes, for example) for defining and categorizing woman and men, females and males, involves a choice of what values, interests, and purposes we see our definitions advancing. Developmental biologist Rebecca R. Helm, for example, posted a widely circulated series of tweets in December 2019 stressing how complicated the idea of biological sex can become (Helm 2019). She notes, for example, that a person can be born with XY chromosomes but if the SRY gene appears on the X chromosome instead of the Y, that person could be physically female, chromosomally male, and genetically female. So which attribute should be considered definitive? In personal correspondence, Helm noted that, "as a developmental biologist, I define male/female as organisms producing sperm/eggs" (2020, emphasis added; see also Griffiths 2020). For the purposes of research as a developmental biologist, production of sperm or eggs (gametes) is "the key feature of biological sex." However, Helm is quick to note that, in other contexts, using gametes as the definitive attribute for biological sex for categorizing humans "would be extremely problematic" (2020).

Similarly, historian and philosopher of science Sarah S. Richardson argues against binary essentialist conceptions of sex and advocates what she describes as "sex contextualism" for the study of sex-related biological variables in basic, preclinical biomedical research. She argues that there are multiple ways to define or "pragmatically operationalize" sex in biomedical research, especially in a laboratory context where the focus might be on hormone levels or chromosomes, for example, or involve "laboratory-tailored materials and technologies" (2021). Inferences about humans may be based on other species with quite different sex-related processes, such as roundworms known as Caenorhabditis elegans. Difference in hormone levels at different ages of mice indicates the most useful interpretation of the data would posit four sex categories, not just two. In short, Richardson's analysis of a series of laboratory studies concludes that the definition/operationalization depends on the specific research context and purpose, so sex should be understood contextually (2021).

In short, as we will see in Part II of this book, the question of whether person $\mathrm{X}$ is male or female may have more than one correct answer. Those that want to rely on the authority of science to end the debate on how to define sex will be disappointed, as more than one definition is defensible, and the applicability of such definitions to public policy matters is open to debate.

The first two strands I have identified focus on destabilizing the concept of biological sex-the first strand by accepting the epistemological privilege of scientific 
knowledge but pointing out how the category of DSD people challenges the exclusivity of the categories of male and female, and the second strand by emphasizing that scientific categories are always dependent on theories that are open to revision, and hence can be thought of as revisable social constructions. The point of both strands is that treating sex as a biological "given" that transcends social and cultural differences is not as obvious as once thought, and hence separating sex and gender relying on the assumption that gender is socially constructed while sex is not is no longer a safe assumption to make.

A third strand suggests that even if one could point to clear biological differences between the sexes, the meaning and significance of those differences is a product of social and cultural factors. That is, the concept of gender would not have emerged if there had not already been considerable cultural baggage associated with ideas of what it means to be male or female, even if those beliefs were not yet categorized as "gender" beliefs. As Judith Butler argues, cultural beliefs about what we now call gender figure in "the very apparatus of production whereby sexes themselves are established" $(1999,11)$. That is, a culture's ideas about gender shape how we understand biological sexes $(1999,139)$.

As an example, think about the contemporary practice of "gender reveal" parties. Friends of a couple expecting a baby gather and a dramatic "reveal" occurs that is always coded male or female, typically with blue or pink objects. The "meaning" of an ultrasound reading is that it signifies a gender-typically, if a penis and scrotum are observed, the prenatal assignment is a boy; otherwise, it is a girl. Even before the baby is born, a host of cultural beliefs and practices are thus activated that reinforce the dominant cultural gender norms. Obviously, the relevant body parts of a baby are "real," but according to Butler, social conditioning makes those body parts meaningful (and gendered). Once declared a boy or girl, the actions of parents, friends, institutions such as churches, schools, the medical establishment, and popular culture all work to socialize the child as to what it means to be a boy or girl. "Society" - if I may use the term as shorthand for the wide variety of socializing agents - both conveys messages about what it means to be a boy or girl, and serves as audience for girls' and boys' "performance" of gender roles (Butler 1988). According to Butler, gender is realized socially by a performative repetition of acts associated with being girls and boys, women and men-how we look, dress, move in the world, speak, think, feel, and behave. It is through such repetitive performance that gender is constituted and perpetuated.

For Butler and certain other feminist philosophers, the fact that our understanding of biological sex is deeply embedded in cultural assumptions and what we now call gender means that we should combine the concepts of sex and gender into a single construct: sex/gender. Gayle S. Rubin's influential 1975 essay, for example, "The Traffic in Women: Notes on the Political Economy of Sex," described what she called the sex/gender system: "the set of arrangements by which a society transforms biological sexuality into products of human activity, and in which these transformed sexual needs are satisfied." Rubin contends that, "Gender is a socially imposed division of the sexes" motivated primarily by economic considerations as 
women are commodified and exchanged within patriarchal societies $(1975,179)$. Historically, one man giving the gift of a daughter or a sister to another man for the purpose of matrimony fosters kinship ties between two men and the transfer of "sexual access, genealogical statuses, lineage names and ancestors, rights and people" to take place $(1975,177)$. Women become "gendered" when the distinction between male giver and female gift is made in such exchanges.

While some theorists have embraced the blended term "sex/gender" to stress how interdependent the two concepts are, others have adopted the practice of treating the term "gender" as superordinate to include beliefs, assumptions, and practices about biological sex. Raewyn Connell and Rebecca Pearse's definition of "gender" is an example: "Gender is the structure of social relations that centers on the reproductive arena, and the set of practices that bring reproductive distinctions between bodies into social processes" $(2015,11)$. In both cases-treating gender as the superordinate label, or adopting the blended term sex/gender-the point of this third strand is that the deep-rooted social and cultural assumptions about what it means to be a man or a woman, male or female make a clear distinction between "sex" and "gender" problematic.

The authority of science and scientific knowledge is often invoked to further various social, cultural, and political values. As a salient example, when infants were born with an apparent DSD (Difference in Sex Development), the result would be what Katrina Karkazis calls a "social emergency in which medical experts are called on to intervene." The breach of the social order "caused by the birth of a baby with atypical genitals (and thus no obvious gender assignment) produces a crisis that must be addressed because it threatens social norms" (2008, 96). The decision to pathologize what used to be called a hermaphroditic condition is a cultural one, not simply an objective diagnosis. A decision by doctors to do surgery to "fix" DSD infants' genitalia to make them into a boy or girl, was often based on their subjective assessment of genital size (Fausto-Sterling 2020b, 59-66). It has been only in the past few decades that a more patient-centered approach has emerged that questions whether infant surgery should be allowed until the person with DSD conditions can consent meaningfully (Davis 2015; Dreger 2015; Kessler 1998; Luthra 2020).

It should be remembered that homosexuality was pathologized in the American Psychiatric Association's Diagnostic and Statistical Manual of Mental Disorders (DSM) to varying degrees until $1987 .{ }^{15}$ The removal from the DSM was politically important to gay rights. Dr. Jack Drescher credits those changes for facilitating legal changes for homosexuals, and in particular the legal path toward same-sex marriage. Writing three years before the Supreme Court decision legalizing same-sex marriage, Drescher noted the progress of gay rights and declared: "Whatever that outcome, none of these changes in executing and discussion social policies that affect gay people would have occurred without the APA decision" $(2012,133)$.

The APA's decision was not necessarily the end of the story; it may have been a necessary condition for gay rights, but not a sufficient one. The role of science is unpredictable when it comes to issues of sexual and gender identity. There was 
a time when the search for the so-called "gay gene" was heralded by some gay rights advocates as proving that homosexuality was as an immutable characteristic and thus justified protection against discrimination. ${ }^{16}$ But as Robert Alan Brookey warned, had a gay gene been discovered, it could have become the basis for new lines of pathologizing tests and treatments by the biomedical industry $(2002,128) .{ }^{17}$

The fact that research is emerging in the 21 st century that claims there may be a genetic explanation for gender identity is a mixed blessing, and should be treated with caution. The most provocative research in this vein posits that transgender people appear to be born with brains more similar to the gender with which they identify rather than their assigned gender (Wu 2016). ${ }^{18}$ On one hand, such research may persuade those who doubt the "realness" of expressions of gender dysphoria. On the other hand, as soon as one identifies a genetic basis for behavior some consider abnormal, it is not difficult to envision the emergence of tests and interventions with less than supportive aims (Swartz 2018). This does not mean such research should not be conducted, it means that the results need to be interpreted with care (see Powell, Shapiro, \& Stein 2016).

In short, this last strand of thinking about sex/gender reminds us of the influence of culture and politics. As Fausto-Sterling noted in an essay titled "Science Won't Settle Trans Rights" — citing political scientist Laura Ephraim's important work (2017) on the political work that scientific "world-building" performs:

Gone are the days when only medical experts define sex, gender, and sexuality. As social movements disrupt a previously comfortable scientific consensus, traditional scientific groups grapple with questions of authority. Who, in this new world, speaks for science, and for whom does science speak? The answer is both unsettling and unsettled.

Similarly, Eric Vilain suggests the scientific situation with biological sex is sufficiently unclear that it might be easier just to ask people their gender identity:

So if the law requires that a person is male or female, should that sex be assigned by anatomy, hormones, cells or chromosomes, and what should be done if they clash? "My feeling is that since there is not one biological parameter that takes over every other parameter, at the end of the day, gender identity seems to be the most reasonable parameter," says Vilain.

(Ainsworth 2018) $)^{19}$

\section{Defining gender in the 21st century: Fluid and multi-dimensional}

Not surprisingly, different definitions of "gender" have proliferated, ranging from very broad descriptions to sophisticated efforts to specify how gender is understood in a specific population. 
An example of a broad definition is the one cited previously from the World Health Organization: "Gender refers to the roles, behaviours, activities, attributes and opportunities that any society considers appropriate for boys and girls, and men and women" (Manandhar et al. 2018). Or, consider the American Psychological Association:

Gender refers to the attitudes, feelings, and behaviors that a given culture associates with a person's biological sex. Behavior that is compatible with cultural expectations is referred to as gender-normative; behaviors that are viewed as incompatible with these expectations constitute gender non-conformity.

$(2012,11)$

Such definitions are necessarily general, since specific gender norms can vary over time and across cultures. As sociologist Mary Holmes has stated, gender is a complex phenomenon, the meaning of which in a specific moment in history and in a specific geographic location is influenced by issues of class, race, beliefs about the human body, and political ideology (2007). Accordingly, the best an initial definition of gender can do is to gesture toward the fact that cultures have different norms and expectations for women and men, though the details vary considerably.

Furthermore, many gender theorists see the constraining influence of gender norms as a social force to be opposed. Some favor the idea and practice of gender bending - that is, dressing or behaving in a non-gender conforming manner-as a form of activism to challenge dominant gender norms. Some promote the labels "gender fluid" or "gender fluidity" to stress the wide variety of social, cultural, and individual preferences (Hines 2018). Of course, what counts as gender bending is just as culturally variable as gender itself. A man wearing high heels and a lengthy wig might be considered gender bending today, but both were quite conventional for privileged men in Europe in the 17th and 18th century.

In contrast to efforts by some gender theorists to define gender broadly and deliberately loosely, other scholars have attempted to become increasingly detailed and specific in their understanding of how gender is understood in specific cultures. Psychologists in the United States studying gender are a good example.

The Bem Sex Role Inventory was an attempt to measure masculinity and femininity as discrete if potentially complementary wholes, that is, the different items on the masculine and feminine list would be added together to create a single score on masculinity and a single score on femininity. This means that the BSRI treats masculinity and femininity as distinct dimensions of one's personality, even if one person could score high in both. In the parlance of social science, the concepts of masculinity and femininity are each treated as unidimensional.

In recent decades, social scientists have explored masculinity and femininity as multi-dimensional, suggesting that a single individual might conform to some societal expectations regarding their gender but not others.

An example of a multi-dimensional approach to gender can be found in the work of psychologist James R. Mahalik and his colleagues, who produced the 
"Conformity to Masculine Norms Inventory" (2003) and the "Conformity to Feminine Norms Inventory" (2005). These norms include the following:

\title{
Conformity to Masculine Norms Inventory
}

$\begin{array}{lll}\text { Winning } & \text { Controls Emotions } & \text { Risk Taker } \\ \text { Accepts Violence } & \text { Playboy } & \text { Dominance } \\ \text { Power over Women } & \text { Self-Reliant } & \text { Work is Primary } \\ \text { Disdain for Homosexuality } & \text { Pursues Status } & \end{array}$

\section{Conformity to Feminine Norms Inventory}

\author{
Nice in Relationships \\ Cares for Children \\ Values Sexual Fidelity
}

Values Thinness

Domestic

Modest

Interested in Appearance

Values Romance

Mahalik et al.'s inventories have been cited by literally hundreds of other studies and are influential examples of an effort to operationalize what is meant by gender in the 21st century, though - like many of the terms in the Bem Sex Role Inventorymost of the norms might be understood as stereotypes of how masculinity and femininity are perceived. Other examples of scales or inventories that explore femininity multi-dimensionally include the Adolescent Femininity Ideology Scale (Tolman \& Porche 2000) and the Feminine Gender Role Stress Scale (Gillespie \& Eisler 1992). Other examples that explore masculinity multi-dimensionally include the Male Role Norms Scale (Thompson \& Pleck 1986) and the Male Role Norms Inventory (Levant et al. 1992). By 1990, hundreds of tests and measures associated with gender roles and issues had been developed and made available in handbooks (Beere 1990a, 1990b).

While social scientists have tried to articulate conceptions of gender with increasing specificity and accuracy, other scholars have advocated an understanding of gender that goes beyond the traditional categories of masculine and feminine with such concepts as gender fluidity, variability, transgender, gender-queer, and gender nonconformity. In The Apartheid of Sex: A Manifesto on the Freedom of Gender, Martine Rothblatt advocates a chromatic system of gender would differentiate among hundreds of different gendered personality types-343 "shades" of gender, in fact (1995).

Thus, for various reasons, we enter the 21st century with less certainty and consensus about how to define "sex" and "gender" than in any other point in modern history. The situation has become even more uncertain in light of the Transgender Exigency, and so it is to that topic I now turn. 


\section{Notes}

1 McCloskey (2019, 50-51, emphasis in the original).

2 Email to the author, July 31, 2021.

3 I limit my focus mostly to the United States and approximately the past seven decades for the purposes of clarity. If one looks beyond mainstream and mostly white U.S. culture, the notion of third sex (or more) has an older history, including among Native Americans. And in the United States one can find antecedents of transgender lifestyles dating back centuries. See, for example, Susan Stryker's Transgender History (2017) and Jen Manion's fascinating book, Female Husbands: A Trans History (2020).

4 See, for example, Crisler and McHugh (2011).

5 "Hermaphrodite" is no longer the term preferred to describe DSD individuals, as I discuss later on. See Vilain et al. (2007) and Lundberg, Hegarty, and Roen (2018).

6 For a detailed account of Money's work and its legacy, see Germon (2009), especially Chapter 2.

7 The phrase "gender role" can be found as early as 1955 (in Money, Hampson, \& Hampson 1955), but Stoller's formulation is generally credited as the one informing subsequent gender theorists: "The term [gender identity] was introduced to the psychiatric/ psychoanalytic worlds in 1964" in Stoller's article (Green 2010, 1457).

8 Such tests included the Wechsler Adult Intelligence Scale (WAIS) Masculinity-Femininity Index, the masculinity and femininity scales of the California Psychological Inventory, the Masculinity-Femininity score of the Franck Drawing Completion Test, and the Mf scale of the Minnesota Multiphasic Personality Inventory (MMPI). These tests were used as diagnostic tools for mental health purposes, or, in the case of the Franck Drawing Completion Test, an effort to explore the relationship between personality attributes and creativity.

9 I suspect Bem would have been a fan of the subreddit group, "pointlessly gendered": www.reddit.com/r/pointlesslygendered/

10 See the Corpus of Historical American English (COHA) and Google Books Ngram Viewer (https://books.google.com/ngrams/) search for "gender" in English and American English.

11 Other examples include the Hijra of South Asia, dating back centuries (Nanda 1994), the so-called third gender muxe of the indigenous Zapotec people of Mexico (Stephen 2002); the femmenielli of Neapolitan culture that dates back centuries (Bertuzzi 2015), and the kathoey (กะเทย) of Thailand (Morris 1994; Totman 2003).

12 See Richardson (2013) for a valuable account of the various efforts in the past century to find "sex itself" in the human genome.

13 Fausto-Sterling's oft-cited figure of $1.7 \%$ is based on a research review conducted with her students and reported in the American Journal of Human Biology (Blackless et al. 2000). Hull (2003) accuses Blackless et al. of a variety of serious errors and suggests a figure of $0.37 \%$. Sax's (2002) figure of $0.018 \%$ is based on a definition that only "counts" congenital adrenal hyperplasia (CAH) and complete androgen insensitivity syndrome as DSD conditions. Conditions that Sax excludes but Fausto-Sterling includes are LateOnset Congenital Adrenal Hyperplasia, Vaginal Agenesis, and any sex chromosome combinations other than XX or XY (including but not limited to Klinefelter syndrome 47, XXY, Turner syndrome 45X, XXX, XYY, and other "less frequent arrangements"). Sax's explanation for the exclusion of these categories is that they do not cause ambiguous genitalia or, he believes, "any confusion regarding sexual identity" $(2002,177)$. He notes that $88 \%$ of those whom Fausto-Sterling classifies as "intersex" (DSD) are those with Late-Onset Congenital Adrenal Hyperplasia or nonclassic CAH (LOCAH). Hull makes a similar argument $(2003,113)$. Sax claims: "From a clinician's perspective, however, LOCAH is not an intersex condition. The genitalia of these babies are normal at birth, and consonant with their chromosomes: XY males have normal male genitalia, and XX females have normal female genitalia" (176). Any medical problems people with 
LOCAH have, Sax argues, are not "intersexual in nature" (176). See also Fausto-Sterling (2020b, 324-326).

14 The idea that the meaning of individual scientific terms, including so-called "observation terms," depend on a larger theory is typically credited to Duhem (1954) and Hanson (1958).

15 After lobbying by gay rights advocates, "in December 1973, APA's Board of Trustees voted to remove homosexuality from the DSM" (Drescher 2015, 571). The removal was neither immediate, nor complete. If a person with same-sex attraction was distressed, they could still be diagnosed as having "Sexual Orientation Disturbance" (SOD), according to the DSM II. In DSM III, published in 1980, "Sexual Orientation Disturbance" was re-named "Ego Dystonic Homosexuality." Thus even in 1980, "cures" and "conversion therapies" persisted and doctors could justify their actions with reference to the DSM as a source of scientific authority. Thus, while the change in 1973 was significant and is still widely celebrated as a turning point, it did not end efforts by many to treat homosexuality as a pathology (Drescher 2015, 571). It was only in 1987 that a revision of the DSM III finally and permanently removed "Ego Dystonic Homosexuality."

16 For a critique of such scientific research, see Stein (1999). For an argument against an entrenched "bioessentialist" approach to conceptualizing LGBTQ citizenship, see Wuest (2022).

17 The current scientific consensus appears to be that there is no such thing as the gay gene (Lambert 2019).

18 The idea that there are meaningfully different "male" and "female" brains has been critiqued at length (Eliot 2009; Rippon 2019). There are observable differences between certain physical features of female and male brains (cortical thickness, white matter variation, etc.), and it is these differences that have been compared to transgender subjects. Some studies conclude that the brains of transgender individuals are closer in structure, function, and activation patterns to the brains of their self-identified gender. See, for example, Bakker (2018) and Guillamon, Junque, and Gómez-Gil (2016).

19 As a scholar of argumentation, I need to note here that the existence of difficult border cases or exceptions does not completely vitiate the utility of categories. The headline to Ainsworth's article is: "Sex Redefined: The Idea of 2 Sexes is Overly Simplistic," followed with the subtitle "Biologists now think there is a larger spectrum than just binary female and male" (2018). While facially valid in light of research on people with DSD, there are some who infer from such headlines that the ideas of male and female are mere fictions. An equally valid headline could read: "The Idea of 2 Biological Sexes is Accurate for $98 \%+$ of the population." That is, because the vast majority of humans have an anatomy, hormones, cells, and chromosomes that are consistently male or female, most of the time and in most contexts, people use the words "female" and "male" without confusion or fear of contradiction. Once we add the idea of gender identity, of course, matters become more complicated. 
$\because$ Taylor \& Francis

Taylor \& Francis Group

http://taylorandfrancis.com 


\section{Transgender voices}

"I have been out in rock and roll as transgender for 28 years. It was a different world back then. When I came out, the cross-dressing laws were across all the nation, so everything that I did as a trans person was illegal."

Venus de Mars ${ }^{1}$

"That was the first day I ever heard the word 'transgender.' I remember feeling this overwhelming sense of relief that there was finally a word that described me- a girl who had accidentally been born into a boy's body."

Jazz Jennings ${ }^{2}$

"Visibility, of course, is not the same as belonging. Language creates nuance, but not necessarily legislation. Stories save lives and also, paradoxically, endanger them."

Thomas Page McBee (2021) 


\section{3}

\section{THE TRANSGENDER EXIGENCY}

An exigency is a situation marked by an urgent need or demand, and the point of this book is that the rise of transgender visibility and civil rights has created a need for thinking through how we define sex and gender. I describe the situation as an exigency because attitudes, practices, and laws are changing rapidly and, as social and political efforts clash, lives are in the balance. Because the very method of defining sex and gender is now contested, we can describe the current exigency as a definitional rupture calling for a thoughtful consideration of the process of defining itself.

This chapter begins by noting the evidence for substantial prejudice against transgender people. I then provide a brief description of the dramatic rise in transgender visibility that took place in the 2010s in the United States. That rise in visibility has had mixed results. On one hand, research proves that as people learn more about a minority group, including transgender people, there is an opportunity for prejudice to be reduced and civil rights to advance. On the other hand, the evidence is clear that there has been a backlash in certain contexts, resulting sometimes in the deliberate exclusion of transgender people. Some of the specific contexts where definitions of sex and gender are being contested are examined in Part II of this book.

To illustrate how far and how fast U.S. culture has moved with respect to transgender individuals, I share two examples drawn from popular film that many readers of a particular age will recall.

In the 1991 comedy Soapdish, the villain of the movie is Montana Moorehead (played by Cathy Moriarty), an actress who schemes to undercut and replace the beloved star of a soap opera, Celeste Talbert (played by Sally Fields) and her newly united adult daughter, Lori (played by Elizabeth Shue). Just as Montana is about to triumph with Celeste's character's demise on a live broadcast, it is revealed from an old high school yearbook photo that Montana is actually a transsexual, formerly 
“Milton Moorehead, of Syosset, Long Island.” Humiliated and horrified by the onair revelation, Montana flees the set, defeated.

A year later, The Crying Game was released. Described as a thriller, the movie explores themes of race, gender, nationality, and sexuality against the backdrop of the conflict in Northern Ireland. One of the most talked-about scenes in the movie occurs when the lead character, Fergus (played by Stephen Rea) is about to make love with Dil (played by Jaye Davidson), but discovers that Dil is transgender when he sees Dil has a penis. ${ }^{3}$ After hitting Dil in the face, Fergus rushes to the bathroom to vomit.

Soapdish assumed audiences would find it funny that Montana Moorehead was a transsexual and understand her reaction to being revealed as such. Crying Game similarly assumed we would find Fergus's initial reaction plausible-even if the movie went on to demonstrate Fergus's acceptance of and love for Dil. In both cases, the characters in the movie illustrate the "natural attitude" toward sex and gender described in the previous chapter; that is, the widespread and takenfor-granted belief that people should be classified biologically into one of only two "natural" gender categories, each of which is determined by the presence of particular genitals and for which exceptions are temporary or pathological. The considerable societal forces at work to perpetuate traditional sex and gender roles discussed in the last chapter function to normalize masculine heterosexual males and feminine heterosexual females and thus treat deviations from those norms as "unnatural" or "abnormal."

Thirty years later, attitudes toward sexual minorities are more complicated than when Soapdish and Crying Game were released. ${ }^{4}$ A sexual minority-now more often referred to as a Sexual and Gender Minority or SGM-is a group whose sexual identity, orientation, or practices differ from the heterosexual majority and who consider themselves part of the LGBTQ (Lesbian, Gay, Bisexual, Transgender, \& Queer or Questioning) ${ }^{5}$ population (Herek, Gillis, \& Cogan 2009). If a given person believes that the only "natural" or "normal" sex is heterosexual sex between masculine men and feminine women, and believes that biology determines one's sexual and gender identity, then that person is more likely to hold prejudicial beliefs about SGMs.

There is considerable research documenting prejudice against SGMs in the United States. Particularly important are those surveys specific to attitudes about transgender individuals. In the first major national study, surveying 2,281 heterosexual U.S. adults in 2005, Aaron T. Norton and Gregory M. Herek reported that, "ratings of transgender people were strongly correlated with attitudes toward gay men, lesbians, and bisexuals, but were significantly less favorable" $(2013,738)$. Norton and Herek used a holistic measure known as a "feeling thermometer" to assess how warmly or coolly respondents felt about different groups using a score from 0 to 100 , with 50 being a neutral response. In their study, women and men rated "women in general" as a group at an average "temperature" of 67.56 and "men in general" at 62.44. The average score for "gay men" was significantly cooler at 38.89 and for "lesbians" at 42.10. The average score for "transgender people" was 32.01, 
with males' average score at 27.63 and females' at 36.22. As noted by Norton and Herek, these scores are highly correlated with those for gay men and lesbians, but notably lower. "Highly correlated" means that if a person provided a low score for gay men, they were likely to provide a low score for transgender people as well (see also Billard 2018).

Studies reported by other scholars in the first decade of the 21 st century documented similar negative attitudes toward SGMs, especially transgender people. Hill and Willoughby (2005) found that test subjects who were committed to traditional gender roles were more likely to hold negative views of SGMs. Julie Nagoshi and her colleagues (2008) found strong differences between men and women in their attitudes toward transgender people, with "hypermasculine" males in particular more likely to dislike homosexuals and transgender people. Shelia T. Brassel and Veanne N. Anderson confirm in a study of over 1,000 students that anti-trans prejudice correlates with "gender traditionalism," similar to what I have described as biological essentialism (2020).

Such negative attitudes toward SGMs matter. There is considerable evidence of discrimination and violence against transgender people in the United States. A report by the Gay, Lesbian, \& Straight Education Network states that 75\% of transgender students felt unsafe at school because of their gender expression (GLSEN 2017). The Report of the 2015 U.S. Transgender Survey reported that students "perceived as transgender while in school (K-12) experienced some form of mistreatment, including being verbally harassed (54\%), physically attacked (24\%), and sexually assaulted (13\%) because they were transgender. Further, 17\% experienced such severe mistreatment that they left a school as a result" (James et al. 2016, 4). Life after school is no easier for transgender people. According to the same survey,

In the year prior to completing the survey, $30 \%$ of respondents who had a job reported being fired, denied a promotion, or experiencing some other form of mistreatment in the workplace due to their gender identity or expression, such as being verbally harassed or physically or sexually assaulted at work. In the year prior to completing the survey, $10 \%$ of respondents were sexually assaulted, and nearly half (47\%) were sexually assaulted at some point in their lifetime.

(James et al. 2016, 4-5)

A survey of over 80,000 youth in Minnesota found that transgender and gender nonconformity teens reported a suicidal ideation rate more than three times higher than cisgender youth (Eisenberg et al. 2017). In a survey of over 1,500 self-identified LGBTQ adults in June, 2020, 62\% of transgender Americans reported facing discrimination of some kind in the past year: "Two-thirds (66 percent) reported that discrimination moderately or significantly affected their psychological wellbeing, with nearly half (46 percent) reporting moderate or significant physical impacts" (Mahowald, Gruberg, \& Halpin 2020). 
Zack Marshall and a team of researchers (2019) published an extensive literature review of publications between 2010 and 2014 that focused on research with transgender, nonbinary, and other gender diverse individuals and communities. They identified 99 articles exploring discrimination and marginalization of transgender people, and another 47 documenting violence and trauma. In November 2020, the Human Rights Campaign published An Epidemic of Violence: Fatal Violence Against Transgender and Gender Non-Conforming People in the United States in 2020, reporting at least 22 transgender and gender nonconforming people killed in 2019 at the time of the report (HRC 2020). The American Medical Association also used the term "epidemic" to describe increasing violence against transgender people, especially transgender women of color (AMA 2019). A review of 42 studies conducted between 1989 and 2015 by the Williams Institute reported that for transgender people, between 31 and 50\% experience Intimate Partner Violence in their lifetime (Brown \& Herman 2015; see also Hoston 2018). Wikipedia maintains a constantly updated "List of unlawfully killed transgender people."

Transgender people often face formidable obstacles to obtaining needed medical care. There is a shortage of knowledgeable and well-trained health care providers to aid transgender patients. Other obstacles include "financial barriers, discrimination, lack of cultural competence by providers, health systems barriers, and socioeconomic barriers" (Safer et al. 2016, 168). Transgender individuals can become so desperate for medical support for transitioning that they turn to "Do It Yourself" measures:

Without access to quality medical care, trans people around the world are seeking hormones from friends or through illegal online markets, even when the cost exceeds what it would through insurance. Although rare, others are resorting to self-surgery by cutting off their own penis and testicles or breasts.

(Santora 2020; see Rotondi et al. 2013)

Though the Supreme Court has ruled that employment discrimination against transgender people violates federal law, no such protection exists for health care. The Trump administration reversed the Obama-era protection against discrimination for LGBTQ people in health care and health insurance (Simmons-Duffin 2020). The Biden administration at the time of this writing is in the process of reversing the Trump administration's anti-transgender policies, though it is clear that such efforts will encounter resistance from conservatives (Schmidt, Wax-Thibodeaux, \& Balingit 2021).

Thus, in the early decades of the 21 st century transgender people face considerable prejudice, too often culminating in violence. Simultaneously, we are witnessing an unprecedented rise in visibility of transgender people. While there is evidence that public attitudes are gradually changing, prejudicial attitudes are fueling a backlash in some states (Andrew 2021; Moreau 2021). 


\section{Declaring a transgender moment}

The second decade of the 21st century was a pivotal one for transgender people in the United States. On October 30, 2012, then-Vice President Joe Biden was quoted calling transgender equality "the civil rights issue of our time" (Bendery 2012). ${ }^{6}$ Time magazine featured transgender actress and advocate Laverne Cox on its June 9, 2014 cover and declared "The Transgender Tipping Point: America's next civil rights frontier." Less than eight months later, in his 2015 State of the Union Address, Barack Obama became the first U.S. president to utter the word "transgender" in public. Sarah McBride was the first transgender speaker in history at a major party national convention when she spoke to the Democratic National Convention in July, 2016. It is likely that Lady Gaga's halftime song "Born This Way" at Super Bowl LI was the first time the word "transgender" was uttered in that internationally televised venue (McNamara 2017). In 2020, a record number of openly transgender candidates ran for public office (Prager 2020), and transgender protections were included in the first slate of Executive Orders issued by the Biden administration in January 2021. Collectively, such moments signify the arrival of a new era in U.S. social and political history. ${ }^{7}$

People who identify themselves with such labels as "transvestite," "transsexual," or "transgender" have been around for a long time, and efforts to organize for transgender rights are not new (Nownes 2019). As we enter the third decade of the 21st century, however, the moments mentioned earlier along with others make clear that we are in new conceptual and political territory. As Jack Halberstam declares, "In the last decade, public discussions of transgenderism have increased exponentially. What was once regarded as an unusual or even unfortunate disorder has become an accepted articulation of gendered embodiment as well as a new site for political activism" $(2018,17)$.

For most people, the first contact with a transgender person is through mass media, and for many in the United States their introduction occurred when Caitlyn Marie Jenner came out as a trans woman in April 2015 in a televised interview with Diane Sawyer (Dooley et al. 2015). Jenner's transition was noteworthy because she was already a global celebrity as a result of a highly acclaimed career as an Olympic athlete in the 1970s and her appearance in the reality series Keeping $U p$ with the Kardashians that began in late 2007.

\section{Why would such media exposure matter?}

Social psychologists have generated literally hundreds of studies studying what is known as the Contact Hypothesis or Intergroup Contact Theory (Pettigrew \& Tropp 2006). The theory is based on the belief that prejudice is often based on ignorance, thus meaningful personal contact under proper circumstances with members of a minority group can challenge negative stereotypes and lead to a better understanding of that particular category of people. A stereotype is an 
oversimplified, typically false, negative attribute or quality that is associated with a group of people. Thus, as we learn about that group of people, we learn that the stereotype is false, or overgeneralized, and we learn about positive attributes of that group. The result can be a reduction of prejudice. ${ }^{8}$

A good deal of research has identified what the necessary conditions are to influence prejudicial beliefs, including sufficient contact that disconfirms stereotypes and forges intergroup friendships. Under the right conditions-including sustained and meaningful contact, equal status, shared goals, and lack of opposition by salient authority figures-majority group members are more likely to change how they categorize minority group members (Schiappa 2008, 94). The category may still exist (such as "Arabs" or "gay men") but the relevant attributes that "define" the category can be modified if the contact experience has been sufficiently positive to change attitudes (Brewer \& Brown 1998; Hewstone, Rubin, \& Willis 2002, 589-593; Oakes, Haslam, \& Reynolds 1999, 64). Though "definition" is too formal a term in this context, we can say that a person's list of defining attributes for a minority group can change through the process of getting to know members of that minority group under the right conditions.

My colleagues and I conducted a series of studies that were the first to document empirically that mediated or "parasocial" contact also can reduce prejudice (Schiappa, Gregg, \& Hewes 2005, 2006). We called our theory the Parasocial Contact Hypothesis and in the years since it has been introduced, a number of other studies also have proven that prejudice toward minority groups, and in particular Sexual and Gender Minorities, can be reduced through positive mediated contact (see, for example, Bond \& Compton 2015; Vezzali, Stathi, Giovannini, \& Trifiletti 2015). Our studies focused primarily on the portrayal of gay men on such shows as Will E Grace, Six Feet Under, and Queer Eye for the Straight Guy, but we also found that mediated contact from watching a televised stand-up comedy routine by cross-dressed Eddie Izzard could reduce prejudice toward transvestites, and portrayals of SGMs in feature movies could reduce prejudice (Schiappa 2008, 110-112, 151-155).

The potential influence of parasocial or mediated contact is strongest for people who lack an opportunity to meet members of a minority group in person. Our research found that the largest reductions of prejudice took place with individuals with the least amount of "real world" contact with sexual minority group members. Since surveys have shown that most people are not aware of knowing transgender people personally, mass media contact can play a particularly important role for people to learn about them.

The number of non-trans people directly familiar with transgender people is still small but has increased significantly. In 2015, GLAAD (formerly the Gay \& Lesbian Alliance Against Defamation) relayed the results of a Harris Poll of over 2,000 U.S. adults that found that the number of people reporting knowing or working with someone who is transgender had doubled from 8\% in 2008 to $16 \%$ in 2015 (Adam \& Goodman 2015). Similarly, political scientist Barry Tadlock and his colleagues (2017) conducted two national surveys in 2015 involving nearly 3,000 respondents and found that $15 \%$ reported knowing at least one transgender person. 
Using the feeling thermometer measure discussed earlier, Tadlock et al. found that the scores for transgender people were lower than most other groups, including gay and lesbian thermometer scores. As Contact Theory would predict, those respondents who knew transgender people personally reported higher feeling thermometer scores, suggesting they felt more warmly toward transgender people than did those without personal contact. Higher thermometer scores also correlated with greater support for civil rights policies for transgender people. Other research supports the applicability of Contact Theory to transgender people as a sexual minority. Jordan E. Greenburg and A. Celeste Gaia found that among a group of undergraduate students, interpersonal contact predicted lower prejudice toward transgender people, while acceptance of stereotypes and traditional gender roles predicted higher levels of prejudice (2019). Andrew R. Flores (2015) reports that positive attitudes toward transgender rights increase when there is direct contact with gay and lesbian friends or family, which Flores calls secondary interpersonal contact. A study of over 800 randomly selected Hong Kong Chinese residents found that previous contact with trans people was significantly associated with decreased social discrimination and "transprejudice," and increased support for transgender civil rights (King, Wainter, \& Webster 2009). Susan Walch and her colleagues documented that contact, even as minimal as attending a panel discussion featuring transgender people discussing their experiences, can lead to at least a short-term reduction in prejudice (Walch et al. 2012). Similarly, Flores and his colleagues found that people unfamiliar with transgender people could have their prejudice reduced even with brief, "mere exposure" to a photograph and brief vignette (Flores et al. 2018a). Collectively, such research suggests that learning about the particularities of transgender people's lives through direct contact can reduce prejudice, just as it has been shown to reduce prejudice toward other minority groups.

Research also demonstrates that mediated or parasocial contact with transgender people can decrease prejudice, as the Parasocial Contact Hypothesis would predict. The Caitlyn Jenner story is a possible example. In a survey of nearly 2,000 adults in 2015, Patrick R. Miller and his colleagues found that nearly $80 \%$ of respondents followed the story to some degree. As they note, "Jenner may be the first transgender person that many encountered either directly or parasocially. And, even among those who know a transgender person, Jenner could be the first familiar person they 'knew' throughout their gender transition" (Miller et al. 2020, 624).

Because the survey collected data after Jenner's public announcement, it cannot prove directly whether learning about the transition changed attitudes. Nonetheless, some of the data imply that Jenner's public announcement made an impact, especially among older respondents who remember Jenner's Olympic career. The authors found that

older respondents who were more transphobic were less likely to see her story as representing negative social trends if they followed it in the media. 
Furthermore, more transphobic older respondents were more likely to support pro-transgender policies if they viewed Jenner's story less negatively.

Using a statistical technique known as Propensity Score Matching, Miller et al. report in an unpublished version of the study that exposure to the Jenner story predicted reduced prejudice, thus "following the Jenner story itself as a form of parasocial contact may have caused ameliorated attitudes towards transgender people and rights" $(2019,26) .{ }^{9}$ Miller and his colleagues conclude that "the parasocial contact effect" underscores

the critical role of mass media portrayals of transgender persons-real or fictional-in shaping transgender rights attitudes. These portrayals can be politically impactful and are likely to reach larger audiences than transgender Americans can easily reach in face-to-face social interactions given their small numbers.

(2020, 631)

Moreover, Minjie Li's analysis of news coverage on major TV and newspaper outlets concerning transgender topics in the months before and after Caitlyn Jenner's coming out showed a significant change.

After Jenner's 20/20 interview, national news outlets are significantly more likely to apply alternative gender discourses, feature gender nonconforming individuals, address the complexity of transgender issues through mentioning race, class, and sexuality differences, differentiate transgender issues from LGB [lesbian, gay, bisexual] issues, and apply a thematic reporting approach.

Jenner's story was not the only case of increased transgender visibility. Though not receiving the same level of media coverage, the child of Cher and Sonny Bono transitioned from "Chastity" to "Chaz" between 2008 and 2010. A series of stories on Entertainment Tonight in 2009 provided national exposure to Chaz's transition, which reached the milestone of a legal name and gender change in May 2010. In 2013, Chelsea Manning (assigned Bradley Edward Manning at birth) medically transitioned while serving a seven-year (2010-2017) imprisonment for violating the U.S. Espionage Act for providing classified materials to Wikileaks about U.S. military actions in Iraq and Afghanistan.

In addition to the extensive media coverage of Jenner's transition in 2015, a reality show titled I am Cait ran for two seasons in 2015 and 2016. Other popular reality shows also featured transgender characters. Debuting in 2015, I am Jazz features "Jazz Jennings," a transgender teen young woman, and her family dealing with "typical teen drama through the lens of a transgender youth" (Grinberg 2015). As of 2020, I am Jazz is in its sixth season. New Girls on the Block, another reality 
show but one that features six transgender women, also debuted in 2015 and ran one season. Becoming Us was a reality show that ran for 10 episodes in 2015 focusing on a family whose father came out as a trans woman. Li's analysis of I am Cait, I am Jazz, and Becoming Us demonstrates

1) how family members unlearn gender hegemony and redefine gender and sexuality, and 2) how trans individuals reevaluate what it means to be a transgender person through negotiating with family members and other trans people. Together, they demonstrate a multidimensional construct of transgender subjectivity, which embraces and transcends transgender people.

(2021, 518)

Cumulatively, the shows provide an opportunity for parasocial contact through which cisgender viewers can learn about what it means to be transgender. As Li notes, "Most importantly, the depiction of the psychological shifts and coping mechanisms of transitioning with transgender loved ones guides outgroup audience through the process of learning what transgender identity is, how to live with it, and unlearning gender hegemony" (2021, 518).

In February 2017, the National Geographic network aired a two-hour documentary titled Gender Revolution: A Journey with Katie Couric that explored "the rapidly evolving complexities of gender identity" (Couric 2017). The program explored the history and changing beliefs and practices concerning the birth of babies with "intersex" (DSD) characteristics, as well as interviewing a number of transgender individuals of varying ages.

In addition to reality and news programing, fictional TV programs also increased transgender visibility. It is worth noting that the studies referenced earlier suggest that attitudes toward minority groups can be changed through mediated contact whether that contact is with "real" or fictional characters. Orange is the New Black debuted in 2013 and introduced the world to Laverne Cox as Sophia Burset, a transgender inmate in a woman's prison. The popular and award-winning comedy Transparent, starring Jeffrey Tambor, debuted in 2014 and ran for 41 episodes. Transgender characters have become increasingly common in mainstream programming, such as the introduction of "Nia Nal" in the fourth season of Supergirl in 2018, played by real-life transgender actress Nicole Maines. ${ }^{10}$ GLAAD reports that in the 2020-2021 television season, there were 29 regular and recurring transgender characters, a record high (2021).

Traditional television and movies are not the only media through which people can learn about transgender people. YouTube, for example, has emerged as a particularly noteworthy platform for transgender youth to share their experiences. Film Studies professor Laura Horak suggests that

trans YouTube videos succeed because their formal strategies exploit the platform's penchant for the personal and the spectacular. Trans 'talking head' videos expand the tradition of the feminist consciousness-raising documentary 
to establish trans youth as experts and create a sense of intimacy between vloggers and viewers.

Brandon Miller surveyed the content of YouTube videos and studied an enormous amount of educational content by eight popular transgender YouTubers. Because the Internet is a relatively safe space for people to explore new information and lifestyles, Miller hypothesizes that "the Internet may be able to function as a tool for decreasing transphobia in society” (2017). Nikkie de Jager, a highly successful Dutch YouTuber who specializes in beauty tutorials, came out as transgender in January 2020 to her 13 million subscribers ("NikkieTutorials" 2020). As of October 1, 2021, her 17-minute "I'm Coming Out" video has been viewed over 37.5 million times. ${ }^{11}$

Cumulatively, such media content provides an opportunity for many viewers to get to know transgender people and learn about their experiences. Such parasocial contact has the potential to reduce anti-trans prejudice and, indirectly, increase support for transgender rights (Flores et al. 2018b). A promising empirical example is reported by $\mathrm{Li}$, who conducted an experiment using short clips from the reality show Becoming Us, to support the contention that a positive narrative involving a transgender character can result in a modest improvement in attitudes toward transgender people as a whole (2019a).

The positive influence of parasocial contact is not limited to programming that focuses chiefly on transgender characters. A study involving over 400 U.S. adults conducted by scholars at the University of Southern California examined whether exposure to a single episode of Royal Pains that focused on a transgender character could influence attitudes: "Those U.S. respondents who saw a storyline featuring a transgender adolescent on the TV show Royal Pains had more positive attitudes toward transgender people and policies compared to Royal Pains' viewers who did not see this particular storyline" (Gillig et al. 2018, 523). For the purposes of educating those without direct personal contact with transgender people, "even single-episode characters and relatively brief storylines can be influential" (2018, 523). The fact that the lead character of Royal Pains is not transgender may have increased the odds that viewers who were not otherwise trans-friendly might view the episode and still learn from the parasocial contact. As the study's authors note, "smaller storylines featuring transgender characters in mainstream programming have the potential to improve the attitudes of more conservative viewers who may not seek out transgender depictions" $(2018,524)$. This sort of attitude influence is not limited to television or video. Ligia Orellana, Peter Totterdell, and Aarti Iyer found that even reading fictional narratives involving transgender characters has the potential to decrease prejudice (2020).

According to a survey commissioned by the Human Rights Campaign in 2016, $35 \%$ claimed to know someone personally who is transgender (HRC 2016). And in a survey reported by The Economist in 2019, that number had climbed to $39 \%$ (Frankovic 2019). These figures are considerably higher than surveys conducted a 
year or two earlier and may be statistical outliers. Or it may be that the dramatic increase in transgender visibility in 2015 led more transgender people to come out as trans, or perhaps those answering the survey felt that they knew people via the media well enough to "count" as personal acquaintances. In any case, the significant increase in the number of people claiming to know someone who is transgender is noteworthy.

\section{The Transgender Exigence}

It is clear that transgender visibility is increasing, and with it, a reduction of antitrans prejudice among some Americans resulting from direct or mediated contact. In the legal sphere, the reduction of anti-trans prejudice has been accompanied by "remarkable success" in the advancement of transgender rights (Taylor, Lewis, \& Haider-Markel 2018, 302). The past 25 years of gay and lesbian legal rights demonstrates how quickly the legal situation potentially can change for a sexual minority (Michelson \& Harrison 2020). In a relatively short time, historically speaking, the United States has moved from being a nation in which homosexual acts could be criminalized (affirmed by the Supreme Court in 1986 in Bowers v. Hardwick), to one in which homosexuals could not be singled out as a group by discriminatory laws (Romer v. Evans 1996), could not be prosecuted for homosexual conduct (Lawrence v. Texas 2003, overturning Bowers), to having a constitutionally protected right to marry (Obergefell v. Hodges 2015), and be protected from job discrimination (Bostock v. Clayton County 2020).

Just as public opinion and the U.S. court system has become more favorable toward the rights of gay men and lesbians, one might anticipate a similar shift toward more favorable attitudes toward transgender equality. When asked in general terms, most survey respondents claim to support rights and legal protections for transgender people (Jones \& Cox 2011). In a 2017 survey of 1000 people, for example, $73 \%$ agreed with the statement that transgender people should be protected from discrimination (Luhur et al. 2019). A PBS NewsHour/NPR/Marist poll reported in April, 2021 that about two-thirds of Americans "are against laws that would limit transgender rights," including legislation that would prohibit gender transition-related medical care for minors and that prohibits transgender student athletes from joining sports teams that match their gender identity (Loffman 2021, cf. McCarthy 2021).

Despite signs of progress, however, reports of increasing violence against transgender individuals, especially women, underscored the extreme antipathy still held by many. As trans author Katelyn Burns claims, the decade 2010-2019 was a double-edged sword for trans people: "The internet made trans people visible. It also left them vulnerable" to various backlash efforts (2019). Mia Fischer in her book, Terrorizing Gender, describes the increased visibility of transgender people as a "trap." Fischer quotes trans activist Tourmaline: "Just because we're being seen, doesn't mean we're any safer. Hypervisibility endangers us, representation is a trap" (2019, 169; see also Stanley, Burton, \& Gossett 2017). 
Media coverage can contain "legitimizing" as well as "delegitimizing" language to describe transgender individuals and issues. Thomas J. Billard analyzed nine aspects of the language used in media coverage and argues that delegitimizing language can "detrimentally impact both the projected legitimacy of transgender claims in the political arena and public perceptions of the transgender community" (2016, 4193). Barry L. Tadlock notes that the dominant frames in mainstream newspaper coverage during the period of 1992-2011 of transgender people and issues was different from the framing of gay and lesbian issues. While framing of lesbian and gay rights issues typically pit equality versus "traditional values," the frames for articles about trans issues or people were more diffused and included education, equality, liberty, safety/security, and pathology. Transgender issues are almost always described in highly individualistic rather than systemic terms. Tadlock also found that in about half of the studies analyzed, there is "an explicit positive or negative perspective" articulated about rights. Ten of the 29 articles with an explicit orientation were "antirights" $(2014,36)$.

How do we reconcile support stated in surveys for transgender rights with the considerable evidence of discrimination and prejudice toward transgender people? First, while many people will agree with abstract statements about transgender civil rights, the answers turn in a less tolerant direction when the issues are more concrete. Political Scientist Philip Edward Jones and his colleagues' study of public attitudes toward transgender people, for example, found “majority support on most policy questions, but more tepid views of transgender people, and solid opposition to supporting a transgender candidate for office" (Jones et al. 2018).

Second, it is worth recalling that productive, prejudice-reducing contact requires the support - or at least the lack of opposition — of salient authority figures. In the aftermath of the election of Donald Trump as president in 2016, "attacks on transgender rights intensified both at the national and local levels," as the Trump administration moved quickly to reverse Obama-era protections for transgender students, prison inmates, and troops (Michelson \& Harrison 2020, 6). As Jones and Paul R. Brewer document, public opinion toward transgender rights can be influenced by what political elites publicly advocate (2020). Beginning in 2016, liberal and conservative elites became increasingly and visibly polarized on transgender rights, and their debates in turn influenced the electorate: "If political elites continue to send ideologically polarized messages in the future, then we would expect to see increasing polarization among the mass public" (Jones \& Brewer 2020, 82). Such continued polarization is evidenced by the fact that by early 2021 , more than 20 "anti-LGBTQ" bills have been introduced in more than a dozen states (Andrew 2021; Moreau 2021).

Third, for reasons researchers are still exploring, prejudice toward transgender people is more resistant to change than prejudice toward gay men and lesbians. The sources of prejudicial attitudes and behaviors toward transgender people can include the belief in heteronormativity that animates anti-gay prejudice, but also includes lack of accurate information, deeply held beliefs in a gender binary, lack of contact with transgender people, and political conservatism (Michelson \& 
Harrison 2020, 7). Jones and Brewer summarize the survey research: "Respondents who hold higher levels of authoritarianism, more disgust sensitivity, less egalitarian attitudes, more conservative ideologies, and greater religiosity view transgender people less warmly and are less likely to support their rights" (2020, 72). Furthermore, the contexts associated with transgender rights-such as access to public bathrooms - appear to elicit fears that no longer surface in discussions of gay rights. In some contexts - notably in competitive sports - the gains made by transgender people may be perceived as requiring a commensurate loss by cisgender people. As Melissa R. Michelson and Brian F. Harrison note in their book, Transforming Prejudice: Identity, Fear, and Transgender Rights:

Transgender women Marsha Johnson and Sylvia Rivera were leaders of the Stonewall Riots of 1969 that marked the symbolic launch of the modern gay rights movement. Yet, 50 years later, the ability of transgender people to live openly and without fear of discrimination or violence lags far behind that of gay men and lesbians.

(2020, 154)

As is explored at length in Part II of this book, there are multiple sites of conflict in the U.S. over transgender rights that are informed by conflicting definitions of sex and gender. While some states have moved to enable high school transgender athletes to compete with the gender of their choice, other states have moved in the opposite direction to forbid transgender athletes from competing. There is disagreement over how to define men and women for the purposes of incarceration in state and Federal prisons. State and local efforts arose in 2016 to preclude transgender individuals from using the public bathrooms of their choice, leading to highly visible political battles amplified by calls for economic boycotts of jurisdictions passing such restrictions. In 2017, President Trump announced his intention to ban transgender individuals from the U.S. military, eliciting considerable opposition and claims of illegal discrimination. In 2021, one of the first actions of President Biden was to reverse Trump's ban. There is disagreement over whether transgender students should be allowed to matriculate to single-sex high schools and colleges. Some academic and activist feminists are at odds over whether and how to "count" transgender women. Cumulatively, these factors have made it clear that there is considerable disagreement over how sex and gender ought to be understood and defined as well as who should have a right to define them.

The situation will grow more urgent as we move forward. Andrew Flores and colleagues estimated in 2016 that $0.6 \%$ or 1.4 million Americans identify as transgender (Flores et al. 2016). ${ }^{12}$ That number is likely to grow in the future. Data collected by the Minnesota Department of Education in 2019 about nearly 125,000 students in the 8 th, 9 th, and 11 th grade found that $1.4 \%$ of them described themselves as transgender, nonbinary genderqueer, genderfluid or "something else" other than cisgender. About half of those students identified as transgender, the other half as nonbinary genderqueer, genderfluid or "something else." 13 The 
number may be higher nationally: Survey data collected in 2017 from 10 states and nine urban school districts reported to the Centers for Disease Control and Prevention found that an average of $1.8 \%$ of high school students identify as transgender (Johns et al. 2019). What sort of rights will they have? Who should have the power to define sex and gender?

As stated in the Introduction, there are two quite disparate ways of defining sex and gender. Biological determinists argue that gender and biological sex are evident at birth or earlier, and that one's medical designation should determine a host of legal and societal constraints based on one's assigned sex. For example, the Southern Baptist Convention approved a resolution on transgender identity that affirmed "God's good design that gender identity is determined by biological sex and not by one's self-perception - a perception which is often influenced by fallen human nature in ways contrary to God's design" (“On Transgender Identity” 2014).

On the other end of the spectrum, those who might be called autonomous nominalists or advocates of an unadulterated version of "self-identification" contend that gender identity is a purely personal decision and, as such, should be respected and never regulated or discriminated against. The very first item in the International Bill of Gender Rights approved at the fourth annual International Conference on Transgender Law and Employment Policy states that "all human beings have the right to define their own gender identity regardless of chromosomal sex, genitalia, assigned birth sex, or initial gender role; and further, no individual shall be denied Human or Civil Rights by virtue of a self-defined gender identity which is not in accord with chromosomal sex, genitalia, assigned birth sex, or initial gender role" (Frye 1995, ix). An example of the practical application of that right can be found in the San Francisco Human Rights Commission's Compliance Guidelines to Prohibit Gender Identity Discrimination, which states: "An individual determines their own gender identity and the sole proof of a person's gender identity is that person's statement or expression of their self identification" (2003).

Regulatory definitions involving sex/gender are where the proverbial rubber meets the road when it comes to transgender rights. I turn now, in Part II, to a series of contexts where such definitions are being contested.

\section{Notes}

1 De Mars (2017).

2 Jennings $(2016,14)$.

3 For a discussion of the cultural significance of the scene, see Piatkowski (2017).

4 The documentary Disclosure (2020) illustrates how pervasive negative portrayals of transgender people have been in TV and film history and how much progress has been made.

5 There are longer acronyms that are even more inclusive, including LGBTQQIAAP: Lesbian, Gay, Bisexual, Transgender, Queer, Questioning, Intersex, Allies, Asexual, Pansexual.

6 Biden repeated this comment in the Foreword to McBride (2018, xii).

7 In the world of academia, it is worth noting that Transgender Studies Quarterly began publication in May 2014. 
8 The Contact Hypothesis was an important argument in racial desegregation cases in the 1950s, including Brown v. Topeka Board of Education (Jackson 2001).

9 Propensity Score Matching is a statistical matching technique that estimates the effects of a test condition (in this case, engagement with the Jenner story) by accounting for the covariates that predict receiving the test condition (Rosenbaum \& Rubin 1983). The relevant portion of the unpublished essay is as follows: "Propensity Score Matching: Our analysis thus far suggests that engagement with the Jenner story corresponded to improved attitudes towards transgender people and rights, most notably for older respondents who also exhibited higher transphobia. Obviously, our ability to draw conclusions about the mechanisms at work here are limited given the observational nature of our survey data. If we conceive of following the Jenner story as the dichotomous 'treatment' to which respondents were either exposed or not, a clear limitation in our non-experimental data is systematic self-selection in choosing whether to follow that story which then confounds any comparison of outcomes between the two treatment groups.

However, addressing RQ2, it is possible to estimate treatment effects from nonexperimental or observational data using propensity score analysis which is conventionally interpreted as inferring causality (Guo \& Fraser 2015). We used the Stata psmatch2 package for our propensity score analysis, using nearest neighbor greedy matching with replacement and a standard caliper of 0.25 SD. Given these specifications, all cases were matched. As with our earlier analysis, the treatment was whether the respondent followed the Jenner story to any degree (1) versus not at all (0). Consistent with our analysis of following the Jenner story, variables used to calculate propensity scores included: age, church attendance, education, income, race, sex, partisanship, ideology, and LGBT identity. Bias on matches was within the conventional $5 \%$ tolerance.

Using this method, we assessed treatment effects on four outcomes: the transphobia scale, a transgender feeling thermometer, comfort with transgender persons, and the transgender rights policy scale. In the unmatched analysis, the mean scores on all four outcome measures for the treated group that followed the Jenner story varied significantly in the pro-transgender direction from the mean scores of the untreated group: These included mean differences of 0.55 units on the transphobia scale $(p<.001), 0.34$ units on the comfort item $(p<.001), 11.56$ units on the feeling thermometer $(p<.001)$, and 2.61 units on the policy scale $(p<.001)$. The matched analysis respectively reduced the magnitudes of these differences to 0.47 units $(p=.005), 0.25$ units $(p=.044), 8.56$ units $(p<.001)$, and 1.37 units $(p=.027)$. The treatment, then, yielded significant differences on the four outcome variables. Though these matched effects were of reduced magnitude, this suggested that following the Jenner story itself as a form of parasocial contact may have caused ameliorated attitudes towards transgender people and rights" (Miller et al. 2019, 25-26).

10 Wikipedia maintains a page titled "List of transgender characters in film and television" that documents the increasing frequency of transgender characters in T.V. and film.

11 My thanks to Lauren Murray for calling my attention to NikkieTutorials and the impact of her coming out as transgender.

12 The question of counting the number of transgender people in the U.S. is more complicated than citing a simple figure would suggest. In 2015, the entire February issue of Transgender Studies Quarterly was devoted to a discussion of "tensions among what to count, whom to count, how to count, why to count, or whether to count or be counted at all" (Currah \& Stryker 2015, 1). See also the meta-analysis of medical literature published by Collin et al. (2016).

13 Data available at: https://public.education.mn.gov/MDEAnalytics/DataTopic.jsp?TO $\mathrm{PICID}=242$ 
$\because$ Taylor \& Francis

Taylor \& Francis Group

http://taylorandfrancis.com 


\section{PART II}

\section{Definitional contexts}

Part II of the book does not attempt to discuss all situations in U.S. life that segregate females and males, but rather focuses on a set of contexts where there are controversies specifically involving transgender men and women. It is my hope that the principles, values, and interests involved in these contexts can be applied by analogy to other contexts. The modus operandi of these chapters is to describe the history and rationale for separating males and females in a particular context, then explore the definitional controversies evinced by what I am describing as the Transgender Exigency. Then we can be in a position to explore the questions: Who has the right to define? What is the purpose of definition in this context? What values and interests are advanced by different definitions?

It may be useful at this juncture to distinguish between two related but distinct phenomena. What I am describing as the Transgender Exigency is the challenge to traditional definitions of women and men fueled by individuals whose gender identity is specifically at odds with their assigned sex. Well-known examples include Caitlyn Jenner and Chaz Bono, discussed in Chapter 3. These two examples involved a medical as well as social transition from one gender to another. I fully recognize that not all transgender people undergo medical transitioning efforts that include hormones and/or surgery. Nonetheless, categories come to be understood with what are prototypical examples, and I think it is fair to say that for most people, as noted in the Introduction, the category "transgender" describes people whose personal sense of gender does not correspond to their assigned sex, and they wish to transition at least socially if not physically.

As noted earlier, the transgender phenomenon is related but conceptually distinct from a larger cultural phenomenon of gender variance. People who exhibit gender variance have been described variously as androgynous, gender fluid, gender bending, gender diverse, nonbinary, pangender, and in general "gender nonconformist." The distinction can be important. For feminist scholars of the 1970s and 
1980s, the point of identifying gender norms and social conventions was to undercut their cultural force-to free people from behavioral and social expectations that were based on their biological sex. For some gender nonconformists, traits traditionally identified as masculine or feminine are accepted as masculine or feminine, but nonconformists want the freedom to express their gender with whatever combination of traits they choose. For example, a person can present as a "femme" transgender woman and still consider themselves as nonbinary (Williams 2019).

To the extent that labels of being a woman or a man are important to the individual, the strongest form of gender nonconformity is consistent with the idea previously described as autonomous nominalism (self-identification), but with the added idea that any particular gender identity can be ephemeral — that is, transitory and temporary - as opposed to an enduring commitment. Such a position stands in opposition to typical regulatory requirements that connect "the legitimacy of an identity with its duration across time" (Draz 2019).

For some gender nonconformists the very idea of "gender" seems obsolete and as a society we should embrace "postgenderism." Shulamith Firestone advocated the spirit of postgenderism even before "gender" entered the vocabulary of feminist politics. She wrote in 1970 that, "[The] end goal of feminist revolution must be, unlike that of the first feminist movement, not just the elimination of male privilege but of the sex distinction itself: genital differences between human beings would no longer matter culturally" (11). Similarly, though Sandra Bem did not use the term "post-gender," in hindsight it seems fair to describe her dream as a postgender society: "[H]uman behaviors and personality attributes should no longer be linked to gender, and society should stop projecting gender into situations irrelevant to genitalia" $(1983,616)$.

Though I know of no empirical work yet done on the question, I would hypothesize that a majority of (though certainly not all) transgender individuals do not adopt a "post-gender" attitude; in fact, the choice to transition most often accepts the gender categories of women and men. I concede it is hazardous to generalize. Indeed, in the inaugural issue of Transgender Studies Quarterly, Eric A. Stanley suggests that an ethic of gender self-determination must resist efforts to normalize and thus perpetuate traditional gender categories. Apparently well-meaning transgender equity efforts "work to translate and in turn confine the excesses of gendered life into managed categories at the very moment of radical possibility" (Stanley 2014, 90).

The famous transgender tennis player, Renée Richards, is interviewed in the documentary Gender Revolution and explicitly accepts a binary approach to gender: "I had a very happy life for 40 years as a man and I'm having a very happy life for 40 years as a woman, but that doesn't mean that I'm gender fluid" (Couric 2017; see also Pieper 2012). Asked about the gender binary, Richards comments "I think it's appealing and I like it." In the same interview, trans activist Hari Nef, by contrast, hopes for what she calls a fluid and "gender chill future," which sounds much closer to a post-gender culture. Surveys of adolescents find that an increasing number embrace a label other than cisgender or transgender. In addition to the data 
reported by the Minnesota Department of Education, cited in the last chapter, a 2017 national survey of over 17,000 young people (13-17 years old) who identify as LGBTQ found over twice as many described themselves as nonbinary than as transgender (Watson, Wheldon, \& Puhl 2020).

Why is it useful to draw a distinction between the Transgender Exigency and the larger question of gender nonconformity? The definitional rupture I describe as the Transgender Exigency matters only when a person is committed to being a woman or man in a particular organizational or institutional context that actively separates men and women, such as competitive sports, single-sex schools, prisons, etc. If I was assigned the sex "male" upon birth, how I choose to express my gender-how I dress, how I behave, and how I describe myself-is up to me until such time that I interact with organizations or institutions that regulate membership or activities according to how they define gender. As sociologist Tey Meadow observes, "We all carry a gendered subjectivity, but we live that subjectivity intersubjectively" (2018, 226). That is, when gender is a salient feature of our social identity that requires social recognition, sometimes negotiation, then definitional regulation may be part of that process. It is the process of reformulating these regulatory definitions in a time of growing awareness and controversy over transgender rights that is the focus of the following chapters.

Each chapter will consider a specific context in which there are competing definitions of sex and/or gender. As mentioned in Chapter 1, the classic Aristotelian form for definition is " $\mathrm{An} \mathrm{X}$ is (a kind of) class name that has such-and-such attributes." Accordingly, the initial question when describing and understanding competing definitions is: What attributes are considered definitive? Then we are in a position to ask: Why? What values, interests, or purposes are served by privileging one set of attributes, say, $X X$ v. $X Y$ chromosomes, over other attributes, such as one's gender expression (a person's behavior, mannerisms, interests, and appearance that are associated with a recognized gender) in a particular cultural context?

\section{A note about terminology}

For the rest of the book, I use the word sex when a conventional biological sense is appropriate (often reflected with the terms male/female), gender when the focus is on cultural recognition of the social roles we associate with girls/boys, women/ men, and sex/gender when it strikes me as prudent to treat the two concepts as different sides of the same coin, as described in the third stage of theorizing sex and gender in Chapter 2. 


\section{Transgender voices}

"I had a bit of suspicion that my application [to Smith College] would not receive the same treatment as any FAAB (female assigned at birth) applicant."

"When I was younger, I went to an all-boys school, and right across there was this school just for girls. And I remember telling myself, oh my gosh, I want to go there." [After arriving at Wellesley] "as soon as I put my feet into the ground, I just rooted like a tree. I told everybody, 'I belong here! I belong here!'”

Ninotska Love, first openly transgender student at Wellesley College, $2017^{2}$

"What I love so much is that Barnard really challenges you to rethink and reshape the identities you come in with and to both form a space and a self that has room for everything you want to be. . . This is not a space that I think of as excluding people who don't fall into a predetermined category of women, but rather of coming together to reshape how we draw those categories for ourselves and for our peers and for our community."

Aydan Shahd ${ }^{3}$ 


\section{4}

\section{SINGLE-SEX SCHOOLS}

\section{Colleges}

Colleges in the United States began as male-only institutions, typically funded by religious denominations. What is now known as Harvard University was founded in 1636 to train clergy for the growing colonial population from England. Harvard, like other colleges founded before 1800, such as Yale, Princeton, William \& Mary, St. John's, and the University of Pennsylvania, only admitted men. The first coeducational college in the United States was Oberlin College in Ohio. Though founded in 1833, its first female students did not matriculate until 1837. The first women's colleges were Wesleyan College in Georgia, chartered in 1836, and Mount Holyoke College in western Massachusetts in 1837.

The exclusion of women from U.S. colleges reflects the cultural norms of the time. Men were educated to participate in the public sphere of business and politics whereas women were largely confined to the private sphere to care for home and family:

The colonial view of woman was simply that she was intellectually inferior-incapable, merely by reason of being a woman, of great thoughts. Her faculties were not worth training. Her place was in the home, where man assigned her a number of useful functions.

(Rudolph 1962, 307-308)

Women's colleges were founded with a mission to provide young women with an education of the same quality as that available to men. As historian Estelle B. Freedman noted, "When elite male institutions refused to educate women, the sister colleges of the East, like their counterparts elsewhere, took on the task themselves" (1979, 517-518). 
While some early women's institutions of higher learning were limited mostly to preparing women to be wives and mothers, others were designed to be seminaries for women, and others still had a more feminist goal of educating and empowering women to be successful leaders in any field (Horowitz 1993). The very idea of women attending college was opposed by some who felt that women belonged in the home, or that women were too frail for college, or would lose their femininity by attending college. In the famous Declaration of Sentiments emerging from the first Women's Rights Convention at Seneca Falls, one of the injuries on the part of man toward woman is that "He has denied her the facilities for obtaining a thorough education, all colleges being closed against her" (Stanton 1848). Social movements such as women's suffrage and the abolition movement contributed to the founding of some women's colleges (Langdon 2001). The founder of Wellesley College declared in The Spirit of the College that

We revolt against the slavery in which women are held by the customs of society - the broken health, the aimless lives, the subordinate position, the helpless dependence, the dishonesties and shams of so-called education. The Higher Education of Women is one of the great world battle-cries for freedom; for right against might. It is the cry of the oppressed slave. It is the assertion of absolute equality.

(Durant 1890, 3$)^{4}$

Only some founders of women's colleges publicly embraced tenets we would now call feminist (indeed, some felt the need to be quite circumspect in their politics), but in hindsight the establishment of significant number of high-quality women's colleges can be seen as a profoundly feminist accomplishment.

We have moved from an age when all U.S. colleges were single-sex (specifically male) to an era where single-sex colleges are a rarity. Of the 233 women's colleges in 1960 (Langdon 2001), less than 40 remain operating today, and there are only four men's colleges left. Women's colleges persist largely for what can be described as feminist reasons - to counteract the discrimination and sexism that is still evident in coeducational institutions, even though women now outnumber men in college (Goldin, Katz, \& Kuziemko 2006), and thus to provide a more supportive and favorable climate for women's learning and achievement (Langdon 2001).

Describing how these single-sex colleges have responded to the Transgender Exigency is the objective of this chapter.

\section{Women's colleges}

In 2013, Calliope Wong, a transgender woman who was a senior in high school, was denied admission to Smith College because her Federal Student Aid application form identified her as male. Her application and application fee were returned to her with the explanation that Smith College required applicants to be female at the time of admission. Wong certainly was not the first trans woman 
to seek admission to an all-women's college, but aided by the power of social media, she became a cause célèbre as her blog and her story were widely shared and became national news. Sympathetic Smith students formed Facebook groups in support, and national organizations such as the Transgender Legal Defense \& Education Fund rallied to her cause (see, for example, McQuade 2013). Wong ultimately chose to attend the University of Connecticut. Nonetheless, accounts of women's colleges' policies toward transgender applicants typically point to her efforts as a catalyst for women's colleges to clarify and publicize their policies. Admission policies involving transgender applicants ultimately turn on a question that resists but requires definition: "What does it mean to be a woman?" (Davis 2017, 82).

A year later, in May of 2014, Mills College became the first U.S. women's college to create a formal written admissions policy that includes transgender and gender fluid applicants. Their stated policy says "Mills admits self-identified women and people assigned female at birth who do not fit into the gender binary" (Mills 2020). Both Mills and Smith Colleges claim to have been open to transgender students before their official policy statements, but because such decisions were made on an ad hoc basis, there was a lack of clarity that could lead to controversies such as Wong's denial of admission to Smith (Bennett-Smith 2013; Martin 2013; Mitchell 2014). Smith College followed suit in May of 2015, and in a remarkably short period of time, most women's colleges in the United States have published policies allowing transgender women to apply.

As of April, 2020, a substantial majority of the 39 colleges that are members of the Women's College Coalition have revised their policies to permit transgender women as applicants, including Agnes Scott College, Alverno College, Barnard College, Bay Path University, Bennett College for Women, Brenau University, Bryn Mawr College, Cedar Crest College, College of Saint Benedict, Converse College, Cottey College, Hollins University, Mills College, Moore College of Art and Design, Mount Holyoke College, Russell Sage College, Salem College, Scripps College, Simmons University, Smith College, Spelman College, Stephens College, Sweet Briar College, Trinity Washington University, Wellesley College, and Wesleyan College. ${ }^{5}$

The precise definitional criteria at work at these institutions vary. At one end of the spectrum, some institutions merely require applicants to self-identify as women. Smith College's admission policy declares, "We welcome applicants who identify as women, including those who were assigned male at birth. No specific documentation is required to verify an applicant's gender" (Smith 2020, emphasis added). Bennett College for Women, Cedar Crest College, Mills College, Russell Sage College, Simmons University, are others who simply ask for self-identification, and Cedar Crest explicitly says "We do not require government issued documentation for purposes of identifying an applicant's gender identity" (Cedar Crest 2020). Mount Holyoke's admission webpage states simply, "We welcome applications from female, transgender and nonbinary students" (Mount Holyoke 2020). Put into the form of a regulatory definition (X counts as $\mathrm{Y}$ in context $\mathrm{C}$ ), then the sole definitive attribute is 
self-identification: Anyone who self-identifies as a woman (X) counts as a woman $(\mathrm{Y})$ in the context of applying to this institution (C).

A second common definitional approach goes a step further to require applicants to have an established history as women. The most common wording here requires applicants to "consistently self-identify and live as women." Similar wording to "consistently live and identify as women" can be found at a variety of schools, including Alverno, Barnard, Bryn Mawr, Spelman, and Wellesley. The FAQs for some colleges admission policies answer the obvious follow-up question of "What does it mean to consistently live and identify as a woman?" Barnard College states:

The applicant must identify herself as a woman and her application materials must support this self-identification. If the applicant is concerned about discrepancies in her application materials, she can speak with an admissions counselor or address any concerns in the essay or personal statement.

(Barnard 2019)

Hollins University similarly suggests that "The applicant must affirmatively identify herself as a woman and her application materials must support this self-identification" (Hollins 2020). It is not unusual at these institutions to seek supporting evidence of this self-identification (see also Bryn Mawr 2020; Wesleyan College 2020). Hence the regulatory definition could be formulated as: Anyone who consistently lives and identifies as a woman (X) counts as a woman (Y) in the context of applying to this institution (C).

The first definitional approach, explicitly requiring only self-identification, varies from this second approach primarily based on the reduced emphasis on the definitive attribute of duration. Sherie Gilmore-Cleveland, Director of Admissions of Mills College, states,

Students' self-identification does not have to match school documentation. If we have questions regarding a student's self-identification we inquire with the student based on their answers for clarification. The question of eligibility is based on the student's self-identification not a span of time.

(Gilmore-Cleveland 2020)

The President of Cedar Crest College, Dr. Elizabeth Meade, explained that decisions about gender identity sometimes emerge late in adolescence, and some students may come from homes where gender nonconformity might not feel comfortable or safe. A decision to transition to female might begin at the start of college, in other words. Accordingly, at Cedar Crest there is no specific requirement about the previous duration of an applicant's self-identification as a woman, but there is an "expectation that you will come to the college and continue to identify as a woman" (Meade 2020).

A third and less common definitional requirement is that applicants must have completed the process of legally changing their sex on official documents. 
According to the survey conducted by Vox (North 2017), Converse College, Cottey College, Salem College, and Scripps College will admit trans women if they have been legally assigned female. Sweet Briar College will admit a trans woman if she has been able to change her birth certificate to female. Stephens College admission policy says they "will also admit and enroll students who were not born female, but who identify and live as women; those students will need to provide legal documentation that they are legally women or that they are transitioning to female" (Stephens College 2018). Thus the regulatory definition would be anyone who is legally recognized as a woman $(\mathrm{X})$ counts as a woman $(\mathrm{Y})$ in the context of applying to this institution (C).

It is interesting to note that some institutions have loosened definitional criteria over time. In a 2017 survey, Hollins University required applicants to have legally and surgically transitioned (North 2017). As of 2020, their website uses the more common wording of requiring applicants to "consistently live and identify as women" (Hollins 2020).

The other area of variation is how different women's colleges treat students who transition from female to male while attending the institution. Some institutions require such students to leave, while others allow them to stay and graduate (North 2017). Converse College, for example, stresses that, "At the heart of Converse College is a women's college which offers a distinctive undergraduate program for women." Accordingly, taking a new self-identification seriously, the College does not permit students who transition to male (medically or legally) to continue their studies there, and may relocate them in terms of their campus housing (Converse College 2020). Wellesley College, on the other hand, explicitly states that they will "support" students who no longer identify as women after matriculation, allowing such students to stay at Wellesley or transfer to another institution (Wellesley College 2020). At Mills College, a transgender man not only was permitted to stay at the college but was elected student body president (Mitchell 2014).

Why have women's colleges moved to accept transgender applicants? The core value that seems to inform the changing policies is a commitment to the cause of feminism, which includes an acknowledgment that women have long endured discrimination. Priya Kandaswamy, a faculty member at Mills College who was on the subcommittee that drafted their new transgender policy, is quoted as saying "We strongly identify with our original mission, but we do think that women's colleges were originally founded to make education more accessible for those who were discriminated against based on gender and today that includes transgender" (in Mitchell 2014). Similarly, trans activist and law professor Dean Spade argued that trans people "fit" at women's colleges to create a space "that is about addressing gender oppression in higher ed" (Spade 2014). In a public letter by Wellesley College's president and Board of Trustees chair announcing the decision to consider any applicant who "lives as a woman and consistently identifies as a woman," it was noted that the origin of Wellesley was an important social-political accomplishment: "The creation of Wellesley College was a revolutionary act, challenging and confounding entrenched views about the roles and capacities of women." They 
further said, "Despite all the progress of the past century, women still face hurdles in realizing their potential." Accordingly, the feminist rationale for the formation of the College continues: "It is clear to us that the concept of a women's college, and the reasons for having one, are as valid today as they have been at any time in the past" (Gates \& Bottomly 2015).

As described in Chapter 2, feminist scholars were the first to describe the social and cultural variability of gender identity. Thus, for one graduate of Mills, allowing transgender women to apply was "the right move" to "remain a women's college while also having a more inclusive view of gender identity rather than relying on what it says on a person's documents" (in Mitchell 2014). It is also worth mentioning at this point that women generally report lower levels of transgender prejudice or "transphobia" than men do (Nagoshi et al. 2008).

Not everyone at women's colleges is happy with the admission of transgender students. There is a strand in contemporary feminist theory that will be examined at greater length in a later chapter known as "gender critical" feminism that questions whether cisgender women and transgender women share sufficient history and interests to be politically allied. At times the debates between feminist scholar/ activists have grown quite heated. In April 2020, Ninotska Love, one of the first openly transgender woman admitted to Wellesley College, was subjected to a series of hostile postings in the online platform Reddit in a discussion group titled Gender Critical Feminism (with roughly 60,000 members). ${ }^{6}$ The incident prompted Wellesley's president to send out an email reaffirming the College's commitment to "the basic human rights, dignity, and well-being of all Wellesley transgender and gender nonbinary community members" and declaring that the incident is "currently being investigated by both our Title IX coordinator and by Campus Police" (Johnson 2020).

To summarize the chapter thus far, women's colleges have responded to the Transgender Exigency in various ways. Some do not admit transgender women, and those that do vary in the definitional criteria used to decide who "counts" as a woman for the purposes of admission. The colleges and universities that admit transgender women do so, it would seem, because they see "women" as a category in which cisgender and transgender women share similar social-political status.

\section{Men's colleges}

As of 2020, the number of single-sex colleges for men has dwindled to four in the U.S.: Wabash College in Crawfordsville, Indiana; Morehouse College, a historically black men's college in Atlanta, Georgia; Hampden-Sydney College in HampdenSydney, Virginia; and Saint John's University in St. Joseph, Minnesota. Currently, two of the four do not admit transgender men (Jaschik 2019). St. John's University announced in November 2016 that it would consider transgender applicants:

In furtherance of our mission, tradition, and values as an undergraduate college for men, and in recognition of our changing world and evolving 
understanding of gender identity, Saint John's University will consider for undergraduate admission those applicants who consistently live and identify as men, regardless of the gender assigned to them at birth.

(SJU Trustees 2016)

The mission of St. John's University is specific to men:

Grounded in Catholic and Benedictine values and tradition, Saint John's University provides young men a distinctive residential liberal arts education, preparing them to reach their full potential and instilling in them the values and aspiration to lead lives of significance and principled achievement.

(SJU 2020)

Furthermore, the University identifies a set of values to which the institution is committed:

- Community built upon relationships of hospitality, respect, cooperation, and challenge.

- Openness to learning, inquiry, beauty, truth, and difference.

- Respect for persons, tradition, creativity, experience, faith, reason, and religious practice.

- Depth in understanding, relationships, faith, and spirituality.

- Sacredness of God, being, truth, place, nature, and knowledge.

- Passion for excellence, truth, learning, beauty, love, and personal growth.

Less than three years later, Morehouse College announced that it would admit transgender men, though if a student transitions from a man to a woman, that student would be asked to leave (Dodd 2019). Specifically, the policy states that,

In furtherance of our mission, tradition, and values as a men's college, and in recognition of our changing world and evolving understanding of gender identity, Morehouse will now consider for admission applicants who live and self-identify as men, regardless of the sex assigned to them at birth.

(Morehouse College 2019)

The mission statement of Morehouse College is worth quoting here:

The mission of Morehouse College is to develop men with disciplined minds who will lead lives of leadership and service. As the only historically black college or university dedicated to the development of men into leaders, we realize this mission by providing a world-class liberal arts education while emphasizing the intellectual and character development of our students. We assume a special responsibility for teaching the history and culture of black people.

(Morehouse College 2021) 
Like St. John's, Morehouse also identifies a series of values that shape the College's culture, including spirituality, community, accountability, trust, respect, integrity, honesty, civility, and compassion.

The point is that St. John's University and Morehouse College saw no conflict between their mission and values as men's colleges and a definition of "men" that includes transgender men. They both ask only that applicants "live and self-identify" as men. The definitive attributes identified here are twofold: To self-identify is an explicit act that is at the discretion of the applicant. To live as a man is obviously more vague, given that there are many ways of living as a man. In an email exchange with a former administrator at St. John's University, I learned that they do not necessarily expect evidence of a past commitment but rather are looking toward the future: There is no requirement for

legal documentation or previous requirement of identifying as a trans man. Our expectation has been that the trans applicant intends to identify as a man going forward. In other words, we would accept a trans student who intends to identify as a man throughout his college career.

Vice President for Student Development at the College of Saint Benedict, Mary Geller, who helped formulate the admission policy for both Saint Benedict and St. John's, confirmed that future intention is more important than past duration (Geller 2020). Thus, for all practical purposes at St. John's, the two attributes collapse into one and function in a manner similar to women's colleges that only require self-identification.

Hampden-Sydney College (or H-SC) only allows applicants who were assigned male at birth and identify as male (Jaschik 2019; Stimpert 2020). H-SC is the tenth oldest college in the United States, founded in 1775. It is located in Prince Edward County, notoriously known for having refused to abide by the Supreme Court's desegregation decision in Brown v. Topeka Board of Education (Green 2015). Vestiges of racism linger: In 2012, a group of about 40 students protested the reelection of Barack Obama as president, gathering outside the minority students' union. Students "shouted racial slurs, tossed bottles, set off fireworks and threatened physical violence," leading to four of the protesting students being disciplined (Winter 2012).

There is no question that there are progressive elements within the College and student body ${ }^{7}$ nonetheless, the College has earned a reputation overall of being conservative, and that conservatism apparently includes gender politics. For example, in 2016 the College first terminated, then reappointed, a visiting faculty member who had made public statements that were interpreted by some as advocating violence against transgender women who use a women's restroom (Kapsidelis 2016). More recently, the editor-in-chief of the student newspaper published an editorial titled "Transgender Lies Become Tyrannical" that, among other things, refers to the "false ideology of transgenderism" and considers the word "transphobic" to be a "nonsense word." Proclaiming that "The transgender delusion has carried on far 
enough," the author argues that opposition to "transgenderism" is being censored to a degree he considers tyrannical (Bredin 2019). The editorial is consistent with other conservative press coverage that treats transgender claims with skepticism, such as the headline "Women's college to admit male students posing as women" (Haverluck 2018). Implicit in the H-SC editorial is a commitment to biological determinism, though obviously it cannot be assumed that commitment is shared by the College's administration. Furthermore, the editorial swiftly received substantial criticism from parties from within and outside of H-SC (Black 2019; Gender Issues Committee 2019; Page 2019; Plichta-Kellar 2019; Stimpert 2019; Utzinger 2019).

Dr. Larry Stimpert, President of Hampden-Sydney College, explained that H-SC's commitment to form "good men and good citizens" dates back to the College's founding and continues to inform its policies today (2020). The admissions policy has evolved since 2011 from requiring that applicants be legally considered male (which, in theory, might allow a transgender applicant who had changed his birth certificate) to a 2017 requirement that applicants must be born and identify as male. When asked, President Stimpert did not identify a rationale for excluding transgender men other than the historic commitment of the College to being a men's college. With the University of Virginia beginning to admit women as undergraduates in 1970, and the Supreme Court requirement that the Virginia Military Institute admit women in 1996, H-SC is the last men's college in Virginia. Stimpert noted that an on-going concern of alumni and Board of Trustees is staying true to that commitment and tradition, and that there is resistance to changes that might be interpreted as moving the college toward becoming co-educational. Admitting transgender applicants could be perceived by some as just such a move. At the same time, Stimpert noted that there have been discussions among senior leadership about what to do if a current H-SC student transitioned to become a woman, and the unanimous response was that the College would support such a student to complete their degree at $\mathrm{H}-\mathrm{SC}$ rather than requiring the student to leave. ${ }^{8}$

Wabash College's Student Senate debated the question of admitting transgender men several times and rejected the idea because they felt admission would, in fact, hinder the College's pursuit of its mission. A spokesperson for Wabash told Inside Higher Ed that

the college's admissions policy is to evaluate candidates based on our singular and historic mission to be a liberal arts college for men chartered in the state of Indiana. All of our programs and policies are designed to support our mission." Asked if this meant that the college would admit only those classified by the government as male, he said, "legally male as defined by the state in which we are chartered."

(Jaschik 2017)

The explicit Mission Statement for Wabash College is not all that different from those of Morehouse or St. John's: "Wabash College educates men to think 
critically, act responsibly, lead effectively, and live humanely" (Wabash 2020). The Core Values advertised differ a bit from those of St. John's and Morehouse:

\section{Our Core Values}

\section{A rigorous liberal arts education that fosters}

- An appreciation for the intellectual and physical aspects of a good life

- An understanding of and appreciation for other cultures

\section{A personal context to teaching and learning that encourages}

- Candid, respectful, face-to-face conversations

- Freedom of thought

- A local scholarly community that creates lifelong relationships

\section{Individual responsibility and trust that are}

- Based on moral and ethical awareness

- Expressed in the Gentleman's Rule

- Required for leadership and teamwork

\section{A socially, economically, and ethnically diverse student body characterized by}

- A dedication to the serious pursuit of learning

- A culture of competition without malice

- A few years of residence, a lifetime of loyalty

\section{A tradition and philosophy of independence that}

- Keeps the College from external control

- Allows the Wabash community to shape significantly its own destiny

- Promotes independence and self-reliance in its students and graduates

(Wabash 2020)

One might interpret the emphasis on the Gentleman's Rule, competition, independence, and self-reliance as reflecting certain traditional masculine norms, and, indeed, there is evidence that at least some who opposed the admission of transgender students were motivated by a desire to maintain those norms. Though one needs to be careful not to overgeneralize, concerns have been expressed about the degree of sexism on campus. An account in the Chicago Tribune reported that some faculty "worry about the locker-room talk that sometimes erupts in classrooms, and the sexist attitudes some students express. Classroom 
discussions that touch on women's issues can be particularly strained" (Breslin 2001). A student editorial in the school newspaper, The Bachelor, defends Wabash as a Brotherhood of Men, and argued that "allowing a transgender individual here would violate our single-sex education as well as our Brotherhood" (Russel 2018). Criticizing the idea that "traditional male gender roles are harmful," the author defends the norms of "self-reliance, competition, and dominance" as "helpful in life." Echoing what I have described earlier as biological determinism, the student states, "I believe, as do many of my brothers, that a person is born with their sex determined" (Russel 2018). An equally strong statement about the biological basis for sex was articulated by a Student Senator who opposes the admission of transgender students: "I fully disagree with the idea that somehow somebody's perception in their mind changes their biological and genetic nature. Honestly the only common denominator when it comes to manhood is that genetic [component]. You are genetically male or female" (Block 2016, 3). Another student editorial argued, "it is unproductive to push for the admittance of women who claim to be men, not only because it would cease to make Wabash an all-male school, but it would utterly distort the nature of authentic manhood on campus" (Kaufman 2016).

The author's choice of words here, referring to "the nature of authentic manhood," is described as the language of essentialism (Schiappa 2003, 36). The language of essentialism refers to linguistic practices that reflect and depend on metaphysical absolutism - the belief that things have independent, "objective" structures or essences that are knowable "in themselves" (Barnes 1982, 79-83). One can discern such metaphysical absolutism when a distinction is made between "real" versus "apparent" Xs, as in this case between "the nature of authentic manhood" versus, implicitly, inauthentic or only apparent manhood. My argument in Defining Reality is that the language of essentialism is problematic for two reasons.

First, metaphysical absolutism is a mostly discredited philosophical doctrine when it comes to the practice of definition. Most philosophers have long since rejected the idea that we can identify timeless essences to describe what the "nature" of things are (Schiappa 2003, 39-41). Rather, as described in Chapter 2, our definitions of things, even in the physical sciences, depend on historically situated theories that change over time. Indeed, the point of Chapter 2 was to illustrate that we are at a moment of history when the question of how to define sex and gender, in particular, has never been so unsettled. Our culture is very far from a shared understanding of what "the nature of authentic manhood" is.

Second, deploying an alleged metaphysical distinction often obfuscates important social needs and values that are involved in acts of definition. As William James pointed out over a century ago, what we deem as an "essential" attribute of a thing is motivated by our purposes: "The 'essence' of a thing is that one of its properties which is so important for my interests that in comparison with it I may neglect the rest" $(1981,961) .{ }^{10}$ That is why, for example, Rebecca R. Helm stipulated, "as a developmental biologist, I define male/female as organisms producing sperm/eggs" (2020, emphasis added). 
If someone says "oh that is not 'real' music" or "he's not a 'real man'," we can be sure that the person has a preferred form of music or definition of manhood that s/he has deemed "essential," "authentic," or "real." Thus, in a definitional controversy, it is important to put one's cards on the table, so to speak, and identify the attributes that define "men" or "manhood" in the context of a college setting that one considers as most valuable. Only then can an assessment of whether transgender men should "count" as men in that context be made.

Wabash College and Hampden-Sydney rely on one's assigned sex at birth to define men and women. Why? ${ }^{11}$ At least in the case of Wabash, there is some evidence that the exclusion of transgender men is based on a belief in biological determinism:

[Our] brotherhood exists due to the very nature of our experience grounded in and shaped by our biological masculinity that sets us apart, but not above, women. Once we make one move to change this standard, it will compromise what manhood means at this institution and we will never recover from that.

(Kaufman 2016)

One might ask why Morehouse College and St. John's University decided otherwise? Both institutions' official policy state simply that they will admit transgender students "[i]n furtherance of our mission, tradition, and values as an undergraduate college for men, and in recognition of our changing world and evolving understanding of gender identity" (SJU 2016; Morehouse 2019).

It is worth noting that Morehouse and St. John's both coordinate with sibling all-women's colleges-Spelman College for Morehouse and the College of Saint Benedict for St. John's. The institutions share curriculum and access to certain facilities of the other. The conversation at Morehouse was prompted, at least in part, by Spelman College's decision in 2017 to admit transgender women (Jaschik 2019). I suspect it would be difficult to explain why a women's college should accept transgender applicants while their sibling men's college should not. If a commitment to self-identification and living as a woman is sufficient for the women's college, why should it not be functionally similar for the affiliated men's college? At this point in time, I am not aware of any affiliated sibling single-sex institutions that have conflicting policies.

To sum up, there are two regulatory definitions at work for men's colleges. Excluding transgender applicants, the first can be formulated as: Only those assigned the sex male at birth (X) count as men (Y) in the context of applying to this institution (C). Including transgender applicants, the second can be described as: Those who consistently live and identify as men, regardless of the gender assigned to them at birth $(\mathrm{X})$ count as men $(\mathrm{Y})$ in the context of applying to this institution (C). These competing regulatory definitions appear to be informed not only by competing approaches to definition (biological determinism versus self-identification) but also competing values associated with different visions of what it means to be a man. 


\section{What about single-sex K-12 schools?}

There are over 1,400 single-sex K-12 schools in the U.S. (Reilly 2019). Even focusing solely on high schools, the vast majority of single-sex schools do not have publicly stated policies about admitting transgender students. This does not mean that none do, but rather that "official" policy statements are rare and most handle the matter on a case-by-case basis. Many schools are still wrestling with the challenges of minors facing difficult choices and circumstances, and balancing a desire to serve students with care with the traditions associated with a single-sex school (Lane 2016). Not only are single-sex schools devising admission policies for transgender students, but they also must enact policies for whether to allow students who transition "out" of the school's single sex to stay or ask them to transfer. Meanwhile, transgender students across the nation report higher rates of depression, poor educational performance, and face greater risks of self-harm (GLSEN 2017). A number of high schools that my research assistants and I called or emailed for further information about their transgender admission policies did not respond. Those that did said that they had not received applications from students selfidentified as transgender, though it is possible some have applied without outing themselves as trans. ${ }^{12}$

Generally speaking, women's colleges have moved to a more inclusive model than most girls' secondary schools, despite the rise of public discussion and awareness about transgender issues at the high school level (Swartz 2017). A study done in spring 2017 gathered information from a sampling of 33 independent girls' schools and found that while 29 of the 33 reported having at least one transgender student, only eight had yet approved guidelines or policy for admissions decision (Mencher 2017). Reuters' news service contacted dozens of girls' schools in 2018 and found that "several said they had already developed transgender policies, some said they are having early discussions or have created taskforces and a number of others have taken no action" (Kvetenadze 2018). A chart provided by the National Coalition of Girls' Schools published in 2018 about independent all-girls schools suggests that the trend is toward admitting transgender girls on a case-by-case basis and relying on student selfidentification, at all educational levels, to determine eligibility (NCGS 2018). The NCGS provides a database of research and advice about serving the needs of transgender students (2020).

The International Boys' Schools Coalition lists a Transgender Task Force and Transgender Resources on their website, but does not publicly provide a position statement or policy recommendations. An internal document does not take a definitive position concerning the admission of transgender boys, but recommends an individualized and incremental approach:

Because each school is different and each boy's journey is unique, IBSC encourages schools to establish guiding principles and then to work with students and families on a case-by-case basis, rather than adopt rigid policies. 
This recommendation includes the enrollment process and students' full experiences at the school.

It is unclear how much interest there is among transgender boys to apply to allboys schools at the K-12 level. Former Head of School of the all-boys Belmont Hill School, Rick Melvoin, told me that "on my watch we would have absolutely welcomed the application of a trans boy," but no such applications were received. The Director of Admissions at an elite all-boys school on the east coast similarly told me that they had not received applicants who have identified themselves as transgender. A school counselor at an all-boys school told me that she was not aware of trans applicants, but there may well be applicants who are trans that refrain from disclosing that status in order to avoid discrimination in the application process.

Should a transgender boy apply to an all-boys' school? It is a difficult question. On one hand, past research has suggested that all-boys schools cultivate "more sexist environments" and that students at boys' schools "display more traditional forms of masculinity" than co-ed schools (Reilly 2019). One could imagine that trying to attend such a school at the age of 14 or 15 would be daunting for a transgender boy. Filmmaker and Professor of Philosophy and Gender Studies Thomas Keith agrees, contending that all-boys schools are more likely to be characterized by what Keith terms "bro culture," which

is made up mainly of boys and men who eschew the feminine and bond around their sexist and homophobic alliances with one another. Those of LGBTQ communities are typically used as fodder for insults, homophobic and transphobic punch lines in jokes, and people to deride and castigate in the service of bonding around their cisgender, heterosexual alliances to each other.

(Keith 2020)

It is reasonable to assume that trans boys who fear the risks of such a culture might want to avoid it.

On the other hand, it is clear that the leadership of some boys' schools is striving to improve the culture. A survey by the International Boys' Schools Coalition

found that boys' school leaders think the most important challenge facing their schools today is "healthy concepts of masculinity and relationships." Asked about the challenges that boys' schools will face over the next five years, a plurality of respondents said "gender issues".

(Reilly 2019)

Furthermore, some parents want to be convinced that "a boys' school will not be an incubator of male privilege and entitlement and misogyny" (Reilly 2019). Former Headmaster Melvoin told me that he felt the "bro culture" accusation was 
"dramatically exaggerated," and pointed to greater acceptance of self-identified gay students as an example of progress. He suggested that the environment of boys' schools can give boys more freedom to explore who they are than often is the case in coed schools (2020). Similarly, Jason Robinson, the Headmaster of St. Albans School, claims that boys' schools "provide an affirming environment for boys to 'interrogate unhealthy notions of masculinity' and discuss anxieties and frustrations without feeling self-conscious" (Reilly 2019).

Adam Howard, Professor of Education, is not so sure. His ongoing research of young alums (18-25) acknowledges that all-boys schools "are increasingly facilitating activities, experiences, discussions and so on around issues of gender and sexuality as well as privilege and social justice in response to what's happening in larger society." However, the alums in his research "largely describe these efforts as 'going through the motions' and not really a significant learning experience. Some participants, in fact, understand it as an 'attack' on men and masculinity" (2020; see also Howard 2019). Accordingly, it seems too soon to know whether the progress that some boys' schools report provides a climate that would be supportive of transgender students.

The more pressing issue for all-boys schools appears not to be admission policy but what to do when a student admitted and attending a boys' school decides to identify as a girl. The limited information available suggests that decisions about whether to allow a student to remain in a single-sex school after they transition is done on a case-by-case basis, and depends in part on where the student is in their education. For example, a student at a private boys' school in Virginia who attended the school beginning in kindergarten and who transitioned to identify as a woman the spring before their senior year requested and was given permission to graduate with their cohort.

\section{Conclusion}

As described in Chapter 1, regulatory definitions have three characteristics. First, regulatory definitions are formulated and authorized by recognized organizations or institutions. In this case, individual schools have been the organizations formulating the definitions. National organizations have refrained from advocating specific policies and definitions so far. There is, at this point in time, no particular legal or regulatory mechanism to compel a common definitional practice across the nation.

Second, regulatory definitions are designed to promote denotative conformity; that is, when using language, we want to be able to observe a phenomenon and agree that $\mathrm{X}$ is a $\mathrm{Y}$. It is clear that at this point in time, we lack denotative conformity with respect to gender identification for admission to single-sex schools because the definitions vary in a nontrivial manner. For some institutions, only cisgender males or females "count" as men or women for the purposes of admission. For others, a transgender applicant can count as an eligible boy or girl, woman or man, but the specific definitive attributes vary significantly, requiring only self-identification 
on one end of the spectrum, to some evidence of duration in the middle ("consistently live and identify as Y"), to having "legally" transitioned to the school's gender on the other end of the spectrum.

What this means is that we are still in a state of definitional rupture, wherein a specific person would be defined as a boy or man by one school and a girl or woman by another.

A third characteristic of regulatory definitions is that words are defined to serve one or more specific purpose and promote certain values or interests for those involved. It is reasonable to infer that when there are different and competing definitions, it is a result of competing values and interests at work. This point is, I believe, key to understanding why different single-sex schools have generated different definitions.

At the collegiate level, it seems reasonable to generalize that colleges permitting transgender women to apply have done so because such institutions often have feminist histories, values, and commitments-by which I mean a distrust of biological determinism (often used to justify the oppression of women), an acknowledgment that transgender women face discrimination similar (though not identical) to what cisgender women experience, and a desire to empower women for success in a world still dominated by sexism.

The four remaining men's colleges are currently divided 50/50. Both Saint John's University and Morehouse will admit applicants who "consistently live and identify as men," but there is little public indication of $w h y$. Saint John's University simply says the change was made "in recognition of our changing world and evolving understanding of gender identity" (SJU 2016). Morehouse College offers identical wording: "in recognition of our changing world and evolving understanding of gender identity" (Morehouse 2019). Again, it is worth noting that both schools work closely with partner women's schools. In either case, it is clear that neither institution sees a problematic conflict between their historical missions, traditions, and values as men's colleges and the admission of transgender men. The other two men's colleges, Wabash and Hampden-Sydney, are reluctant to make public statements explaining their decision, but from the limited available evidence it seems evident that there remains a commitment to biological determinism and traditional notions of masculinity.

There is a paucity of information about the motivations of single-sex K-12 institutions. Most note that they need to demonstrate care for their students while protecting the historical mission of their institutions. One could reasonably surmise that the competing values and interests are parallel to those facing colleges, with the added complication of the young age of K-12 students. The question of when young people are in position to decide about such a fundamental question as gender identity is a matter of contestation, but not one I can pursue here.

\section{Notes}

1 Quoted in Bennett-Smith (2013).

2 Love (2020) and Carapezza (2018). 
3 Quoted in Cregan (2018).

4 Durant gave the speech in the year Wellesley College was founded, 1875, though the speech was not published until 1890 for a gathering of the Alumnae Association (Taylor \& Glasscock 1975, 1). My thanks to Wellesley College library archivist Natalia Gutiérrez-Jones for her assistance.

5 This list comes from the research efforts of Wellesley undergraduate Grace (Yongxi) Pan and from North (2017).

6 The discussion group subsequently was banned, and moderators launched an invitationonly site with far fewer members called Ovarit.com (Fain 2020).

7 The school's Equity and Inclusion webpage states: "Hampden-Sydney College is committed to an inclusive structure that is coordinated and integrated, that celebrates all forms of diversity, and that ensures equitable educational and social benefits for all.' Such a statement, alumni and faculty from H-SC told me, primarily reflects the College's efforts to support minority and gay cisgender male students.

8 Interestingly, H-SC has a long-standing policy to allow the admission of daughters of faculty and staff. The numbers are quite low each year (zero to two). President Stimpert (2020) relayed that there was some controversy when one of these young women graduated first in her class. As senior staff has reviewed the College's admission policy, he reported, they have discussed whether ending the policy would reinforce the college's commitment to being a men's college.

9 It is not altogether clear what it means to be "legally male as defined by the state." To change one's birth certificate in Indiana requires a court order, and to change a driver's license requires either an updated birth certificate or State Form 55617 signed by a physician that the applicant successfully underwent treatment to permanently change gender (National Center for Transgender Equality 2020).

10 Scare quote marks added. James did not believe in essences in the way the idea was understood by most metaphysicians of his time, but is pointing out that the attributes we take as a thing's essence is a reflection of our own needs, interests, and values.

11 I asked the President and Director of Admissions at Wabash College to provide a brief explanation of why they do not admit transgender men applicants, and was told they had nothing to add other than what was reported in Jaschik (2017).

12 My thanks to Wellesley student Alex Hussey for her research efforts in this regard. 


\section{Transgender voices}

"I've been out for almost 30 years as transgender. . . I learned how to self-dehydrate myself, so that I could avoid bathroom stops while I drove across the country for eight, maybe ten hours, if I do it right. And I do this still today because I am more nervous now about using the public washrooms than I was before because of the political atmosphere with trans people presently."

Venus de Mars ${ }^{1}$

"I was screamed at in a women's bathroom that I was a 'pervert' and should be 'harassed to my death' as I was chased out. I was cornered in a men's bathroom, being asked by some huge guy 'how the fairy got in here'."

Skylar ${ }^{2}$

The principal told my mom that because Bixby [High School] had only male and female restrooms, no unisex, it was too complicated for me to be a student there."

Katie $^{3}$

"I was in a Russian club in New York and was dressed in tight pants and a little jacket. My hair was short, and I had no makeup on. So I entered the boy's bathroom, because how could I go to the women's bathroom? The usher literally grabbed me and said 'Miss, Miss you're in the wrong bathroom!' And to this day that was probably one of the best experiences in my life. I was just so grateful that someone could see in me what I was also seeing in myself."

Ninotska Love ${ }^{4}$

"At last, my victory feels final. But I shouldn't have had to fight this hard."

Gavin Grimm ${ }^{5}$

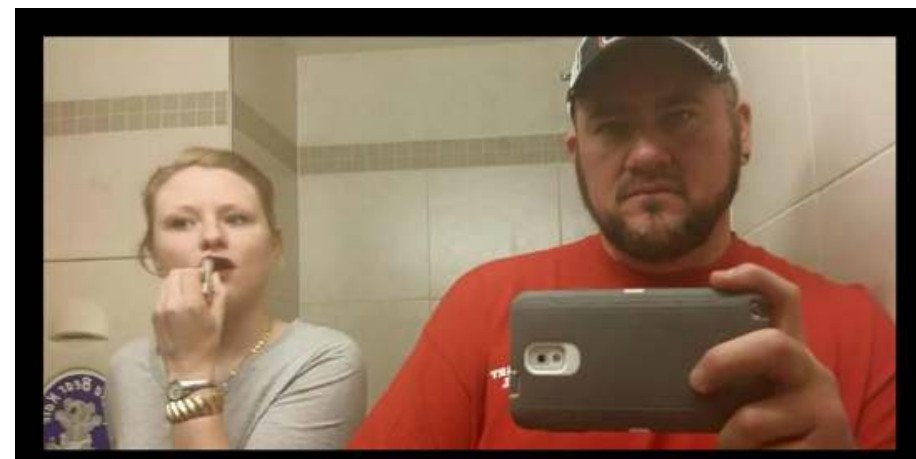

Republicans want to put me in the restroom with her, because I was assigned female at birth - do I look like I belong in women's facilties?

\#occupotty \#wejustneedtopee \#letmypeoplepee \#translivesmatter michaelhughes.co@michaelhughes1

FIGURE 5.1 Tweet by Michael Hughes, used by permission.

Source: Photo by Michael Hughes, used by permission 


\section{BATHROOMS}

The practice of bathroom sex segregation is relatively recent, historically speaking. In the United States, restrooms were all single-user water closets, privies, or outhouses until the 1870s when plumbing and public works infrastructure advanced to the point that multi-user public restrooms were feasible. The design and regulation of public restrooms in the latter 19th century did not take place in an ideological vacuum (Kogan 2007). Feminist historian and rhetoric scholar Karlyn Kohrs Campbell describes the dominant gender ideology of the 19th century, known as the cult of domesticity or the cult of true womanhood:

As the cult of domesticity was codified in the United States in the early part of the [19th] century, two distinct subcultures emerged. Man's place was the world outside the home, the public realm of politics and finance; man's nature was thought to be lustful, amoral, competitive, and ambitious. Woman's place was home, a haven from amoral capitalism and dirty politics, where "the heart was," where the spiritual and emotional needs of husband and children were met by a "ministering angel." Woman's nature was pure, pious, domestic, and submissive. She was to remain entirely in the private sphere of the home, eschewing any appearance of individuality, leadership, or aggressiveness.

(Campbell 1989, 10)

Laws requiring separate restroom facilities for women and men emerged at a time when the philosophy of separating public and private spheres by gender was colliding with the economic necessities of women working in the industrial revolution (Kessler-Harris 1995). The well-known "Cult of True Womanhood" was a myth, but one that Victorian society was loathe to abandon (Kogan 2007, 23). A growing number of women entered the workforce, their participation regulated 
(and limited) in the name of their health and safety. Such regulations were supported by a collection of disparate advocacy groups juggling “women's legitimate demands for economic independence and thus increased role in the workplace on the one hand, and a desire to preserve traditional family life under a mother's influence on the other" (Kogan 2007, 17).

The first state law mandating that workplace toilet facilities be separated by sex was enacted in 1887 in Massachusetts (Kogan 2007). Other states soon followed suit, typically by amending statutes on the books designed to protect women in the workplace. Such legislation was motivated less by the sort of philosophical or religious motivations of earlier times and more by supposed scientific research documenting the differences between the sexes that declared women weaker and in need of protection, especially in light of the need to safeguard women's reproductive capacity: "Moved by the scientific pretensions of realism after mid-century . . . legislators began to take seriously the threat that allowing vulnerable women into the public realm would endanger both their own weaker bodies and the welfare of future generations" (Kogan 2007, 27).

In addition to laws regulating how women could participate in the workplace, the second half of the 19th century also saw the growth of protected public spaces for women. Public libraries created "ladies' reading rooms," there were designated "ladies' cars" on railroads, and various businesses created separate "parlor" spaces for women in department stores, hotels, and restaurants: "While acknowledging the ever-increasing presence of women in public, these spaces reinforced the cultural message that, as the weaker sex, women needed special home-like protections when they ventured outside their domestic havens" (Kogan 2007, 34).

Kogan's examination of an extensive 1910 Department of Commerce and Labor study on the condition of women and child wage earners found an endorsement across all industries to separate toilet facilities by sex. His reading of the study identified four justifications:

1 The sex-separated water closet was necessary as a haven to protect the weaker body of the woman worker.

2 The sex-separated water closet was necessary as one aspect of a factory's providing its workers with sanitary — "clean and adequate" — toilet accommodations.

3 The sex-separated water closet was necessary to protect a worker's interest in privacy.

4 The sex-separated water closet was necessary to protect and vindicate social morality, a morality rooted in the early nineteenth century separate spheres ideology.

(Kogan 2007, 41, emphasis in original)

Kogan's account concludes that,

the historical and social justifications for the ubiquitous practice of separating public restrooms by sex were based not on a gender-neutral policy related to 
simple anatomical differences between men and women. Rather its origins were deeply bound up with early nineteenth century moral ideology concerning the appropriate role and place for women in society.

$(2007,55)^{6}$

Similarly, the debate over bathroom bills in the 21 st century is informed by beliefs about gender. I list the four justifications identified by Kogan because three of the four emerge, implicitly or explicitly, in the debate over so-called bathroom bills. Writing in 2007, Kogan presciently noted,

Separate public restrooms for men and women foster subtle social understandings that women are inherently vulnerable and in need of protection when in public, while men are inherently predatory. Moreover, the tworestroom model teaches that there are two, and only two sexes, a message highly problematic to the public's acceptance of transsexual and intersexual people.

$* * *$

Laws that require the construction of separate bathroom facilities are not, of course, the same as laws or regulations concerning who uses them. Not all jurisdictions prohibit the use of a sex-designated restroom by a member of the "opposite" sex, but many do. For example, the Raleigh, North Carolina, municipal code regarding toilet facilities states that, "it shall be unlawful for a member of one sex to enter or use a facility provided for members of the opposite sex" (Section 13-2015). Many jurisdictions rely, instead, on regulating specific behavior. For example, if a proprietor tells a customer $s / h e$ is in the "wrong" restroom or locker room and should leave, and the customer persists, the behavior could be considered criminal trespass. ${ }^{7}$ Behavior in bathrooms also is governed by laws that prohibit disorderly conduct or assault. In other words, unless a bathroom user acts in a manner considered inappropriate, such as a man trying to open a toilet stall being used by a woman, ${ }^{8}$ merely using the restroom of one's choice is unlikely to encounter legal difficulties. Jurisdictions that have a regulation concerning bathroom use have not typically taken the extra step of defining what counts as male or female, so if we were to describe such regulations as a regulatory definition, the key would appear to be perceptions of appropriateness; thus, a person perceived as a male/female (X) counts as a man/woman $(\mathrm{Y})$ in the context of public bathrooms and changing facilities (C).

Obviously, perceptions can be subjective, and without specific legislative or regulatory guidance in place, DSD, gender nonconforming, and transgender people are vulnerable to implicit or explicit sanctions, including being denied access to the restroom consistent with their gender identity, loss of employment, harassment, and acts of violence. In the 2015 U.S. Transgender Survey, 75\% of transgender men and $53 \%$ of transgender women reported that they "sometimes or always 
avoided [public] bathrooms in the past year" (James et al. 2016, 228). The Survey also reported,

Respondents were also asked if they had experienced any physical problems as a result of avoiding restrooms in public places, at work, or at school. Nearly one-third (32\%) of the sample avoided drinking or eating so that they would not need to use the restroom, and $8 \%$ reported having a urinary tract infection or kidney-related medical problem as a result of avoiding restrooms in the past year.

The consequences of hostility toward transgender people using the restroom consistent with their gender identity are significant. Sociologist Sheila Cavanagh's research team interviewed 100 transgender and gender-nonconforming individuals and found that "public reactions to their presence in the toilet, ranging from curiosity, inquisition, surprise, confusion, and avoidance to fear, anger, hostility, and hatred" (2010, 55). The experiences relayed by her interviewees document profoundly negative consequences to their lack of acceptance in the restroom of their preference, even if the responses are limited to nonverbal expressions that communicate the interviewee is in the "wrong" bathroom: "Trans interviewees often say that transphobic looks generated by aggressive and intentional gender misreadings are nullifying and devastating to one's person" $(2010,58)$. Other reactions reported include efforts to contact security, threats, harassment, physical assault, and arrest.

There is considerable research demonstrating that school environments, in particular, are stressful for transgender students (Davies, Vipond, \& King 2019; James et al. 2016). This stress is aggravated by concerns about bathroom access. Transgender people report that safe access to restrooms is one of their most persistent and frightening challenges (Doan 2010). A survey of 23,000 LGBTQ students between the ages of 13 and 21 found that transgender students attending a school with transgender or gender-nonconforming policies or guidelines felt greater belonging to their school community, were less likely to miss school because they felt unsafe, and less likely to be compelled to use bathrooms of their "legal" (assigned at birth) sex (Kosciw et al. 2018, xxiv). A study of college students in Colorado found that when transgender identities are not considered in bathroom designs, transgender students, staff, and faculty experience exclusion and invisibility, tend to feel less safe on campus, and try to avoid bathrooms on campus (Seelman et al. 2012). A survey of 507 transgender and gender-nonconforming students found that gender-inclusive restroom policies received the highest importance score of 17 trans-inclusive policies and practices (Goldberg, Beemyn, \& Smith 2019).

Kristie L. Seelman's (2016) analysis of over 2,300 people completing the National Transgender Discrimination Survey found that denial of access to gender-appropriate bathrooms in colleges or universities was correlated to increased suicide attempts. Seelman's analysis controlled for multiple variables, including 
income, race, disability, and other interpersonal victimization, and found that those who had been denied access to a school bathroom or other facility due to being transgender are 1.32 times as likely to have attempted suicide compared to those who were not denied access to a school bathroom or facility $(2016,1389)$. That is to say, a person who was denied access is $32 \%$ more likely to attempt suicide than a transgender or gender nonconforming individual who has not.

Efforts to protect the rights of transgender individuals to use the restroom of their choice have been made through a combination of court cases, legislative initiatives, and guidance by government offices. Beginning even before the period I have described as the Transgender Exigency, states including Colorado (2008), Connecticut (2011), Hawaii (2006), Iowa (2007), Maine (2005), Massachusetts (2016), Nevada (2011), New Mexico (2003), Oregon (2007), Rhode Island (2001), Vermont (2007), and Washington (2015) enacted legislation or regulations that prohibits discrimination in public accommodations based on gender identity. California passed a law specific to public educational institutions in 2013. There are also at least 200 municipal statutes that prohibit discrimination based on gender identity (Wang et al. 2016).

In May 2016, the U.S. Departments of Justice and Education released a "Dear Colleague" guidance document to stipulate that Title IX's prohibition of discrimination based on sex included gender identity: “The Departments treat a student's gender identity as the student's sex for purposes of Title IX and its implementing regulations" (Lhamon \& Gupta 2016, 2). The document addressed the issue of restrooms and locker rooms explicitly: "A school may provide separate facilities on the basis of sex, but must allow transgender students access to such facilities consistent with their gender identity" (Lhamon \& Gupta 2016, 3).

The key definitive attribute at work in the regulatory definition informing these anti-discrimination efforts is a person's self-identified gender. Thus, a person whose (self-declared) gender identity is male/female $(\mathrm{X})$ counts as a man/woman $(\mathrm{Y})$ in the context of public bathrooms and changing facilities $(\mathrm{C})$.

We can describe these first two definitions as the "perceptual" definition and the "self-identified" definition of sex/gender for the purposes of sex-segregated bathrooms and locker rooms. There can be a tension between the two inasmuch as the same person might "count" as male in one context or jurisdiction and female in another. The situation became even more complicated with the imposition of the "strict biological" definition.

On May 28, 2014, the Houston City Council passed an anti-discrimination ordinance known as the Houston Equal Rights Ordinance (HERO). HERO prohibited discrimination on the basis of sexual orientation, gender identity, sex, race, color, ethnicity, national origin, age, religion, disability, pregnancy, genetic information, family, marital, and military status. HERO applied to businesses that serve the public, private employers, housing, city employment and city contracting. Religious institutions were exempt (Feldman 2014). Of the various forms of discrimination banned in the ordinance, it was discrimination on the basis of sexual orientation and gender identity that gained the most attention. 
Almost immediately, critics condemned HERO specifically because they thought the ordinance permitted transgender people to use public restrooms consistent with their gender identity. Following city law, opponents of HERO successfully petitioned to have HERO subject to voter approval as a ballot question. At the core of stated opposition to Proposition 1 was the fear of male sexual predators entering women's restrooms. Texas Lt. Governor Dan Patrick recorded a 30-second video in opposition to Proposition 1. He claimed that it was not about equality, but “it's about allowing men in women's locker rooms and bathrooms" (Patrick 2015). Rev. Max Miller of the Baptist Ministers Association of Houston similarly argued, "We're standing up to protect our women and our children" (in Morris 2014). The Houston Chronicle reported that, "Foes have dubbed the measure [HERO] the 'Sexual Predator Protection Act'" (Morris 2014). An organization called Campaign for Houston aired a television ad that claimed "even registered sex offenders could follow women or young girls into the bathroom and if a business tried to stop them they'd be fined." Filmed in black and white and presented with an ominous soundtrack, the ad ends with a young girl going into a bathroom stall, only to be followed by what appears to be an adult male predator. The voiceover concludes with the admonition to "protect woman's privacy, prevent danger, vote no" (Campaign for Houston 2015b).

Despite the support of Houston Mayor Annise Parker and organizations including the ACLU and Houston's NAACP chapter, on November 3, 2015, a 27\% voter turnout of the city of Houston voted on "Proposition 1" to overturn it by a 61\%-39\% margin.

The failure of Proposition 1 meant that gay and transgender people in Houston continue to lack legal protection against discrimination. Its failure also left intact a status quo that permits businesses to deny bathroom access to gay and transgender people without fear of violating anti-discrimination laws. Other jurisdictions across the U.S. would soon consider taking bathroom regulation a step further by explicitly forbidding transgender individuals from using public restrooms consistent with their gender identity. The first state to pass such legislation was North Carolina.

In February 2016, the City Council of Charlotte, North Carolina, passed Ordinance Number 7056, which expanded the city's anti-discrimination laws to prohibit discrimination on the basis of "marital status, familial status, sexual orientation, gender identity, [and] gender expression" (Charlotte 2016). The ordinance previously prohibited discrimination on the basis of race, gender, religion, national origin, ethnicity, age, or disability. Passage of what would appear to be a routine update and addition to the city's anti-discrimination policy triggered a swift response from the North Carolina General Assembly, which was called back into session to pass the "Public Faciities Privacy and Security Act" on March 23, about a week before the Charlotte amendment was scheduled to take effect. The law, commonly known as HB2 (for "House Bill 2") requires public educational institutions and most state offices to "require every multiple occupancy bathroom or changing facility to be designated for and only used by persons based on their biological 
sex." HB2 defined "biological sex" as "The physical condition of being male or female, which is stated on a person's birth certificate" (General Assembly 2016). The law says that "places of public accommodation" must be free of discrimination because of "race, religion, color, national origin, or biological sex," but preempts ordinances like Charlotte's by specifying that only discrimination based on biological sex is actionable.

As the language of the bill suggests, there was a straightforward commitment to biological determinism being the sole definitional authority on gender. Governor Pat McCrory characterized transgender people as "boys who may think they're a girl" (Garloch 2016), a characterization that erases and delegitimizes transgender categories altogether. The General Assembly felt strongly enough about promoting its biological deterministic definition that $\mathrm{HB} 2$ preempts any local jurisdictions within the state of North Carolina from permitting transgender people from using the public restroom of their choice. ${ }^{9}$

Based on HB2, the "strict biological" regulatory definition could be formulated as: Only a "documentable" (by birth certificate) biological male/female (X) counts as a man/woman $(\mathrm{Y})$ in the context of public bathrooms and changing facilities (C).

One might reasonably ask why such a law was necessary.

Though the governor and General Assembly did not lay out a clear case for HB2 prior to its passage, efforts were made to justify it soon after. Similar to the argument advanced in Houston against Proposition 1, the governor and supporters defended the bill as designed to prevent men who may be sexual offenders from pretending to be a woman and entering a woman's restroom or changing area (Kelly 2016). Defending the law on Fox News, the governor emphasized the importance of protecting educational settings, including high schools, middle schools, and elementary schools. Asked by Megyn Kelly for the evidence that allowing people to use the restroom of their gender identity "was a problem," the governor shifted to the importance of "respect for privacy," especially for young people entering a bathroom or shower room: "It's a tradition we have had for many years." Blaming "the Left" for creating the problem ostensibly by trying to protect transgender students' rights, the governor argued HB2 is just "common sense." In the same story, Ted Cruz was shown making fun of the idea of gender identity by declaring, "If Donald Trump dressed up as Hillary Clinton, he still can't use the girl's restroom" (in Kelly 2016). McCrory's comments repeat a refrain that was used repeatedly in Houston's debate and vote on Proposition 1. Steven Hotze, President of Campaign for Houston, described opposition to HERO as "standing up for common decency and common sense" (Campaign for Houston 2015a). And Lt. Governor of Texas Daniel Patrick proclaimed that, "Men in women's bathrooms defies common sense and common decency" (Patrick 2015).

Comments such as those by McCrory, Cruz, Hotze, and Patrick illustrate what was described in Chapter 3 as the natural attitude toward sex and gender; that is, the taken-for-granted "common sense" belief that people can be classified biologically into one of only two "natural" categories. As famed anthropologist Clifford Geertz noted, "common sense" represents entrenched beliefs that are 
culturally specific, and what may be common sense in one culture may be absurd in another. ${ }^{10}$ Appropriately enough, one of Geertz's examples is sex and gender. Noting that, "Gender in human beings is not a purely dichotomous variable," Geertz discusses the differences among how three cultures treat "intersex" individuals $(1975$, 13). Geertz cites a 1964 paper by Robert B. Edgerton that notes the American response to what we now call Differences in Sex Development "combines psychological horror with social incompatibility," including such practical problems as "How can an intersexed person behave in school shower rooms, [and] in public bathrooms?” (1964, 1289). Not surprisingly, psychologists Matthew Callahan and Kyle Zukowski found that negative reactions to transgender people using the bathroom corresponding to their gender identity is correlated with a belief in biological essentialism - the "natural attitude" toward biological sex discussed previously (2019). Those believing in biological essentialism "may conclude that it is impossible to change one's gender-that one's birth sex remains a fixed, immutable social category" $(2019,17) .{ }^{11}$ Apparently, "common sense" for some in the United States regarding bathroom sex segregation has not progressed all that far in the past century. Advocates of bathroom bills, as illustrated with Governor McCrory's and others' defense, echo three of the four reasons that Kogan (2007) identifies from the late 19th century, including providing a "haven" for the weaker sex from would-be predators, protecting privacy, and validating a kind of social morality of what is "proper" for men and women.

Contrary to the claims of "common sense," there is no evidence that allowing transgender people to use the restroom of their choice poses any sort of threat to anyone. Reports from 12 states that protect gender identity as the basis of bathroom use reported no evidence that non-discrimination laws "have any relation to incidents of sexual assault or harassment in public restrooms" (Maza 2014). Similarly, The Advocate reported that

Although hundreds of trans-inclusive nondiscrimination ordinances have been in force in cities around the country for several decades, there has never been a verifiable, reported instance of a trans person harassing a cisgender person, nor have there been any confirmed reports of male predators "pretending" to be transgender to gain access to women's spaces and commit crimes against them.

(Brydum 2015)

A study by researchers at the Williams Institute of the UCLA School of Law noted in 2019 that "reports of privacy and safety violations in public restrooms, locker rooms, and changing rooms are exceedingly rare" and that fears of increased safety and privacy violations resulting from nondiscrimination policies "are not empirically grounded" (Hasenbush, Flores, \& Herman 2019, 70). A year before HB2 was proposed, spokespeople from the Human Rights Campaign, ACLU, and Transgender Law Center all reported that "no statistical evidence of violence exists 
to warrant this [bathroom] legislation" (Bianco 2015). Dr. Janet A. Laylor, writing in the American Journal of Public Health, described the alleged threat of predatory men to be "complete nonsense, as there has never been a single documented case of this occurring" (2016). In short, prior to the passage of HB2, no credible evidence suggested that it was needed to protect bathroom users in North Carolina.

North Carolina was not the only jurisdiction to consider a bathroom bill. Between 2013 and 2019, a bill was introduced in a majority of states to restrict access to multiuser restrooms, locker rooms, and other sex-segregated facilities on the basis of one's biological sex, typically defined as the sex assigned at birth (Ali 2019; Kralik 2019). In 2017 alone, 16 states considered such legislation, with another six considering legislation to preempt municipal and county-level antidiscrimination laws or ordinances. The state of Texas considered several bathroom bills, including HB 1748 in 2015, which

would make it a Class A misdemeanor-punishable by up to one year in jail and a maximum $\$ 4,000$ fine - for any person 13 years or older to use a restroom that does not match the "gender established at the individual's birth or by the individual's chromosomes."

(Gordon 2015)

To date, none of these state-level proposals have been enacted. The decision to refuse such laws may be due to what unfolded in North Carolina after the passage of their bathroom bill. The passage of HB2 provoked an immediate outcry, including public protests and calls to boycott doing business in the state. Musicians such as Bruce Springsteen, Ringo Starr, Boston, Pearl Jam, and others cancelled scheduled concerts in North Carolina in protest (Glum 2016). Multiple states barred government employees from non-essential travel to the state, film companies canceled production plans, and major sporting events, including the National Basketball Association and the NCAA, canceled planned events in the state. ${ }^{12}$ In a matter of months, North Carolina lost an estimated $\$ 400$ million as a result of concerts and sporting events moving out of the state because of HB2 (Ellis 2016).

Furthermore, the Department of Justice filed suit against North Carolina, claiming that,

access to sex-segregated restrooms and other workplace facilities consistent with gender identity is a term, condition or privilege of employment. Denying such access to transgender individuals, whose gender identity is different from their gender assigned at birth, while affording it to similarly situated non-transgender employees, violates Title VII.

(Sterling, McLaughlin, \& Berlinger 2016)

Title VII is a section of the Civil Rights Act prohibiting discrimination against workers on the basis of sex, race, color, national origin, and religion. The federal suit also said the state was in violation of Title IX, "the Education Acts Amendment 
of 1972 that bans gender discrimination in education, and the Violence Against Women Reauthorization Act that outlaws discrimination on the basis of sex" (Sterling, McLaughlin, \& Berlinger 2016). North Carolina responded by filing a countersuit, claiming the Obama administration had overstepped federal authority because transgender status is not a protected class under federal law.

The economic blow that North Carolina experienced appears to have deterred other states from following suit. Despite enthusiastic support initially by Governor Greg Abbott and Lt. Governor Dan Patrick for a bathroom bill in Texas, by election time in 2018, the governor had changed his stance to say it was no longer a priority. Business leaders in the state "worried that Texas could invite the same economic blows the Tar Heel State faced after passing a similar bill, including canceled corporate expansions and sports tournaments" (Ura 2017). The Texas Association of Business was reported as estimating that Texas "could have lost about $\$ 5.6$ billion through 2026 if it had enacted such a measure" (Reuters 2018).

It did not take the North Carolina General Assembly long to reconsider the decision to pass HB2. Governor McCrory unsuccessfully attempted to strike a deal where HB2 would be repealed if the city of Charlotte would repeal its ordinance (Campbell, Morrill, \& Harrison 2016). McCrory was defeated in his attempt to gain a second term as governor. In 2017, a compromise bill was passed by the Republican-controlled legislature and signed by the newly elected Democratic governor that repealed HB2's documented sex requirement but maintained the ban on local anti-discrimination ordinances until 2020 and gave the General Assembly "sole power" to regulate access to "multiple occupancy restrooms, showers, or changing facilities" (Fausset 2017). In a subsequent settlement of the lawsuits challenging the constitutionality of the bathroom bills, a federal judge approved an agreement "that prohibits the state government from banning transgender people from using bathrooms in state buildings that match their gender identity" (Levin 2019), thus bringing an end to North Carolina's efforts to impose a strict biological definition to determine bathroom eligibility.

$$
* * *
$$

The debate over bathroom bills is far from settled (Flores \& O'Neill 2020). On one hand, there appears to be, at the time of this writing, little appetite for statelevel laws such as North Carolina's HB2. What I have called the "strict biological" regulatory definition apparently has been shelved at the state level. But its spirit certainly lives on, and absent specific ordinances or laws that protect transgender rights to access the bathroom consistent with gender identity, the "perceptual" regulatory definition is left intact, along with the risk of implicit or explicit sanctions for violating perceived propriety. Furthermore, school districts and local jurisdictions can impose their own versions of HB2 that are informed by a strict biological definition of sex/gender.

On the other hand, additional jurisdictions have moved to protect transgender bathroom rights, or to otherwise add "gender identity" as a protected category 
against discrimination (Ali 2019). Thus, all three definitions - the "perceptual," "self-identified," and "strict biological" regulatory definitions remain at work in the U.S. in different contexts.

The election of Donald Trump as president in 2016 further complicated the regulatory landscape. Soon after Trump assumed office, the Departments of Justice and Education sent out a new "Dear Colleague" letter that formally withdrew the May 2016 letter sent out by the Obama administration, thereby rescinding the legal interpretation that prohibitions against discrimination based on "sex" protect transgender students (Battle \& Wheeler 2017). The reversal had important implications, since it left open which regulatory definition should be at work in public schools, work places, and public accommodations.

An example of the implications of the reversal can be seen in the case of Gloucester County School Board v. G. G. The case involves a high school student named Gavin Grimm, who challenged the local school board's policy that prohibited transgender students from using sex-segregated facilities consistent with their gender identitya policy described as similar to $\mathrm{HB} 2$. At the time the case was filed, the legal arguments were, in part, based on the Obama administration's interpretation of Title IX's prohibition of sex discrimination. However, with the rescission of that interpretation by the Trump administration, the Supreme Court vacated an appeals court decision favorable to Grimm and sent the case back for further consideration. In August 2019, U.S. District Court Judge Arenda L. Wright Allen ruled for Grimm, declaring that the School Board's policy “violated Mr. Grimm's rights under the Fourteenth Amendment to the United States Constitution and Title IX of the Education Amendments of 1972" (Allen 2019). The case was appealed (Marimow 2020), with the School Board advocating a strict biological definition of sex, arguing that Gavin "remains biologically and anatomically female" (Corrigan et al. 2019). In August of 2020, the U.S. Court of Appeals for the Fourth Circuit affirmed the District Court ruling on the basis of equal protection (under the Fourteenth Amendment) and Title IX, invoking the June 2020 Supreme Court decision in Bostock v. Clayton County (Floyd 2020). In June 2021, the Supreme Court without comment refused to review the case further, effectively ending the case in Grimm's favor (Liptak 2021).

Federal judges in Illinois, Oregon, and Pennsylvania have also ruled in favor of transgender students suing for access to the restroom consistent with their gender identity (Zaveri 2018). The U.S. Court of Appeals for the 11th Circuit recently upheld a federal judge's earlier ruling in Adams v. School Board of St. John's County, Florida that it is unconstitutional for schools to ban transgender students from using the restroom matching their gender identity (Cohen 2020). Other suits and appeals are in progress, so it is possible that the matter will go before the Supreme Court (Moreau 2018b, Sheer 2020). On June 16, 2021, the Biden administration reasserted that Title IX protects students from discrimination based on gender identity (U.S. Department of Education 2021). Thus, the definitional rupture continues, with three different, competing regulatory definitions at work in various contexts across the United States. 
It is likely that so-called bathroom bills and regulations will continue to be politically controversial at least in the short run. Opinions tend to correlate with age and political persuasion. In a survey of nearly 700 young people (14 to 24 years old), $79 \%$ stated that bathroom use by transgender people should not be restricted. Their reasons included:

1) bathroom use is private and should be a personal decision; 2) choosing bathrooms is a matter of equality, freedom, and human rights; 3 ) transgender people are not sexual perpetrators; and 4) forcing transgender people to use particular bathrooms puts them at risk.

(Crissman et al. 2019)

In an analysis of 9,764 online comments posted on the 13 most-shared articles or blog posts about transgender bathroom accommodation from September 2015 to September 2016, Blumell, Huemmer, and Sternadori (2019) found support for transgender access was most prevalent in discussions on left-leaning sites, whereas opposition was most prevalent in discussions on right-leaning sites. Common themes from opponents included arguments promoting what the authors call "benevolent sexism"- the belief that women and girls need protection by men and from men, and that sex differences are biologically natural. Vestiges of the cult of true womanhood persist into the 21 st century.

Some scholars and activists have argued that we should rethink sex-segregated bathrooms altogether. As I stated at the beginning of this chapter, sex-segregated bathrooms are a relatively recent development in U.S. history. Sociologist Sheila Cavanagh, for example, advocates a move to gender-neutral toilet designs: "The institutionalization of gender-neutral toilet designs is an urgent and important political project to ensure access for all who depart from conventional sex/gender body politics" (2010, 5). Similarly, Terry Kogan advocates a rethinking of how public accommodations are designed: "sex-segregated public restrooms be replaced by all-gender, multi-user facilities that protect the privacy and safety concerns of all patrons, while discriminating against no one" $(2017,1205)$.

Transgender scholar and activist Heath Fogg Davis points out that transgender people are not the only ones subject to problems in contexts where the perceptual regulatory definition is at work:

[M] any people who do not self-identify as transgender are in fact harmed by this institutionalized social custom. This includes masculine-appearing cisgender women, feminine-appearing cisgender men, as well as all people who are directed to use female-designated bathrooms. I describe this farreaching sexism as sex-identity discrimination. And because sex-segregated public restrooms, by their very nature, always prompt and enable this kind of discrimination, I argue that we should eliminate them, and use inclusive design to build no-gender public restrooms that meet our reasonable expectations for personal privacy and safety. 
The U.S. still may be some distance from universal unisex public restrooms, but given the available evidence from jurisdictions that have protected transgender people's right to access the restroom of their choice, it appears difficult to justify defining sex/gender in a manner to try to exclude transgender access.

\section{Notes}

1 De Mars (2017).

2 Kergil $(2017,505)$.

3 Hill and Schrag $(2016,150)$.

4 Love (2020).

5 Grimm (2021), referring to the Supreme Court's refusal to review the Court of Appeals decision granting Grimm the right to bathroom access matching his gender identity (Liptak 2021).

6 Carter (2018) criticizes Kogan for not acknowledging the legitimate threat to women's safety, but does not seem to recognize the underlying sexist ideology that informs both the threat to women and the protective response.

7 See Commonwealth of Pennsylvania v. White 538 A.2d 887 (Pa. Superior Court 1988), where the court affirmed a conviction for criminal trespass after a male defendant entered the women's restroom of an athletic club; or In re S.M.S., 196 N.C. A170 (2009), where a juvenile boy was guilty of second-degree trespass for running through the girls' locker room at a high school while girls were changing clothes.

8 For example, in Commonwealth of Pennsylvania v. Young 535 A.2d 1141 (Pa. 1988) the defendant entered a co-ed dormitory and after entering a women's restroom, opened a toilet stall being used by a woman and said "Hey baby, what you doing?" and subsequently was found guilty of disorderly conduct.

9 It is not entirely clear whether transgender individuals who changed their birth certificate would be permitted to use the restroom of their choice. The law repeatedly uses the phrase "biological sex," which would imply the gender assigned at birth. However, since the law defines "biological sex" as "The physical condition of being male or female, which is stated on a person's birth certificate" (General Assembly 2016), one could envision a scenario where someone had undergone sex reassignment surgery and obtained a change on their North Carolina birth certificate, thereby meeting the law's requirement.

10 Philosopher Richard Rorty advocates that we use language with a sense of irony, recognizing that our linguistic categories are contingent creations open to revision. $\mathrm{He}$ notes: "The opposite of irony is common sense. For that is the watchword of those who unselfconsciously describe everything important in terms of the final vocabulary to which they and those around them are habituated" $(1989,74)$.

11 Similarly, a study of over 1,000 user comments from 190 online articles about transgender women in women's restrooms found that the most negative comments were by cisgender men who still see transwomen as biological men (Stones 2017).

12 A Wikipedia page devoted to the Public Facilities Privacy \& Security Act includes a detailed section on the Economic Impact of HB2: https://en.wikipedia.org/wiki/ Public_Facilities_Privacy_\%26_Security_Act 


\section{Transgender voices}

"I went to Afghanistan. I did all these things. I mean, what does that [Trump's ban] tell me? That tells me I'm not welcome. That tells me that I am not respected as myself."

Navy Petty Officer 1st Class Brock Stone ${ }^{1}$

"No matter how much he trained and succeeded in the SEALs-

perhaps one of the manliest professions in the world, the inner female didn't entirely disappear."

Kristen Beck \& Anne Speckhard, Warrior Princess ${ }^{2}$

"When I was working at the Pentagon, I worked for a new boss and I told him that I was trans and why it was important. And about 10 months later, he retired and before he did, he called me into his office and he said, 'you know what? You broke my stereotype.

He said, 'just by coming to work and getting the job done every day, you smashed my expectation of who and what a transgender person is'."

Air Force Lt. Colonel Bree Fram ${ }^{3}$

"Why must I justify my equality?"

Riley Dosh, West Point graduate; refused a commission by the

Trump administration in 2017

"All people have dignity and value, as citizens, as servicemembers, as public servants, and most importantly as shared stakeholders in a healthy society. Transphobia and its fruits are antithetical to both that cherished ideal and our national security today."

Shawn Skelly, Assistant Secretary of Defense ${ }^{4}$ 


\section{6}

\section{THE MILITARY}

When we think of transgender people in the U.S. military, there are two possible historical narratives. Officially, until 2016, there were no transgender soldiers allowed, period. Unofficially, a different and more complicated story involving assigned sex, sexual orientation, and gender identity can be told.

For most of U.S. history, military service that includes combat traditionally has been restricted to males. Thus, if we describe the eligibility from the standpoint of a regulatory definition, the situation was straightforward: Only biological males (X) count as potential soldiers $(\mathrm{Y})$ in the U.S military (C).

Nonetheless, there are historic accounts of women serving in combat from the very start of U.S. history. In some cases, these women served as women, however temporarily and unauthorized. One unofficial Revolutionary War narrative describes a woman named Mary Hays McCauley who, like other "camp followers," provided support and carried water to troops during battle, thus gaining the nickname "Molly Pitcher." At the Battle of Monmouth in June 1778, the story is that her husband collapsed, either from the heat or from injury, so she took over his position at his artillery piece firing on the oncoming British (Biography.com Editors 2020; Diamant 1998, 119-120; Nix 2020). Margaret Cochran Corbin was the first woman to receive a military pension for her fighting in the Battle of Fort Washington on November 16, 1776. There she dressed as a man and helped her husband load his cannon until he was killed, at which time she took over his post and fought until she was severely wounded. In 1779, the Continental Congress awarded her a pension equivalent to half that of male soldiers (Diamant 1998, 112-113; Michals 2015b).

There are also stories of women disguising themselves as men in order to fight, both in the Revolutionary War and the Civil War. Deborah Sampson disguised herself and assumed the name of Robert Shurtleff in order to join the Fourth Massachusetts Regiment during the Revolutionary War. She served for two years 
without detection, despite being wounded twice, and was only revealed to be a woman when hospitalized during an epidemic and falling unconscious. She received an honorable discharge and received a military pension from the Commonwealth of Massachusetts (Diamant 1998, 35-38; Michals 2015a). Though documented cases during the Revolutionary War are rare, the historical consensus is that the number of disguised women soldiers during the Civil War ran well into the hundreds. One of the most famous examples is Jennie Irene Hodgers, a.k.a. Private Albert Cashier. Hodgers emigrated to the United States from Ireland, and first assumed the identity of a man to gain employment at a shoe factory. After the Civil War broke out, Hodgers became Albert Cashier and volunteered for the 95th Infantry, Illinois in August 1862. Cashier took part in 40 engagements, including the critical Siege of Vicksburg, and served a full three-year tour of duty. Cashier is sometimes called the first transgender soldier because he continued to live as a man after the war (O'Dowd 2019). Only late in life was his secret revealed when hospitalized for dementia. Nonetheless, he was buried in uniform with full military honors, and his tombstone lists his name as Albert D. J. Cashier (O’Dowd 2018, 2019).

The extensive physical examinations required for recruits starting in World War I made it all but impossible for women to disguise themselves to become combat soldiers in the United States military. ${ }^{5}$ During the war, there are accounts of a handful of women in European countries who joined the military disguised as men. Russia officially formed combat units called Women's Battalions made up entirely of women in 1917 (Stoff 2006).

In the U.S. military, women participated in World War I primarily as nurses and switchboard operators. Female switchboard operators were part of the U.S. Army's Signal Corps and had to be bilingual in English and French. Though they wore U.S. Army uniforms and were subject to Army regulations, after the War they were not given honorable discharges or veteran benefits, as they were defined, after the fact, as "civilians" employed by the military due to the fact that Army Regulations specified the male sex-an injustice not rectified until 1977 under the Carter administration (Hanes 2007).

During World War II, the Women's Army Corps (WAC) was formed and reached a peak strength of 100,000 women (Treadwell 1954). The creation of WAC altered who was eligible for military service, though in a manner strictly segregated by sex and that forbid women from combat roles. Thus the regulatory definition that "Only biological males $(\mathrm{X})$ count as potential soldiers (Y) in the U.S military (C)" was in effect complemented by the rule "Only biological females (X) count as potential servicepeople (Y) in the WACs (C)." The range of noncombat roles women fulfilled is described in a booklet in 1944 as follows:

As the tempo of war accelerated, WACs arrived overseas aboard liners and cargo boats in ever increasing numbers. They were assigned to ETOUSA [European Theater of Operations of the USA] headquarters, to the Air Forces, to services mushrooming from SOS, Ordinance, Quartermaster, Transportation, Medical, Chemical Warfare, Engineers. They plotted aircraft 
and V-1s, teleprinted, operated switchboards, typed, filed, made mapsfrom air-sea rescue rooms they "brought home" lost planes and pilots. They assessed combat films, cooked, gave inoculations, drove jeeps and trucks, and sweated out missions from control towers. These were only a few of the 239 jobs for which WACs were trained.

(Wilson 1944)

WAC was disbanded in 1978 when women were integrated into the U.S. Army. By that time, there were noncombat roles for women in all branches of the U.S. military, and the Army, Air Force, Coast Guard, and Naval Academies all admitted women. It was not until January 2013, however, that the traditional ban on women serving in combat roles was finally lifted by Secretary of Defense Leon Panetta. Implementation is occurring slowly and not without controversy. Nonetheless, from a definitional standpoint, being assigned to the male sex is no longer a requirement for any military occupation, combat or noncombat. In 2017, women represented $16 \%$ of the overall active duty force, and $18 \%$ of all commissioned officers (Barroso 2019).

Historically, the U.S. military has not only been a bastion of masculinity, but heterosexuality as well. ${ }^{6}$ For most of U.S. history, homosexual acts were forbidden by civil anti-sodomy laws and thus were grounds for dishonorable discharge. By World War II, the U.S. Army classified homosexual "proclivities" as disqualifying inductees from military service, both for men in the Army and women in WAC (Bérubé 1990). For women, screening of recruits included judgments about physical appearance and gender conformity in order to attempt to identify and exclude lesbians (Meyer 1996). By 1949, the Defense Department codified anti-homosexual regulations across all branches of the military: "Homosexual personnel, irrespective of sex, should not be permitted to serve in any branch of the Armed Forces in any capacity, and prompt separation of known homosexuals from the Armed Forces is mandatory" (quoted in Bérubé 1990, 261). In 1982, the Defense Department policy memorandum 1332.14 stated flatly: "Homosexuality is incompatible with military service. The presence in the military environment of persons who engage in homosexual conduct or who, by their statements, demonstrate a propensity to engage in homosexual conduct, seriously impairs the accomplishment of the military mission" (GAO 1992, 2).

Thus, even while the biological attribute of "sex" slowly lost relevance as a required definitional attribute for military service, heterosexuality has been maintained, though it has been defined by negation. That is, to be eligible for military service, one must not be non-heterosexual, i.e., homosexual.

Between 1994 and 2011, the Defense Department implemented what became known as the "Don't Ask, Don't Tell" policy toward homosexuality. A Defense Department Directive issued December 21, 1993 declared that, “A person's sexual orientation is considered a personal and private matter, and is not a bar to service entry or continued service unless manifested by homosexual conduct" (section E1.2.8.1). In other words, as long as servicemen and women kept their sex life 
private, in theory they could continue to serve. The policy took effect on February 28, 1994, and lasted until its repeal in 2011. The policy was controversial, as gay rights activists emphasized that the policy was still discriminatory and was used as a tool of harassment by anti-gay soldiers and officers, and conservatives still insisting that homosexuality is inconsistent with military service. It is estimated by the Servicemembers Legal Defense Network that more than 14,500 service personnel were discharged while "Don't Ask, Don't Tell" was in effect (McVeigh \& Harris 2011). A University of California Blue Ribbon Commission Report estimated that the cost of implementing the policy between 1994-2003 was over $\$ 300$ million (Barrett et al. 2006).

In 2010, Congress passed legislation initiating a process of ending the "Don't Ask, Don't Tell" policy. Despite Republican efforts to delay the end of the policy, the statute's required certification that ending the policy would not harm military effectiveness progressed, and the policy officially ended September 20, 2011. A study that began six months after the policy's end and completed at the one-year mark, and conducted by an impressive list of academic and military scholars, states:

Our conclusion, based on all of the evidence available to us, is that DADT repeal has had no overall negative impact on military readiness or its component dimensions, including cohesion, recruitment, retention, assaults, harassment, or morale. If anything, DADT repeal appears to have enhanced the military's ability to pursue its mission.

(Belkin et al. 2012, 588)

Gay, lesbian, and bisexual individuals who wished to serve in the U.S. military are now legally able to do so.

Not so for transgender people.

Though there was not an explicit policy using the term "transgender" until relatively recently, transgender military personnel would be excluded either for violating proscriptions against homosexuality or because "transvestitism," "transsexualism," and "gender identity disorder," were considered mental afflictions. The Diagnostic and Statistical Manual of Mental Disorders included "Transvestitism” as a sexual deviation in the 1968 edition (DSM-II), and listed "Transsexualism" and "Gender identity disorder" in 1980 (DSM-III). In 1984, a team of psychiatrist military officers reported on six case studies of requests for sex reassignment surgery, noting that, "To the military, transsexualism is a disqualifying medical condition in which separation is to be handled through administrative channels, just as are homosexuals and those with significant personality disorders" (Jones, Deeken, \& Eshelman 1984). As recently as 2010, a Defense Department memo on "Medical Standards for Appointment, Enlistment, or Induction in the Military Services" precluded those with a "Current or history of psychosexual conditions, including but not limited to transsexualism, exhibitionism, transvestism, voyeurism, and other paraphilias" (Defense Department 2010, 48). ${ }^{7}$ 
The fact that transgender military service is officially prohibited has not stopped transgender individuals from serving, albeit covertly. Information about transgender participants in the U.S. military has emerged slowly and in a piecemeal fashion. A study was published by a military psychiatrist, Captain George R. Brown (USAF), in 1988 concerning 11 "male gender-dysphoric patients meeting DSMIII criteria for transsexualism" who were seen by the doctor over a three-year period (Brown 1988). All were requesting hormone treatment and/or sex reassignment surgery, after spending years trying to escape their gender dysphoria by plunging into what the psychiatrist called "hypermasculinity" in the military. One patient said, "I tried to do things to make me feel more masculine, like joining the Navy and getting married." Another said, "I joined the Air Force as a cover. In uniform, my masculinity would not be questioned-I was above reproach" (Brown 1988, 529). Brown reports that most of those treated were discharged from military service prematurely, many within their first year of duty (1988, 533; see also Jones, Deeken, \& Eshelman 1984). Interestingly, an opinion issued by the Judge Advocate General's Air Force office, quoted by Brown, suggested that a policy of excluding "transsexuals" would be hard to defend:

The short of the matter seems to be that if we propose to base the policy of discharging members who undergo sex change operations on promotion of good order, discipline, morale, or other similar virtues, we must prepare for a challenge on the ground that there is no empirical evidence that transsexuals have an adverse impact on those values.

(OpJAGAF 1984)

The military experience of transgender veterans has been documented in autobiographies, including that by Roberta Cowell, a British racing driver and fighter pilot in World War II, who was the first known British transgender woman to undergo sex reassignment surgery (Cowell 1954); Christine Jorgensen, who was drafted into the U.S. Army during World War II (Jorgensen 1967); Jan Morris, a Welsh historian and author who also served in World War II (Morris 1974); and Renée Richards, the famed tennis player who served in the U.S. Navy (Richards 1983).

A recent and visible U.S. example is Kristin Beck. Beck served as a Navy SEAL for 20 years, reaching the rank of Senior Chief Petty Officer. She served in 13 deployments, including seven combat deployments, and at one point was a member of the counter-terrorism unit known as SEAL Team Six. She received multiple awards and decorations, including a Bronze Star and Purple Heart. Throughout her military career, she wanted to live life as a woman. Beck transitioned after retiring, and co-authored a book about her life titled Warrior Princess: A U.S. Navy SEAL's Journey to Coming out Transgender (Beck \& Speckhard 2013).

The previous examples all concern transgender soldiers who transitioned after leaving military service. This is not surprising given that the military has precluded 
transgender service members until quite recently. A notable exception is Caroline Paige's autobiography, which shares the story of her becoming the first openly transgender officer to serve in the UK Armed Forces (2017).

A Whitepaper prepared for the Palm Center and the Transgender American Veterans Association reports the results of a survey completed by over 800 transgender veterans and active service personnel. Of the 660 participants who identified as "transsexual," 97\% reported they were unable to transition before leaving the military (Bryant \& Schilt 2008, 1). Though the paper cautions that the results relied on a convenience sample rather than a random sample, and thus cannot claim to be representative of all transgender service members, the data provided an important first step toward understanding the experiences of transgender soldiers, and the accounts are consistent with the anecdotal research reported by Jones, Deeken, and Eshelman (1984), Brown (1988), and published autobiographies.

Historical data on how many transgender people are in the military are hard to find, though multiple sources estimate that there is a higher proportion of transgender people in the military than in the general U.S. population (Yerke \& Mitchell 2013). Informed by the Defense Department's first-ever effort to collect data on gender identity in 2016, it was estimated "that the number of currently serving transgender troops is 14,707 , of whom 8,980 are in the Active Component, and 5,727 are in the Selected Reserve" (Belkin \& Mazur 2018). These figures are similar to those estimated by the Williams Institute at the UCLA School of Law in 2014 that "approximately 15,500 transgender individuals are serving on active duty or in the Guard or Reserve forces. We also estimate that there are an estimated 134,300 transgender individuals who are veterans or are retired from Guard or Reserve service" (Gates \& Herman 2014, 1). A survey conducted by the National Center for Transgender Equality found that among current service members, slightly over half $(52 \%)$ thought no one thought or knew they were transgender. Among those who believed their leadership thought or knew they were transgender, approximately one-quarter $(23 \%)$ believed their leadership or commanding officer had taken actions to discharge them. On the other hand,

Many reported that their leadership or commanding officer responded to their transgender status in a variety of positive ways, including supporting their name change $(47 \%)$ and supporting their transition-related medical treatment (36\%). Thirty percent (30\%) reported that their leadership or commanding officer ignored their transgender status or looked the other way.

(James et al. 2016, 169)

Respondents who separated from military service more than 10 years before the survey was taken in 2015 were asked about the circumstances of their discharge: " $19 \%$ believed their discharge was either partially related (14\%) or completely 
related (5\%) to being transgender" (170). It is also clear that the U.S. military's antitransgender policy resulted in a loss of personnel:

Nearly one in ten $(9 \%)$ respondents who separated from military service more than ten years ago left the service in order to transition, and an additional 19\% said they left the service to avoid being mistreated or harassed as a transgender person.

If the ban was lifted, nearly two-thirds said they "would" or "might" return to military service (173).

\section{The Obama and Trump administrations and transgender military service}

The end to the "Don't Ask, Don't Tell" policy involving lesbians, gay men, and bisexuals was brought about by substantial pressure upon the Obama administration by LGBT advocates (Frank 2013). The next step taken by the administration was to reconsider the prohibition on transgender people in the military. In May 2014, Defense Secretary Chuck Hagel said that the military should "continually" review its prohibition on transgender people serving in the armed forces, declaring, "Every qualified American who wants to serve our country should have an opportunity if they fit the qualifications and can do it" (Cooper 2014). Ashton B. Carter, who succeeded Hagel as Defense Secretary, announced a little more than a year later that the Pentagon would move to allow transgender people to serve openly. He noted that "We have transgender soldiers, sailors, airmen and Marines-real, patriotic Americans - who I know are being hurt by an outdated, confusing, inconsistent approach that's contrary to our value of service and individual merit" (Bromwich 2017). In October 2015, Vice President Joseph Biden repeated a claim he had made several years before that transgender rights were "the civil rights issue of our time" and argued that transgender people should be allowed to serve in the military (Bromwich 2017).

A study by the Rand Corporation commissioned by the Defense Department was released in May 2016 and found that allowing transgender people to serve openly would cost little and have no significant impact on unit readiness (Schaefer et al. 2016). Acknowledging that the data are far from clear, the report estimated the number of transgender active and reserve service members is about 3,960, though not all would seek to transition medically even if the opportunity was made available (16). ${ }^{8}$ Based on those numbers, the estimated cost of additional health care would be in the range of $\$ 2.9$ to 4.2 million (35). The report also examined the impact of allowing transgender people to serve in the military in Australia, Canada, Israel, and the United Kingdom, and found "In no case was there any evidence of an effect on the operational effectiveness, operational readiness, or cohesion of the force" (xiii). 
In June 2016, Secretary Carter announced an end to the ban on transgender people serving. As quoted in the New York Times, "Effective immediately, transgender Americans may serve openly," Mr. Carter said. "They can no longer be discharged or otherwise separated from the military just for being transgender" (Rosenberg 2016). The announcement was transmitted to the military through what is known as a Directive-type Memorandum (16-005), titled "Military Service of Transgender Service Members" and stated explicitly that "transgender individuals shall be allowed to serve in the military," and noted that the policy takes effect immediately (Secretary of Defense 2016). The memorandum states it will expire effective June 30, 2017, and that it will be converted to a new DoDI (Department of Defense Instruction). The key changes in procedures were described as follows:

a Effective immediately, no otherwise qualified Service member may be involuntarily separated, discharged or denied reenlistment or continuation of service, solely on the basis of their gender identity.

b Transgender Service members will be subject to the same standards as any other Service member of the same gender; they may be separated, discharged, or denied reenlistment or continuation of service under existing processes and basis, but not due solely to their gender identity or an expressed intent to transition genders.

c A Service member whose ability to serve is adversely affected by a medical condition or medical treatment related to their gender identity should be treated, for purposes of separation and retention, in a manner consistent with a Service member whose ability to serve is similarly affected for reasons unrelated to gender identity or gender transition.

(Secretary of Defense 2016)

The new policy clearly stated that those currently serving in the military could not be discharged solely to transgender status. It also created a new definitional criterion for transgender "accession," or entry, into the military. Medical standards still stated that gender dysphoria or a history of medical treatment, including sex reassignment surgery, would be "disqualifying" unless the applicant had been stable in their gender for 18 months or more. The 18-month requirement could be waived, in whole or in part, "in individual cases for applicable reasons" (Secretary of Defense 2016). Specific Department of Defense "Instruction" detailing the policy was required to be in place by July 1, 2017.

From a definitional standpoint, the 18-month requirement is similar to the requirement of some single-sex colleges that required applicants either to have completed their transition or otherwise meet a "durational" definitive attribute: Only transgender recruits stable in their gender identity (X) count as potential soldiers (Y) in the U.S military (C). The explanation provided by Secretary Carter was: "Medical standards for accession into the Military Services help to ensure that those entering service are free of medical conditions or physical defects that may require excessive time lost from duty." For practical and political reasons, the policy 
was not designed to permit transition immediately after enlistment, or in the midst of basic training. At the same time, the policy affirmed that transgender Service members "may transition gender while serving" (Secretary of Defense 2016). Such a policy is consistent with how the military treats a range of medically necessary but non-emergency medical treatments (Belkin 2020). The 18-month requirement was a compromise between those who wanted a shorter durational criterion and those seeking a two-year requirement (Lamothe 2016).

The new policy was greeted as "historic" and a "momentous victory" by various advocacy groups, and was met with "jubilation" by transgender service members (Lamothe 2016). The National Center for Transgender Equality's Executive Director Mara Keisling said:

Like other institutions, including allied militaries, the Defense Department has found straightforward answers for all the questions that have come up. This is the right decision for the military and brings much needed certainty for thousands of currently serving soldiers who have put their lives on the line for their country, as well as for their units.

(Tobin 2016)

President of the LGBT military group SPARTA (Service members, Partners, Allies for Respect and Tolerance for All), Sue Fulton, said "The Obama administration will go down in history as one of the most significant for LGBT Americans” (Margolin 2016).

In an analysis of how the ban on transgender military service "unraveled" so quickly, political scientist and Director of the Palm Center Aaron Belkin suggested that a number of recent factors contributed, including the removal of the combat exclusion rule against women, the lack of strong "opinion leadership" opposed to transgender inclusion, momentum from the repeal of the "Don't Ask, Don't Tell" policy, and effective advocacy strategies that "humanized the issue for journalists and the public at large; proved that transgender service works; and publicly discredited the primary justification for the ban" (Belkin 2016, 2). The policy has significant public support. A survey in 2015 showed 42.5\% disagreeing with the statement "transgender people should not be allowed to serve openly in the military" with 35\% neutral. A year later, a survey showed 68\% agreeing or completely agreeing with the statement "Transgender people should be allowed to serve openly in the military" (Taylor, Lewis, \& Haider-Markel 2018, 77-79). Six polls took place in the first five months of 2019 surveying over 14,000 Americans, with an average support of $67 \%$ for inclusive policies for transgender service members (Palm Center 2019).

The election of Donald Trump as president in November 2016 was an ill omen for transgender people for a variety of reasons, not the least of which was Vice President Mike Pence's record of opposition to LGBTQ rights (HRC 2018). The nominations of General James Mattis as Secretary of Defense, Heather Wilson as Secretary of the Air Force, and Mark Green as Secretary of the Army were all viewed by advocates as opponents of LGBTQ rights (Belkin 2020). Green 
withdrew his name from nomination in light of highly publicized comments about LGBT and Muslim people, including the claim that if psychiatrists were polled, they would conclude that "transgender is a disease" (Lamothe 2017).

Confirmation of the Trump administration's lack of support for LGBTQ rights or the new Obama policy concerning transgender service emerged in May 2017 when two transgender cadets-one at the Air Force Academy and one at West Point-learned after four years of training to become officers that they were denied their commissions. Pentagon officials claimed that the transgender policy covered only those on active duty and thus did not apply to new officer "candidates." It was reported by The New York Times that,

Brad Carson, a former acting under secretary of defense who is the architect of the transgender policy, said its authors "envisioned that the same rules that apply to active-duty service members today would also apply to service academy personnel, because they're already in the military."

(Stolberg 2017)

Described in the press as a loophole, the Pentagon followed the standard procedure that cadets were governed by the policy concerning accession rather than policies governing active duty members of the military.

The question is why did the Pentagon decide not to allow either cadet to be commissioned? Former Superintendent of the United States Air Force Academy, Lt. General Michelle D. Johnson (ret.), confirmed (2020) that the cadet was recommended for commissioning since the cadet had completed "all the military training requirements for commissioning as an officer" and "wanted to serve." Nonetheless, commissioning "was denied by the Air Force for the cadet not meeting medical qualifications.” Johnson noted:

In early 2017, Department of Defense (DoD) policy development was still nascent regarding transgender uniformed military service and medical qualifications. With the overarching policy still in development, the DoD medical community, including USAFA and headquarters Air Force in the Pentagon, also conferred at length on this specific case, especially with respect to how the concepts of gender dysphoria and transition might apply. Finalizing policy details was further complicated by emerging messages from the newly elected President of the United States.

(Lt. Gen. Johnson 2020)

The name and details concerning the Air Force cadet were never revealed, but the identity of the West Point cadet became a matter of public record. According to the New York Times,

The superintendent of West Point, Lt. Gen. Robert L. Caslen Jr., sought a 'medical waiver' from the Pentagon to allow Ms. [Riley] Dosh her 
commission. But the request was denied, a Pentagon spokeswoman said, because Defense Department officials 'did not think it appropriate' to grant a waiver while the accessions policy was still under review.

(Stolberg 2017)

Given the support of Lt. General Caslen and a policy in place that supports transition for active service personnel, it is hard to understand why such a waiver would be inappropriate. Lt. General Caslen, now retired from the military, said he did not have direct knowledge of the reasoning of senior Army leadership, though he believes that the fact that the Air Force Academy had denied a commission to their transgender cadet set a precedent that the Army would be reluctant to break ranks from, and it is reasonable to assume that leadership would be "sensitive" to White House policies (Caslen 2020). West Point graduate Dosh says she was never given an explanation, but was simply informed on May 5, 2017, that the waiver had been denied, despite Dosh meeting all requirements and passing the commissioning physical. Roughly a third of the graduating class of 2017 were granted medical waivers of one sort of another (Caslen 2020). Understandably, Dosh concluded, "I suspect no reason other than transphobia" (2020; see also Dosh 2019). Former Secretary of the Army Eric Fanning states that he unequivocally and "absolutely" would have granted the waiver request had he still been Secretary, and agreed that "prejudice is the most significant motivator for denying transgender people the right to serve in the military" (2020).

In late June, Defense Secretary Mattis provided the heads of the military branches a six-month delay "to determine if allowing transgender individuals to enlist in the armed services will affect the 'readiness or lethality' of the force." Mattis claimed that the delay "does not presuppose the outcome of the review" (Baldor 2017a).

Less than a month after Secretary Mattis's announcement, on the morning of July 26th, President Trump sent out a series of tweets that were stunning in their scope and abruptness:

After consultation with my Generals and military experts, please be advised that the United States Government will not accept or allow . . . Transgender individuals to serve in any capacity in the U.S. Military. Our military must be focused on decisive and overwhelming ... victory and cannot be burdened with the tremendous medical costs and disruption that transgender in the military would entail. Thank you.

(Trump 2017)

The announcement was met with immediate criticism, in no small measure because the pronouncement was "confusing for its timing, substance, and rationale" (Graham 2017). The decision was described as blindsiding his military and Republican congressional leaders.

One account of the decision claims that Trump was presented on July 26 with four different options related to the military's transgender policy that were 
intended to frame an ongoing discussion. Instead, according to reporter Michael Wolff, ten minutes after the briefing Trump announced a wholesale ban via Twitter without further consultation with advisors, the Pentagon, or the Joint Chiefs of Staff $(2018,515)$. There were different hypotheses about why Trump made the decision. According to Wolff, the preceding week had been calamitous for Trump, and he was "seething" that day because a speech he had given the day before to the Boy Scouts of America prompted the group to apologize for his remarks (Stack 2017). An alternative explanation was that the ban was intended to resolve

a quietly brewing fight on Capitol Hill over whether taxpayer money should pay for gender transition and hormone therapy for transgender service members. The dispute had threatened to kill a $\$ 790$ billion defense and security spending package scheduled for a vote this week.

(Davis E Cooper 2017)

The bill included funding for Trump's so-called "border wall" with Mexico, and Republican insiders "feared they might not have the votes to pass the legislation because defense hawks wanted a ban on Pentagon-funded sex reassignment operations" (Bade \& Dawsey 2017). ${ }^{9}$ Rather than address the specific issue of funding medical treatment, Trump opted to announce the sweeping policy change.

The "decision was announced with such haste that the White House could not answer basic inquiries about how it would be carried out, including what would happen to openly transgender people on active duty. Of eight defense officials interviewed, none could say" (Davis \& Cooper 2017). In contrast with the careful formulation and staged announcement of the repeal of "Don't Ask, Don't Tell" and the repeal of the ban on transgender military service under the Obama administration, Trump's hurried decision "was not accompanied by a formal order, a fact sheet, or any of the other information that typically accompanies such a policy shift" (Graham 2017). Press Secretary Sarah Sanders was unable to answer questions about the announced policy, and "when reporters kept trying to ask, she threatened to end the briefing" (Graham 2017).

In August 2017, Trump issued a Memorandum to clarify the administration's policy on Military Service by Transgender Individuals. The Memorandum stated:

In my judgment, the previous Administration failed to identify a sufficient basis to conclude that terminating the Departments' longstanding policy and practice would not hinder military effectiveness and lethality, disrupt unit cohesion, or tax military resources, and there remain meaningful concerns that further study is needed to ensure that continued implementation of last year's policy change would not have those negative effects.

(Presidential Memoranda 2017) 
The specific directives of the Memorandum were as follows:

The Secretary of Defense, and the Secretary of Homeland Security with respect to the U.S. Coast Guard, shall:

(a) maintain the currently effective policy regarding accession of transgender individuals into military service beyond January 1, 2018, until such time as the Secretary of Defense, after consulting with the Secretary of Homeland Security, provides a recommendation to the contrary that I find convincing; and

(b) halt all use of DoD or DHS resources to fund sex reassignment surgical procedures for military personnel, except to the extent necessary to protect the health of an individual who has already begun a course of treatment to reassign his or her sex.

The Memorandum identified three reasons for the ban on transgender military service; namely, that transgender troops would hinder military effectiveness and lethality, disrupt unit cohesion, or tax military resources. Military effectiveness, unit cohesion, and cost had been discussed in the Rand Corporation study and were found unproblematic by the Obama administration. ${ }^{10}$ The estimated increase in military health care was estimated to require an increase of $0.1 \%$, which critics pointed out was about a tenth of what the military spends on erectile dysfunction medicines (Ingraham 2017). Two different federal judges soon found the Trump administration's justification wanting and struck down the ban in October and November (Philipps 2017a, 2017b). Judge Marvin J. Garbis found the policy "capricious, arbitrary, and unqualified" and declared "There is absolutely no support for the claim that the ongoing service of transgender people would have any negative effective on the military at all" (Philipps 2017b). After a third federal court ruled against the policy, the Pentagon announced that it would begin to allow transgender people to enlist in the military beginning January 1, 2018, using accession requirements similar to those planned by the Obama administration (Baldor 2017b). In February 2018, the Pentagon confirmed that the first transgender person had signed a contract to join the United States military, "a development made possible after a federal judge ruled that the military must accept transgender recruits" (Browne 2018).

In March 2018, Defense Secretary Mattis announced a revised policy, criticizing the Rand Corporation report and the decision by the Obama administration (Mattis 2018). ${ }^{11}$ The policy banned transgender military service except for a very narrow set of exceptions. The policy stated that:

- Transgender persons with a history or diagnosis of gender dysphoria are disqualified from military service, except under the following limited circumstances: (1) if they have been stable for 36 consecutive months in their 
biological sex prior to accession; (2) Service members diagnosed with gender dysphoria after entering into service may be retained if they do not require a change of gender and remain deployable within applicable retention standards; and (3) currently serving Service members who have been diagnosed with gender dysphoria since the previous administration's policy took effect and prior to the effective date of this new policy, may continue to serve in their preferred gender and receive medically necessary treatment for gender dysphoria.

- Transgender persons who require or have undergone gender transition are disqualified from military service.

- Transgender persons without a history or diagnosis of gender dysphoria, who are otherwise qualified for service, may serve, like all other Service members, in their biological sex.

(Mattis 2018)

The new policy effectively returns the military to the transgender ban prior to June 2016. First, in terms of accession, applicants with a history of gender dysphoria may access into the military only if they can demonstrate 36 consecutive months immediately prior to their application that they no longer experience gender dysphoria, have not transitioned, and are "willing and able to adhere to all standards associated with their biological sex" (Mattis 2018, 42). In other words, one can join the military only if one is willing not to live life as transgender. Second, in terms of retention, only active duty members who were diagnosed with gender dysphoria between June 2016 and March 2018 could continue to serve and receive medical treatment. Otherwise, transgender service members could remain in the military only if they do not transition and are willing to serve in their assigned birth sex. Otherwise, as was the case prior to June 2016, a diagnosis of gender dysphoria is grounds for separation from military service.

The new policy was soon challenged in the courts. In November 2018, the Trump administration petitioned the Supreme Court to overrule the various injunctions constraining the new policy. By a vote of 5-4, in January 2019 the Court allowed the new policy to be implemented while the matter worked its way through the courts. The Court technically took no stance on the legality of the ban.

On April 12, 2019, the policy described by Secretary Mattis a year earlier was implemented into policy in a Directive-type Memorandum (19-004) by Acting Deputy Secretary of Defense, David L. Norquist. The policy appears to have been written to withstand legal challenges, as it begins by stating that it is DoD policy that no one, solely based on his or her gender identity, will be denied accession, involuntarily discharged, denied reenlistment, or subject to adverse action or mistreatment (Norquist 2019, 2). However, the policy also states that all policies that are gender-related, such as uniform and grooming standards, bathroom, and shower facilities, "all persons will be subject to the standard, requirement, or policy associated with their biological sex" (2). "Biological sex" is defined in the Memorandum as "A person's biological status as male or female based on chromosomes, gonads, 
hormones, and genitals" (14). Secretaries of the military departments may grant waivers in individual cases (5). Otherwise, the restrictions outlined in the Mattis policy from March 2018 apply to new accessions and current active personnel.

Both Trump and DoD claimed that the policy was not a ban on transgender individuals. But as critics noted, the policy amounted to saying that one can be transgender as long as one does not try to live in a manner consistent with their gender identity. As one news story described the contradiction, a Pentagon spokesperson said "It's absolutely not," when asked if it was a ban. "She did say, however, that new recruits will be rejected if they've undergone a gender transition, that they cannot transition while in service, and that they must conform to the uniform and fitness standards of their birth sex" (Holden 2019).

On March 28, 2019, the U.S. House of Representatives debated and passed a resolution opposing the ban on transgender members of the Armed Forces. The resolution critiqued the three reasons offered to justify the policy-military readiness, unit cohesion, and cost - and noted that no evidence had been provided of any adverse impacts of the Obama administration's policy during the two years it was in effect. The resolution quoted a statement by 56 retired generals and admirals that argued the ban would be harmful to the military:

This proposed ban, if implemented, would cause significant disruptions, deprive the military of mission-critical talent, and compromise the integrity of transgender troops who would be forced to live a lie, as well as nontransgender peers who would be forced to choose between reporting their comrades or disobeying policy.

(H. Res. 124)

Congressperson Adam Smith, ranking Democrat on the House Armed Services Committee, argued that the Trump policy "is based on ignorance and bigotry" (2019, H2898).

In 2020, the constitutionality of the Pentagon's policy was in litigation with four suits in progress. A fifth case was filed in March 2020, when a naval officer ("Jane Doe") filed the first new challenge to the policy in Doe v. Esper. In midMay, the Navy granted a waiver, as permitted under the Norquist policy, thus exempting Jane Doe from the prohibition of living consistently with her gender identity (Starr \& Kelly 2020). However, in his first week in office as president, Joe Biden overturned the Trump ban with an executive order to enable "all qualified Americans to serve their country in uniform" (Biden 2021a). The executive order revoked the Trump actions of 2017 and, though details are yet to be specified at the time of this writing, would seem to revert back to the Obama administration regulations. It is noteworthy that in June 2021, the Department of Veteran Affairs announced that it would begin to fund surgeries for transgender veterans "seeking to alter their physical attributes" (Shane 2021). 
The objective of this book is to identify competing definitions at work in different contexts challenged by what I have called the Transgender Exigency in order to understand the sources of those definitions, the values and interests served by different definitions, and to note who is empowered by institutional arrangements to decide what definitions shall prevail. While such an analytical framework was useful in understanding the contexts of single-sex schools and so-called bathroom bills, the situation with transgender service members is more complicated.

As noted previously, the regulatory definition at work initially in the U.S. military was that Only biological males $(\mathrm{X})$ count as potential soldiers $(\mathrm{Y})$ in the U.S military (C), later complemented by Only biological females (X) count as potential servicepeople $(\mathrm{Y})$ in the WACs $(\mathrm{C})$. Implicit in these definitions, until the final repeal of regulations prohibiting gay and lesbian soldiers, was that males and females must not engage in homosexual conduct. Once "Don't Ask, Don't Tell" was repealed, and women were no longer excluded from combat roles, there was no longer a policy of exclusion based on sex or sexual orientation. The ban on transgender people was lifted in 2016 by the Obama administration, with the requirement that for accession, Only transgender recruits stable in their gender identity $(\mathrm{X})$ count as potential soldiers $(\mathrm{Y})$ in the U.S military $(\mathrm{C})$.

The framework of the Trump administration clearly prohibited certain categories of people who would normally be described as transgender from military service, despite the claim that it is not a ban. But denotative conformity concerning who "counts" as a qualifying or disqualifying individual is complicated when ad hoc waivers may be granted. Thus, the Jane Doe in Doe v. Esper was considered disqualified one moment and granted a waiver the next. And the language that a soldier can "be" transgender as long as they do not try to live as one is positively Orwellian.

The Trump administration policy was incoherent because it was motivated apparently by animus toward transgender people rather than concern for the military or for those in military service. The ban took place in a legal and political environment when identity-based discrimination is unlikely to succeed; accordingly, the policy is framed as a regulation on a medical condition. However, with any other medical condition, active duty personnel would either receive treatment and have an opportunity to prove their fitness to serve, or would receive a medical discharge. Perhaps precisely because transgender service members typically would be able to demonstrate fitness, the retention policy was written in such a way as to require an administrative separation, which cannot be challenged in the same way. As Belkin explains, "DoD tries to fit a square peg through a round hole by running discharges for a medical condition (the need to transition) through the administrative separation process. The other big reason for the policy's incoherence is that it is driven by animus but can't admit that. Hence, DoD had to make up phony reasons for the policy" (2020, see also Arthur et al. 2018).

The influence of biological determinism is clear, both in the texts of the DoD policies and in the source of political pressure leading to the transgender ban. Despite claiming to be an ally to "LGBT people" during the 2016 presidential 
campaign (Diamond 2016), after his election it became clear that Trump was far more invested in bolstering political support from social conservatives. The day before Trump's declaration, Foreign Policy ran an article noting that Vice President Pence was working with members of Congress to reverse the Defense Department's policy to cover medical procedures for transitioning service members, and conservative groups like the Family Research Council, Heritage Action for America, and Alliance Defending Freedom were working to convince members to support the measure (McLeary 2017). Tony Perkins, head of the Family Research Council-which condemns homosexuality and was designated a hate group by the Southern Poverty Law Center-lobbied Trump for months to repeal Obama's policy (Peters 2017).

In October 2018, a memo obtained by The New York Times revealed that the "Trump administration is considering narrowly defining gender as a biological, immutable condition determined by genitalia at birth," leading to the headline “' 'Transgender' Could Be Defined Out of Existence Under Trump Administration” (Green, Brenner, \& Pear 2018). The Department of Health and Human Services memo was drafted to guide interpretation of Title IX, the federal civil rights law that bans discrimination in education programs, and it is consistent with the rollback of the "Dear Colleague" instructions issued during the Obama administration concerning bathroom access (discussed in the previous chapter). According to the Times,

The Department of Health and Human Services has called on the "Big Four" agencies that enforce some part of Title IX - the Departments of Education, Justice, Health and Human Services, and Labor-to adopt its definition in regulations that will establish uniformity in the government and increase the likelihood that courts will accept it.

(Green, Brenner, \& Pear 2018).

The memo's definition was formalized in an announcement on June 12, 2020: "HHS will enforce Section 1557 by returning to the government's interpretation of sex discrimination according to the plain meaning of the word 'sex' as male or female and as determined by biology" (HHS Press Office 2020). The memo's and policy's definition of sex and its erasure of transgender people began to appear in other policy statements of the Trump administration, as well, including a letter of "Impending Enforcement Action" from the Department of Education that posits a definition of sex for the purposes of Title IX that would exclude transgender athletes (Blanchard 2020). In short, the definition is the extreme version of biological determinism described at the outset of this book, which is consistent with those who see transgenderism as a fiction.

$* * *$

It is noteworthy that the Trump ban was not particularly popular even with Republicans, with support among Republicans for transgender service increasing by $10 \%$ 
between 2017 and 2019 (Blake 2019). A study, funded by the Pentagon, found "broad support" for transgender military service across all four branches of the military ranks, and contradicted the belief that transgender service members degrade unit readiness (Dunlap et al. 2021). Given that the restoration of something like the Obama policies under the Biden administration are starting at the outset of Biden's term, as opposed to the end of Obama's, it would seem likely to have a better chance to survive as the long-term policy of the U.S. military.

\section{Notes}

1 Quoted in Dwyer (2021).

2 Beck and Speckhard (2013, 125).

3 Quoted in Dwyer (2021).

4 Skelly (2020). As of July 2021, Skelly is the highest ranking trans defense official in U.S. history (Yurcaba 2021).

5 Historical film footage archived on YouTube shows group showers and a physical examination process that took place with the recruits totally nude. See CriticalPast (2014).

6 Belkin (2012) provides a fascinating historical account of military masculinity in the 20th century that complicates military stereotypes.

7 For a more detailed account of military policies that function to exclude transgender people from service, see Yerke and Mitchell (2013).

8 The figure of 3,960 is an estimate based on studies done in California and Massachusetts, which yielded a rate of $0.1 \%$ in California to $0.5 \%$ in Massachusetts. Extrapolating those rates to the over 2 million active and reserve members yields a minimum of 2,140 and a possible maximum of 10,790 . The estimate of 3,960 is based on an averaging of the two rates, adjusted for the male/female distribution in the military and is described in the report as a "midrange estimate" (Schaefer et al. 2016, xi).

9 Some weeks earlier, moderate Republicans and Democrats defeated a proposed amendment to the budget bill that would have denied funding for gender reassignment surgeries and treatments for transgender active-duty personnel. As a result, conservative groups and Republicans began to lobby the White House directly (Bade \& Dawsey 2017).

10 "Lethality" was a new criterion introduced by Mattis, one that is ill-defined and largely redundant with military effectiveness (Krapfl 2019). Belkin suggests that, similar to the way "unit cohesion" was used as an excuse to exclude military service by gay and lesbian people (Frank 2009), Mattis added "lethality" as an attempt to reframe the discussion by putting the onus on proving inclusion of transgender troops would not decrease "lethality" rather than a fair comparison of the various costs and benefits of an inclusive policy and costs and benefits of a ban (Belkin 2020, see Arthur et al. 2018).

11 A report by a group of former chiefs of military medicine, responding to Mattis, was published with the title, DoD's Rationale for Reinstating the Transgender Ban is Contradicted by Evidence (see Arthur et al. 2018). 
$\because$ Taylor \& Francis

Taylor \& Francis Group

http://taylorandfrancis.com 


\section{Transgender voices}

"I have found it is nearly impossible to be both trans and an athlete. Being an athlete and being trans are both a part of my identity. I wish I didn't feel like I have to choose one or the other."

"To deny us the opportunity to participate and to compete and to potentially excel is to take away part of ourselves that we cherish."

—Donna Rose, Transgender Activist, Wrestler ${ }^{2}$

"I've been on the cross country and track teams since before I started to transition. At first, I had to be on the boys' team. I always felt terrible, out of place, and like I was living a lie. When I first started to transition, I was able to be on the girls' team. I was so excited to be with the girls, but I was not allowed to 'officially' compete and that was hard."

-Anonymous High School Student Athlete ${ }^{3}$

"Cis, trans, and intersex women are women and must be included in women's sport without restriction. This is my life's goal."

Dr. Veronica Ivy ${ }^{4}$

When you think about the impact that sport has on a society, you think about the support structure that's afforded through coaches, teachers, discipline, role models, belonging, and community. To deny someone the opportunity to benefit from those things, it goes beyond just policy and rules. It's a complete violation of a person's human rights. What scrutiny and inhumane hoops are you going to put the trans community through to access something that is rightfully everyone's? Trans people belong in sport, and anything less than full access is unjust and degrading."

JayCee $^{5}$

"I would never would have competed against girls or women without suppressing my testosterone. There's no way it would have been fair. My testosterone levels were so much higher than any of the girls I would've been running against."

Juniper Eastwood ${ }^{6}$

"I believe that you need to look at the issue of transgender women in sport on a case-bycase basis with attention to the sporting context (level of competition, the particular sport) and the transgender individual's situation (medical factors and past sporting history). At the end of the day, I don't want to see transgender women discriminated against but I also don't want to see sporting opportunities unfairly taken from other women. Should the rules be more restrictive for some high contact high risk sports like boxing? Probably. Should Olympic competition have more scrutiny than Sunday morning soccer league? Sure. That does not mean that you deny all transgender women the ability to play but it also means that maybe some cannot. We also need to be open to reviewing the evidence as it develops."

Jami K. Taylor 


\section{7}

\section{SPORTS}

Organized sports have been segregated by sex throughout most of its history in the United States, with much more limited opportunities for women than for men. If one takes a longer historical view, there certainly have been cultures that encouraged women's sports, dating back to the ancient Greeks. As Mary Ann Case notes, "In ancient Greece and Africa as well as in medieval and early modern Europe, women's sports often formed part of mating rituals, and a successful female competitor was seen as a desirable mate" $(2017,26)$. In some of those cultures, men and women competed directly (Guttman 1991). In the United States by the late 19th century, however, not only was competition segregated, girls' and women's athletics were typically discouraged:

In the nineteenth century, however, athletic and other sporting competition often was seen as doubly debilitating to a woman's chances for heterosexual success: not only would sweating and the development of muscles make her unattractive, but strenuous physical exercise was thought to risk physiologically compromising her reproductive capacity.

(Case 2017, 26-27)

Sandra Bem, discussed in Chapter 2, describes the three core beliefs that perpetuate gender discrimination as biological essentialism, androcentrism, and gender polarization (1993). All three are evident in last 150 years of sports history. ${ }^{8}$ It required over a century and a federal law to dismantle the beliefs and practices that prevented women from having the opportunities to compete in organized sports that are available today.

I begin with biological essentialism: For much of human history, women often-but not always - have been considered weaker and more fragile than men. Presumed to be prone to overexertion, strenuous physical activity during 
menstruation was considered particularly hazardous (Bell 2008). In the 19th century, some physicians were influenced by a theory that each person possesses a finite amount of vital energy, and energy spent in some parts of the brain or body was at the expense of others:

It is in the power of the individual to throw, as it were, the whole vigor of the constitution into any one part, and, by giving to this part exclusive or excessive attention, to develop it at the expense, and to the neglect, of the others.

(Clarke 1875, 43; see also Bem 1993, 9-11)

Athletic competition theoretically drained this energy from reproductive capabilities (Schultz 2014; McCrone 1988). As Dr. Edward Hammond Clarke opined in Sex in Education: A Fair Chance for Girls, nature requires a young woman's body to dedicate its energy to develop the reproductive system properly:

Both muscular and brain labor must be remitted enough to yield sufficient force for the work. If the reproductive machinery is not manufactured then, it will not be later. If it is imperfectly made then, it can only be patched up, not made perfect, afterwards. To be well made, it must be carefully managed. Force must be allowed to flow thither in an ample stream, and not diverted to the brain by the school, or to the arms by the factory, or to the feet by dancing.

Kathleen Hall Jamieson notes that 19th-century theorists "focused on the claim that intellectual activity damaged a woman's reproductive and sexual capacity," while 20th-century writers perpetuated the belief that "biology disqualified women for leadership" based on "raging hormones" $(1995,58)$. As Bem documents, biologybased arguments for limiting the roles for women have ancient roots yet continue to this day (1993, chapter 2). And, as will be shown in this chapter, biology-based arguments continue to play a central role in sex segregation in sports, albeit in a more sophisticated and scientific manner.

Androcentrism refers to defining the male as normal and the female as less than or different from the norm. Sociologist Eric Dunning described sports as a "male preserve," especially "combat sports" such as rugby, soccer, hockey, boxing, and football (1986). Until relatively recently, for many the word "athlete" conjures a male figure, while "cheerleader" conjures a female figure. Even in competitive sports, it is still common for sports competitions involving men to be called simply sports, while athletic teams featuring women are called "women's sports." Thus the National Basketball Association (NBA) is understood in the United States as men's basketball, and the WNBA refers to the Women's NBA. Similarly, at many high schools and universities, one will hear reference to the basketball team (denoting the men's team) and the women's team described in other terms, such as the University of Tennessee's phenomenally successful team called the Tennessee Lady 
Volunteers basketball team or simply the Lady Vols. One study estimates that more than half of U.S. colleges and universities "had some form of sexism in the symbolic representation of their women's athletic teams” (Eitzen \& Zinn 1993, 35).

Gender polarization refers to the mental habit of defining men and women in opposing terms. Here, the fact that the adjective "athletic" was coded as masculine in the Bem Sex Role Inventory and was not considered gender neutral is telling. In Mahalik et al.'s Conformity to Masculine Norms Inventory, a number of the norms are attributes associated with athletic competition, including Winning, Risk Taker, Dominance, and Pursues Status (2003), while such Feminine Norms as Values Thinness and Modest (2005) are not qualities we typically associate with athletic competitors. Gender polarization in sports has a long history. As sociologist of sport David Rowe observes, "Sport is historically a male-dominated sphere of popular culture, and during the late-19th century it came to define masculinity itself" (2016). Particularly since "the institutional establishment of sport as a regulated, professionalized form of physical activity in the nineteenth century, sport has been a major focus of sex/gender division and hierarchy" (Rowe 2014, 395). Baron Pierre de Coubertin, who revived the modern Olympics in 1894, opposed adding women's competition, claiming that doing so was "impractical, uninteresting, ungainly, and, I do not hesitate to add, improper." He declared the concept of the Olympic Games to be "the solemn and periodic exaltation of male athleticism, based on internationalism, by means of fairness, in an athletic setting, with the applause of women as the reward" $(1912,713)$.

The three concepts of biological essentialism, androcentrism, and gender polarization coalesced in the manner most sports took place. As Jennifer Hargreaves notes concerning late 19th-century sports,

Because organized sports for women were for the most part separated from men's sports, it was easy to define them as qualitatively different, in tune with conventional ideas about "femininity" and "masculinity". In order to survive, organized female sports tended to accommodate to traditional biological assumptions, rather than openly challenging them.

$(1994,30)$

Such social norms did not keep women from such activities as horseback riding, archery, golf, tennis, skiing, and skating. However, women must be dressed appropriately and compete in a lady-like manner. Assumptions about the biological and temperamental differences between the sexes "provided the historical basis for the idea that there should be 'feminine-appropriate' sports and 'masculineappropriate' sports, and a pattern of sex-role stereotyping was established" (Hargreaves 1994, 30).

In the final two decades of the 19th century, women competed in an increasing number of organized sports' competitions, including badminton, skating, tennis, lacrosse, and even hockey. We were still a long way from the status of women's sports in the 21 st century, however. Imagine hockey players wearing wool gloves 
and hats, high-necked blouses along with skirts and petticoats (Hargreaves 1994, 93). And men were banned from attending the first intercollegiate basketball game in 1896 between Stanford and the University of California (Stanford125 2016). Not long after, Stanford ended their women's basketball team along with all of its women's intercollegiate sports. According to Stanford's 125th anniversary history, "In December 1899, Stanford put an end to women's intercollegiate team sports, according to the faculty, 'for the good of the students' health' and, according to the Daily, for 'the unpleasant publicity accompanying the contests"' (Stanford125 2016).

The perceived incompatibility of being a woman and being an athlete continued for decades. A number of historical accounts document the struggle to advance women's sports in the United States (see, for example, Cain 2001; Cohen 2014; Gerber et al. 1974; Guttmann 1991; Hargreaves 1994; Lucas \& Smith 1982). Two brief quotations may help illumine the types of beliefs that needed to be overcome. A male doctor asserted in 1931 that "[Females in a] combative game like basketball develop ugly muscles and scowling faces and the competitive spirit." Eventually, he argued, women athletes would "find it more difficult to attract the most worthy father for their children" (quoted in Reft 2014). Four decades later, a Connecticut judge decided against a girl who was suing for the right to participate on an all-boy high school track team. The judge claimed "Athletic competition builds character in our boys. We do not need that kind of character in our girls, the women of tomorrow" (quoted by Dunkle 1975, 291).

One way the slow progress of women's sports can be quantified is by looking at the Olympics. In the first modern Olympics in 1896, there were no female competitors at all. By the 1972 Olympics, only $17.6 \%$ of the competitors were female (Hargreaves 1994, 219-220).

The imbalance is evident if one focuses only on U.S. interscholastic competition. In the 1971-1972 academic year, at the high school level, girls made up 7.5\% of all sport competitors-less than 300,000 out of 4 million total (National Federation 2011). That same year at the college level there were nearly 30,000 female athletes compared to over 170,000 males, or about 15\% (National Coalition for Women and Girls in Education 2012, 9).

The turning point in the United States, as is well known, was the passage of Public Law No. 92-318 in 1972. Formalized in 20 U.S. Code $\$ S$ 1681-1688, the most relevant part of this legislation is better known simply as Title IX. Section 1681 declared that, with certain exceptions, "No person in the United States shall, on the basis of sex, be excluded from participation in, be denied the benefits of, or be subjected to discrimination under any education program or activity receiving Federal financial assistance."

"Title IX" is typically used as shorthand to refer both to the statute (which consists of the above "sex-blind non-discrimination rule") and regulations subsequently enacted to permit "sex-affirmative exceptions" (Coleman, Joyner, \& Lopiano 2020,69). The exceptions permit schools to take sex into account "to address 
imbalances in admissions, academic programing, and sport" (Coleman, Joyner, \& Lopiano 2020, 69).

Such a regulatory approach "was designed to and has yielded extraordinary results for women and girls, and for society more generally" (Coleman, Joyner, \& Lopiano 2020, 70).

Indeed, the impact of Title IX was rapid and substantial. Participation of high school girls in competitive sports quadrupled from 7\% of all high school athletes in 1970-1971 to 28\% in 1976-1977. The National Federation of State High School Associations reports that in 2018-2019, they recorded 4,534,758 male athletes to 3,402,733 female athletes, thus female athletes made up $42.9 \%$ of high school athletes (NFSHSA 2019). The total number of high school girls competing in sports has increased ten-fold since before Title IX (NCWGE 2017).

At the collegiate level, schools offering athletic scholarships for women rose nine-fold from 60 in 1974 to 500 in 1978 (Holland \& Oglesby 1979, 81). According to the NCAA, in 2017-2018 there were 98,021 male athletes and 86,465 female athletes, thus female athletes made up $46.9 \%$ of all intercollegiate athletes (NCAA 2018). In 1972, the average number of teams offered for female athletes were 2.50 per university; by 2004, the number increased to 8.32 (Bell 2008). The total number of women competing in intercollegiate sports has increased sevenfold since the passage of Title IX (NCWGE 2017).

The numbers have improved at the Olympics as well. In 2018, 41\% of the winter games competitors were women. By 2016, 45\% of participants in the Olympics summer games were women and the Tokyo 2020 summer Olympics were described as the first ever gender-balanced games in history, with $49 \%$ of the athletes being women (Olympics.com 2021).

Competitive sports have proven to benefit high school girls in various ways. The National Coalition for Women and Girls in Education (NCWGE) summarizes the benefits as follows: "Female athletes are less likely to develop health problems, less likely to engage in risky behavior, and more likely to do well in school than their non-athlete peers. They also develop leadership skills that can help them succeed professionally" $(2017,38)$. Research suggests that athletic participation correlates with lower obesity (decreasing the risk of high blood pressure and diabetes), decreased unplanned pregnancy, and reduced odds of cigarette smoking (Kaestner \& Xu 2010; NCWGE 2017). Furthermore, "Regular physical activity also decreases a young woman's chance of developing a range of other diseases, including heart disease, osteoporosis, and breast cancer" (NCWGE 2017, 41).

Girls who compete in sports in high school are more likely to graduate, have higher standardized test scores, and higher grades in general (NCWGE 2017). As NCWGE notes, "A whopping 94\% of female business executives played sports, with the majority saying that lessons learned on the playing field contributed to their success" $(2017,42)$. A survey of high level female business executives showed that $86 \%$ credited sports for their self-discipline, $81 \%$ for their teamwork, $69 \%$ for their leadership skills, and 59\% for their competitiveness (Claussen 2007). 
Economist Betsey Stevenson noted that many studies in economics and sociology have documented "a positive relationship between participation in high school athletics and educational aspirations, educational attainment, and wages later in life" (2010, 284). Her study looked specifically at the time period after Title IX to examine the effects of increased female student participation and economic indicators over time. Consistent with previous research regarding male athletes, Stevenson found that a rise in state-level female sports participation generates an increase in college attendance and an increase of females in the labor force. She also found an impact on higher wages and that the "effect of athletics on women's wages is as large as that for men" (286). She concludes: "Athletic participation has important causal effects on women's educational and labor market outcomes" (2010, 300).

Title IX dramatically changed the lives of literally millions of U.S. girls and young women. ${ }^{9}$ The law was an important step toward redressing that historic inequality in education in general, and athletics in particular. Title IX has been described by law professor Deborah L. Brake as "pragmatic feminism" (2007). That is, though the goal of complete equality has not yet been achieved due to various compromises made in its implementation over its history, Title IX nonetheless has achieved "remarkable success in encouraging and facilitating creative opportunities for resisting traditional gender norms that constrain female athleticism" (2007, 513). Brake's conclusion may prove to be valuable advice concerning the definitional issues now facing sports: "Rather than picking a theoretical approach for its consistency and abstract purity, feminist scholars should treat legal theory as contingent and context-specific, while continually evaluating it for how it serves our feminist agendas" $(2007,545) .{ }^{10}$

\section{Why sex segregation in sports continues}

Competitive sports remain, for the most part, segregated by sex. In the process of explaining why this is the case, I use the words male and female to refer to athletes by their biological sex as assigned at birth. For the moment, my focus is on cisgender athletes for reasons that will be apparent. Transgender athletes will be discussed later.

After the passage of Title IX, females' athletic performances steadily improved by all objective measures. Centuries of cultural norms and gender socialization that had discouraged women from competing in athletics meant that the availability of training and competition yielded rapid improvement (Sandbakk, Solli, \& Holmberg 2018). The sex differences between world record holders declined in the 1970s and 1980s. In 1992, a letter to Nature analyzed the rate of improvement in running events and (wrongly) predicted that the gap would continue to decline with women matching men in the marathon in 1998 and in all running events within the first half of the 21st century (Whipp \& Ward 1992). ${ }^{11}$

Since the 1990s, research has shown relatively stable sex differences in performances, and most experts agree that a portion of the difference is due to anatomical 
and physiological differences between adult females and males that give males an advantage in certain forms of athletic competition. These differences are evident both between average males and females as well as between elite athletes. On average, adult males have a larger body size with more muscle mass, more muscle strength (grip strength, e.g.), greater tendon force and stiffness, larger bone structure, a lower percentage of body fat, stronger cardiovascular function, higher blood hemoglobin, and a greater maximal delivery of anaerobic and aerobic energy (Sandbakk, Solli, \& Holmberg 2018, see also Green, Fraser, \& Ranney 1984; Lepley et al. 2018; Ransdell \& Wells 1999). I say “adults” because the most relevant sex differences in body size, composition, and testosterone level begin to develop at the onset of puberty (Handelsman 2017). Prior to puberty, the difference between males and females is less pronounced and may be due more to socialization than physical differences. For example, female swimmers under the age of 10 outperform males (Knechtle et al. 2020), and "top running speed is almost identical in ten-year-old boys and girls” (Epstein 2013, 67).

With the onset of puberty, stark differences emerge: "At fourteen, the throwing gap, already wide, becomes a chasm. Boys develop stronger arms and wider shoulders, and by eighteen the average boy can throw three times as far as the average girl" (Epstein 2013, 67). Testosterone increases muscle mass and strength, and stimulates the production of red blood cells, so those with higher testosterone levels can use more oxygen than those with less (Hirschberg 2020). "World agegroup records in sprinting are nearly identical for boys and girls at age nine, before puberty, when there is little biological reason for gender segregation in sports. By fourteen, however, the records are no longer in the same athletic universe" (Epstein 2013, 68). By that age, 15-year-old adolescent males already outperformed the contemporary female world records (Hilton \& Lundberg 2021, 204). The available evidence

makes it highly likely that the sex difference in circulating testosterone of adults explains most, if not all, the sex differences in sporting performance. This is based on the dose-response effects of circulating testosterone to increase muscle mass and strength, bone size and strength (density), and circulating hemoglobin, each of which alone increases athletic capacity, as well as other possible sex dichotomous, androgen-sensitive contributors such as mental effects (mood, motivation, aggression) and muscle myoglobin content.

(Handelsman, Hirschberg, \& Bermon 2018, 823)

Accordingly, most researchers conclude that the peak performance gap between females and males will persist in many forms of athletic competition. Samuel N. Cheuvront et al., note with respect to running events that,

Women's times have now reached a plateau similar to that observed for men at comparative performance milestones in the marathon. Sex differences at 
distances from 100 to $10,000 \mathrm{~m}$ show similar trends. The remaining sex gaps in performance appear biological in origin.

Specifically, Cheuvront and his colleagues conclude that, "Men possess greater muscular strength and a larger aerobic capacity. As a result, the gap in running performances between men and women is unlikely to narrow naturally" $(2005,1022)$.

A team of researchers, led by Valérie Thibault, conducted an analysis of best performances and world records in 82 events since the beginning of the modern Olympic era: "each event in swimming, athletics, track cycling, weightlifting and speed skating" to compare male and female records. Their study concluded that the gender gap ranges from $5.5 \%$ (800m freestyle, swimming) to $36.8 \%$ (weightlifting). "The mean gap is $10.7 \%$ for running performances, $17.5 \%$ for jumps, $8.9 \%$ for swimming races, $7.0 \%$ for speed skating and $8.7 \%$ in cycling" (Thibault et al. 2010, 214).

Similarly, a review by Øyvind Sandbakk, Guro Strøm Solli, and Hans-Christer Holmberg documents, after rapid improvement in the 1970s and 1980s, sex differences between the world's elite athletes in most events "have remained relatively stable at approximately 8-12\%" $(2018,2)$. The gap between world record holders is apparent in all running events, speed skating, cycling events, and shorter swimming competitions. The difference becomes smaller in swimming competitions of longer distances, which has been attributed to females' superior hydrodynamic properties. In fact, females have outperformed males in open-water "ultra-distance" swimming competitions (Knechtle et al. 2020; Sandbakk, Solli, \& Holmberg 2018). On the other hand, in competitive events in which upper-body strength is particularly helpful, such as kayaking, canoeing, and throwing events, the difference between males and females is more than $12 \%$, sometimes considerably more. Hilton and Lundberg's (2021) review of the literature concerning elite athletes notes an 18\% gap in jumping events, 20\% between fastest recorded tennis serves, and "the gaps between fastest recorded baseball pitches and field hockey drag flicks exceed 50\%" (203).

Research is ongoing to identify the specific physiological factors that give one sex or another an advantage in any particular athletic competition, including metabolic differences. In swimming, other than ultra-distance events, Knechtle et al. argue that anatomical and physiological differences contribute to the performance gap, "longer limbs, larger muscle mass, greater aerobic capacity and lower fat mass" on race time. They conclude: "Current evidence indicates that women will not swim as fast as men in Olympic events, which justifies sex segregation in these individual sport disciplines" $(2020,3651) .{ }^{12}$

Though physical differences between males and females play a major role in many athletic competitions, social-cultural factors are still relevant to performance outcomes. Further research is needed to prove which differences in competitive achievement are due to gender socialization versus physical differences (Roth \& Basow 2004). Laura Capranica et al. argue that "The gender gap in sport, although 
closing, remains, due to biological differences affecting performance, but it is also influenced by reduced opportunity and sociopolitical factors that influence full female participation across a range of sports around the world" $(2013$, 99). Such factors include reduced opportunity, significantly less media coverage, and lower financial incentives (Claussen 2007). In rowing, for example, male rowers outperformed female rowers between 1997 and 2016; however, women consistently improved more than men every year, which was paralleled by "an increase in participation of the women relative to the men in collegiate rowing. Overall, our work suggests that decreased opportunities and participation are major contributors explaining at least part of the observed sex differences in elite athletic performance" (Keenan, Senefeld, \& Hunter 2018, 12). The key word here is "part." Though the gap may be decreased through an improvement in social-cultural factors, there is no doubt that anatomical and physiological differences will persist.

$$
* * *
$$

Before considering the definitional controversies evinced by the Transgender Exigency, four points about sex segregation in sports are worth emphasizing: First, competitive athletics is a context in which females have been discriminated against for most of its history. Second, in the United States, Title IX improved the situation markedly, resulting in a dramatic increase in the quantity and quality of athletic participation by females. Third, since 1972, young females in particular have benefitted directly and significantly by the increased opportunity to compete in sports. And fourth, while the sheer variety of athletic events complicates effort to generalize about differences between female and male athletic performances, there are certain anatomical and physiological differences between the sexes that advantage males and have justified dividing competition by sex in many athletic events.

\section{Enter Renée Richards}

Most narratives about transgender athletics begin with the story of Renée Richards, and this one is no exception. As told by Lindsay Parks Pieper, the tale begins with Richards' outing as a "transsexual" (the term used at the time):

In 1976, an inquisitive reporter covering a California tennis tournament watched with awe as the impressive six-foot-two-inch rookie Renée Clarke effortlessly defeated her opponents. Dick Carlson, a journalist from San Diego, was amazed by the ease of her volleys and the precision of her baseline shots. Intrigued by the sudden emergence of this unknown star, he searched for background information. At first Carlson had simply wanted to create a light-hearted piece about a local standout. Instead, he produced a revealing expose that forced the national spotlight onto the California tennis tournament and its new star. Carlson identified Renée Clarke as Renée Richards, the former male professional tennis player Richard Raskind. 
Long before transitioning, Richards competed in high school on the football, baseball, and swimming team (Abrams 2010, 54). Later, Richards was a solid collegiate tennis player, was named captain of the Yale University men's team in 1955, and had modest professional success between 1953 and 1960. Richards graduated from medical school in 1959 and practiced as an ophthalmologist in the Navy and in private practice, all the while continuing to play competitive tennis. In 1975, after a lifetime of dealing with what we now call gender dysphoria, Dr. Raskin transitioned and became Dr. Renée Richards.

Richards moved into the national spotlight when she announced her intention to compete in the 1976 U.S. Open Tennis tournament. Seeing Richards as a "menace" to the newly popular women's tennis tour, the U.S. Tennis Association and Women's Tennis Association barred her participation "by instituting a chromosomal check for all female participants" (Pieper 2017, 13). Richards sued for the right to compete and won a victory in the New York Supreme Court.

Justice Alfred M. Ascione wrote the court's opinion. He quoted Richards as stating, after her sex reassignment operation, "'for all intents and purposes, I became a female, psychologically, socially and physically, as has been attested to by my doctors." ${ }^{13}$ He further quotes Richards as noting, "I underwent this operation after many years of being a transsexual, a woman trapped inside the body of a man."

At stake in the case were two competing approaches to defining who "counts" as male or female in the context of USTA competition. The USTA defines male and female according to the results of the sex-chromatin test, which looks for the presence of a Y chromosome (also known as the Barr Body test). In fact, this was the sole regulatory definition set forth by the USTA, which they instituted specifically in response to Richards' efforts to compete at the U.S. Open. Richards' attorney offered a series of alternative definitional criteria: External genitalia, based on the reassignment surgery, was now female. Furthermore, "prior to and after the sex reassignment operation, Dr. Richards underwent endocrinological testing and administration of female hormones so as to change Dr. Richards' endocrinological hormonal balance to that of a woman." Richards also presented as female. One expert witness, Dr. Leo Wollman, was quoted by Ascione as arguing that "if she has the external genital appearance, the internal organ appearance, gonadal identity, endocrinological makeup and psychological and social development of a female, she would be considered a female by any reasonable test of sexuality." John Money, the psychologist quoted in Chapter 2 who introduced the notion of "gender role," also argued that aside from the Barr test,

Dr. Richards is a female, i.e., external genital appearance is that of a female; her internal sex is that of a female who has been hysterectomized and ovariectomized; Dr. Richards is psychologically a woman; endocrinologically female; somatically (muscular tone, height, weight, breasts, physique). Dr. Richards is female and her muscular and fat composition has been transformed to that of a female; socially Dr. Richards is female; Dr. Richards' gonadal status is that of an ovariectomized female. 
The court did not strike down the use of the Barr test, per se, but contended it should not be the sole defining criterion. Furthermore, Ascione noted that the purpose of the test is to prevent fraud, "i.e., men masquerading as women." The court "rejects any such suggestion as applied" to Richards:

When an individual such as plaintiff, a successful physician, a husband and father, finds it necessary for his own mental sanity to undergo a sex reassignment, the unfounded fears and misconceptions of defendants must give way to the overwhelming medical evidence that this person is now female.

The case was specific to the state of New York, which had on the books a Human Rights Law forbidding discrimination based on sex. The court "ruled her legally a woman" (Pieper 2017, 20). Richards competed for five years, never achieving success in singles but reaching the finals of women's doubles in 1977 and the semi-finals in mixed doubles with partner Ilie Nastase in 1979.

The rise of transgender visibility and rights that have taken place in the 21st century has brought renewed attention to Renée Richards, though not in the manner one might expect. Not surprisingly, Richards has embraced her femininity and applauds the traditional gender binary. Somewhat more surprising is that she came out opposed to the International Olympic Committee's (IOC) 2004 "Stockholm Consensus," which granted transgender athletes eligibility if they had undergone surgical reassignment and hormone therapy, despite the fact that such a policy would have allowed her to compete (Pieper 2017, 20). Furthermore, she has said she would not have competed had she transitioned in her 20s because it would have been unfair to female competitors (Eccleshare 2019). ${ }^{14}$ Nonetheless, her story illustrates how transgender athletes challenge definitional practices used to segregate athletic competitions by sex, and highlights the specific concern that male-to-female transgender athletes threaten the fairness of women's competitions.

\section{The Transgender Exigency in sports}

Sex verification in elite athletics appears to have historical roots not so much as a result of cheating by men dressed as women, but as a response to athletes we would now call "intersex" or people with a Difference in Sex Development (DSD). Such concerns can be traced back to the 1930s (Eger 2017; Heggie 2017; Skirstad 2000). ${ }^{15}$ In 1946 the International Amateur Athletics Federation (IAAF) implemented a rule requiring female athletes to have a medical document certifying their female sex; in 1948 the British Women's Amateur Athletic Association and the IOC followed suit (Eger 2017). Such a rule sometimes required female athletes to participate in a "nude parade" in front of female doctors. Beginning in 1966, the IAAF began requiring the Barr test - the one the USTA required of Renée Richards-which was in effect until 1992. The IAAF then briefly moved to an ad hoc approach "on the basis of suspicion" informed by athletes' phenotypic 
appearance as male, based on secondary sex characteristics such as deeper voice or facial hair (Harper 2020, 73). The IOC also required gender verification by genetic tests between 1968 and 1998. There was a period of time after 1999 when the IOC ended compulsory sex testing and verification, though it reserved the right to test selected individuals based on individualized suspicion (Harper 2020, 76; Vilain et al. 2017). ${ }^{16}$

By the dawn of the 21st century, sports' governing organizations moved away from using chromosomes as the sole definitional attribute for sex. Not all chromosomal "abnormalities" necessarily impact athletic performance, and some athletes with relevant DSD had a gonadectomy in childhood. The dichotomy of $X X$ or $X Y$ came to be seen as overly simplistic. Awareness of the biological-let alone the social-complexities of defining sex and gender compelled sports organizations to refine their thinking about the purpose behind the regulatory definitions used to determine who "counts" as female or male for the purposes of athletic competition.

Wrestling with defining "male" and "female" for the purposes of eligibility became more exigent with growing recognition of transgender rights. The Olympics, as mentioned previously, altered their policy regarding eligibility of transgender athletes in 2004. An ad hoc committee convened by the IOC Medical Commission met and approved a statement regarding sex reassignment in sports in October 2003. In light of the research on the importance of circulating testosterone, the IOC's approach moved away from chromosomes and genitalia and to the hormone most often credited for the male athlete's advantage. Thus: "Early crude genital checks or 'nude parades' were replaced first by chromosome checks, then by checks of external phenotype-i.e., secondary sex characteristics - and finally by a testosterone rule" (Coleman 2021). The statement was adopted by the IOC's Executive Board in May 2004. The requirements were not solely concerned with testosterone, as they included durational, legal, anatomical (surgical) and hormonal definitional criteria:

- Surgical anatomical changes have been completed, including external genitalia changes and gonadectomy

- Legal recognition of their assigned sex has been conferred by the appropriate official authorities

- Hormonal therapy appropriate for the assigned sex has been administered in a verifiable manner and for a sufficient length of time to minimise genderrelated advantages in sport competitions.

(Statement 2003)

The group recommended that eligibility should begin no sooner than two years after gonadectomy, presumably to minimize the advantage of male-to-female transitioning athletes from benefiting from higher testosterone levels. Such strict definitional criteria represented IOC's effort to maintain fairness in competition while also providing transgender athletes the possibility to compete. The IOC's eligibility 
policies subsequently were adopted by a number of athletic regulatory organizations throughout the world (Jones et al. 2017).

Balancing the competing values of fairness and inclusion continued to be a challenge for the IOC, and in 2015 the organization revised their requirements. The November 2015 IOC Consensus Meeting on Sex Reassignment and Hyperandrogenism was an effort to address issues raised by emerging knowledge of transgender and DSD athletes. The statement produced by the group is noteworthy in several respects. First, it acknowledged the changing social and legal status of transgender athletes, and the "growing recognition of the importance of autonomy of gender identity in society." The IOC reiterated that that the two values it was trying to advance were first, the "overriding" objective of fair competition, and second, to ensure "insofar as possible" that transgender athletes "are not excluded from the opportunity to participate in sporting competition" (IOC 2015, 2).

To advance the twin goals of fairness and inclusion, the new policy focused on two definitional criteria: duration and testosterone levels. Those transitioning from female to male are eligible to compete as males "without restriction," the presumption being that such athletes do not have an anatomical or physiological advantage over other male competitors. ${ }^{17}$ Those who transition from male to female were deemed eligible only if they have declared her gender identity is female and that the declaration "cannot be changed, for sporting purposes, for a minimum of four years." Furthermore, transgender female athletes must demonstrate "that her total testosterone level in serum has been below $10 \mathrm{nmol} / \mathrm{L}$ [nanomoles per liter] for at least 12 months prior to her first competition." Such a number reflects the fact that $95 \%$ of males have between 7.7 to $29.4 \mathrm{nmol} / \mathrm{L}$, and $95 \%$ of females having much lower levels, normally between 0 and $1.7 \mathrm{nmol} / \mathrm{L}$ (Handelsman, Hirschberg, \& Bermon 2018, 807; see also Travison et al. 2017; Mayo Clinic 2020). ${ }^{18}$ The $10 \mathrm{nmol} / \mathrm{L}$ limit was seen as progressive and inclusive: "While 99 percent of cisgender women fall between the $1-3 \mathrm{nmol} / \mathrm{L}$ figure, a limit of $10 \mathrm{nmol} / \mathrm{L}$ became known as the hyperandrogenism rule, and provided a buffer for women born with unnaturally high testosterone" (Connell 2018). These new guidelines were in effect for the 2016 Rio Olympics and 2018 Pyeongchang Olympics, though no openly transgender athletes competed in either.

The new policy recommendations, despite eliminating the requirement of surgical reassignment, were not without critics from all sides, with some arguing that the science behind the policy was weak (Lee 2019), some arguing that "the advantage to transwomen afforded by the IOC guidelines is an intolerable unfairness" (Knox, Anderson, \& Heather 2019), and others arguing that anything short of gender self-identification is unacceptable (Connell 2018). A year later, in a paper that counted among its authors three members of the IOC group, an ad hoc group noted the need for additional research:

Given the paucity of relevant research and the likely impact of decisions relating to transgender and intersex athletes, there is now an urgent need to determine not only what physical advantages transgender women carry after 
HRT [Hormone Replacement Therapy] but also what effect these advantages may have on transgender women competing against cisgender women in a variety of different sports. Properly designed intervention studies are required to investigate the effect of the transition (both MTF and FTM transitions) on trainability and performance as well as the effects of HRT on performance in intersex individuals.

(Pitsiladis et al. 2016, 387)

Acknowledging the need for additional research and consultation, the IOC has delayed issuing new transgender guidelines until after the 2020 [2021] Tokyo Olympics (Pavitt 2020). Some scientists felt that the $10 \mathrm{nmol} / \mathrm{L}$ testosterone limit was too high and should be cut in half. For example, Handelsman, Hirschberg, and Bermon (2018) recommend an eligibility requirement for female athletic events be set at $<5.0 \mathrm{nmol} / \mathrm{L}$ based on mass spectrometry measurements like all anti-doping tests. Others have argued that testosterone suppression for transgender women "has little effect on reducing muscle strength even after a year of treatment. That indicates that at least some of the physical advantages of those who have gone through male puberty are maintained even after transitioning" (Ingle 2019). An important paper by scientists Emma N. Hilton and Tommy R. Lundberg reports that longitudinal studies of transgender athletes suggests that "the biological advantage enjoyed by transgender women is only minimally reduced when testosterone is suppressed" (2021). Similarly, Roberts et al. studied 49 trans women who started gender affirming hormones while in the U.S. Air Force. They concluded:

The 15-31\% athletic advantage that transwomen displayed over their female counterparts prior to starting gender affirming hormones declined with feminising therapy. However, transwomen still had a 9\% faster mean run speed after the 1 year period of testosterone suppression that is recommended by World Athletics for inclusion in women's events.

(2021, 577)

A recent systematic review of the literature by Joanna Harper et al. concluded that hormone therapy rapidly reduces hemoglobin to levels comparable to cisgender women, and reduces muscle strength significantly but not to the same degree: "These findings suggest that strength may be well preserved in transwomen during the first 3 years of hormone therapy" (2021).

Harper, a Canadian transgender marathon who also published a study comparing race times for transgender and cisgender runners (2015), noted the need for additional research on how transitioning impacts athletic competition. Interviewed in 2021, she said that while trans women maintain some strength advantage over cis women, it's unclear by how much, especially for elite athletes (Hollingsworth 2021). Harper, Martinez-Patino et al. nonetheless contend that at elite levels, such as the Olympics, "it is necessary to use an evolving evidence-based scientific method to separate athletes into male and female categories. Although imperfect, 
the best currently available scientific approach is the use of serum testosterone levels" (2018, 43-44). Harper, Lima et al. (2018) propose therefore that segregation, where necessary, be based on what they describe as "athlete/athletic gender" based on serum testosterone levels as opposed to legal categories of female/male-an idea that was strongly supported in a survey the authors conducted. Harper's current position is that

at recreational levels of sport, we should just let people play in the male or female or some other category as they see fit. However, in high level sport, it is perfectly reasonable to require trans women to reduce their testosterone to female-typical levels before competing in the women's category.

Controversy over who is eligible to compete as a woman at the Olympics will surely continue. In July 2021, weightlifter Laurel Hubbard qualified as the "first openly transgender athlete ever to compete at the Olympics," and her entry "generated a fierce debate on gender, sexism and sport"-celebrated by some, condemned by others (Hollingsworth 2021; see also Jones 2021). Hubbard's case brings into sharp relief the question of what are the appropriate definitional requirements, given that weightlifting is a sport where males have an especially large performance advantage over females-36.8\%, according to Thibault and her colleagues (2010; see also Hilton \& Lundberg 2021, 203). In any case, the Tokyo Olympics featured more "out" transgender women athletes than any previous Olympics, and their visibility elicited, predictably, both cheers and jeers (Ingle 2021; Ivy 2021; Mitchell 2021). A survey taken shortly before the Olympics in Tokyo found a majority of respondents opposed to or undecided about allowing transgender athletes to compete (Gonzales 2021).

Though Caster Semenya is not transgender as defined in this project, her challenges with elite athletic competition illustrate the complexity of balancing fairness and inclusivity. Semenya is a highly successful South African middle-distance runner who has twice won an Olympic gold medal in the women's 800m. She was assigned female at birth. Though she has XY chromosomes and testes, she also has 5-alpha reductase deficiency, which leads to "intersex" or Difference in Sex Development (DSD) status (Johnson 2019). ${ }^{19}$ As a result, her circulating testosterone level is in a range more characteristic of males than females. The International Association of Athletics Federations (IAAF) ruled in 2018 that Semenya and other women with similar DSD cannot compete in middle-distance races $4400 \mathrm{~m}, 800 \mathrm{~m}$, and $1500 \mathrm{~m}$ ) unless they take medication to reduce their testosterone level (Court of Arbitration for Sport 2019). Semenya has decried the ruling and accused the IAAF as using her body "as a human guinea pig experiment": "Even though the hormonal drugs made me feel constantly sick, the IAAF now wants to enforce even stricter thresholds with unknown health consequences" (in Ingle 2019). Semenya has challenged the Court's rulings, but so far her appeals have been unsuccessful (Longman 2020; Ramsay \& Martin 2020). 
Semenya's situation underscores the fact that some athletes with a DSD face a definitional rupture when it comes to competing regulatory definitions; that is, Semenya is both female and not-female, male and not-male, depending on the definitional criteria and context. Semenya "counts" as female based on her birth certificate (a standard legal context) and the fact that she has lived as a woman (the durational criterion). Semenya "counts" as male chromosomally (XY), gonads (testes), and based on testosterone level (hormonal criteria). As I have argued throughout this project, which attribute is definitive depends on the purpose of the defining authority and context. The IAAF "Eligibility Requirements for the Female Classification" emphasizes the testosterone level criterion in light of the research suggesting the importance of testosterone in athletic performance. ${ }^{20}$ Accordingly, to "count" as female for the purposes of IAAF competitions, athletes with DSDs that result in circulating testosterone levels above $5 \mathrm{nmol} / \mathrm{L}$ must be recognized at law either as female or having a DSD, reduce her blood testosterone level to below $5 \mathrm{nmol} / \mathrm{L}$ for at least six months prior to competition, and maintain such a level to maintain eligibility to compete. The IAAF describes their eligibility requirement as an effort to balance inclusivity and fairness:

The IAAF respects the dignity of all individuals, including individuals with DSDs. It also wishes the sport of athletics to be as inclusive as possible, and to encourage and provide a clear path to participation in the sport for all. The IAAF therefore seeks to place conditions on such participation only to the extent necessary to ensure fair and meaningful competition.

On the collegiate level in the United States, the largest ruling athletic organization is the NCAA (National Collegiate Athletic Association), with over 1,200 member institutions and conferences. In 2011, the NCAA's Office of Inclusion published a handbook titled NCAA Inclusion of Transgender Student-Athletes that included guidelines for eligibility policies for sex-segregated sports. Again, the twin values of inclusivity and fairness emerge as key factors in the document. And again, the key definitional attribute involves testosterone. The NCAA policy is as follows:

1 A trans male (FTM) student-athlete who has received a medical exception for treatment with testosterone for diagnosed Gender Identity Disorder or gender dysphoria and/or Transsexualism, for purposes of NCAA competition may compete on a men's team, but is no longer eligible to compete on a women's team without changing that team status to a mixed team.

2 A trans female (MTF) student-athlete being treated with testosterone suppression medication for Gender Identity Disorder or gender dysphoria and/ or Transsexualism, for the purposes of NCAA competition may continue to compete on a men's team but may not compete on a women's team without changing it to a mixed team status until completing one calendar year of testosterone suppression treatment. 
A second edition of the handbook is in the works, according to a recent "Inclusion Forum" (Carroll, Griffin, \& Mosier 2018). The NCAA has clarified the policy to state that female-to-male transgender athletes not undergoing hormone treatment may participate either on a men's or women's team, while male-to-female transgender athletes may not compete on a woman's team. Furthermore, students who identify as gender fluid, genderqueer, nonbinary, or "another gender outside the gender binary not taking hormones may participate in sex-separated sports activities in accordance with the individual's assigned birth sex" (Carroll, Griffin, \& Mosier 2018).

Policies at the high school level vary widely, ${ }^{21}$ but can be grouped into five categories. First, there are states such as Alabama, Arkansas, Georgia, Idaho, Kentucky, Louisiana, Mississippi, New Mexico, South Dakota, Tennessee, and Texas that can be described as having biological essentialist regulations, meaning that one can only compete on sex-segregated teams that match one's assigned gender at birth as recorded on one's birth certificate. Second, there are states, such as Delaware, Indiana, Maryland, Missouri, Nebraska, North Dakota, Ohio, Oklahoma, with policies similar to the NCAA's or the 2004 IOC's, that is, that require either surgery or hormone therapy for at least a year. Third, there are states, such as Arizona, Florida, Illinois, and Iowa, that require some level of documentation that a student's gender identity is and will continue to be different than their assigned sex at birth (similar to the durational requirement of some single-sex schools discussed in Chapter 4), but otherwise permits transgender athletes to participate in the team consistent with their gender identity. Fourth, there are states that simply state that students are allowed to participate on teams consistent with their gender identity. This can be described as self-identification, pure and simple. Such states include California, Connecticut, Massachusetts, Minnesota, New Jersey, Rhode Island, Vermont, and Washington. Fifth and finally, some states have no explicit policy at all, such as South Carolina and West Virginia. It should be noted that this summary describes a quickly evolving situation. As of May 2021, legislators in more than 30 states have introduced over 100 bills to limit transgender rights, and more than half are about limiting sports participation (Loffman 2021). It is clear the issue has become highly politicized.

At the high school level in particular we have the classic sign of a definitional rupture: A given individual would "count" as female in some states for the purposes of sports eligibility but not others. The tension between the values of fairness and inclusion is especially acute at this age. On one hand, transgender youth are especially vulnerable to discrimination and stress when they come out as trans; as a result, some advocates argue that there should be no requirement for hormone therapy or surgery at the high school level (Carroll 2017), and that denying transgender athletes the chance to compete deprives them of the valuable benefits of athletic competition (Goldberg 2021). On the other hand, the physical advantages of male puberty create a challenge to fair competition at precisely the age when females (as assigned at birth) are most benefitted by competing in sports. 
The Women's Sports Policy Working Group is a bipartisan group of former elite athletes including Donna De Varona, Martina Navratilova, Donna Lopiano, and Nancy Hogshead-Makar. Supporters include such noteworthy athletes as Chris Evert, Wendy Hilliard, Edwin Moses, Benita Fitzgerald Mosley, Renée Richards, Sanya Richards-Ross, and Pam Shriver. Their stated mission is to try to balance the competing values:

Our mission is to affirm the legal permissibility of separate girls' and women's competitive sport teams while including all trans girls and trans women under the girls' and women's sports umbrella. We reject both the effort to exclude trans girls and trans women from girls' and women's sport and the effort to disadvantage females by forcing them to compete against some trans athletes with male sex-linked physical advantages. There is a middle way.

(Women's Sports Policy Working Group 2021a)

The Working Group advocates eligibility restrictions similar to the NCAA and IAAF regulations described previously. Transgender athletes assigned male at birth who have not experienced puberty should be included on girls'/women's teams without condition. Those who have experienced puberty should be allowed to be on teams to "to participate fully in the camaraderie and socialization associated with team membership," but not compete head-to-head against females (as assigned at birth) in competitive (as opposed to recreational) events, unless they have "mitigated their male sex-linked advantages through surgery and/or gender affirming hormones" (Women's Sports Policy Working Group 2021b). The Group's goal is to foster opportunities for all students to gain the benefits of athletic participation, while balancing the issue of fairness in contexts where male anatomy and physiology provides a distinct advantage. Not surprisingly, the Group's efforts to forge a "middle way" means there are critics on both sides (Schultz 2021).

No doubt, the eligibility rules concerning transgender athletes will continue to be controversial and highly politicized. Predictably, the matter is now in the courts. On February 7, 2019, two transgender girls won first and second in the final of the 55-meter dash in the Connecticut girls Class S indoor track meet at Hillhouse High School in New Haven, Connecticut (AP 2019). Their success at this and other meets led to a lawsuit brought by the parents of three female (assigned at birth) Connecticut high school students in February, 2020, known as Soule $v$. Connecticut Association of Schools, Inc. According to the complaint, two transgender athletes

have taken 15 girls' state championship titles formerly held by nine different Connecticut female athletes - often setting records far faster than the best times ever achieved in Connecticut by a girl. They have displaced girls from at least 40 separate opportunities to advance to participate in higher level competitions in the 2017, 2018, and 2019 seasons. 
The petitioner argued that the Connecticut Interscholastic Athletic Conference policy of permitting eligibility based on self-identification violates Title IX and thus discriminates on the basis of sex. In addition to being denied the opportunity to compete fairly, the complaint alleges that the plaintiffs incur psychological harms as well: "Plaintiffs suffer emotional distress, anxiety, and even depression and nausea on an ongoing basis, race after race" (Memorandum 2020, 28). The complaint refers to the transgender athletes simply as males, explaining in a footnote that they are referring to competitors who are "biologically male" (Memorandum 2020, 1, note 1). This particular example is often cited by legislators in other states proposing a ban on transgender athlete competition, and sometimes is the sole evidence offered for the need for such legislation (Crary \& Whitehurst 2021).

In April 2021, the Connecticut suit was dismissed on procedural grounds by U.S. District Judge Robert Chatigny since the two transgender athletes had graduated and the plaintiffs could not identify other transgender athletes (AP 2021a). The ruling did not address the constitutional aspects of the complaint, so it is likely that the matter will return to the court system in the future.

Not long after the Connecticut suit was filed, the Trump administration's Office for Civil Rights in the Department of Education issued a Letter of Impending Enforcement Action indicating their support for the claim that Connecticut's policy violates Title IX (Blanchard 2020). As discussed in previous chapters, the Trump administration consistently advocated a biological essentialist approach to defining sex, meaning that one's assigned sex at birth is the sole criterion used to define sex/gender for the purposes of Title IX. With the election of Joe Biden as president, the direction of the policies of the Departments of Education and Justice have been reversed with an executive order issued on literally the first day of the Biden administration. That executive order directs the head of each relevant Federal agency to review policies and action and to consider whether to "revise, suspend, or rescind" actions that discriminate on the basis of gender identity or sexual orientation (Biden 2021b). On June 16, 2021, the U.S. Department of Education announced that Title IX protects students from discrimination based on gender identity (2021). It remains to be seen whether self-identification will be treated as legally presumptive. While we can be certain that the subsequent Federal policy toward transgender athletes will not be based on biological determinism, it will take time for details to be formulated.

The question of K-12 student athletes competing in sex-segregated sports has become a contentious issue in multiple states. As just mentioned, some 30 states are considering legislation to require student-athletes to compete only as indicated by the sex assigned at birth (McCarthy 2020; Sharrow 2020). Such a law passed in Idaho in March 2020 and is being challenged in federal District Court in the case of Hecox et al. $v$. Little et al. for excluding transgender and DSD students from competition, thereby violating the 14th Amendment's Equal Protection Clause. The issue promises to be contentious, as some conservatives are doing their best to ridicule the new administration's policies. Fox News commentator Tucker Carlson, for example, proclaimed "Now, for the first time in history, men will be allowed 
to compete in, for example, girls' field hockey, and then change in the girls' locker room afterward. Joe Biden has signed an executive order requiring it" (2021).

Meanwhile a study reports that nationally, and specifically in self-identification states such as Connecticut and California, participation by girls in sports has not declined, and a recent report suggests that "Evidence from states that already have transgender-inclusive policies suggests that girls' sports participation may even increase alongside inclusive policies" (Goldberg 2021, 15). Of course, participation is not the only measure of impact, and only time will tell what sort of regulatory definitions strike the optimal balance between inclusiveness and fairness.

It is possible that the question of how transgender individuals' sex/gender should be defined for the purposes of Title IX, and in particular for the purposes of determining sports team eligibility, will end up in the U.S. Supreme Court. The sole Supreme Court case concerning transgender rights is Bostock v. Clayton County (2020), which the U.S. Department of Education cited when they announced gender identity would be protected under Title IX. The Court was able to reach a 6-3 decision favorable to transgender employees because the liberal and some conservative justices agreed that the case violated the "plain meaning" of the word "sex" in Title VII of the 1964 Civil Rights Act in the context of employment. It is, of course, the meaning of "sex" in Title IX that is complicated by the Transgender Exigency, especially with respect to the context and "institutional mission" of competitive sports (Coleman 2017). One can hope that by the time such a case is considered by the Supreme Court that there will be a stronger consensus among scientists and sports organizations about how to strike the difficult balance between fairness and inclusion. ${ }^{22}$

\section{Whither sex segregation in sports?}

Some have argued that traditional sex segregation in sports should be eliminated. Transgender scholar-activist Heath Fogg Davis, for example, argues that such segregation perpetuates binary norms concerning masculinity and femininity, problematically policing female masculinity, and unintentionally perpetuates androcentrism (2017, Chapter 4). For Davis, sex segregation is sexist, plain and simple. Similarly, Lindsay Parks Pieper, an expert on the history of gender verification in the Olympics, worries that "the various iterations of sex/gender testing all suggested that athleticism and femaleness were antithetical." Quoting Canadian sports policy advisor Bruce Kidd, "It's still the old patriarchal fear, or doubt, that women can do outstanding athletic performances. If they do, they can't be real women" (Pieper 2016, 187).

Are there alternatives to segregating sports strictly by sex? There are a number of interesting ideas now being discussed. If the IOC maintains a policy based on testosterone levels, then Davis suggests low testosterone men should be able to compete in women's events $(2017,138)$. Davis and others suggest creating new and different competition categories: "policy makers should consider using physiological features such as height, weight, and, in the case of elite athletes over the age of 
eighteen, androgen levels as sorting measures" $(2017,138)$. For example, interscholastic wrestling is already divided by weight, and in some states high school girls already compete with boys and have, in fact, won state championships. ${ }^{23}$

Michelle Sutherland, Wassersug, and Rosenberg (2017), draw attention to the advantages the male bone structure provides and note that this advantage cannot be negated by sex reassignment surgery or hormone therapy. They suggest one parsimonious solution would be to offer a separate category of competition for trans women athletes, though they recognize there are too few athletes at this point to fill such a category. They also suggest that an Osteological Index could be created that would quantify specific osteological parameters (such as height and relative hip width to height ratio) by their influence on one's "ability to succeed in a specific sport" $(2017,186)$.

Eric Vilain et al. suggest the possibility of different competition categories that select criteria and impose handicaps "that would place athletes in categories other than sex and compensate for a range of natural performance advantages relating to weight and height" $(2017,157)$. The authors admit it might be difficult to design a fair system with such characteristics, though a number of individual sports do so successfully. For example, both boys and girls gymnastics feature competition at specified skill levels and it is normally the coach who determines eligibility at each level. Similarly, almost all team sports have junior varsity and varsity levels. In other words, at the amateur level-which would include K-12 competition-athletic events have long "sorted" competitors. Vilain argues that "higher levels of the male hormone testosterone are associated with better performance only in a very small number of athletic disciplines," and suggests that any regulation of transgender athletes at the non-elite levels (interscholastic) of competition should favor the goal of inclusivity (Ermyas \& Wakeam 2021).

Bioethicists Taryn Knox and Lynley Anderson, along with Physiologist Alison Heather (2019), have set forth alternatives to current methods of sex segregation, including the creation of multiple divisions that could be guided by "An algorithm that accounts for (a) Social parameters including gender identity and socioeconomic status. (b) Physiological parameters" (401). Physiological parameters could include:

- $\quad$ Size, for example, height and weight.

- Haemoglobin levels.

- Maximal oxygen uptake $\left(\mathrm{VO}_{2} \max \right)$.

- Whether the athlete transitioned before, during or well after puberty.

- Past and present testosterone levels, and the presence of testes.

- Previous characteristics of physiology that are not changed via hormone therapy, that is, bone strength or structure, lung capacity and heart size. (401)

At the current time, such a radical overhaul of organized sports to replace women's and men's competitions completely is implausible and most likely a practical impossibility. As noted earlier, the history of Title IX is a feminist success story; 
young cisgender females have benefitted directly and significantly by the increased opportunity to compete in sports after centuries of discrimination. The importance of maintaining the value of equitable and fair opportunity should not be minimized. Even Davis does not contend that there is never a need for sex segregation in sports: "It depends on factors such as age, level of play, and specific policy goals" $(2017,135)$. The key is that sex classification must relate to legitimate organizational goals.

At the same time, the value of inclusion and nondiscrimination for transgender athletes is also worthy of pursuit, and it is important not to limit transgender athletes for the wrong reasons. One such wrong reason is simple anti-transgender animus. Flores and O'Neill (2020) found in a survey of over 1,000 people that self-identified sports fans are generally opposed to transgender athletes competing, especially if such sports fans believe in traditional gender roles.

Finding the right balance between these competing histories and sets of values promises to be one of the most difficult challenges of the Transgender Exigency.

\section{Notes}

1 Quoted in Griffin and Carroll $(2010,18)$.

2 Quoted in Griffin and Carroll $(2010,17)$.

3 Quoted in Griffin and Carroll $(2010,23)$.

4 Ivy (2019).

5 Quoted in Goldberg $(2021,31)$.

6 In Hobson (2021). The quotation is drawn from this passage: "In an interview, Eastwood said she never would have competed against girls or women without suppressing her testosterone. In high school, she set a Montana state record in the 800 meters that, had she been running on the girls' team, would have broken the women's world record.

'There's no way it would have been fair,' she said. 'My testosterone levels were so much higher than any of the girls I would've been running against.'”

7 Taylor (2021).

8 Athletic "sport" is understood here simply as "the organized playing of competitive games according to rules" (Handelsman 2020).

9 Implementation of Title IX is still controversial to some and there remain barriers to full equality. See, for example, Brake 2010, Claussen 2007, NCWGE 2017, 43-45, Osborne 2017.

10 For a somewhat different view, see Koller (2010).

11 Fausto-Sterling discusses the rate of improvement in women's performance around this time, noting the narrowing of the performance gap in some sports but acknowledging that in others "men and women will probably always perform differently" $(1985,220)$.

12 A notable exception to sex segregation in sports is in equestrian events, where males and females compete in the same events (Skirstad 2000, 116).

13 All quotations from Ascione's opinion can be found in Richards v. United States Tennis Association, 93 Misc. 2d 713; 400 N.Y.S.2d 267 (8/16/1977).

14 Richards' position continues to evolve, as indicated by her involvement with the Women's Sports Policy Working Group, discussed later in this chapter (see: Schultz 2021).

15 See, for example, the interesting case of Dora Ratjen as recounted by Berg (2009). My thanks to Joanna Harper for drawing my attention to this case.

16 For a history of sex testing in sports, see especially Pieper (2016) and the relevant chapters of Harper (2020). 
17 Trans men athletes must submit TUE (Therapeutic Use Exemption) documentation to demonstrate that their testosterone is in the normal range for non-trans males. Otherwise, an artificially high testosterone level is considered a form of doping.

18 According to Handelsman, Hirschberg, and Bermon, it is important to conduct measurements using the more accurate method of liquid chromatography-mass spectrometry (LC-MS) rather than conventional testosterone immunoassays, which are particularly unreliable with respect to measuring low levels of testosterone $(2018,806)$.

19 Most news outlets do not mention Semenya's XY status, but as Johnson (2019) points out, the ruling by the Court of Arbitration for Sport (CAS) specifies that individuals with XX chromosomes are "not subject to any restrictions or eligibility conditions under the DSD Regulations" and are limited to those with "46 XY DSD" (2019). The lengthy document in which the CAS made their ruling suggests that Semenya is 46XY with 5-ARD or 5-alpha reductase deficiency (Court of Arbitration for Sport 2018).

20 The IAAF requirement is not without its critics. See, for example, Vilain and MartinezPatiño (2019).

21 The website transathlete.com includes information on each state's regulations concerning high school students. My approach to categorizing these regulations differs from theirs.

22 For an introductory discussion of the constitutionality of different state policies toward transgender athletes, see Lenzi (2018).

23 In 2006, Michaela Hutchinson became the nation's first female state wrestling champion (Abbott 2016). Others have followed, including Heaven Fitch in 2020 (McCarriston 2020). 


\section{Transgender voices}

"They don't care if you got a beautiful face.

Beautiful breasts, beautiful hips, beautiful legs, beautiful voice, feminine personality.

If you got [a penis]. . . . You're going to a men's prison."

Taylor $^{1}$

"The guards were just cruel. As soon as our hair would grow out they would take us down and strap us in a chair and put crazy haircuts on our heads or shave one side off and leave the other side. It was cruel."

Cora $^{2}$

"They really don't want to give [hormones].

They're too afraid we might blossom into beautiful women."

Cassandra $^{3}$

"We are not demons. We are not Anti-Christ. We are human just like you, we just happen to love who we love. And identify how we identify. That's why we are LGBTQ, we have different identities, we have different preferences. We have diversity. We're not the same people, and that's what people don't understand. We are people too. We are human. I bleed just like you. I cry just like you. I smile just like you. I do all of these things that say that I am human.

And me personally, I demand that I be treated as human." 


\section{8}

\section{PRISONS}

\section{Written with Grace (Yongxi) Pan}

The historical legacy of sex segregation in prisons ${ }^{5}$ is unlike the contexts examined thus far in this book. The establishment of prisons for women separate from men was not the sort of feminist achievement that women's colleges were, nor was it an effort to correct centuries of discrimination, as was the case in U.S. athletic competitions. Nonetheless, how sex segregation developed in U.S. prisons was and remains a function of beliefs about gender and about the role of incarceration (Owen, Wells, \& Pollock 2017).

According to Nicole Hahn Rafter's influential account, Partial Justice: Women in State Prisons, 1800-1935, sex segregation of U.S. prisons in the 19th century was carried out in three stages. First, women were confined in separate rooms or individual cells, but remained part of the general prison population; second, women were put in separate spaces in or near the men's section, such as an attic or annex; and finally, women were relocated to a separate building altogether (1985). Prison facilities for women were typically inferior to those of male prisoners, with less access to fresh air and exercise yards. A chronic lack of supervision in female prisons led, in some states, to exploitation, rape, and forced prostitution. Rafter attributes these differences and exploitations to

Gender-based perceptions - that female prisoners were the source of sexual mischief; that they could not earn as much as men [through forced prison labor]; that they had gone beyond the pale redemption - combined with the problem of smaller numbers to create a situation in which women's needs were slighted.

$(1985,13)$

For nearly the first century of U.S. history, prisoners in general were seen as irredeemable; women in particular were described as "fallen," marked by "a stigma that once attached could never be removed" (Banks 2003 2).

Because women were viewed as being more pure and moral by nature than men, the woman who dared to stray or fell from her elevated pedestal was 
regarded as having fallen a greater distance than a male, and hence as being beyond any possibility of reformation.

(Dodge 1999, 908)

Not surprisingly, one stated reason for sex segregation in prisons was that such fallen women exerted a "pernicious" influence on the "good order and discipline" of male inmates. In the mid-19th century, a consistent theme within non-segregated prisons was that "female convicts were more trouble than male" (Dodge $1999,912)$. This is a manifestation, albeit an unusual one, of androcentrism:

$[\mathrm{M}]$ asculine criminality has always been deemed more 'normal' than feminine criminality. There has always been a tendency to regard those women who have been publicly punished by the state for their misbehaviors as significantly more aberrant and far more threatening to society than their numerous male counterparts.

(Davis 2003, 66)

Beginning in the mid-19th century, prison reform began to shift its focus from punishment to differing forms of rehabilitation. In women's prisons, architectural changes included the creation of the "cottage plan" with "homes," serving to promote a more domestic setting. In some prisons, women were allowed to keep their babies with them to encourage the motherly and nurturing instincts. Domestic training was seen as "the key to women's salvation" (Banks 2003, 7). Not all prisons were so idealistic, of course, and in some states the situation for prisoners, women included, was abysmal. The aftermath of the Civil War, for example, saw the emergence of southern prison farms for men and women that "adopted techniques of slavery such as the overseer with his lash and the practice of working bands of subjects on farms" (Rafter 1985, 88). Even into the Progressive Era of the early 20th century, practices that can be described only as torture were used to discipline inmates (Rothman 2017).

The history of the U.S. penal system is complex and riddled with systemic failures that extend far beyond the scope of this book. ${ }^{6}$ Understanding that beliefs about sex and gender have always informed prison design and practices is, however, essential to our understanding of more recent developments, with a direct relevance to the Transgender Exigency.

The United States is the largest incarcerator in the world. Despite having its lowest incarceration rate in 20 years, the United States accounts for about $25 \%$ of the world's prison population, with over 2.1 million people in U.S. prisons as of 2018 (ICPR 2021). The prison population in 1972 was under 200,000, almost 2 million less than it is today (Langan et al. 1988). The United States incarcerates 629 people per 100,000, the highest rate in the world (ICPR 2021). According to research done by Peter Wagner and Wendy Sawyer at the Prison Policy Initiative,

The American criminal justice system holds almost 2.3 million people in 1,833 state prisons, 110 federal prisons, 1,772 juvenile correctional facilities, 
3,134 local jails, 218 immigration detention facilities, and 80 Indian Country jails as well as in military prisons, civil commitment centers, state psychiatric hospitals, and prisons in the U.S. territories.

According to the U.S. Department of Justice, during the Reagan administration the number of state and federal prisoners increased by over $90 \%$ between 1980 and 1988 (Bessette 1989). In Texas, for example, the state incarcerated 182 people for every 100,000 residents in 1978; by 2003, that figure increased to 710 (Cullen 2018).

Historically, far fewer women have been incarcerated than men. In 2015, men made up $92.8 \%$ of state prison populations, down from 96.3\% in 1978 (Sawyer 2018). In federal prisons, as of July 25, 2020, 93.2\% of inmates are identified as male with the remaining 6.8\% being female (Federal Bureau of Prisons 2020). While the rate of incarceration in the U.S. began to climb dramatically in the 1980 s with the War on Drugs, the increased rate for women significantly outpaced those for men: "Nationwide, women's state prison populations grew 834\% over nearly 40 years - more than double the pace of the growth among men" (Sawyer 2018).

The status of incarcerated women is especially relevant here, as will be discussed in the following sections. Fearing assault in men's prisons, transgender men rarely request to be housed with male prisoners and typically prefer to be housed with women (Sosin 2020).

Historically, conditions for women inmates have been far worse than for men. In In Search of Safety, criminologist Barbara Owen and her colleagues describe "features of the physical plant and the prison environment that threaten women's safety, among them crowding, unsanitary conditions, and unconstitutional health care" (Owen, Wells, \& Pollock 2107, 43). Most jurisdictions have fewer facilities for women than for men; this restricts women's "ability to be placed in community programs or other programs requiring a low-custody designation" (Owen, Wells, \& Pollock 2017, 52). Because there are fewer facilities for women, they are often isolated and a significant distance not only from the families of women inmates, but also from legal and community resources. Women tend to be housed all in one facility, regardless of the severity of their crimes.

Men, in contrast, generally are assigned to prisons based on a variety of factors, including their criminal offense, prior criminal history, and psychological profile. Also, because of the greater number of male institutions, men stand a much better chance of being housed near their place of residence, thus making it easier for family, friends, and attorneys to visit.

(HRW 1996)

As physician/anthropologist Carolyn Sufrin's important work documents, the U.S. prison system treats males as the "default" prisoners, and institutions of incarceration "are designed with men in mind" $(2017,10)$. One especially problematic 
effect of such androcentrism is that women's reproductive health is routinely neglected:

Research and public narratives document a systematic lack of reproductive health care for incarcerated women on a national scale, from absent or substandard prenatal care, to forced withdrawal from opiates in pregnancy (despite the known pregnancy risks), to lack of access to abortion and contraception.

(Sufrin 2017, 10)

Women's institutions often have more rules about conduct, and they are sometimes described as "pettier": "even when the rules in both prisons are broadly identical, women seem to be subject to stricter supervision than men and are often punished for behavior that would not be sanctioned in men's prisons, such as cursing, failing to eat all the food on one's plate, and sharing shampoo" (Banks 2003, 67).

A two-and-a-half-year study by Human Rights Watch found widespread sexual assault against women prisoners by male guards (HRW 1996). Though the report found that all groups suffer sexual misconduct, it also reported that lesbian and transgender prisoners are sometimes singled out for misconduct by officers. While assault between inmates occurs, a significant amount of assault is perpetrated by male prison staff (Davis 2003, 60-83). The U.S. Commission on Civil Rights noted that while

men and women in prison report similar rates of staff-on-inmate misconduct (2.4 percent vs 2.3 percent), nearly 82 percent of the female victims in prison said they were pressured by staff to engage in sexual activity, compared to 55 percent of male victims in prison. For both male and female inmates, the perpetrator of staff sexual misconduct was most often of the opposite sex.

(2020, 109)

According to Brenda V. Smith, Professor of the American University Washington College of Law and Former Commissioner of the National Prison Rape Commission, despite the passage of the Prison Rape Elimination Act in 2003 (discussed later), "It is evident that sexual abuse is still a serious contemporary issue facing women in custody. Sexual victimization of women in custody is an enduring theme in the history of women in custody" (U.S. Commission on Civil Rights 2020, 111). For example, in a survey of 18,000 former state prisoners by the Bureau of Justice Statistics, 9.6\% reported one or more incidents of sexual victimization during their most recent period of incarceration. The rate of inmate-oninmate sexual victimization for women reported was $13.7 \%$ - three times higher than for men at 4.2\% (Beck \& Johnson 2012, 5).

In recent years, while progress has been made to reduce the national rate of incarceration, progress has been slower for women. According to Wendy Sawyer of 
the Prison Policy Initiative, this slower progress is due to three reasons: Incarcerated women are more likely to receive disciplinary action and more severe sanctions for similar behavior compared to men; Women have less access to alternative programs for first-time offenders than men; and states continue to "widen the net" through various efforts to criminalize women's behavior, including (for example) schoolaged girls' misbehavior (2018).

As we turn to the implications of the Transgender Exigency, it is worth noting that while incarceration is no doubt an awful experience for men and women, in certain respects women have the worst of it and have been subjected to a disproportionate share of abuse and sexual assault.

\section{The Transgender Exigency}

The proportion of transgender people who are incarcerated is estimated to be larger than the proportion of transgender people in the general U.S. population. Contrary to the impression we may have from high profile transgender celebrities such as Caitlyn Jenner, many transgender people struggle financially: "Discrimination by potential employers and landlords and rejection by family force many transgender people into the underground economy" (Schwartzapfel 2020). According to the U.S. Transgender Survey of 2015, one in five transgender people have participated in the underground economy for income at some point in their lives, including 12\% who have been involved in sex work (James et al. 2016, 12). Moreover, the survey suggests that transgender people were more than twice as likely to live in poverty than the general population, and are more likely to face prison time (James et al. 2016). In some cases, transgender women are arrested for prostitution just walking down the street, a crime that activists describe as "walking while trans." Two percent of transgender people interviewed said they had been arrested in the previous year; $58 \%$ of transgender respondents reported experiencing mistreatments from the police or law enforcement officers in the past year. Such mistreatments involved verbal harassment, references to a wrong gender, and physical or sexual assault; $57 \%$ claimed that "they would feel uncomfortable asking the police for help if they needed it" (James et al. 2016, 12).

Transgender people who are incarcerated do not fare any better. In the same survey, $23 \%$ of transgender inmates reported experiencing physical assault from prison staff or other prisoners in the previous year, and one in five $(20 \%)$ were sexually assaulted. Compared with the general U.S. prison population, transgender prisoners are five times more likely to be sexually abused by prison staff and nine times more likely to be sexually assaulted by other inmates (James et al. 2016, 211-212). Accordingly, the segregation of prisoners by sex has put transgender prisoners, a group expanding in number and estimated as at least 4,890 individuals today-1,097 people self-reported as transgender among 141,500 prisoners $(0.7 \%)$ in Texas alone-in an awkward and often unsafe situation (Sosin 2020).

The fact that transgender prisoners fall prey to sexual violence behind bars has been documented for decades. In 1989, Dee Farmer, a Black trans woman housed 
in a maximum-security male prison in Indiana, was raped by another male inmate. She then sued prison officials who had transferred her from her previous cell in Wisconsin to the cell in Indiana. She demanded compensation for her "mental anguish, psychological damage, humiliation, swollen face, cuts and bruises to her mouth and lips and a cut on her back, as well as some bleeding" resulting from the rape (Strangio 2014; Flowers 2014). The case made it to the Supreme Court after five years. On June 6, 1994, the Court unanimously ruled in Farmer v. Brennan that the prison officials' "deliberate indifference" to inmate health and safety violated Farmer's Eighth Amendment protection against cruel and unusual punishments, and thus the officials should be held liable for damages (Strangio 2014).

Farmer v. Brennan marks an early effort by the Supreme Court to address the issue of prison rape (Flowers 2014). It was followed by the passage of the Prison Rape Elimination Act (PREA) by Congress in 2003 (Stahl 2018). Though the act did not explicitly refer to transgender prisoners, it referred to Farmer v. Brennan when stating that "the high incidence of sexual assault within prisons involves actual and potential violations of the United States Constitution." Setting a zero-tolerance goal for prison rape, the PREA established a "National Prison Rape Elimination Commission" (NPREC), mandated the Department of Justice to "make the prevention of prison rape a top priority in each prison system," and instructed national standards to be developed and instituted through research and data collection to "prevent, detect, and reduce sexual violence in prisons" (National Institute of Justice Staff 2006; Kaufman 2008).

As required by the PREA, the Department of Justice's Bureau of Justice Statistics and the National Institute of Justice (NIJ) collected data and conducted research on prison rape. A survey conducted by the Bureau of Justice Statistics found that in 2006, 1.3 million prisoners reported 60,500 cases of sexual violence ranging from unwanted touching to rape, a rate of $4.6 \%$ (Kaufman 2008). In 2007, a study of California prisons conducted by the University of California, Irvine's Center for Evidence-Based Corrections found that transgender women housed in male prisons were 13 times (59\%) more likely to experience sexual offenses than cisgender inmates (4.4\%) (Jenness et al. 2007). Data from multiple years by the Bureau of Justice Statistics found that nearly $40 \%$ of transgender prisoners experienced sexual abuse in federal and state prisons, as opposed to $4 \%$ of the general incarcerated population (Beck 2014).

In 2012, after a decade of research and review, the guidelines and standards for eliminating prison rape drafted by NPREC, commonly referred to as the PREA Standards, were finalized and implemented. In the standards, whether a prisoner is transgender, gender nonconforming, or DSD is officially listed as a required factor for screening for risk of victimization and abuse. The information gathered concerning gender identity, along with other factors such as prior acts of sexual abuse, body shape, age, and criminal history, are to be used to inform "housing, bed, work, education, and program assignments with the goal of keeping separate those inmates at high risks of being sexually victimized from those at high risk of being sexually abusive" (PREA Standards 2012, 20). 
The standards require a case-by-case evaluation for housing and programming assignments. They also state that assignments for "each transgender or intersex inmate shall be reassessed at least twice each year to review any threats to safety experienced by the inmate" (115.42[d]) and that transgender and DSD inmates" "own views with respect to his or her own safety shall be given serious consideration" (115.42[e]). By making it clear that a person's gender as assigned at birth no longer stands as the sole factor for housing assignments, the new set of standards brought an end to strict sex segregation in prisons based purely on a biological definition of sex. The standards applied to all federal prisons starting in 2012 and required state compliance beginning in 2013.

Implementation of the new transgender policies has been slow. It was reported that even under the Obama administration, "a high level of prison facilities were ignoring PREA standards" (Moreau 2018a). The very first transfer of a transgender female prisoner from a male prison to a female prison took place in September 2018, six years after the PREA standards were in place (Levenson 2019).

The PREA standards formulated in 2012 did not incorporate details on the criteria and procedures for the decision-making. In 2016, the Bureau of Justice Assistance published a more specific interpretation of the PREA standards through the National PREA Resource Center website. It notes that "Any written policy or actual practice that assigns transgender or intersex inmates to gender-specific facilities, housing units, or programs based solely on their external genital anatomy violates the standard. A PREA-compliant policy must require an individualized assessment. A policy must give 'serious consideration' to transgender or intersex inmates' own views with respect to safety." In terms of the criteria to include in the "serious consideration," the notice states that the "assessment, therefore, must consider the transgender or intersex inmate's gender identity." A policy

may also consider an inmate's security threat level, criminal and disciplinary history, current gender expression, medical and mental health information, vulnerability to sexual victimization, and likelihood of perpetrating abuse. The policy will likely consider facility-specific factors as well, including inmate populations, staffing patterns, and physical layouts.

(National PREA Resource Center 2016)

Prison policy was complicated by the case of Rhames $v$. United States in 2017. Female inmates Brenda Rhames, Rhonda Fleming, Charlsa Little, and Jeanettte Driever were housed in the Federal Medical Center, Carswell, a federal women's prison. They sued the federal government in Texas District Court, arguing that their rights to personal privacy and dignity had been violated by being housed with men who claim to be transgender women in the prison. The amended complaint filed in May 2017 stated:

Housing male inmates in facilities otherwise housing only female inmates creates a situation that incessantly violates the privacy of female inmates; 
endangers the physical and mental health of the female Plaintiffs and others, including prison staff; increases the potential for rape; increases the potential for consensual sex which is nonetheless prohibited by prison regulations; increases the risk for other forms of physical assault, violates the Plaintiffs' right to freely exercise their religion; and causes mental and emotional distress that must be promptly mitigated by preliminary and permanent injunctive relief.

(Fleming, Little, Driever, \& Rhames v. U.S. 2017)

The case was dismissed in 2019, in part because the plaintiffs lost standing (Rhames left prison, for example), and in part because of changes in policy made by the Bureau of Prisons (BOP). The Trump administration-in part because of this case-revised the language of the BOP's Transgender Offender Manual one year after its initial publication in 2017. Before the revision, the manual recommended the housing of transgender inmates to be consistent with their "gender identity"; the modified version in 2018 strikes through the original recommendation and requires officials to "use biological sex as the initial determination" for designation and placement. The revised manual makes clear that the placement decision shall not only consider the health and safety of the transgender inmate, but also "the management and security of the institution" and "risk to other inmates in the institution." In light of these criteria, the manual stipulates that "the designation to a facility of the inmate's identified gender would be appropriate only in rare cases" (Inch 2018). The revision restores "biological sex" as the presumptive criterion for housing inmates, which creates a very unfavorable situation in light of the increasing prominence of self-identification among the transgender community. In fact, research suggests that more than $80 \%$ of transwomen in the United States retain their male genitalia (James et al. 2016, 102). The regulatory definition at work introduced by the Trump administration's revision assumes the following form: A prisoner whose biological sex is male/female $(\mathrm{X})$ counts as a man/woman $(\mathrm{Y})$ in the context of U.S. prisons (C).

The policy shift was met with considerable disapproval from transgender advocacy groups. Mara Keisling, the executive director of the National Center for Transgender Equality, called the revision an "inhumane agenda," saying that "the extreme rates of physical and sexual violence faced by transgender people in our nation's prisons is a stain on the entire criminal justice system"; Aryah Lester, the founder of Trans Miami, remarked that the new policy will "lead to increased violence against transgender individuals" and that the policy proves that to Trump, “trans people's lives don't matter" (Moreau 2018a).

A specific criticism made of the revised policy is that "biological sex" is not defined by the BOP and, according to the ALCU's Staff Attorney Chase Strangio, until recently "the term appeared nowhere in federal or state law" (2018). Strangio calls "biological sex" a dog whistle for "trans exclusion." Furthermore, the new rule violates the PREA, which requires federal and state prisons to give inmates' own sense of safety and identity serious and careful considerations before making 
the final placement decision (Strangio \& Fettig 2018). Nancy Ayers, a spokesperson for the Bureau of Prisons, said that she believes the revised policy does consider individual needs in accordance with the PREA: "The manual now addresses and articulates the balance of safety needs of transgender inmates as well as other inmates, including those with histories of trauma, privacy concerns, etc., on a caseby-case basis" (Gathright 2018).

Despite the Trump administration's rollback of transgender protections, some state and local jurisdictions have implemented policies similar to those advanced in PREA.

In 2014, a specialized Transgender Housing Unit for transgender women was opened in Rikers Island in New York City. Correction Commissioner Joseph Ponte stated, "Providing [transgender women] with specialized housing and services is good policy and meaningful reform and is expected to reduce incidents involving these individuals while also leading to better long-term outcomes, including possible reductions in recidivism" (Mathias 2014).

In May, 2018, Connecticut was the first state to enact a policy requiring the state Department of Correction to house prisoners according to their gender identity. The law only applies to those who are "diagnosed with gender dysphoria or had their gender marker legally changed" (Riley 2018). ${ }^{7}$ The key definitive attribute informing Connecticut's regulation of housing transgender prisoners is documentation: A prisoner who is legally or diagnostically documented gender as male/female $(\mathrm{X})$ counts presumptively as a man/woman $(\mathrm{Y})$ in the context of Connecticut prisons (C).

Massachusetts General Laws c.127 \32A amended by the Criminal Justice Reform Act of 2018 stipulates that transgender inmates "with or without a diagnosis of gender dysphoria or any other physical or mental health diagnosis" shall be addressed and if requested, housed in a manner consistent with their gender identity, unless the commissioner certifies that such placement would not ensure prisoners' safety or would present management or security concerns (MassGov 2018). Such an approach empowers inmates' own sense of identity as the presumptive criterion for inmate placement decisions. Only when inmates' own preferences pose security risks would the default decision based on identity be challenged. Similarly, California passed legislation, signed into law in September 2020, requiring that transgender inmates "Be housed at a correctional facility designated for men or women based on the individual's preference" in all situations unless there are "management or security concerns" (SB-132 2020, sec. 4). ${ }^{8}$

In July 2021, the New Jersey Department of Corrections adopted a new policy to make it customary for prisoners who identify as transgender to be assigned a prison stay in line with their gender identity (Diaz 2021). The policy was an outcome of a settlement in a case brought by a transgender woman after she spent 18 months in four different men's prisons, during which she "faced humiliating strip searches in front of male guards. Male prisoners exposed themselves to her. She faced sexual harassment, discrimination and physical threats from corrections officers and inmates alike" (Diaz 2021). 
In any case, the regulatory definition reflected by such policies therefore would be: A prisoner whose self-identified gender identity is male/female (X) counts presumptively as a man/woman (Y) in the context of the relevant jail or prison (C).

Other states have moved in the more conservative direction. State prisons in Texas house transgender inmates based on their "sex at birth" (McGaughy 2018). Thus: A prisoner whose assigned birth is male/female (X) counts as a man/woman $(\mathrm{Y})$ in the context of the state prison $(\mathrm{C})$.

Justice Louis Brandeis famously said that states may "serve as a laboratory" to "try novel social and economic experiments" (1932, 311). As states experiment with different definitional policies with regard to transgender inmates, undoubtedly data will emerge to show the relative strengths and weaknesses of different definitional approaches. For example, there have been allegations that a policy of placement based on self-identification is being abused in one county facility in the state of Washington, and that at least one inmate incarcerated for a sex offense arrived "from a male facility" and raped a female in the women's prison soon after (Monson 2021). The Los Angeles Times reports that "A transgender woman at a men's prison, who asked not to be identified for fear of retaliation, said that she knows at least five inmates who have applied to transfer under false pretenses and that staffers have asked her to help identify such inmates" (Miller 2021). True or not, such allegations raise fears of cisgender male inmates trying to game the system to get placed in women's facilities (see, for example, Shrier 2021).

Overall, prisons have been slow to house transgender inmates based on their gender identity, even after new laws such as California's is enacted (Ferrannini 2021). The ALCU's Chase Strangio claims that "Placement of transgender women in women's facilities is exceedingly rare and where it does happen, it is often the result of years of advocacy by the individual prisoners and detainees" (in Stahl 2018). Data collected by NBC News showed that out of 4,890 transgender inmates in U.S. state prisons, only 15 cases of prisoners housed according to their lived gender could be confirmed, or $0.3 \%$ (Sosin 2020). Among the 15 cases, 13 were transgender women housed in women's facilities, and two were transgender men housed in men's facilities. In Texas, none of the 980 transgender prisoners $(891$ transgender women and 89 transgender men) lived in gender-consistent housing. The consequences can be significant. PREA Data Collection Activities in 2015 reported that in the previous year, "An estimated 35\% of transgender inmates held in prisons and 34\% held in local jails reported experiencing one or more incidents of sexual victimization by another inmate or facility staff in the past 12 months" (U.S. Justice Department 2015).

Opposition to policies designed to assist transgender inmates, particularly transgender women, has brought together unlikely allies. When New York City announced efforts to respect transgender women's gender identity, the decision was denounced on the conservative website Breitbart.com. The news story began, "The mayor of New York is offering male criminals the chance to move into women's jails, providing the men say they have a 'female gender identity", (Munro 2018). The Christian legal advocacy group Alliance Defending Freedom (who 
also advanced the "bathroom bills" agenda elsewhere) intervened in the Rhames $v$. United States lawsuit in support of the cisgender female plaintiffs, claiming that American prisons' actions to alleviate the risks for incarcerated transgender people are a response to crisis "contrived" by transgender people and the prisons that adapt to their gender identity. According to the Alliance, cisgender women in prison are harmed by prisons accepting what the ADF calls "gender identity ideology" (Stahl 2018).

From a very different political starting point, a group opposing California's SB-132 identifies itself as "unapologetically radical feminists," and describes SB-132 as "a stunning act of female erasure and elevation of men's feelings over women's physical and psychological safety” (WoLF 2019). As a result, the bill would

harm one of the most vulnerable groups in society: incarcerated women. It would allow any male at any time to self-declare that he has a woman "gender identity," and on that basis allow him to demand to be housed in a women's correctional facility.

$\left(\right.$ WoLF 2019) ${ }^{9}$

In sum, the transgender situation in U.S. prisons is ill-defined, no pun intended. Both extremes of presumptive self-identification and biological essentialism can be found at work, as well as efforts to find a middle ground. The differences among states' requirements illustrate a definitional rupture in the context of the U.S. prison system-a transgender inmate can count as male in one state and as female in another. The values that the competing definitions represent are nominally the same; that is, the desire to protect vulnerable groups of inmates.

Regarding future directions, a brief account of the experience with transgender inmates in the United Kingdom provides worthwhile insights. UK law dealing with gender identity in general and regulations concerning transgender prisoners in particular are significantly more developed than in the United States.

\section{The UK experience}

The roots of transgender legal rights in the UK can be traced back to a resolution by the European Parliament in 1989 to protect the rights of "transsexuals" known as Recommendation 1117 (Parliamentary Assembly 1989). The Recommendation included a call for legal protections in cases of "irreversible transsexualism," including changing birth certificates, identity papers, and in general prohibiting "all discrimination in the enjoyment of fundamental rights and freedoms" (Parliamentary Assembly 1989).

In 2002, the European Court of Human Rights ruled in Goodwin \& I v. United Kingdom that the English law that denied the plaintiff Christine Goodwin, a 65-year-old transgender woman, from changing her gender marker on her birth certificate breached respect for privacy and right to marry under the European Convention on Human Rights (BBC News 2002b). Around the same time, a 
different transgender woman lost a bid to change her birth certificate; the judge ruling that "The register of births is a historical register of fact" (BBC News 2002a). Resolution to these conflicting rulings came in the form of a new law, the Gender Recognition Act of 2004. At the heart of the Act was the creation of a Gender Recognition Certificate (GRC) that would function as legal affirmation of what was called an acquired gender.

To receive a GRC, an applicant must be 18 years old or more, and under standard circumstances must meet three criteria:

- They have, or have had, gender dysphoria

- They have lived fully for the last two years in their acquired gender and continue to do so

- They intend to live permanently in their acquired gender until death

(Government Equalities Office 2018)

The United States lacks a comparable process, with each state having different rules and processes for changing names and legal documents of transgender people, and yet another set of procedures for changing one's sex on a U.S. passport or in Social Security's records. The UK also has, by law, added gender reassignment as a "protected characteristic" protected against discrimination in the 2010 Equality Act. Thus, the legislative status of transgender protection at a national level is quite different in the UK than in the U.S., and this national approach is reflected in national prison policies.

The Ministry of Justice issued The Care and Management of Transsexual Prisoners as the first policy directive to address procedures for transgender prisoners (2011). The directive, referred to as PSI 07/2011, defined "transsexual" as

someone who lives or proposes to live in the gender opposite to the one assigned at birth. The gender in which the transsexual person lives or proposes to live is known as that person's acquired gender. A transsexual person may or may not have been diagnosed with gender dysphoria.

$(2011,2)$

Despite the statement that a diagnosis of gender dysphoria is not required, it should be noted that to receive a GRC, such a diagnosis is required, and having a GRC certainly made it much simpler to request and receive a prison housing assignment consistent with one's gender identity. Otherwise, decisions are made on a case-bycase basis. ${ }^{10}$ With a GRC in hand, the policy states that "A male to female transsexual person with a gender recognition certificate may be refused location in the female estate only on security grounds" $(2011,5)$. Even if the inmate is guilty of violent crimes against other women, including attempted rape, the presumption is that the inmate would be housed in the female "estate" (facility). Transgender men with GRCs "may not be refused" location in the male estate. The policy can be summarized as advancing a regulatory definition that only legally documentable 
(GRC or GRC-in-progress) or biologically males/females (X) count as a man/ woman (Y) in the context of UK prisons (C).

An example of a relocation of a trans inmate under the 2011 policy was Tara Hudson. Hudson was a transgender woman who had gone through reconstructive surgery but had not yet obtained a GRC by the time she was sentenced to a 12-week jail term for headbutting a barman. Lacking a GRC, she was placed in a male prison but appealed to transfer to a female prison. The news of her appeal then became viral on the internet and led 140,000 people to sign a petition rooting for her transfer. She was successfully transferred to a female jail in 2015, despite her "worrying criminal record" of eight previous convictions, including battery. The prison officer explained their decision by saying although the longstanding policy is to place offenders according to their legally recognized gender (as per PSI 07/2011),

our guidelines allow room for discretion and in such cases, medical experts will review the circumstances in order to protect the emotional wellbeing of the person concerned. Our top priority is the safety and welfare of those in our custody and decisions relating to the location of transgender prisoners are taken by a range of people including psychologists, healthcare professionals and prison staff.

(BBC News 2015b)

Nonetheless, two high profile deaths in 2015 of transgender women placed in men's prisons, Vikki Thompson and Joanne Latham-both of whom also lacked GRCs - raised questions about the adequacy of PSI 07/2011 procedures (Alison \& Pidd 2015; Pidd 2017). In 2016, the Ministry of Justice issued a new version of The Care and Management of Transgender Offenders (PSI 17/2016) to replace the former PSI 07/2011. Not only did the title change from "transsexual" to the more inclusive "transgender," the policy document loosened the requirement for a GRC to qualify for gender identity-consistent housing. The policy is described at some length here for reasons that will be explained later on.

The new policy requires transgender offenders to be asked their view of "the part of the prison estate (i.e. male or female) that reflects the gender with which they identify" (Ministry of Justice 2016, 9). If they do not have a GRC, then the request must be made by a Transgender Case Board. The offender is then asked to provide "evidence of living in the gender with which they identify." The policy continues,

The strength of this evidence must be considered within the context of a Transgender Case Board together with all known risk factors before a decision is made. Each offender must be assessed on a case by case basis and discretion may be applied following a Transgender Case Board. Transgender offenders must be allowed to live in the gender they identify with during this process. 
Figure 8.1 describes the types of evidence that can be provided and ranks their relative strength (Ministry of Justice 2016, 28). In the evidence description, documented evidence such as the GRC and birth certificates still counts as the strongest evidence ("full confirmation"), second to which are "strong confirmation" including health care information and "actual life" traces of living consistently in one's acquired gender. The absence of actual lifestyle evidence, along with covert attempts to use gender role to sway judicial decisions function as counterevidence. All of these made it more likely in theory for transgender inmates without GRCs

\section{Evidence of Living in the Gender with which the Offender Identifies}

When an offender discloses that they are transgender, the following chart may assist in assessing the strength of evidence of living in the gender the offender identifies with in order to inform location decisions and sentence plans.

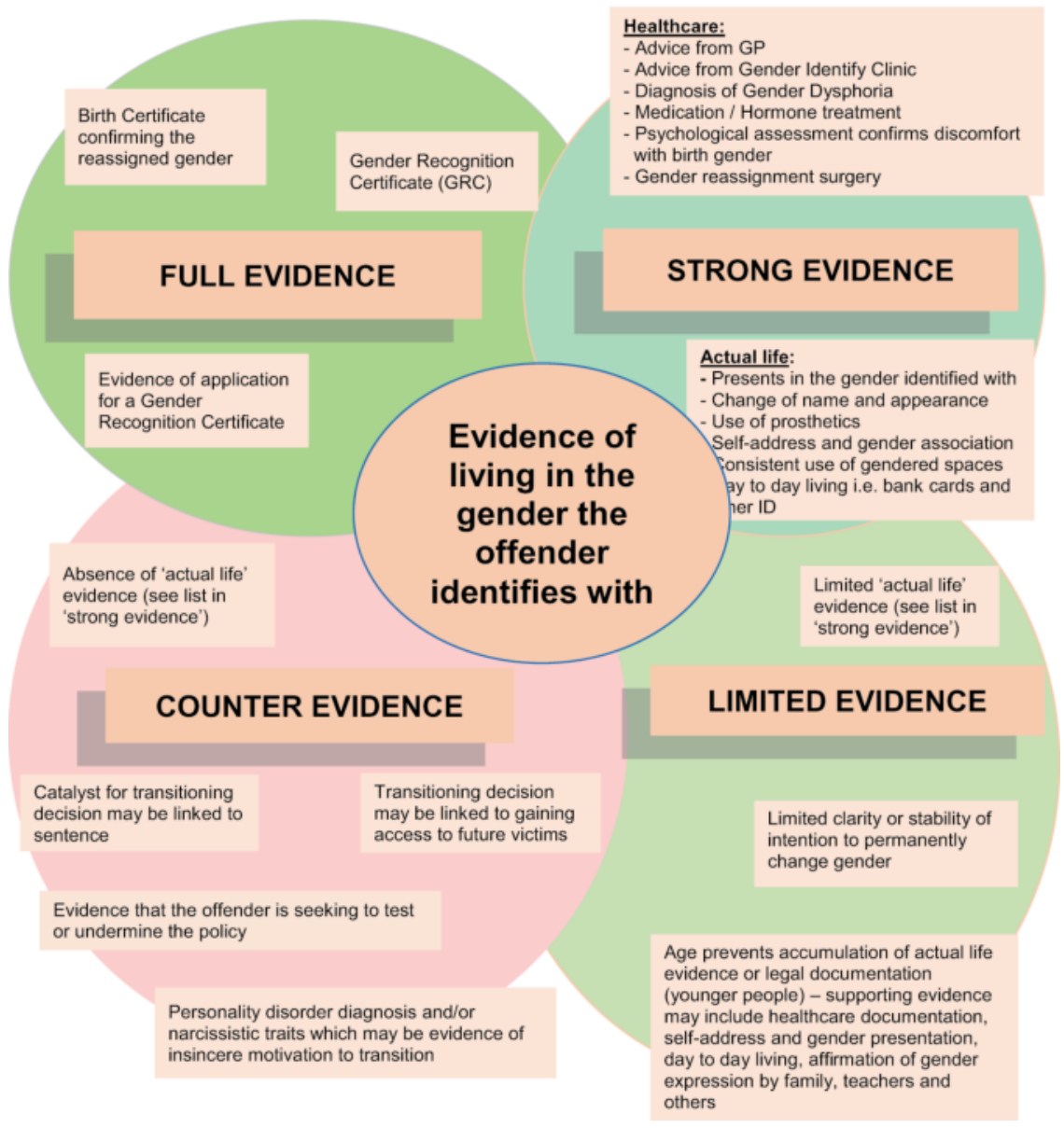

FIGURE 8.1 UK Evidence of Living in the Gender with which the Offender Identifies 
to be housed based on their gender identity if they can provide "strong confirmation" evidence.

The new policy reduces the dependence on documentation or surgical requirements and instead commits to a "durational" attribute, seeking to testify from one's everyday lifestyle that the inmate has been living consistently in their "acquired" gender. Thus, the regulatory definition can be written as: Transgender prisoners who can provide adequate evidence of living consistently and permanently in a specific gender category $(\mathrm{X})$ count as women/men $(\mathrm{Y})$ in the context of UK prisons $(\mathrm{C})$.

Just as the new policy took effect, a notorious incident took place that further complicated the policy situation in the UK. Karen White, a transgender woman, was incarcerated on remand for "for grievous bodily harm, burglary, multiple rapes and other sexual offences against women" in 2017, just as PSI 17/2016 took effect (Parveen 2018a). Although she neither had a GRC nor had gone through reconstructive surgery, White was placed in a female prison under the new policy. In the female facility, she sexually assaulted two female inmates within her first three months of imprisonment. The incident caused a media storm across the nation as an illustration of the potential danger associated with placing transgender women in women's prisons. White was sentenced to life in prison in October, 2018, for two counts of rape, two sexual assaults and one count of "wounding." She had previous convictions for indecent assault, indecent exposure and gross indecency involving children, animal cruelty and dishonesty (Parveen 2018b). The Ministry of Justice apologized for placing her into a women's prison, noting that her previous criminal history had not been taken into account when the housing assignment was made by the "Local Transgender Case Board" and that the case was not reviewed by a second board (a "Complex Transgender Case Board") that should have assessed the particulars (Parveen 2018a, 2018b). As noted by reporter Nazia Parveen, "both sides of the transgender rights debate are united in the belief mistakes were made" in the case (2018a).

The Ministry of Justice's count of transgender prisoners between March and April 2017 gave an estimate of 125 transgender inmates in England and Wales. ${ }^{11}$ This number grew to 139 in 2018 and 163 in 2019. Among these 163 individuals, 129 reported their legal gender as male, 32 as female and two did not state their legal gender. When asked about the gender with which the prisoner identified, 130 identified as female, 20 as male and 13 did not provide a response (Ministry of Justice 2019b, 14-15). The number of trans inmates identifying as female is further complicated by allegations of a high percentage of sexual offenders among the trans prison population. The controversial advocacy group Fair Play for Women examined individual prison inspection reports in 2017 and concluded that at least $41 \%$ of transgender women (whom they refer to as "transgenderidentifying males") in prisons in England and Wales were convicted sex offenders (2017). This figure is twice as high as the $19 \%$ of all prison populations convicted of sexual offenses calculated by the Ministry of Justice in 2018, and becomes even more salient when compared to $3.2 \%$, the estimated percentage of sexual offenders 
among the entire female-estate population (The Ministry of Justice 2018; Fair Play For Women 2017). Fair Play's numbers were criticized in a fact check article by the BBC, which suggested the percentages were skewed because many transgender inmates were not included in the count (Reality Check Team 2018). Nonetheless, adding to concerns about proper placement of transgender inmates is the fact that the number of inmates claiming to be transgender rose dramatically, with one watchdog survey suggesting "there are up to 1,500 transgender inmates among the 90,000 prisoners in England and Wales, more than ten times previous estimates, and at least four times the number in the general population" (Hymas 2019). Officials representing the Prison Officers Association and the Victim Rights Campaign expressed the concern that the inmates were merely trying to obtain "prison perks" such as separate showers, separate cells, and access to women's housing facilities (Hymas 2019). Consequently, the challenge confronting the UK government after the Karen White incident was to improve their ability to assess and control the potential risks of abuse associated with transgender prisoners and at the same time to hold the ground for transgender prisoners' basic rights.

In 2019, another revision of The Care and Management of Individuals who are Transgender was introduced to replace PSI 17/2016. The new policy categorizes its primarily concerned subjects into the following two groups: (1) individuals who express a consistent desire to live permanently in the gender with which they identify, and which is opposite to the biological sex assigned to them at birth, regardless of the intent to pursue a new legal gender recognition; (2) individuals who identify as transgender but do not seek to acquire a new gender, including Intersex, nonbinary, gender fluid, and transvestite individuals.

Substituting for PSI 17/2016, the new policy builds on the previous version in ways that include requiring the initial location of all prisoners to match their legal gender until the CCB (Complex Case Board) has approved a transfer, and changing the convening time of Initial Local Transgender Case Board to "within 14 days," not three days as per PSI 17/2016, to allow for a suitable amount of time for disclosure and informed risk assessments. The key addition is in the area of "risk assessment." While the policy retains the "evidence list" from PSI 17/2016, it stipulates that "a balanced approach must be adopted where the safety and wellbeing of the individual who is transgender is balanced by an informed assessment of any risks that the individual presents to other people" (Ministry of Justice 2019a, 11). The risk assessment procedure considers two kinds of risk: (1) potential risk to the transgender individual from others, and (2) potential risk to others from the transgender individual.

The examination of the first type of risk, risk of abuse committed by cisgender inmates upon a transgender inmate, considers the following factors ( $\star$ indicates critical factors):

*Mental health and personality disorder; ${ }^{\star}$ History of self-harm; *Anatomy, including risk of sexual or violent assault; $\star$ Testimony from the individual about a sense of vulnerability, e.g. in a male environment, in a particular 
prison, or from a particular prisoner or group of other prisoners; ${ }^{\star}$ Risk of suicide; ${ }^{\star}$ Medication including the absence of medication and the impact of known side effects; ${ }^{\star}$ History of being attacked, bullied or victimised; ${ }^{\star}$ Intelligence including evidence of coercion, manipulation, or threats towards the individual; Family circumstances/relationship; Age; Physical health; Learning disabilities or difficulties.

(Ministry of Justice 2019a, 12)

The assessment of the second type of risk, risk of harm committed by transgender inmates, considers the following factors ( $\star$ indicates critical factors):

*Offending history, including index offence, past convictions and intelligence of potential criminal activity- e.g. credible accusations; *Anatomy, including considerations of physical strength and genitalia; ${ }^{\star S e x u a l}$ behaviours and relationships within custodial/residential settings; $\star$ Use of medication relating to gender reassignment; and use of medication generally; ${ }^{\star}$ Past behavior in custody, the community, in the care of the police, or in the care of prisoner escort services; ${ }^{\star}$ Intelligence reports; ${ }^{\star}$ Evidence of threats towards others; ${ }^{\star}$ Mental health and personality disorder; Learning disabilities or difficulties; Substance misuse.

(Ministry of Justice 2019a, 12-13)

The regulatory definition of gender in the UK prison context has evolved to assume the following form: Only prisoners who can provide sufficient evidence of living consistently and permanently in a gender identity and whose associated risks posed by and to other inmates are not particularly high $(\mathrm{X})$ are eligible to count as women/men (Y) in the context of UK prisons (C). Under very specific circumstances, inmates can be placed in a manner consistent with their gender identity or housed separately in facilities limited to transgender inmates. The UK opened the first transgender cell at HMP Downview in Sutton, Surrey in 2019. The cell unit now houses three transgender women inmates, all of whom have attained GRCs (Anonymous [The Economist] 2019; Hymas 2019).

\section{What might the U.S. learn from the UK experience?}

The procedures put into place by UK in 2019 may seem complicated, but they appear to be a sincere effort to balance competing values involving the rights of transgender inmates and the safety of cisgender women inmates. As noted in the 2019 UK policy, the management of individuals who are transgender "must seek to protect both the welfare and rights of the individual, and the welfare and rights of others in custody around them" (Ministry of Justice 2019a, 5). A recent legal challenge to the 2019 policy was refused, while the court noted that the government has to "consider competing interests and to balance competing rights," and acknowledged that "this is a sensitive area, in which it is unlikely that any policy 
could be devised which would be to the satisfaction of all persons affected by it" (Regina [FDJ] v Secretary of State for Justice 2021). The extreme approaches found in the United States, ranging from presumptive self-identification to a strict biological definition that effectively defines transgender women out of existence, privilege one set of values and, arguably, neglect the other.

The UK experience also suggests that policies may be drafted with the best of intentions, but implementation is another matter. The expression "culture eats policy for breakfast" suggests that no matter how well designed an institution's new policies are, if they run counter to the habitual practices and values of that institution, they are likely to fail. Thus, accusations remain that the vast majority of transgender inmates are in the "wrong" prison facility (R. Smith 2019; Ministry of Justice 2019b). And despite the creation of separate facilities for trans inmates at institutions like Riker's Island in the U.S., trans women continue to die unnecessarily, as in the tragic case of Layleen Polanco. ${ }^{12}$

Valerie Jenness, Distinguished Professor of Criminology, Law, and Society at the University of California, Irvine, has observed state officials charged with the placement of transgender inmates. She notes that a "case-by-case" approach to placement is shrouded in layers of ambiguity about how best to apply abstract criteria. This, in turn, creates a situation in which the same set of "facts" about the person and the context in which they are incarcerated can create a double-bind. For example, if a trans person who is incarcerated in a facility for men makes a request to move to a facility consistent with their gender identify, their disciplinary record is likely to be discussed by the team in charge of responding to the request. If the person has a disciplinary record the request might be denied in order to avoid "rewarding" negative behavior and out of concern for the women with whom the person would be housed if the request were approved. On the other hand, if the person does not have a disciplinary record, then their case file can be read as evidence that they have acclimated successfully into their current facility and thus should remain in it (Jenness 2020; see also Sumner \& Jenness 2014).

Of course, institutional inertia is no reason not to improve policies, and as all parts of the criminal justice system gain more experience with transgender populations, one can hope that implementation practices will improve on both sides of the Atlantic. In any case, compared to the rampant inconsistency of U.S. federal and state policies, the UK approach should be considered a model worthy of careful study and consideration.

\section{Notes}

1 Quoted in Hughto et al. $(2018,75)$.

2 Quoted in Kilty $(2020,11)$.

3 Quoted in Hughto et al. $(2018,76)$.

4 Quoted in Kilty $(2020,18)$.

5 Unless otherwise noted, the word "prison" in this chapter refers to federal and state prisons and penitentiaries. Other places of incarceration will be identified specifically where relevant. 
6 Hinton (2016) traces the politics and policy decisions since the War on Poverty that have led to the reliance on mass incarceration in the U.S. See also Davis (2003), Gottschalk (2006).

7 It should be noted that it is challenging to change one's legal ID to reflect a gender change. According to the 2015 U.S. Transgender Survey, only 11\% of respondents reported that all of their IDs had the name and gender they preferred, while more than two-thirds (68\%) reported that none of their IDs had the name and gender they preferred (James et al. 2016).

8 Transgender women inmates have different individual preferences for housing placement. In a study of 315 transgender women incarcerated in 27 California men's prisons, $64.9 \%$ preferred to be housed in a men's prison, while the rest $(35.1 \%)$ preferred to be housed in a women's prison. One prisoner explained her preference to stay in a men's prison by saying, "Women are more vicious. They scare me. Around men, I have my fan base. I'm more pretty than most of the girls here. Plus, I have my boyfriend-my husband - and he will take care of things" (Jenness, Sexton, \& Sumner 2019, 622).

9 Proving that politics makes strange bedfellows, WoLF sometimes partners with conservative groups and think tanks such as the Family Policy Alliance and the Heritage Foundation (Ring 2019).

10 PSI 7/2011 states: "Some transsexual people will be sufficiently advanced in the gender reassignment process that it may be appropriate to place them in the estate of their acquired gender, even if the law does not yet recognise they are of their acquired gender" (Ministry of Justice 2011, 16).

11 The Ministry of Justice's counts of transgender prisoners excluded those who have GRCs and the figures are likely to underestimate the true transgender population in prisons because some of the transgender inmates may not declare their gender identity or have a local case board conference (Ministry of Justice 2019b, p. 14).

12 Because Polanco could not afford $\$ 500$ bail for a misdemeanor charge, she was jailed in Riker's Island. After an altercation, she was put in solitary confinement and died of an epileptic seizure after guards failed to follow correct observation and intervention procedures. Had she been housed with cisgender women inmates, or had the facility followed correct procedure, it is unlikely she would have died in custody. Her family was awarded a $\$ 5.9$ million settlement (Simko-Bednarski 2020). Trans activists point to her case as symptomatic of mistreatment of transgender inmates (Burns 2020; Gajanan 2020; Gold \& Piccoli 2019). 


\section{Transgender voices}

"My gender is not up for debate. I am a woman."

t philosopher ${ }^{1}$

"Women who have struggled against patriarchal ideals of what makes a 'real' woman think nothing of turning around and using the word 'real' against trans women."

$\mathrm{Julia}^{2}$

"Are trans women women or aren't they? Here too the urge to over-simplify gets us into trouble. We imagine we have to line up in two discrete sides, behind an unqualified Yes and an unqualified No. I don't think that's right at all.

Here as in so many other places, the right answer is more like 'In some ways yes, in other ways no'."

Sophie Grace Chappell ${ }^{3}$

"The other hesitation I now have with the gender pluralism notion is that we lose the ability to recognize asymmetry in the workings of gender as a technology to distribute rights and resources. That is all a fancy way of saying that it makes the oppression of women much less visible."

Paisley Currah ${ }^{4}$ 


\section{9}

\section{FEMINISMS}

There are no specific institutions that function under the rubric of feminism $(\mathrm{s})^{5}$ with the authority to enforce specific regulatory definitions of male/female, or woman/man, such as those described in previous chapters. Nonetheless, there are heated debates among feminist activists and academics about the scope of the word "woman" and under what circumstances transgender women should be included. For that reason, a chapter exploring those debates seems worthwhile.

To understand why the question of defining "woman" is contentious, it is first important to understand what is at stake. Feminists wrote about and theorized "woman" as a category because the term denotes a group that historically has been oppressed and discriminated against. As the second section of this chapter illustrates, feminists wrestled with the need to make claims about an oppressed group while not reducing all women to a particular definitive attribute, such as the ability to bear children. For the moment, for the purposes of clarity we can stipulate that "woman" in this account most often refers to cisgender humans denoted by their specific cultures as women and set aside more specific definitive attributes and controversies.

A thorough account of the history of women's oppression goes far beyond the scope of this book, but there are five overlapping areas that should be highlighted: legal rights, safety from violence, economic security, health care, and gender stereotypes.

In the United States, women lacked fundamental legal rights we now take for granted until surprisingly recently. For example:

- In most of the antebellum period of U.S. history, women were commonly regarded as under the authority of men-fathers, then husbands—under a doctrine known as coverture. Married women could not sign contracts or 
control their earnings except under limited circumstances. As recently as 1971, banks could refuse women credit cards issued in their own names (Hill 2020).

- Of the 4.4 million African Americans in the United States in 1860, 4 million were enslaved, and slightly more than half were women (O'Neill 2019).

- As described in Chapter 4, higher education was largely closed to women through the mid-19th century. At that time, in most states married women were allowed to own but not control property unless their husband became incapacitated and even then they might be governed by a trustee.

- There was no national right to vote for women in the United States until the 19th Amendment was passed in 1920. Women did not have an equal right to men to serve on juries until 1966.

Violence against women includes domestic abuse, rape, human trafficking, assault, and murder. Men's control over women's bodies, enforced by violence, can be regarded as a defining element of patriarchy (Whisnant 2007).

- $\quad$ Enslaved women could be beaten and raped legally by their owners or forced into sexual relations with enslaved men, and in both cases their children were enslaved (Marable 2018, 63-64).

- Women are $43 \%$ more likely than men to experience "severe physical violence by an intimate partner (e.g., hit with a fist or something hard, beaten, slammed against something) at some point in their lifetime" (Black et al. 2011, 2).

- According to the 2010 National Intimate Partner and Sexual Violence Survey, nearly one in five women in the United States have experienced rape or attempted rape at some time in their lives; over $90 \%$ of the attackers were an acquaintance or intimate partner (Black et al. 2011, 1).

- $\quad$ A 2015 update to the National Intimate Partner and Sexual Violence Survey reported that " $43.6 \%$ of women (nearly 52.2 million) experienced some form of contact sexual violence in their lifetime" (Smith et al. 2018, 2).

- More than four in five American Indian and Alaska Native women (84.3\%), or more than 1.5 million women, have experienced violence in their lifetime, most by intimate partners (Rosay 2016).

- Until the second half of the 20th century, married men could not be prosecuted for raping their wives (Connerton 1997).

- In all areas of violent crime, women are three times more likely to be victims than offenders, and twice as likely to be murder victims than offenders (Federal Bureau of Investigation 2019).

- The United Nations estimates that in North America 85\% of victims of human trafficking and slavery are women and girls, 71\% of whom are trafficked for sexual exploitation (UNODC 2018, 71).

Until well into the 20th century, women were excluded from various careers and, as described in Chapter 5, women were encouraged generally to limit themselves 
to the private sphere of the home. Legal and cultural practices continue to disadvantage women's economic security.

- Prior to the passage of the Civil Rights Act in 1964, there was almost no protection against employment discrimination based on sex. Indeed, women routinely and legally were excluded from prestigious careers such as lawyers and doctors.

- Women continue to be paid less than men, earning about 81 cents for every dollar a man earns (Institute for Women's Policy Research 2018). According to the Center for American Progress, "women have higher rates of poverty than men across almost all races and ethnicities" (Bleiweis, Boesch, \& Gaines 2020). A report by the World Economic Forum found that the coronavirus pandemic has made matters even worse for women, setting back progress toward gender parity by decades (2021).

- A recent study of women in the U.S. workplace reports that while women represent $48 \%$ of entry level hires in corporations, they make up only $34 \%$ of senior managers and $21 \%$ of C-suite (executive) positions (Thomas et al. 2019).

More than half of the world's countries treat citizens' right to health care as a basic human right (Mull 2019). The United States is not one of them. Health care for women in the United States lags behind that for women in other countries in a number of respects.

- Epidemiologic research documents that women's lower income is correlated with worse health: "women suffer more than men from a host of nonfatal, disabling physical and mental illnesses and are generally expected to live fewer years in good health," despite living longer than men on average (Borrell et al. 2014, 31).

- The majority of health research has been androcentric, focusing mostly or only on men. As a result, scientific knowledge on how to prevent and treat many illnesses in women lags behind that for men, including in important areas such as cardiovascular disease prevention and diagnosis (Bird \& Rieker 2008, 9).

- Longer parental leaves contribute to better mental and physical health outcomes for mothers and infants (Borrell et al. 2014). Prior to the passage of the Pregnancy Discrimination Act in 1978, women could be fired for becoming pregnant and there was no national policy for parental leave until 1993's Family and Medical Leave Act. The United States is the only major industrial country that lacks a legal mandate for paid parental leave (OECD 2019).

- $\quad$ Reproductive health care includes access to birth control and safe abortions. In the United States, states could outlaw the sale of contraceptives until 1965 and abortions until 1973. Conservative state legislatures have advanced multiple 
policies designed to limit women's access to reproductive health care, including efforts to overturn Roe v. Wade (Stein \& Green 2019).

As described in Chapter 2, a major focus of the women's movement in the United States in the 1970s was to challenge the rigid gender norms historically imposed on women and men. Many of the effects of sexist beliefs and practices have been identified in the preceding paragraphs. While many sexist practices have been remedied, there is ample evidence of the continuing harms to women of sexist stereotypes. For example, women in leadership roles continue to have to navigate what Kathleen Hall Jamieson (1995) describes as double binds that have been confronting women for centuries:

- Women can conceive children or ideas, but not both.

- Women who speak their minds are immodest and will be described negatively, while women who are silent are ignored.

- Women are judged against an androcentric standard, and by that standard they lose, whether they claim difference (they fail to measure up) or similarity (they are no longer considered women).

- Women cannot be both feminine and competent.

- As men age they are perceived as gaining wisdom and power, but not so for women (more of a double standard than a double bind).

Though progress has been made toward feminism's primary goal of equality and an end to discrimination, the core tenets of sexism-summarized by Bem as androcentrism, biological essentialism, and gender polarization-persist. Feminists such as Beatrix Campbell argue that we live in an era of "neoliberal neopatriarchy" in which violence against women continues, body anxiety and self-hatred flourishes, rape is committed with impunity, sex trafficking thrives, and the struggle for equal pay continues (2014).

Clearly, much work remains for feminists and feminism(s) to address the sexism and oppression women face in the United States and across the world. ${ }^{6}$ But whom, exactly, do we mean by "women"?

\section{Feminists theorize "woman"}

French feminist Simone de Beauvoir famously proclaimed in Le Deuxième Sexe (The Second Sex): "On ne nait pas femme: on le devient" (1949, vol. 2, 13), which can be translated as "One is not born a woman; one becomes one." She continues, "No biological, psychic, or economic destiny defines the figure that the human female takes on in society; it is civilization as a whole that elaborates this intermediary product between the male and the eunuch that is called feminine" (Beauvoir 2011, 283). ${ }^{8}$

Beauvoir's point is a cultural and political one; namely, that women as a group have been defined, socialized, and subjugated as the Other, the "second" sex under 
patriarchy. In the 70-plus years since The Second Sex, many feminist thinkers have explored competing ways to theorize, categorize, or define "women." I cannot pretend to do justice to all the important work published on this topic, and I would refer readers to summaries by Toril Moi (1999), Mari Mikkola (2019), and Sally Haslanger and Ásta (2018). It is important to acknowledge that feminist philosophers approach the topic from different methodological and theoretical perspectives. Some want to answer to advance a theory of what it is to be a woman, per se, metaphysically speaking; others are interested in the conceptual work performed by the word "woman" as an analytical category, including its various social, theoretical, and political uses; while others want to produce what is known as a real definition, which is to give a theory of what X (woman) is - to explicate its nature. ${ }^{9}$ Thus my narrative oversimplifies matters by implying more commonality in purpose than is the case. I nonetheless hope that the following narrative assists the reader to understand enough of the theoretical controversies to comprehend why efforts to include (or exclude) transgender women have become so challenging. ${ }^{10}$

The Women's Liberation Movement began in earnest in the late 1960s in the United States and, from the start, wrestled with questions of who the "women" were that the movement represented. Did it include non-heterosexual females, for example? Betty Friedan, founding president of the National Organization for Women, famously described lesbians as a "lavender menace" in 1969 and feared that lesbian visibility in the movement would hinder its efforts to gain mainstream respectability (Jay 1999; Samek 2015). The breakthrough year for the movement in terms of national news coverage was 1970. As media scholar Bonnie J. Dow documents (2014), that coverage described a movement almost exclusively white and heterosexual.

Efforts to exclude lesbians from the Women's Movement did not last long. Friedan's term "lavender menace" was embraced by a group of lesbian feminists who protested at the 1970 Second Congress to Unite Women and presented a manifesto titled “The Woman-Identified Woman" (Radicalesbians 1970). The manifesto noted that for men, a lesbian is not considered a "real woman" since she is not sexually available to men, and called for a "revolution to end the imposition of all coercive identifications" (1970, 4). Meanwhile, as the manifesto title implies, if anyone counts as a woman, it would be woman-identified women, including lesbians.

While lesbians generally were welcomed into the movement in the 1970s, in 1978 Monique Wittig concluded a presentation at the Modern Language Association with the statement, "lesbians are not women" (Wittig 1992). Wittig's argument was that there is no "natural group "women"” and, in a 1981 essay invoking Beauvoir, suggests the category "woman" is a myth $(1992,10)$. Echoing the "The Woman-Identified Woman," Wittig points out that lesbians are treated as "unnatural" and hence not "real" women (12). But she claims the subject position of lesbian as liberating for that very reason: "Lesbian is the only concept I know of which is beyond the categories of sex (woman and man), because the designated subject (lesbian) is not a woman, either economically, or politically, or ideologically" 
(20). Jacob Hale returned to the question “Are Lesbians Women?" in 1996. He describes 13 defining characteristics described as "the dominant culture's concept of woman" $(1996,107)$. These include physical characteristics, such as "absence of a penis," social roles such as "having an occupation considered to be acceptable for a woman," "behaving" in a way people recognize as a woman, and self-identification: "having a gender identity as a woman." Hale thus answers his question: "Are lesbians women? Some are, some are not, and in many cases there is no fact of the matter" (1996, 115).

Discussion of the intersection of concerns of feminists with groups oppressed based on race and class also began in the 1970s (Hancock 2016). Members of the Combahee River Collective, for example, called attention to "interlocking" sources of oppression: "We are actively committed to struggling against racial, sexual, heterosexual and class oppression and see as our particular task the development of integrated analysis and practice based upon the fact that the major systems of oppression are interlocking" (Combahee River Collective 1977). The concept of intersectionality, as it is now most commonly called, highlights the fact that oppression experienced by heterosexual white middle-class women is different from oppression experienced by non-heterosexual, black, or poor women (Crenshaw 1989). Accordingly, feminists were challenged to understand how such factors as race, gender, and class affect the status of women (hooks 2014). As Mikkola puts it, "Feminists must be able to address cultural and social differences in gender construction if feminism is to be a genuinely inclusive movement and be careful not to posit commonalities that mask important ways in which women qua women differ" (2019).

As various positions on how to define "woman" emerged and were debated in feminist theory in the 1970s and 1980s, Linda Martín Alcoff provided a summary and analysis that was and continues to be influential. Alcoff described the debate between "cultural feminists" and "poststructuralist feminists" over the question of essentialism as presenting an identity crisis for feminist theory (1988, 2006). She describes feminist authors Mary Daly and Adrienne Rich, among others, as examples of cultural feminists, and concludes that the virtue of cultural feminismthe desire to valorize traditionally marginalized or neglected attributes of women, especially as caregivers - nonetheless reproduces an essentialist gender binary:

To the extent cultural feminism merely valorized genuinely positive attributes developed under oppression, it cannot map our long-range course. To the extent that it reinforces essentialist explanations of these attributes, it is in danger of solidifying an important bulwark for sexist oppression: the belief in an innate "womanhood" to which we must all adhere lest we be deemed either inferior or not " "true' women."

$(2006,139)^{11}$

Poststructuralist feminism, for Alcoff, overcorrects by embracing a philosophy of language that deems the category of "woman" a fiction that feminists should 
dismantle. In a poststructuralist framework, linguistic categories that construct and constrain our understanding of our identity and our "self" are wholly an effect of the dominant discourse. Thus there is no self, or autonomous subject, to be freed from oppression. Alcoff counts Michel Foucault, Jacque Derrida, and Julia Kristeva as the most influential writers in this vein (2006, 139-142). Alcoff's argument, put most simply, is that such a position amounts to feminism selfdestructing: "Poststructuralism thus threatens to deconstruct the feminist subject as well as the female subject, and thus threatens to wipe out feminism itself" (2006, 142).

As an alternative, Alcoff offers what she describes as positionality. Reproductive roles are especially visible phenomena that "positions" women and men quite differently. However: "Gender identity is not exhaustively determined by biology; it is not ahistorical or universally the same. Thus there is no gender essence all women share. But gender is, among other things, a position one occupies and from which one can act politically" (2006, 147-148, emphasis added).

Alcoff's account was published initially in 1988. Since that time, feminists have continued to debate over definitions or other ways to characterize "woman." Mikkola provides a recent summary of feminists who believe that "the articulation of an inclusive category of women to be the prerequisite for effective feminist politics" (2019). She suggests the various positions can be grouped as either "gender nominalist - positions that deny there is something women qua women share and that seek to unify women's social kind by appealing to something external to women," or "gender realist - positions that take there to be something women qua women share" (2019).

Nominalism as a philosophical approach eschews belief in universals or abstract entities such as Plato's Ideal Forms. With respect to the practice of definitions, a nominalist approach posits that we use words to group particular objects into meaningful categories. Thus, "woman" does not refer to a timeless essence of womanhood or womanness, but is a word we use to group together individual human beings in a meaningful way based on perceived similarity. Mikkola describes this category of feminist nominalists as sharing a belief in "resemblance nominalism" (2019). Such a position is consistent with the philosophy of language found in the later works of Ludwig Wittgenstein (1958), who argued that we learn to use certain words by being taught to perceive a "family resemblance" among particular instances of the category the word represents, though there may well be no attributes shared by all and only members of the category.

An example of a gender nominalist approach is provided by Natalie Stoljar (1995, 2011), who argues that the concept of gender is a cluster concept:

that is, there is a cluster of different features in our concept of woman and in order for an individual to satisfy the concept, it is sufficient (and necessary) to satisfy enough of, rather than all and only, the features in the cluster. 
Similar to Wittgenstein's description of family resemblance, Stoljar notes that "Women constitute a type on the basis of the (natural and social) similarities among the members of the type" $(2011,42)$.

Gender realists (generally) seek to identify real-world attributes to define members of a category. It might be useful here to revisit philosopher William James' comments about essentialism. As noted earlier, James argues that claims of "essence" are guided by human purposes that change over time, and "there is no property absolutely essential to any one thing"; rather, "the same property which figures as the essence of a thing on one occasion becomes a very inessential feature on another" $(1981,959)$. James's point is that which particular attribute is deemed "essential" is a matter of relative, not absolute, choice. For example:

A substance like oil has as many different essences as it has uses to different individuals. One man (sic) conceives it as a combustible, another as a lubricator, another as a food; the chemist thinks of it as a hydro-carbon; the furniture-maker as a darkener of wood; the speculator as a commodity whose market price today is this and tomorrow that. The soap-boiler, the physicist, the clothes-scourer severally ascribe to it other essences in relation to their needs.

$(1981,962 n)$

Thus, whether one embraces the term "essentialism" or not, how one defines "woman" depends on the definitive attribute(s) one considers most important. Earlier I quoted a developmental biologist who, for her purposes, defined females and males as "organisms producing sperm/eggs" since for her purposes the production of sperm or eggs (gametes) is "the key feature of biological sex" (Helm 2020). By contrast, feminist philosopher Sally Haslanger's approach is, in her terms, ameliorative; that is, her aim is to elucidate which gender concepts best help feminists achieve their purposes (Haslanger 2000). Accordingly, Haslanger emphasizes political status along with perceived biological role as the key definitive attributes:

$S$ is a woman iff dif and only if, by definition] $S$ is systematically subordinated along some dimension (economic, political, legal, social, etc.), and $S$ is "marked" as a target for this treatment by observed or imagined bodily features presumed to be evidence of a female's biological role in reproduction.

$(2003,6)$

Haslanger's approach is distinctive because it explicitly acknowledges the purpose of generating the definition, which is consistent with the pragmatic approach to definition I advocate. And she puts her cards on the table by identifying the attributes that she sees as most valuable and important for feminists to consider. More recently, Haslanger has taken what can be called a context-sensitive approach when she notes that "sex differentiation occurs within a framework of social meaning" 
and "because there are different frameworks of social meaning, different ways of drawing sex differences will be adequate to those frameworks" $(2016,134) .{ }^{12}$

Approaching the question of what counts as a "woman" from the standpoint of philosophy of language, Jennifer Saul describes a somewhat similar (pragmatic and context-sensitive) linguistic approach:

$X$ is a woman is true in a context $\mathrm{C}$ iff [if and only if] $\mathrm{X}$ is human and relevantly similar (according to the standards at work in C) to most of those possessing all of the biological markers of female sex.

(2012, 201, notes omitted)

Saul clarifies that by "biological markers" she is

referring to those traits commonly taken to be biological which are commonly associated with female sex. Which traits are actually biological, which traits are in fact associated with female sex, and what the terms "biological" and "sex" mean are matters of significant controversy.

(2012, 214)

To anticipate the next section of the chapter, I should note that Saul ultimately rejects this definition because it does not do justice to the "womanhood claims of trans women" (208).

Esa Díaz-León replied to Saul to advocate a contextualist approach that resonates with the pragmatic approach to definition taken in this book and my earlier work (Schiappa 2003):

My proposal, then, is that we should understand the relevant standards at issue in a context as those that are relevant for practical purposes (where these are broadly conceived to include theoretical, prudential, moral, political, and even aesthetic values). On this view, then, when someone utters a sentence of the form "X is a woman," that utterance will be true if and only if $\mathrm{X}$ is similar to most females with respect to the standards that are relevant in X's context, given the practical purposes that are relevant in this context, where this should be determined by our best theoretical and normative considerations.

$(2016,249)^{13}$

Ásta (formerly published as Ásta Sveinsdóttir) offers a contextual account of gender in which gender is a conferred social status. Sex and gender are social categories and in different contexts different attributes serve as possible base features for the conferral of gender (role in biological reproduction, sexual role, self-identification, etc.). Thus, for Ásta, "disputes over what it is to be a woman are disputes over what feature should be the base property for the conferral of the institutional or communal status woman in a particular context" $(2018,90)$. Ásta concludes that 
the question "what is a woman?" must be replaced with a context-specific question "who should be a woman?" (2018, 90).

Iris Marion Young tries to avoid the problems of essentialism by describing gender as seriality (1994). Because women are marked as women within their daily lives (a "milieu of action"), they form a social series or collective, conceptually independent of their intersectional particularities:

Each person's identity is unique - the history and meaning she makes and develops from her dealings with other people, her communicative interactions through media, and her manner of taking up the particular serialized structures whose prior history position her. No individual woman's identity, then, will escape the markings of gender, but how gender marks her life is her own.

(1994, 734)

Theodore Bach advocates an approach he describes as historical essentialism: "The essential property of women, in virtue of which an individual is a member of the kind 'women,' is participation in a lineage of women" $(2012,271)$. That is to say, for Bach, the most important attribute that should be used to delineate "woman" is that a particular example "must be a reproduction of ancestral women, in which case she must have undergone the ontogenetic [socialization] processes through which a historical gender system replicates women" $(2012,271)$.

Charlotte Witt suggests that gender is a "mega social role" that unifies and determines an individual's various social roles (2011). Because gender identity is "essential" to individuals' sense of normative unity, she describes her version of essentialism "uniessentialism" to distinguish it from other forms, including biological essentialism. She concludes: "gender is essential to social individuals because gender normatively unifies social role occupiers so that an individual social agent exists" $(2011,80)$.

Not all feminists agree that a shared definition or understanding of "woman" is necessary. Notably, Judith Butler (whose work is discussed in Chapter 2) suggests that feminists should understand "woman" as open-ended and "a term in process, a becoming, a constructing that cannot rightfully be said to originate or end. As an ongoing discursive practice, it is open to intervention and resignification" (1999, 43). She warns that the construction of the category of women "as a coherent and stable subject" could unwittingly reify gender relations in a manner "contrary to feminist aims" (1999, 9, see also 19-20).

As abbreviated at the preceding summary is, there are two aspects of the debate over "women" in feminist writing I wish to address before turning to the Transgender Exigency. First, the debate continues in part because that is what philosophers and theorists do. That is not meant as a criticism, but simply an acknowledgment that a) though superficially the scholarship is about the conceptualization of "woman," in some cases authors are asking somewhat distinct, refined questions that require different approaches to answer, and b) early feminist efforts to define 
"woman" were written without always considering transgender and DSD people, and feminists now are sincerely trying to enhance their accounts accordingly.

Scholars identify an important question and identify weaknesses with current answers in order to provide their own answer. So, for example, Lena Gunnarsson offers a defense of the category "women" from the standpoint of the philosophy of "Critical Realism" (2011) while Katharine Jenkins seeks to amend Haslanger's ameliorative approach (2016) and Ásta's conferralist approach (2020a). That is how scholarly knowledge grows and improves, and how academics become members of what John Frow calls the "knowledge class" (1995).

Second, there is no way to settle the matter once and for all. Definitions serve different interests and values and it is simply not the case that being a feminist guarantees complete alignment of those interests and values, especially when some of those interests are specific to academic subfields such as metaphysics, epistemology, or ethics. Furthermore, unlike the previous contexts described in chapters 4-8, there is no institution with the authority to impose a singular regulatory definition. Colleges and K-12 schools have the power to define who they will count as a woman for the purposes of admission. The NCAA has the power to define who counts as a woman or man for the purposes of competition. But no one is in a position of power to declare one feminist philosopher's definition to be "correct" and others wrong. In fact, philosophy thrives by keeping the argument open, which is the opposite of the sort of closure one seeks with a regulatory definition.

\section{The Transgender Exigency}

Talia Mae Bettcher begins her entry "Feminist Perspectives on Trans Issues" in the Stanford Encyclopedia of Philosophy with considerable understatement: "The relationship between feminism and transgender theory and politics is surprisingly fraught" (2020). Indeed. The debates described in the previous section were, for the most part, limited to scholarly books and articles that went through peer review and are written mostly in a decorous academic style. The debate concerning transgender women's place in feminism has becomes visible, messy, and arguably indecorous in the past decade as it spread to blogs and online forums, as well into popular, nonacademic, venues. ${ }^{14}$

Some of the earliest feminist reactions to transgender women (then referred to as transsexuals) were openly hostile. The primary objection was that transgender women did not count as real women-thus an implicit regulatory definition of "Only those born as female count as women for the purposes of the women's movement." This sentiment can be found in the Women's Movement of the 1970s. At a 1973 conference, Robin Morgan denounced a transgender woman (Beth Elliot) who was one of the conference organizers and unsuccessfully called for Elliot's expulsion: "If transvestite or transsexual males are oppressed, then let them band together and organize against that oppression, instead of leeching off women who have spent entire lives as women in women's bodies" (1973, 32; reprinted in Morgan 1977). She described Elliot as an "opportunist, an infiltrator," with the 
mentality of a rapist who operates by deception (1973, 32). Not long after, Mary Daly wrote in her influential Gyn/Ecology that, "Transsexualism is an example of male surgical siring which invades the female world with substitutes” $(1978,71)$.

Perhaps the best-known critique is found in Janice Raymond's The Transsexual Empire: The Making of the She-Male (1979). To make a long story short, the key definitional argument of the book is that sex is a matter of biology and biologymotivated socialization: "Maleness and femaleness are governed by certain chromosomes, and the subsequent history of being a chromosomal male or female" (Raymond 1979, 4). In Bettcher's assessment: "Raymond maintains that MTF transsexuals are really men and FTM transsexuals are really women" (2020). The key political argument of the book is that "transsexuals" reinforce "the foundation of sex-role oppression" (Raymond 1979, 18). The key to liberation is to transcend masculinity and femininity rather than replicate them (Raymond 1979, 164).

A preface added to Raymond's 1994 edition of the book updates her terminology with the word "transgender," but repeats her core criticism of those seeking to transition from male to female; namely, that the practice reinforces traditional gender stereotypes that perpetuate sexism:

if the outcome of such a sex reassignment is to endorse a femininity which, in many transsexuals, becomes a caricature of much that feminists have rejected about man-made femininity, then where is the challenge, the transgression, and the breaking of any real boundaries?

(1994, xiii-xix)

Raymond makes a point to try to avoid the charge of biological essentialism by stressing the distinctive history that cisgender women experience. As this is a point that other feminists share, it is worth quoting at length:

Affirming that transsexual surgery cannot change the basic biology of chromosomal sex is not to say that chromosomal sex defines gender. But in some very real senses, female biology shapes female history — a history that men don't have because of their sex-including the history of menstruation, the history of pregnancy or the capacity to become pregnant, the history of childbirth and abortion, the history of certain bodily cycles and life changes, and the history of female subordination in a male-dominant society.

$(1994, x x)$

There were occasional contexts where a regulatory definition was in place and enforced, such as the Michigan's Womyn's Music Festival. The festival was held annually from 1976 to 2015 and was restricted to "womyn-born womyn." The festival's founder, Lisa Vogel, explained that

The Festival, for a single precious week, is intended for womyn who at birth were deemed female, who were raised as girls, and who identify as 
womyn. I believe that womyn-born womyn (WBW) is a lived experience that constitutes its own distinct gender identity.

(Vogel 2013)

She rejected the idea that excluding transgender women was "transphobic" and suggested that other groups, including transgender women, could organize their own spaces: "I believe in the integrity of autonomous space used to gather and celebrate for any group, whether that autonomous space is defined by age, race, ethnicity, sexual orientation, ability, gender, class or any other identity" (2013). Thus, in addition to on-going philosophical and political debates taking place, there were physical contexts where transgender women were excluded.

In contrast to those who would exclude transgender women from the category of "women," some feminists offered definitions or frameworks that explicitly include transgender women. In the previous section I mentioned several examples, and to those examples I wish to add two more. The first is philosopher Naomi Scheman, who compares one's status as being a woman with the status of being a secular Jew $(1997,2016)$. Just as there are people born into the category "Jew," so are there people born into the category "woman" (1997, 144). Accordingly, just as one can convert to Judaism as a religion, Scheman believes one can analogically consider transgender women as converting to womanhood. Both subject positions have historically been the object of prejudice-misogyny for women, anti-Semitism for Jews. Transgender women are women not by some sort of strict definition, but from their family resemblance and their willingness to be in solidarity with cisgender women in the face of oppression: "The issue, then, is not who is or is not really whatever, but who can be counted on when they come for any one of us: The solid ground is not identity but loyalty and solidarity" (1997, 152-153).

The second example is Talia Mae Bettcher, perhaps the most prolific transgender philosopher writing today. Bettcher argues against the prevalent models for understanding transgender individuals, such as the "born in the wrong body" model, and wants to make room for transgender people who do, or do not, accept the traditional gender binary, as well as those who do or do not seek to transition surgically $(2013,2014)$. Self-identification as women by transgender individuals ought to be taken as the presumptive valid starting place for transgender theory and politics (2013, 245-246). Prioritizing "First-Person Authority" for transgender people (2009), Bettcher argues for a two-step definitional process. First, that "trans woman" applies "unproblematically and without qualification to all trans women," if she states she is a woman, regardless of whether there are surgical or hormonal changes in her body $(2013,241$, emphasis in original). Second, "being a trans woman is a sufficient condition for being a woman" (241). Recognizing that there are institutions (such as jail) that segregate sex in a biological essentialist manner, Bettcher describes a "multiple meaning" approach that distinguishes between woman-R ("women" in the resistant sense) and woman-D ("woman" in the dominant sense). Transgender oppression stems from a denial of the authenticity of self-identification and what she describes as "reality enforcement" when specific physical criteria 
(such as surgery) are used to "verify" one's status (2007). As long as reality enforcement takes place (and arguably, all regulatory definitions discussed in this book are types of reality enforcement), transgender people are typically viewed as deceivers and make-believers, a status that fuels transphobia and its attendant violence $(2007$, 2020).

Though most feminist theorists now support the inclusion of transgender women, there are exceptions. Susan Stryker and Bettcher describe a wave of backlash to the emergence of transgender rights within the last decade, in part fueled by feminists (2016). Some have come to be described as TERFs or Gender Critical Feminists. The term TERF stands for Trans-Exclusionary Radical Feminists and was (apparently) coined by feminist writer Viv Smythe in 2008 (Smythe 2018). Smythe simply wanted an abbreviated way to refer to what she considered transhostile rhetoric from some feminists, especially in the UK. Since that time, the TERF label took on sufficiently negative connotations that it has largely been replaced by those so identified with the phrase "gender critical feminists." For some, TERF is a "slur" that has been used as "hate speech," especially on social media (Dyess 2018). ${ }^{15}$ For others, gender critical feminists are a transphobic "cult" (Parsons 2020). The typically staid prose of academic philosophers has spilled into public debate and the arguments have grown quite heated at times.

A self-described group of "gender-critical and radical feminist academic philosophers," including Sophie Allen, Jane Clare Jones, Holly Lawford-Smith, Mary Leng, Rebecca Reilly-Cooper, and Kathleen Stock contend that women, "by definition, are adult human females" and thus, "no trans woman is correctly categorised as a woman" (2019). Philosopher Alex Byrne has published a series of articles titled by questions, which he answers in a manner consistent with "gender critical" theorists: "Is sex socially constructed?" No (2018). "What is gender identity?" The answer remains elusive (2019). "Are women adult human females?" Yes. Since "trans women are not female," they cannot be defined as women, simpliciter $(2020){ }^{16}$

Sheila Jeffreys published the most critical of the critical gender positions since Janice Raymond's The Transsexual Empire in her book, Gender Hurts: A Feminist Analysis of the Politics of Transgenderism (2014). Jeffreys argues that transgender women perpetuate the sort of gender-based stereotypes that second wave feminism sought to end:

Transgenderism depends for its very existence on the idea that there is an 'essence' of gender, a psychology and pattern of behaviour, which is suited to persons with particular bodies and identities. This is the opposite of the feminist view, which is that the idea of gender is the foundation of the political system of male domination.

$(2014,1)$

Jeffreys further argues that surgical transition and long-term hormone use are harmful to transgender people's bodies, and transition treatment for children and 
young adults, such as puberty blockers and hormone therapy, are akin to eugenics. Most salient to this project, Jeffreys joins other "gender-critical" feminists in criticizing efforts to open up women-only contexts to transgender women:

If women's services and spaces, which are fundamental to the possibilities of feminist revival in the present, are to continue or be created anew, then the right of women to gather without men, whether those are men who have transgendered or not, has to be promoted and respected.

$(2014,181-182)^{17}$

The debate has become so acrimonious that the critics sometimes have called for denying "gender critical" scholars a public platform, describing their speech as offensive and unacceptable (Goldberg 2014). There have been protests for providing a public platform for such philosophers as Kathleen Stock (ConkertonDarby et al. 2019) and one graduate student in philosophy announced that she was leaving academic philosophy because of its "transphobia problem" (t philosopher 2019).

One's standing as an icon of feminism has not prevented "no-platform" efforts. Germaine Greer, a major figure in Second-Wave Feminism and author of The Female Eunuch (1970), has expressed on occasion what she describes as an "opinion" that "M-to-F transgender people are [not] women." Going through surgery, she said, "does not make them a woman" (BBC News 2015a). Her views resulted in an unsuccessful Change.org petition to prevent her from speaking at Cardiff University in $2015 .{ }^{18}$ Greer's talk, titled "Women \& Power: The Lessons of the 20th Century," discussed "the suffragette movement, the 'nightmare' of the corporate world, equal pay, systematic sexual abuse of vulnerable girls and abortion" (Morris 2015). She did mention transgender issues, but when asked about the matter during Question and Answer she replied "They [trans people] are not my issue. It should be perfectly clear why not. I think $51 \%$ of the world's population is enough for me to be going on with" (in Morris 2015). When pressed on the fact that transgender people are being killed in the United States because of their status, she pointed to domestic violence that women experience: "We have two women a week being murdered in England by their partners" (Morris 2015).

The debate has been especially fierce in the UK because of efforts to broaden the terms of the Gender Recognition Act of 2004. As noted last chapter, under that law, transgender persons can obtain a "Gender Recognition Certificate" (GRC) if they are 18 or over, have been diagnosed with gender dysphoria, have lived in an "acquired" gender for at least two years, and intend to live in that gender for the rest of their life (Gov.UK 2020). The law was groundbreaking as a nation-wide effort to provide transgender people legal recognition. Nonetheless, the law was criticized by transgender activists as making it too difficult and costly to get a GRC, and by the government's own estimates fewer than 3\% of transgender people in the UK have obtained a GRC (Mordaunt 2018). ${ }^{19}$ The government provided an 
opportunity for citizens to comment on proposed changes that would rely on selfidentification and received over 108,000 responses. This period of consultation spurred at least some gender critical feminists to weigh in against self-identification being codified into law (see, e.g., Stock 2018). In September 2020, the Boris Johnson administration announced it had taken steps to make GRCs less expensive and easier to obtain, but set aside the self-identification measure that Theresa May's administration had favored (Truss 2020). The decision was condemned by transgender rights advocates and welcomed by "gender critical" women's groups (Anonymous [The Economist 2020).

In September 2020 the Manchester Centre for Political Theory held their 17th annual Workshops of Political Theory, and it included a program titled "What is gender and what do we want it to be?" The program included a number of papers that revisit the question of defining "woman" and the implications for transgender women. It is safe to assume that feminist theorists and philosophers will continue to explore the question of how to define "women."

\section{Conclusion}

It would be an act of extreme hubris to pretend I have anything approaching a solution to the debate within feminism about how to define "woman." I agree with those, such as Mari Mikkola, who advocate giving up "the quest" as it has generated "an analytical impasse that looks unsurpassable" (2019). Philosopher Richard Robinson describes the "What is X?" form of question as "the vaguest of all forms of questions" and rejects the impulse to generate a single, correct, "real" definition in response to "What is X?" questions $(1950,190) .{ }^{20}$ His stance resonates with Richard Rorty's pragmatism, which rejects the notion of a "final" philosophical vocabulary with which to describe the world and argues that we have no choice but "to face up to the contingency of the language we use" $(1989,9)$. Our linguistic categories are made, not found, and how they are made is driven by our needs and interests (Schiappa 2003).

In a retrospective essay about her "Queering the Center" essay, Scheman suggests that the continuing debate has "too often been waged as though one or another side needs to win, with an insistence that what should emerge is a single, unitary, clear, and precise definition of what it is to be a woman," which she argues is both impossible and undesirable $(2016,215)$. She concludes with a call for mutually respectful coalitions:

rather than trans women's arguing that there is some core meaning of woman that as a matter of fact includes them, or defiantly claiming the right to self-identify as women freed from any shared social understanding of what that means, there is more political hope in arguing against the currently normative understandings of gender (understandings that - of course for different reasons - cis-female feminists deplore) and struggling to find plural but 
interrelated coalitional understandings that do justice to the wide range of gender's discontents.

Scheman's call for respectful coalitions resonates with Butler's call for contingent coalition building: "Certain political practices institute identities on a contingent basis in order to accomplish whatever aims are in view. Coalitional politics requires neither an expanded category of 'women' nor an internally multiplicitous self that offers its complexity at once" (Butler 1999, 22).

There may be no way to broker peace with those who treat transgender people as irredeemable, such as Raymond (1979), Jeffreys (2014), and, in the case of transgender men, Lothstein (1983). ${ }^{21}$ Setting that sort of extremism aside, I agree with Judith Butler's recent "wager" that "most feminists support trans rights and oppose all forms of transphobia" (Ferber 2020). Relatedly, I am confident that most feminists recognize that solidarity is a stronger political strategy than division. I began this chapter with a summary of how women have been discriminated against, continue to be oppressed, and are too frequently victimized by violence. As described in Chapter 3, transgender people-especially transwomen of color-are also victims of discrimination and violence. It is that commonality that provides the basis for coalition building and solidarity. As Butler puts it, "we have to renew the feminist commitment to gender equality and gender freedom in order to affirm the complexity of gendered lives as they are currently being lived" (Ferber 2020).

In reporting the UK government's decision not to implement self-identification for Gender Recognition Certificates, The Economist quotes professor of law Rosa Freedman as saying "we need a legal definition of four things: woman, female, sex and gender identity" (Anonymous 2020). As argued throughout this book, however, such a uniform legal definitional approach fails to recognize the competing needs and interests served in different definitional contexts, let alone the history that informs such contexts. As discussed in more detail in the final chapter of this book, the considerations involved in deciding who gets to attend a singlesex school, or which bathroom we use, or where one is housed in jail, or who competes with whom in sports, are all quite different. That is why those feminists who advocate a more pragmatic and contextual approach to definition have, in my opinion, the best chance of articulating definitional criteria that recognize our mutual humanity while also respecting the differences that mark us as historical, social creatures.

\section{Notes}

1 t philosopher (2019).

2 Serano $(2007,347)$.

3 Chappell (2019).

4 In Fischel $(2019,89)$. 
5 I pluralize feminism to respect the fact that there are a number of feminist theories and movements, so diverse that it is "impossible to talk about feminism in terms other than the plural"; thus, "We can say that all feminists agree that women suffer social and/ or material inequities simply because of their biological identity and are committed to challenging this, but the means by which such challenges might be made are many and various" (Pilcher \& Whelehan 2004, 48-49).

6 The preceding paragraphs focus on the U.S. since that is the focus of the book. While in the U.S. women have freedoms not enjoyed by women in some countries that deny women the right to vote, work, or even drive, overall the U.S. does not compare worldwide as favorably as the typical American might think. For a brief comparison, see Ravitz (2015).

7 Translation suggested by my colleague Bruno Perreau. The sentence is translated by Borde and Malovany-Chevallier as "One is not born, but rather becomes, woman" (Beauvoir 2011, 283) and by Parshley as "One is not born, but rather becomes, a woman" (Beauvoir 1979, 259).

8 "Aucun destin biologique, psychique, économique ne définit la figure que revêt au sein de la société la femelle humaine; c'est l'ensemble de la civilisation qui élabore ce produit intermédiaire entre le mâle et le castrat qu'on qualifie de féminin" (Beauvoir 1949, vol. 2, 13). NB: There are a number of early printings of the book and in some versions this famous passage appears near the end of volume 1 ; in others, near the start of volume 2. For some scholars, such as noted feminist theorist Judith Butler, Beauvoir here is introducing the distinction between sex and gender in a manner consistent with later authors (Butler 1986). But in other comments Beauvoir seems to tie her definition of "woman" to anatomy (Byrne 2020, fn 11) and the matter is complicated by the fact that the French word sexe can be translated either as "sex" or "gender."

9 I discuss the problems with the idea of "real definitions" in my earlier book on definitions (Schiappa 2003, Chapter 3).

10 My summaries in this chapter are abridged to the point they run the risk of reproducing what historian Leslie Butler calls "glib assumptions of continuity or genealogy" (2012, 169). I can only plead "no contest" to the charge and hope that my narrative is helpful even if it is the proverbial tip of a fascinating and complex historical iceberg.

11 It is often overlooked that some cultural feminists saw gay men as part of the enemy rather than as allies, as they are more typically depicted in contemporary feminist scholarship. Adrienne Rich, for example, decried the culture of homosexual men as "patriarchal" and "tainted by profound hatred for women" $(1979,225)$. On the complex history of gay men and feminist women, see Scott (2020).

12 Arguably, Haslanger's later formulation is compatible with her earlier definition because there she was defining "woman" for the purposes of feminist activism.

13 For a response to Saul's and Díaz-León's contextualism that describes "polysemy ambiguity theory," see Laskowski (2020). Zeman (2020) also engages Díaz-León's to identify areas that may be usefully explored further.

14 For an account of the ways in which-especially in the UK - the scholarly debate has become public, see the special issue of The Sociological Review titled "TERF Wars: Feminism and the fight for transgender futures" edited by Ben Vincent, Sonja Erikainen, and Ruth Pearce (2020).

15 Dyess wrote an oft-cited essay titled "TERF Is Hate Speech and It's Time to Condemn It" in 2018 but has since come to regret the post and describes gender critical feminists as homophobic, transphobic extremists (Parsons 2020).

16 Byrne's paper, "Are women adult human females?" (2020) has been responded to by Dembroff (2021); see also Byrne's reply (2021).

17 For critiques of Gender Hurts see Bresser (2016), Bucur (2017), and Johnston (2014).

18 A counter-petition was also created on Change.org in support of Cardiff's hosting of Greer that obtained over 3,000 signatures. On the topic of deplatforming or censuring critical gender authors, see also 12 Leading Scholars (2019) and Lance (2019). 
19 In September 2020, the Minister for Women and Equalities claimed that "of those who had completed their transition, around 2 in 5 said that they had a Gender Recognition Certificate, a higher proportion than is often believed" (Truss 2020). It is unclear how many people that proportion represents, since those who have completed transition represents an unspecified fraction of those who consider themselves transgender.

20 Not all contemporary philosophers would agree. See, for example, Rosen (2015).

21 Lothstein pathologizes female-to-male "transsexuals" and opposes sex-reassignment surgery: "No matter how entrenched the child's cross-gender identity and role, every effort should be made to treat the problem psychologically, identify the current stressors (and removing them) and prescribing long-term intensive psychotherapy" $(1983,306)$. 
$\because$ Taylor \& Francis

Taylor \& Francis Group

http://taylorandfrancis.com 


\section{PART III}

What now? 


\section{Transgender voices}

"Although I think the Utopian ideal of a genderless society is perhaps interesting, I don't think it sounds like a society I'd like to live in. I like gender, I just don't like the amount of meaning we attach to it. What if gender carried no more meaning than color. What if I wore masculinity today in the same way I wore the color green?"

Anonymous $^{1}$

"During the late 1990s shortly after my transition I had called up a male dean at Harvard and asked him if Harvard could change my degree to the women's college, Radcliffe. 'Oh, I don't think we can do that.' 'But the U. S. State Department,' I whined, 'had no trouble changing my passport from male to female.' Pause. Then with a smile in his voice, 'Yes. But Harvard is older than the U.S. Department of State.'

Goodness. Some things never change."

\section{Deirdre Nansen McCloskey²}

"It is dangerously naïve to assume that men would never self-declare as women with nefarious motives. Most men probably wouldn't, but those who might are the ones that cause concern. Women's boundaries are hardly secure if they have to rely on the assumption that men wouldn't do that, would they?"

Debbie Hayton, teacher and author ${ }^{3}$

"As a matter of public policy, it is important to recognize that there are some single-sex contexts where we need to set some bar to assess eligibility beyond self-identification. The question is where the line is going to be drawn. We also need to be careful to proceed in a manner that does not erase gender self-identification altogether-without which it is hard for the concept of transgender to exist."

Jami K. Taylor ${ }^{4}$ 


\section{0}

\section{A PRAGMATIC APPROACH TO DEFINING SEX/GENDER}

Ask yourself how you would define the category "human." Aristotle was the first in Western philosophy for whom there is extensive evidence documenting efforts to answer such a question and, like many who followed, he focused on how to distinguish humans from other animals based on our linguistic and rational faculties. In Joanna Bourke's important historical survey, she describes many efforts to define what it means to be human, noting at the outset that "It turns out that the concept 'human' is very volatile. In every period of history and every culture, commonsensical constructions of 'the human' and 'the animal' exist, but the distinction is constantly undermined and re-constructed" (2011, 13). Reaching a consensus on how to define "human" is quite difficult: "conventional distinctions between human and nonhuman animals are applied inconsistently, or are simply wrong. Is intellectual ability the crucial criterion? Or self-consciousness? Or the possession of a soul? Or toolmaking? Or private property? Or genetic inheritance?" (15).

In Defining Reality, I argue that new definitions should be thought of as prescriptive and theory-bound $(2003,49-68)$. That is, a new definition is a proposal for how we ought to use a term in the future. And definitions depend on a set of beliefs about the world that can be described as a theory. Paul T. Sagal suggests that asking "what is $[\mathrm{x}]$ questions" is tantamount to asking for a "rigorous, consistent, complete theory" that would include "an implicit definition of x" (1973, 446-447). For those reasons, efforts to define "human" are competing theories that are informed by specific beliefs about the world, including biological, psychological, economic, political, legal, and religious beliefs. The beliefs considered most important or valuable to a thinker will be the ones that influence which traits of human beings are deemed most "essential" or definitive. As needs, interests, and values change over time, so do theories of what is human. And those theories have proven to have important implications for answering such crucial questions as: Are women persons? Are the enslaved human? Do animals have rights? (Bourke 2011). 
Given how difficult it is to define "human," it should come as no surprise that it is equally challenging to define "woman" and "man." That is, if it seems impossible or at least implausible to determine a "final" definition of "human" that meets all potential stakeholders' needs and interests, then it seems straightforward to accept Rebecca Solnit's claim that "There is no one-size-fits-all definition of what a woman [or man] is" (2020). On one hand, a too-narrowly tailored biological definition erases transgender, nonbinary, gender-fluid, and DSD people and perpetuates biological essentialism — a key source of sexist prejudice throughout much of history. On the other hand, pure autonomous nominalism-gender-fluid self-identification unfettered by time or place-denies the possibility of legitimate concerns in specific sex-segregated contexts, as described in Part II of this book. Once we set aside the need for a one-size-fits-all set of definitions, then we are able to look at issues such as who should have the power to define, whose interests are being served, and above all the purpose a given definition is serving in a specific context.

In my earlier book on definitions, I argued that when we are faced with a definitional rupture the "What is X?" question needs to be replaced with questions such as, "How ought we use the word X given our needs and interests?" "What is the purpose of defining X?," and "What should count as X in context C?" I advocated a pragmatic approach that sees definitions as made not found, and treats the definitional process as one involving important ethical questions of values, interests, and power. This book has been an effort to apply such an approach to competing definitions of sex and gender emerging in the 21st century amid what I have described as the Transgender Exigency.

\section{Defining with purpose}

The first theme of this conclusion is that we need to define with purpose. The purpose in defining sex/gender can vary significantly in different contexts. When I asked college-aged Anastazy, who identifies as a nonbinary transgender man, how they fill out paperwork that asks about gender, they replied that it depended on the context:

If it's for something that isn't medical related, I put male. For medical stuff I put female since it's what my body is, and it makes sure that I can get the most care I need. If things were my way, there would be a section where you could fill in the blank. That way it is easier for each person to explain their gender, and it takes some of the stigma away of being trans.

(Anastazy 2020)

The challenge of defining sex/gender for transgender patients in medical contexts is underscored by a tragic case recounted in the New England Journal of Medicine when a transgender man was admitted into the emergency department with lower abdominal pain (Stroumsa et al. 2019). "Sam" (a pseudonym) 
had not transitioned surgically, though he had previously been taking testosterone and presented as a man. Sam was, in fact, pregnant. He had had a positive result with a home pregnancy test that morning, and despite the fact that the triage nurse ordered a pregnancy test (a serum hCG test), she "did not incorporate that possibility [of pregnancy] into the differential diagnosis in a way that would affect ensuing classifications and triage decision making"; as a result, he was not treated with the urgency that his and the baby's health required. A team of doctors analyzing the case after the fact concluded that "the triage nurse did not fully absorb the fact that he did not fit clearly into a binary classification system with mutually exclusive male and female categories": A cisgender woman with the same symptoms would have been "directed to urgent obstetric evaluation" (Stroumsa et al. 2019). Sam was not treated immediately and lost the baby due to undiagnosed umbilical cord prolapse. Doctors concluded that "earlier evaluation might have resulted in detection of the cord prolapse in time to prevent fetal death" (Stroumsa et al. 2019).

The challenge is not solely a matter of definition, but also to advance supportive and understanding attitudes and behaviors toward transgender people in all contexts, especially when it relates to issues of health and safety. A more flexible and pragmatic approach to understanding sex/gender would encourage us to think about our identities as multifaceted, such that no tension is felt between saying I am a man and (not "but") medically you need to check me for pregnancy.

Such flexibility is not easy to put into practice. Aside from proper names, language cannot function without categories. For those categories to "work," they have to be shared and there has to be some level of what I have described as "denotative conformity." Categories succeed by excluding; that is, one's understanding of X typically requires one to understand what is not-X. Much early language acquisition depends on learning prototypical exemplars of what "counts" as an X, and being corrected by more experienced language users when we "overextend" a category — by counting an orange as a ball, say_ or "underextend" a category — by not counting a football or wiffle ball as a ball (Schiappa 2003, 11-29).

However, once a category gains wide acceptance, people adopt the "natural attitude" toward it; that is, we take the category as "given" (rather than socially constructed) and that is when all sorts of problems can emerge, including essentialism, reductionism, and-in the case of categories of people-stereotypes and prejudice. Think of this cycle as the category paradox. That is, we benefit from categories as necessary tools to make sense of reality, but the same cognitive functions that make shared categories socially useful (learning to recognize attributes of category $\mathrm{X}$ and to exclude not-X attributes) often carry the price of forgetting that categories are made not found, revisable and contingent social constructions rather than fixed realities. Ron Mallon calls this "the reification problem": the "mistaken belief in the naturalness of a category can be one of the mechanisms by which the category is sustained" $(2016,216)$.

In the past 50 years, there has been growing recognition that the categories of "woman" and "man" are socially constructed, but what do we do with that recognition? Ian Hacking in his useful book The Social Construction of What? describes 
six gradations of social constructionist commitment: Historical, Ironic, Reformist, Unmasking, Rebellious, and Revolutionary. These gradations begin with the modest acknowledgment that a particular category $\mathrm{X}$ is a product of history: "Someone presents a history of $X$ and argues that $X$ has been constructed in the course of social processes. Far from being inevitable, $X$ is the contingent upshot of historical events" $(1999,19)$. At the other end of the spectrum are activists: "An activist who moves beyond the world of ideas and tries to change the world in respect of $X$ is revolutionary" (1999, 20). Hacking correctly observes that with respect to "gender," one finds the whole range of responses evident:

As our consciousness about gender is raised, some of us find our attitudes moving along from historical to ironic to reformist, and then to unmasking the function of gender relations. With the mask removed, we become rebellious; a few become revolutionary.

$(1999,20-21)$

The ongoing social and political conflicts surrounding transgender issues suggest that, as a society, we are far from all being on the same page as far as how much of the world we are willing to change when it comes to sex/gender. At a minimum, I argue it is crucial that we collectively gather at the ironist/reformist stage. Hacking acknowledges that his label "irony" is informed by Richard Rorty's description in Contingency, Irony, and Solidarity (1989). Hacking notes: "Irony about $X$ is the recognition that $X$ is highly contingent, the product of social history and forces, and yet something we cannot, in our present lives, avoid treating as part of the universe in which we interact with other people, the material world, and ourselves" (1999, 20). Having acknowledged the historicity of sex/gender categories, we can do our best to improve those categories — a stance described by Hacking as Reformist: We may

have no idea at present how to live our lives without $X$, but having seen that $X$ was not inevitable, in the present state of things, we can at least modify some aspects of $X$, in order to make $X$ less of a bad thing. This is reformist constructionism.

$(1999,20)$

For example, a strong reformist element can be seen in recent decades in the scholarship concerning the category of masculinity. We have come a long way from treating masculinity as an essential part of being a man. Instead, today masculinity is more likely to be seen as a historically and culturally contingent set of beliefs, attitudes, and behaviors, or even an ideology. Indeed, since 2000, an academic journal has been dedicated entirely to the Psychology of Men \& Masculinity. Scholars have moved from treating masculinity as unidimensional to multi-dimensional (see Chapter 2), with a variety of measures of masculine norms in use. Moreover, important work by psychologists has investigated the harms of certain forms of 
masculine role socialization, generally studied under the rubric of Gender Role Conflict (GRC). ${ }^{6}$ As of 2015, there have been 350 studies of GRC (O'Neil 2015, 4). Masculine norms are changing in the United States, a fact that underscores the historical and cultural contingency of gender norms: "More than ever before, men are being allowed to be vulnerable, emotional human beings. This transition is hopeful and important, but painfully slow" (O’Neil 2015, 10).

Attitudes and beliefs about gender can now be thought of as ideology - that is, a set of culturally specific political beliefs. "Traditional Masculinity Ideology" (TMI) describes masculine norms that harken back to the time before the questioning of gender roles in the 1970s, including toughness, avoidance of femininity, negativity toward sexual minorities, dominance, and restrictive emotionality. TMI is rooted in "patriarchal, Western, heteronormative, and traditional perspectives of men" (Levant \& Richmond 2016). Of course, one does not need to be born and raised male to embrace Traditional Masculinity Ideology, or to act on such ideology. ${ }^{7}$

To summarize the argument thus far: We are past the point where it is possible to stipulate a one-size-fits-all definition for male/female or woman/man. There is simply no good alternative to recognizing that sex/gender categories must be treated pragmatically. That is, in specific contexts we need to decide whether sex/ gender is even necessary to reference. When there are good reasons to do so, we need to define with purpose. Just as our contexts vary (for example, from a dating site to a doctor's office), so too will the purpose of defining.

As I noted at the beginning of this book, I believe that self-identification, or first-person authority, should be presumptive. "Presumptive" does not mean absolute and unfettered, however. As feminist philosopher Naomi Scheman, cited in the last chapter notes:

while it may often be just fine for me-as it ought to be just fine for a trans woman-to identify simply as a woman, it's not solely up to me to determine when and why it might not be just fine: judgments of importance or appropriateness are not solely mine to make

(2018, 188)

So how do we make decisions about which contexts require something more-in particular, a regulatory definition? That is the question pursued in the next section.

\section{When might self-identification not be enough? The imperfect analogy with race}

Before I turn specifically to the issue of regulatory definitions impacting transgender people, I want to discuss another definitional challenge that may serve as a useful though imperfect analogy. ${ }^{8}$ In particular, I want to consider what has been described as transracialism, hereafter referred to as trans-r. ${ }^{9}$ Trans-r people claim a racial identity for themselves that differs from what can be called their "birth race." The most infamous recent example is Rachel Dolezal, a woman of white ancestry 
and who identified as black and "passed" as black, at one point leading the Spokane, Washington, branch of the NAACP before she was "outed" as white in 2015.

Dolezal is not the only self-identified trans-r person in recent history. German model/actress Martina Adam (or "Martina Big"), who now goes by the name Malaika Kubwa, was born white but underwent dermatological treatment to darken her skin and now claims an African identity (Big 2020). Jessica A. Krug was a professor of history and Africana Studies at George Washington University who revealed on September 3, 2020 that she was born to white parents but had been passing as a black woman throughout her professional life (Lumpkin \& Svrluga 2020). I shall return to Krug's case below, but since her revelation, at least one other white person has confessed to similar efforts to pass as non-white (Vee 2020).

In 2017, prompted by sympathetic media coverage of Caitlyn Jenner and negative coverage of Rachel Dolezal, philosopher Rebecca Tuvel published "In Defense of Transracialism," in which she suggests that "similar arguments that support transgenderism support transracialism" (2017, 275n). Tuvel's essay was not the first philosophical paper to explore such a thesis (see Heyes 2006; Overall 2004), but the publication of her essay in the leading journal of feminist philosophy ignited an academic firestorm. It is not necessary for the purposes of this project to review (let alone resolve) the various issues of contention involved. ${ }^{10}$ The threads from the academic discussion of Dolezal's case that I want to draw attention to are those that reflect the need to triangulate among three issues: Who has the right to define, the purpose of defining, and specific contexts.

Prior to Tuvel's intervention, a group of philosophers informally tackled the question of how to react to Dolezal's claim to be black. The conundrum facing philosophers was and remains to reconcile the widely shared belief that "race" is a social construct and a "biological fiction" with the fact that race often has been used as a tool of prejudice and oppression. As columnist Courtland Milloy put it, "Race is a biological fiction, a concept with no basis in anatomy. It is a myth, pseudoscience, a fraud, a social con job" (2018). Nevertheless, racism persists. As philosopher Kwame Anthony Appiah puts it,

Much of the elaborate scientific superstructure that grew up around race was dismantled in the past century. . . . But the world outside the sciences hasn't taken much notice. Too many of us remain captive to a perilous cartography of color.

$(2018, x v)^{11}$

Thus, Dozenal's case compels theorists to specify how race can be invoked, by whom, and to what purpose. Philosopher Esa Díaz-León acknowledges that race is a social construction, but suggests that two important definitional attributessocial position within a social hierarchy, and shared historical properties - serve "crucial" explanatory roles, "such as explaining a history of racial discrimination and revealing different social structures of oppression." Based on those two sets of attributes, Díaz-León concludes that "it's not clear at the moment that a concept 
of race based (solely) on self-identification is politically useful to a similar extent" (in Weinberg 2015). In a similar vein, Meena Krishnamurthy suggests that the key definitive attribute should be ancestry, which again would challenge the ability to self-identify one's race:

Ancestry is the appropriate basis for referring to people as "black" because it tracks politically relevant considerations such as oppression and slavery (historical political injustices), which are considerations that ought to be given weight to and taken into consideration when we interact with others in the public sphere. This is what self-respect and a just society require.

(in Weinberg 2015)

Note that these philosophers are not making a metaphysical argument about what race "really is," but rather are identifying attributes that they consider "essential" for the pragmatic purposes of social justice. Such an approach resonates with William James's claim (quoted earlier) that "The essence of a thing is that one of its properties which is so important for my interests that in comparison with it I may neglect the rest" $(1981,961)$. Thus, for the purposes of defining race with an eye toward recognizing the historical injustices associated with racism, historical practices and status (including enslavement) are vitally important, and thus should take priority over claims of self-identification. ${ }^{12}$

Similarly, analytic philosopher Quayshawn Spencer notes that the category of race has practical implications in various institutional policies and regulations, and thus a shared definition of race and honesty about ancestry advances goals of social justice:

So, why does any of this matter? Well, one reason is because linguistic competence and honesty about one's racial membership(s) is presupposed in the execution of many social programs designed to promote social justice. For instance, the preferential treatment of Blacks in college admissions and faculty hiring, the federally-mandated racial tracking of mortgage loan borrowers, the [FBI's] racial tracking of hate crimes, and the Department of Health and Human Services' racial tracking of health disparities all rely on Americans being linguistically competent and honest about their racial membership(s) in census racial discourse.

(Spencer, in Weinberg 2015) ${ }^{13}$

Thus, the situation with race and self-identification, as these philosophers see it, is not unlike the approach described in this book with respect to sex/gender. Yes, in most contexts, people can and should be able to identify themselves as they wish. Once that identity is declared in practical or institutional contexts that involve the cooperation of others, however, we are dealing with a social identity that requires social recognition, sometimes negotiation, and if the stakes are high, definitional regulation. In the cases where white academics passing as non-white 
were discovered, the individuals were criticized because they had received material resources to support their work that could have otherwise gone to Black or Latino scholars. In Jessica Krug's case, she lost a tenured faculty position at George Washington University after she was revealed as white and it was learned that she had misrepresented her upbringing as stereotypically non-white and impoverished, such as falsely claiming her parents were addicts and her mother was a sex worker (Wamsley 2020).

On March 22, 2021, the city of Evanston, Illinois, approved a program for local reparations for Black residents, initially focusing on housing. The program "acknowledges the harm caused to Black/African-American Evanston residents due to discriminatory housing policies and practices and inaction on the City's part," and offers financial compensation. Consistent with what the philosophers cited earlier advocate, the program's definitions focus on ancestry, and define "Black or African-American" as "A person having origins in any of Africa's black racial and ethnic groups" (City of Evanston 2021). Similarly, William A. Darity, Jr. and A. Kirsten Mullen, authors of From Here to Equality: Reparations for Black Americans in the Twenty-First Century (2020), argue that two conditions are "critical" for determining eligibility for reparations: "[R]ecipients must have at least one ancestor who was enslaved in the United States"-a requirement consistent with other definitional approaches—and, interestingly, "recipients also must show that they self-identified as Black, Negro or an equivalent designation on an official document for at least 12 years before a reparations program was set in motion" (Mullen \& Darity 2021).

\section{When might regulatory definitions be desirable?}

Returning to the issue of definition with respect to gender, what might be gleaned from the previous discussion of self-identification and race? Put most simply, there need to be compelling reasons to impose a regulatory definition. Activist-scholar Heath Fogg Davis argues in his book, Beyond Trans: Does Gender Matter?, that "all of us would be better off in a society with dramatically fewer sex-classification policies" $(2017,17)$. I agree with the thesis that we do not need regulatory definitions for sex/gender unless a legitimate purpose is being advanced in specific contexts. Davis describes in an appendix and a companion Workbook how to perform a "gender audit exercise" that is intended to encourage gender-inclusive design strategies $(2017,151-157,2018 a) .{ }^{14}$ For example, the dominant practice of sex-segregated restrooms has the stated purpose of ensuring privacy and safety, but properly designed all-gender restrooms could advance such purposes without discriminating based on sex/gender and avoiding the consequences of people being "policed" based on their appearances and gender-based assumptions.

I wish to take Davis's idea of a gender audit a step further to think about a framework for thinking about how and when regulatory definitions of sex/gender are appropriate. Such an approach is consistent with that taken in the UK, where the Equality Act of 2010 permits actions involving sex segregation, including with 
respect to gender reassignment if such acts are "a proportionate means of achieving a legitimate aim" (2010, 150). This notion of proportionate means achieving legitimate aims is pursued in the next section operationalized as "levels of scrutiny."

The United States does not have an Equality Act akin to the UK's Equality Act of 2010, though one has passed in the U.S. House of Representatives (H.R.5 Equality Act). H.R.5 is an act "To prohibit discrimination on the basis of sex, gender identity, and sexual orientation." The bill defines gender identity as follows: Sec. 1101(a) “(2) GENDER IDENTITY.-The term 'gender identity' means the gender-related identity, appearance, mannerisms, or other gender-related characteristics of an individual, regardless of the individual's designated sex at birth." The bill as currently drafted has been criticized in part because of the obvious circularity of the definition of gender identity — “ " gender identity' means the gender-related identity" - and the absence of any sort of framework or regulatory definitions for adjudicating claims for contexts in which sex/gender based segregation may be relevant (as explored in Part II of this book). ${ }^{15}$ In its current form, the Equality Act is unlikely to be approved by the U.S. Senate (AP 2021b; Burns 2021). It is likely that passage will require some sort of pragmatic framework or wording similar to the UK's Equality Act (allowing sex segregation if such acts are "a proportionate means of achieving a legitimate aim”).

It may be recalled from the previous chapters that a number of regulatory definitions for sex/gender have been used or proposed. The simplest way to describe self-identification as a regulatory definition would be: Anyone who self-identifies at the moment as a woman/man $(\mathrm{X})$ counts as a woman/man $(\mathrm{Y})$ in this context $(\mathrm{C})$. Note that there is no temporal requirement of duration stipulated. Most contexts that still prefer sex segregation (for specific contextual reasons) add the requirement of duration, either past or future, such as some of the single-sex schools discussed in Chapter 4: Anyone who consistently lives and identifies as a man/woman (X) counts as a man/woman (Y) in the context of applying to this institution (C). "Lives as" is somewhat open-ended, but in the context of a single-sex school, one's future intentions are salient, and presumably one must transition socially, including using gender-specific pronouns and names.

Some contexts, such as bathrooms in states without the so-called bathroom bills, function with an implicit regulatory definition: People perceived as a male/female (X) counts as a man/woman (Y) in the context of public bathrooms and changing facilities (C). In many non-institutional settings, the only social "requirement" is that one passes. While there may not be "official" sanctions for not-passing, there is a threat of violence that all too many transgender people must contend with. Note that with the single-sex school example, the student has the presumptive power to define herself or himself. As we move to more restrictive regulatory definitions, that power shifts as decisions are a negotiated outcome with others.

Some regulatory definitions attempt to recognize transgender individuals but require more than self-identification, such as the military's requirement for an "official" diagnosis of gender dysphoria. Some institutions defer the authority to define to "official" (i.e., medical or governmental) agencies, such as Anyone who is 
legally recognized as a woman/man (X) counts as a woman/man (Y) in this context (C). Such approaches sometime stipulate the birth certificate as the controlling official document, which is why the ability to amend one's birth certificate is so important to transgender people.

Some regulatory definitions require one either to be receiving hormone therapy and/or undergo surgical reassignment to pass the requirements of a specific definition, such as in elite sports, prisons, or to obtain legal identification in some jurisdictions. Some biology-based regulatory definitions, including that previously advanced by the Trump administration, are intended to ignore the possibility of transgender and DSD people, such as Only those assigned the sex female/male at birth $(\mathrm{X})$ counts as women/men $(\mathrm{Y})$ in this context, or Only those with male/ female chromosomes count as male/female $(\mathrm{Y})$ in this context.

The point is that regulatory definitions range from easy to extremely difficult to satisfy. The argument I am advancing with different levels of scrutiny is a simple one: The more onerous the regulatory definitional requirements, the stronger the justification must be.

\section{Levels of scrutiny}

I advocate an approach analogous to that found in U.S. constitutional law known as different "levels of scrutiny" applied to laws and regulations that restrict individual freedom. ${ }^{16}$ Deference here is to individual freedom, and it is the institution involved that must meet increasingly higher levels of scrutiny as more restrictive regulatory definitions are proffered. It may be useful here to describe the levels of scrutiny recognized in U.S. constitutional law before explaining how I adapt them as levels of scrutiny specific to the regulatory definitions of sex/gender.

Erwin Chemerinsky, Dean of the University of California, Berkeley, School of Law, notes in his influential textbook on constitutional law that "In a sense, the level of scrutiny provides instructions for balancing. It informs courts as to how to arrange the weights on the constitutional scale in evaluating particular laws" (2015, 789). The lowest level of scrutiny is known as the Rational Basis Test. This test holds that government action is permissible as long as it is "rationally related" to a legitimate government purpose. So, for example, state laws that set a minimum age to obtain a driver's license in fact "discriminate" against those younger than the minimum age, but have been supported by the courts because such laws serve a legitimate purpose of public safety. This level of scrutiny sets a very low bar for government regulation as it is presumed that laws have a rational basis; as a result, it has been invoked very rarely by the Supreme Court to invalidate a law or regulation. ${ }^{17} \mathrm{I}$ include the Rational Basis Test only in the interest of contrasting it to the other two levels of scrutiny, which will be far more relevant to the framework I advocate concerning regulatory definitions of sex/gender.

The next level of scrutiny is known as Intermediate Scrutiny. As Chemerinsky states, "Under intermediate scrutiny, a law will be upheld if it is substantially related 
to an important government purpose" (2015, 790, emphasis in original). The wording may seem only subtly different than what I just described as the Rational Basis Test, but note the substitution of two key words - substantially for rationally, and important for legitimate. The idea is that when Intermediate Scrutiny is applied, the stakes are acknowledged as higher, so the burden of proof is increased on the government and justification must be correspondingly stronger. For example, the First Amendment to the U.S. Constitution states that Congress shall make no law abridging freedom of speech, but over the years a number of government restrictions have been permitted by the Supreme Court, such as regulation of commercial advertising, when the justification is substantially related to an important purpose.

A more relevant set of Intermediate Scrutiny cases are those in which the Supreme Court has reviewed regulations based on sex. It was not until 1971 that the Supreme Court first struck down a classification based on sex (Chemerinsky 2015, 1086). Before that time, laws that prohibited women from becoming attorneys, from voting, or that restricted women's ability to work as bartenders, were upheld with the logic of what we now call the Rational Basis Test. In a series of cases in the 1970s, the Court wrestled with what the appropriate level of scrutiny should be with respect to sex classifications, vacillating between Rational Basis and Strict Scrutiny. Finally, in the 1976 case of Craig v. Boren (429 U.S. 190), the Court described what is now labeled Intermediate Scrutiny when it struck down an Oklahoma law that set different ages at which men and women could purchase alcohol, proclaiming that to survive constitutional challenge, "classifications by gender must serve important governmental objectives and must be substantially related to those objectives" (197, quoted in Chemerinsky 2015, 1092). In the important case of United States v. Virginia (518 U.S. 515 [1996]) the Court declared the exclusion of women by the Virginia Military Institute unconstitutional. Justice Ruth Bader Ginsburg applied Intermediate Scrutiny and declared that parties "who seek to defend gender-based government action must demonstrate an exceedingly persuasive justification for that action. . . The burden of justification is demanding and it rests entirely on the State" (515, quoted in Chemerinsky 2015, 1093).

It should be noted that the Court looks closely at the purpose of sex/gender classifications. Restrictions based on gender role stereotypes are not allowed, but classifications "benefitting women designed to remedy past discrimination and differences in opportunity generally are permitted” (Chemerinsky 2015, 1097).

The final and highest level is Strict Scrutiny, under which "a law will be upheld if it is necessary to achieve a compelling government purpose" (Chemerinsky 2015, 791, emphasis in original). Again, the stakes are raised with the terms necessary and compelling. The government action under scrutiny must be shown to be the only way to achieve a crucial and vital purpose. The first case applying Strict Scrutiny was the 1944 decision of Korematsu v. United States (323 U.S. 214), challenging the constitutionality of segregation and internment of all persons of Japanese ancestry from certain parts of the U.S. The decision was the first to apply Strict Scrutiny to government actions based upon racial classifications. Though the Court ruled that 
the need to protect against espionage (the case took place during World War II) outweighed the rights of Americans of Japanese descent, the application of Strict Scrutiny would become an important legal tool in the future against laws discriminating based on race.

To be clear, I am not trying to map my framework for thinking about levels of scrutiny concerning regulatory definitions of sex/gender exactly onto the levels of scrutiny found in U.S. constitutional law. My hope by describing these levels is to facilitate thought and discussion that promotes greater nuance than an either/or choice of autonomous nominalism and biological essentialism.

Given the values and interests explicated in the chapters in Part II, a brief description of the levels can be described as follows:

Level Zero:

Self-Identification is definitive. No need for documentation as self-declaration is sufficient. No temporal constraints; that is, ephemeral status or nonbinary status always acceptable. Examples: Non-institutional social settings, including bathrooms.

Level One:

There is a rational basis, grounded in history, served by sex segregation in this context. Self-identification is sufficient, but may require commitment to live as a gender not necessarily assigned at birth. Social transition required but not medical transition. Example: Single-sex schools.

Level Two:

Intermediate scrutiny: There is an important value or set of values served by sex segregation in this context that requires a documented condition of gender dysphoria and/or a durational criterion to "count" as a gender other than that assigned at birth. Examples: Interscholastic sports, Military, Prisons.

Level Three:

Strict scrutiny: Sex segregation advances an important interest that can only met through meeting specific durational and medical transitional criteria. Example: Elite Competitive Sports.

My placement of different contexts within specific levels is intended to reflect the current rationale (values and interests) for sex/gender segregation as identified in Part II. They are not necessarily a reflection of my personal preferences, nor are they intended to be definitive. Rather, this account is offered as a heuristic framework to stimulate thinking and discussion about regulatory definitions concerning sex/gender in a manner that acknowledges the proposition that as the institutional context changes, so do the stakes. 


\section{Personal identification}

The various forms of identification we routinely use that carry a designation of sex/gender is an example of implicit regulatory definitions at work. As Heath Fogg Davis notes, "[ $\mathrm{t}]$ he government agencies that issue and administer our sex-marked birth certificates, driver's licenses, and passports never define the terms 'sex' or 'gender',' thus how the terms are defined and applied imply rather than spell out specific definitional criteria $(2017,29)$. Formally defined or not, having a name or sex/gender designation on one's ID that is at odds with one's transgender identity can lead to serious difficulties, thus obtaining a name change on documentsnot only government-issued documents but items like bank accounts, academic record, leases, paychecks, etc.- - is an important step for many transgender people (National Center for Transgender Equality 2016a). Thus, the Department of State's announcement on June 30, 2021 that it plans to permit self-identification of gender on passports is significant and noteworthy (Blinken 2021).

The sheer complexity of the matter - the many different jurisdictions and myriad types of IDs and documents involved-prevent more than cursory treatment here. As noted transgender activist and political theorist Paisley Currah observes, "The state is not a singular entity, defined by structure or function, but an array of agencies, legislatures, and courts relying on practices, laws, and norms that operate-often at cross-purposes — at every level of government" (in Fischel 2019, 89). The result is a variety of different regulations and policies to determine, for example, when an individual may change their designated sex on official records:

$[F]$ or these various apparatuses of governing, sex was malleable, dependent on the particular remit of the agency. Sex was not a property to be classified according to some ideal, but rather something to be defined based on what it accomplished for a particular governing rationality.

(in Fischel 2019, 90)

Davis argues that such designations are not necessary for the purpose of government-issued IDs, and he questions whether there is a legitimate government interest "in collecting and recording sex-identity information about us" $(2017,48)$. The pragmatic approach advocated here suggests that sex-identity information on IDs should be limited to contexts where a legitimate purpose is served. If there is no such legitimate purpose, then self-identification should be presumptive, ceteris paribus. If all else is not equal and there is some pressing reason to impose a regulatory definition, then the levels of scrutiny described here would obtain.

An example of such pragmatic reasoning is a recent Federal District Court decision in Corbitt v. Taylor that struck down policy order 63 of the Department of Public Safety in Alabama that specifies people's genitalia must be used to determine the sex indicated on their driver's license. Only transgender people who can document that they have undergone gender reassignment surgery were allowed to change the sex indicated on their driver's license. This requirement functions as a regulatory 
definition since it defines "sex" based on the physical attribute of genitalia. The requirement imposed substantial burdens on transgender people who could not afford or did not desire such surgery, since it required them to "bear a driver license with a sex designation that does not match the plaintiffs' identity or appearance" (Thompson 2021, 7). The court noted, "carrying licenses with sex designations that do not match plaintiffs' physical appearance exposes them to a serious risk of violence and hostility whenever they show their licenses" (8).

As the framework of levels of scrutiny I have described indicates, the more onerous the definitional criteria, the more compelling the institution's rationale must be. And indeed, requiring surgical reassignment is the most onerous requirement possible. In this case, the court explicitly applied "heightened scrutiny" since sexbased classifications were involved. The court ruled that Alabama's rule failed to meet such a standard, because their "interests are insubstantial or were formulated post hoc, and because the policy is inadequately tailored to advancing them" (10). Such state interests as administrative convenience and consistency between procedures to change birth certificates and driver licenses were considered inadequate.

Another justification offered by the state for policy order 63 was to facilitate identification by law enforcement, specifically for booking and search purposes. The court rejected this rationale for two reasons. First, the reason was offered post hoc, after the fact, and there was no evidence that such a purpose was considered when policy order 63 was first created (34-36). Such post hoc rationalizations are not sufficient to pass heightened levels of scrutiny. Second, no evidence was offered "showing how a license with a sex designation that differs from the license-holder's appearance could help officers confirm that the license matches the driver" (40). Indeed, the court noted that the "record suggests that licenses denoting the licenseholder's genital status are wholly unhelpful for this purpose" (40).

The court's reasoning in Corbitt $v$. Taylor nicely illustrates the pragmatic approach to regulatory definitions advocated in this book. The definitional rule imposed by policy order 63 was "People with male (or female) genitals $(\mathrm{X})$ count as male (or female) (Y) in the context of applying for an Alabama driver's license (C)." Requiring evidence of surgical reassignment to "count" as female or male falls under what I have described as Level Three strict scrutiny, and I see no reason to disagree with the court's assessment that it fails even a lesser, intermediate level of scrutiny. The harms caused by such a requirement outweigh the stated benefits and thus fail on pragmatic grounds. One can take the argument one step further, as Fogg does, to question whether or not state driver licenses need a sex classification marker at all (2017), since other information on the license, including the photo, can serve the pragmatic purposes of identification.

\section{The future of defining sex/gender}

It should be clear by now that the definitions of the words "sex" and "gender," "female" and "male," "man" and woman," are in varying degrees of flux. Obviously, context matters. Most of the time and in most places, people use the words 
"sex" and "gender," "female" and "male," "man" and woman" without confusion or fear of contradiction. Usage of such terms typically displays a high degree of denotative conformity. With increasing frequency, however, what would appear to be a straightforward question can turn into a definitional rupture that requires us to consider the purposes and processes of definition itself: Is this person a man or a woman in this particular context? It depends on how we define the words man and woman, which in turn depends on our purposes and interests. When definitions are deployed by institutions with the power to enforce them, they become regulatory definitions that deserve critical examination as policy proposals. Once we set aside the impossible myth of a "one size fits all" definition, then it is possible to appreciate the importance of considering the specific values and interests advanced by competing definitions in specific contexts. The same can be said about methods of definition. That is, self-identification is one method of determining whether an individual is male, female, or gender nonconformist, requiring the use of chromosome analysis is another. Each approach advances different values and interests that can-and should-be evaluated according to the context in which definition occurs.

"Nothing About Us Without Us" is a phrase that can be traced back centuries. Nihil novi literally means "nothing new" but as early as 1505 was associated with the Polish political doctrine Nihil novi nisi commune consensus - nothing new without common consent (Rzegocki 2019). In vernacular Polish this became Nic o nas bez nas, "nothing about us without us." "No taxation without representation" is, of course, an early U.S. version of the sentiment. "Nothing About Us Without Us" became known in the U.S. initially as a key theme of the disability rights movement. In fact, Nothing About Us Without Us was the title of two important books on disability rights published in 1998 (Charlton; Werner); both of which advocated for self-representation and control over the objectives of the disability rights movement.

The principle has been put to good use in a variety of other social movements, including by transgender activists and scholars. ${ }^{18}$ Sasha Constanza-Chock's Design Justice (2020) identifies "Nothing About Us Without Us" as a core commitment for design practices aimed at social change. The point is straightforward: Regulatory definitions can be thought of as tools we create to advance values and interests in specific institutional contexts. An important part of the pragmatic approach to definition I advocate is to consider such questions as who has the right to define and whose interests are served by competing definitions. Given the complexity of the issues described in the preceding chapters, the construction of regulatory definitions necessarily requires both trans and cis people to be at the table. ${ }^{19}$

The U.S. legal process - by which I include legislative and judicial actions-has and will continue to wrestle with these issues. I recognize that some supporters of full gender freedom will take a dim view of the sort of legal incrementalism this book describes (see, for example, Spade 2015), but I concur with Isaac West's argument that our best chance for social progress is not to withdraw from institutions of power and authority but to engage in "impure" politics, for "they are the only 
politics available for those who want to engage strangers in the quest for recognition and justice" $(2014,191)$. Writing in a similar key, Paisley Currah advocates efforts toward incremental reform as well as pursuing long-range efforts to deconstruct regulatory roles based on sex/gender classifications. ${ }^{20}$ In his words:

The short-term objective of recognition in order to alleviate the material problems of misclassified individuals in the here and now, and a long-term project that is necessarily less identitarian and more universalist, that looks at how sex classification figures into the reproduction of capital, race, and nation.

(in Fischel 2019, 95)

Though the Supreme Court majority decision in Bostock v. Clayton County in 2020 claimed to be using a conventional understanding of the word "sex" to decide that discrimination on the basis of sexual orientation or sexual identity violated Title VII's proscriptions against employment discrimination based on sex, it is almost certain that the question of defining "sex" is an issue the Court will need to reckon with again, and at greater depth (see Eskridge, Slocum, \& Th. Gries 2021). The historical situation facing the Court is, of course, symptomatic of the larger cultural pattern of needing to adapt our language use to evolving circumstances. As critical rhetoric scholar John Sloop notes, referencing Judith Butler, we find ourselves as part of a long struggle "in which our commonsense understandings about gender, sex, and sexuality are disarticulated and rearticulated in more contingent arrangements - arrangements that help increase those "possibilities for a livable life' for everyone" $(2004,148)$. Consistent with the sort of pragmatic ironist approach to language advocated here, Sloop concludes: "Literalization and deliteralization, freedom and constraint, each must, in different ways and in different critical moments, continue to be a part of the overall critical project" (149).

As the famed philosopher W. V. O. Quine noted, "Our patterns of thought or language have been evolving, under pressure of inherent inadequacies and changing needs, since the dawn of language; and, whether we help guide it or not, we may confidently look forward to more of the same" $(1969,24)$. The Transgender Exigency is just such a moment when our changing needs require an evolution of our patterns of thought and language. Beginning at an ironist/reformist stage of analysis with something like the tiered scrutiny I have advocated strikes me as a prudent step toward that evolution.

\section{Notes}

1 Quoted in McCreide (2012, 127).

2 McCloskey $(2019,277)$.

3 Hayton (2018). Hayton is a controversial figure and was criticized for wearing a t-shirt that said "Trans Women Are Men. Get over it!" (Hellen 2019). My inclusion of her quotation is not an endorsement of her views, but simply an effort to illustrate the range of transgender voices addressing the issues discussed in this book. 
4 Taylor (2021).

5 In the process of describing the "instability of definitions of who is truly human," Bourke notes that "the human" is "most commonly marked as male" (Bourke 2011, 13-14). Androcentrism has a long, long history that, combined with biological essentialism and gender polarization, has defined women's place as subordinate to men's (Bem 1994). See also Grimshaw (1986, 104-138).

6 GRC is defined as "a psychological state in which socialized gender roles have negative consequences for oneself or others" (O'Neil 2015, 10). An example of a harm to oneself would be the socialized resistance to asking for help or care when one needs it; an example of harm to others is when masculine socialization includes anti-gay beliefs and attitudes.

7 Multiple studies affirm that both men's and women's endorsement of traditional (or "hegemonic") masculinity was a strong predictor of support for Donald Trump for president both in the 2016 and 2020 elections (Vescio \& Schermerhorn 2021).

8 Brubaker (2016) notes that analogical reasoning in the case of transracial and transgender issues has been criticized, but I agree with him that race and gender are "systems of social classification with distinctive yet in some ways converging logics that can fruitfully be compared" (11).

9 I use the construction trans-r because the term "transracial" has been used primarily by those in the adoption community to refer to describe parents who adopt a child of a different race. As Kevin H. Vollmers, Executive Director of Gazillion Strong, notes: "Many members of the White press have appropriated and co-opted a deeply meaningful, historical term - transracial-from the adoptee community" (Wang 2015).

10 For a modest sampling of the discussion Tuvel's article sparked, see Botts (2018), Gordon (2018), Mc Manus (2019), Russell (2019), Sealey (2018), and Tuvel's response to her critics (2018). For an update on her position, see Tuvel (2021).

11 Not all scientists agree that race is a fiction, and some argue for the continued utility of racial categories. See Morning (2011, 2014), Torres (2020), and Yudell (2014).

12 Joshua Glascow, Sally Haslanger, Chike Jeffers, and Quayshawn Spencer collaborated to produce the book What is Race? Four Philosophical Views (2019). The authors nicely illustrate the point that one cannot ask "what is $\mathrm{x}$ ?" questions in a vacuum. The question of "what is race?" is coherent only once there is at least some agreement as to what the purpose of definition is, what interests are being served, and who should have the right to define. Not surprisingly, the book includes passages devoted to the Dolezal case.

13 Kenneth Prewitt argues that the U.S. Census should eventually phase out questions on race and ethnicity, but acknowledges that there is political utility for racial categories for certain public policies, despite their flaws, and that "color-blind arguments" sometimes are deployed "to buttress a conservative challenge to race-sensitive social justice policies (2013, 143).

14 See also the guide to inclusion by Chaudhry (2018).

15 Callie H. Burt offers a "feminist examination of definitional changes and sociolegal ramifications" of the current wording of the Equality Act and offers seven recommendations, including the suggestion that "we maintain the legal distinction between sex and gender" (2020). Several fellow sociologists wrote critical responses, to which Burt replied (2021). It is beyond the scope of this book to try to sort through the debate, though it should be obvious by this point that I believe there are some contexts in which self-identification without even a minimal durational requirement is problematic.

16 Coleman describes a similar approach that is "is based in well-established antidiscrimination law and requires attention to inherent biological differences, institutional mission, and the closeness of the means-ends nexus" $(2017,125)$. Her primary focus is on sex classification in sports, but as she notes, it could be applied to other contexts where segregation by sex is "mission critical."

17 Interestingly, the Massachusetts Supreme Judicial Court in Goodridge v. Department of Public Health (798 N.E.2d 941[Mass. 2003]) ruled that precluding same-sex marriage 
violated the Massachusetts constitution and that none of the reasons for forbidding same-sex marriage could survive even the low bar of the rational basis test (Schiappa 2012b).

18 See, for example, Lindberg (2017), Lynn (2017), and Scheim et al. (2019). The principle is sometimes extended to apply to scholarly writing concerning transgender people, which is why I have done my best to consult with trans scholars and friends throughout the writing of this book. If it is the case that there is no longer a one size fits all definition of sex/gender as this book has argued, then to be truly "about us all" it would benefit both cis and trans scholars to work arm in arm.

19 As Costanza-Chock puts it, "Analysis of political power in the design process-who sits at the table, who holds power over the project, what decision-making process is usedwill be fundamental to the successful future articulation of design justice in theory and practice" $(2020,107)$.

20 Currah's position is worth quoting at length: "As an activist, I have no problem using the language of rights and recognition in particular contexts. I pulled up every old saw about belonging and popular sovereignty in meetings with legislators. I have sat on agency advisory committees and worked with officials to change standards for sex reclassification, relying heavily on a medical model in the process (although a model that uses the authority of medical knowledges to argue against requiring body modification for sex reclassification). As a political theorist, I have suggested that the goal of recognition leaves intact the power of state actors to decide who gets what, and that ending the ability to use sex to distribute resources, rights, and privilege should be a priority for the movement. I have labored to understand, at the most mundane and micro levels of governmentality, what sex is doing and how that doing is imbricated with other systems of social stratification. I hold both positions simultaneously and don't see them as incommensurate" (in Fischel 2019, 95). 


\section{REFERENCES}

12 Leading Scholars. 2019. "Philosophers Should Not Be Sanctioned Over Their Positions on Sex and Gender." Inside Higher Education (July 22). www.insidehighered.com/ views/2019/07/22/philosophers-should-not-be-sanctioned-their-positions-sex-andgender-opinion

Abbott, Gary. 2016. "Alaska’s Michaela Hutchinson was First Girl to Win State Title against Boys.” TeamUSA.org (March 13). www.teamusa.org/USA-Wrestling/Features/2016/ March/13/Michaela-Hutchison-becomes-first-to-win-boys-state-meet

Abrams, Roger I. 2010. Sports Justice: The Law \& the Business of Sports. Boston: Northeastern University Press.

Adam, Seth, \& Matt Goodman. 2015. "Number of Americans Who Report Knowing a Transgender Person Doubles in Seven Years, according to new GLAAD Survey." Press Release (September 17). www.glaad.org/releases/numbern-americans-who-reportknowing-transgender-person-doubles-seven-years-according-new

Ainsworth, Claire. 2018. "Sex Redefined: The Idea of 2 Sexes is Overly Simplistic." Scientific American (October 22). www.scientificamerican.com/article/sex-redefined-theidea-of-2-sexes-is-overly-simplistic1/

Alcoff, Linda Martín. 1988. "Cultural Feminism versus Post-Structuralism: The Identity Crisis in Feminist Theory." Signs: Journal of Women in Culture and Society 13.3: 405-436. . 1991. "The Problem of Speaking for Others." Cultural Critique 20: 5-32. Press.

— et al. 2019. “On Philosophical Scholarship of Gender: A Response to'12 Leading Scholars'." Blog of the American Philosophical Association (August 7). https://blog. apaonline.org/2019/08/07/on-philosophical-scholarship-of-gender-a-responseto-12-leading-scholars

Ali, Diana. 2019. "The Rise and Fall of the Bathroom Bill: State Legislation Affecting Trans and Gender Non-Binary People." National Association of Student Personnel Administrators (April 2). https://naspa.org/blog/the-rise-and-fall-of-the-bathroom-bill-state-legisla tion-affecting-trans-and-gender-non-binary-people 
Alison, Eric, \& Helen Pidd. 2015. "Second Transgender Prisoner Found Dead in Male Jail." The Guardian (December 1). www.theguardian.com/society/2015/dec/01/secondtrans-prisoner-joanne-latham-apparently-takes-own-life-in-male-jail.

Allen, Arenda L. Wright. 2019. Order. Gavin Grimm v. Gloucester County School Board, U.S. District Court for the Eastern District of Virginia (August 9).

Allen, Sophie, Jane Clare Jones, Holly Lawford-Smith, Mary Leng, Rebecca Reilly-Cooper, \& Kathleen Stock. 2019. "Doing Better in Arguments about Sex, Gender, and Trans Rights.” Medium.com (May 23). https://medium.com/@kathleenstock/doing-betterin-arguments-about-sex-and-gender-3bec3fc4bdb6

American Medical Association (AMA). 2019. "Press Release: AMA Adopts New Policies on First Day of Voting at 2019 Annual Meeting." (June 10, 2019). Retrieved March 28, 2020 from www.ama-assn.org/press-center/press-releases/ama-adopts-new-policiesfirst-day-voting-2019-annual-meeting

- 2021. "Press Release: AMA to States: Stop Interfering in Health Care of Transgender Children.” (April 26). www.ama-assn.org/press-center/press-releases/amastates-stop-interfering-health-care-transgender-children

American Psychological Association. 2011. "Definition of Terms: Sex, Gender, Gender Identity, Sexual Orientation." The Guideline for Psychological Practice with Lesbian, Gay, and Bisexual Clients. Retrieved June 7, 2013 from www.apa.org/pi/lgbt/ resources/sexual ity-definitions.pdf.

- 2012. "Guidelines for Psychological Practice with Lesbian, Gay, and Bisexual Clients." American Psychologist 67.1: 10-42. https://doi.org/10.1037/a0024659.

Anastazy. 2020. Personal Interview (April 30).

Andrew, Scottie. 2021. "Lawmakers in 14 States Have Proposed Anti-LGBTQ bills, Many of which Target Trans Youth." CNN.com (January 27). www.cnn.com/2021/01/27/us/ anti-lgbtq-bills-2021-trnd/index.html

Angel, Buck. 2019. "I was Born Biologically Female. . .." Twitter (December 23). https:// twitter.com/BuckAngel/status/1209236297140834304

Anonymous. 2019. “Transgender Prisoners: A Tough Cell.” The Economist (March 9), 430.9133: 22.

- 2020. "Britain's Gender Recognition Act Won't Change." The Economist (September 26). www.economist.com/britain/2020/09/26/britains-gender-recognition-actwont-change

AP (Associated Press). 2019. "High School Athletes File Complaint over Transgender Policy." NBC News (19 June). www.nbcnews.com/feature/nbc-out/high-school-athletesfile-complaint-over-transgender-policy-n1019306

_. 2021a. "Judge Tosses Suit that Sought to Block Transgender Athletes." APNews.com (April 25). https://apnews.com/article/connecticut-courts-gender-identity-lawsuitshigh-school-sports-e881f5a74c82b931650142dee0e59fd3

— 2021b. "Prospects Dim for Passage of LGBTQ Rights Bill in Senate." NBCNews. com (May 10). www.nbcnews.com/nbc-out/out-news/prospects-dim-passage-lgbtqrights-bill-senate-rcna879

Appiah, Kwame Anthony. 2018. The Lies That Bind: Rethinking Identity. New York: Liveright Publishing.

Arthur, Vice Admiral Donald C., Major General Gale Pollock, Rear Admiral Alan M. Steinman, Nathaniel Frank, Diane H. Mazur, \& Aaron Belkin. 2018. DoD's Rationale for Reinstating the Transgender Ban is Contradicted by Evidence. San Francisco: The Palm Center.

Ascione, Alfred M. 1977. Opinion in Richards v. United States Tennis Association, 93 Misc. 2d 713; 400 N.Y.S.2d 267 (August 16). 
Ásta. 2018. Categories We Live By: The Construction of Sex, Gender, Race, and Other Social Categories. New York: Oxford University Press.

Bach, Theodore. 2012. "Gender is a Natural Kind with a Historical Essence." Ethics 122.2: 231-272.

Bade, Rachael, \& Josh Dawsey. 2017. "Inside Trump's Snap Decision to Ban Transgender Troops." Politico.com (July 26). www.politico.com/story/2017/07/26/trump-trans gender-military-ban-behind-the-scenes-240990

Bakker, Julie. 2018. "Brain Structure and Function in Gender Dysphoria." Endocrine Abstracts 56: S30.3. www.endocrine-abstracts.org/ea/0056/ea0056s30.3

Baldor, Lolita C. 2017a. "Mattis Delays New Transgender Policy for US Military." Military Times (June 30). www.militarytimes.com/news/pentagon-congress/2017/07/01/ mattis-delays-new-transgender-policy-for-us-military/

- 2017b. "Pentagon to Allow Transgender People to Enlist in Military." AP news. com. https://apnews.com/ad450a96c6e245668ed96e0f2bb4e145/APNewsBreak:-Trans gender-people-can-enlist-in-military-Jan-1

Banks, Cyndi. 2003. Women in Prison: A Reference Handbook. Santa Barbara: American Bibliographic Center-CLIO.

Barnard College. 2019. "Transgender Policy." https://barnard.edu/transgender-policy

Barnes, Barry. 1982. T. S. Kuhn and Social Science. New York: Columbia University Press.

Barrett, Frank, et al. 2006. Financial Analysis of "Don't Ask, Don't Tell": How Much Does the Gay Ban Cost? A University of California Blue Ribbon Commission Report. University of California. www.palmcenter.org/wp-content/uploads/2018/11/Blue-RibbonReport.pdf

Barroso, Amanda. 2019. "The Changing Profile of the U.S. Military: Smaller in Size, More Diverse, More Women in Leadership." Pew Research Center (September 10). www.pewre search.org/fact-tank/2019/09/10/the-changing-profile-of-the-u-s-military/

—. 2020. “61\% of U.S. Women Say 'Feminist' Describes them Well.” Pew Research Center. https://pewrsr.ch/2DjsXV4

Battle, Sandra, \& T. E. Wheeler. 2017. "Dear Colleague Letter.” (February 22). www.jus tice.gov/crt/page/file/942021/

Baumgartner, Frank R., Jeffrey M. Berry, Marie Hojnacki, David C. Kimball, \& Beth L. Leech. 2009. Lobbying and Policy Change. Chicago: University of Chicago Press.

BBC News. 2002a. "Transsexual Loses Birth Certificate Battle." (June 20). http://news.bbc. co.uk/2/hi/uk_news/england/2055626.stm

_. 2002b. “Transsexual Wins Right to Marry.” (July 11). http://news.bbc.co.uk/2/ hi/uk/2122094.stm

—. 2015a. "Germaine Greer: Transgender Women are 'Not Women'." BBC News (October 24). www.bbc.com/news/av/uk-34625512

- 2015b. "Transgender Woman Tara Hudson Moved to Female Prison." BBC News (October 30). www.bbc.com/news/uk-england-34675778.

Beauvoir, Simone de. 1949. Le Deuxième Sexe. Paris: Gallimard.

. 1979. The Second Sex. Translated by H. M. Parshley. Franklyn Center, PA: Franklyn Library.

- 2011. The Second Sex. Translated by Constance Borde and Sheila MalovanyChevallier. New York: Vintage Books.

Beck, Allen J. 2014. Sexual Victimization in Prisons and Jails Reported by Inmates, 2011-2012:

Supplemental Tables: Prevalence of Sexual Victimization Among Transgender Adult Inmates. U.S. Department of Justice, Bureau of Justice Statistics. www.bjs.gov/content/pub/pdf/ svpjri1112_st.pdf 
Beck, Allen J., \& Candace Johnson. 2012. Sexual Victimization Reported by Former State Prisoners. U.S. Department of Justice, Bureau of Justice Statistics. www.bjs.gov/content/ pub/pdf/svrfsp08.pdf

Beck, Kristin, \& Anne Speckhard. 2013. Warrior Princess: A U.S. Navy Seal's Journey to Coming Out Transgender. McLean, VA: Advances Press.

Beere, Carole A. 1990a. Gender Roles: A Handbook of Tests and Measures. Westport, CT: Greenwood Press.

- 1990b. Sex and Gender Issues: A Handbook of Tests and Measures. Westport, CT: Greenwood Press.

Belkin, Aaron. 2012. Bring Me Men: Military Masculinity and the Benign Façade of American Empire, 1898-2001. Oxford: Oxford University Press.

- 2016. Here Today, Gone Tomorrow: Why the U.S. Military's Transgender Ban Unraveled so Quickly. San Francisco: The Palm Center.

. 2020. Personal correspondence with the author (June).

Belkin, Aaron, Morten G. Ender, Nathaniel Frank, Stacie R. Furia, George Lucas, Gary Packard, Steven M. Samuels, Tammy Schultz, \& David R. Segal. 2012. "Readiness and DADT Repeal: Has the New Policy of Open Service Undermined the Military?" Armed Forces \& Society 39.4: 587-601.

Belkin, Aaron, \& Diane H. Mazur. 2018. Department of Defense Issues First-Ever Official Count of Active Duty Transgender Service Members. San Francisco: The Palm Center.

Bell, Richard C. 2008. "A History of Women in Sport Prior to Title IX." The Sport Journal 21 (March 14). https://thesportjournal.org/article/a-history-of-women-in-sportprior-to-title-ix/

Bem, Sandra Lipsitz. 1974. "The Measurement of Psychological Androgyny." Journal of Consulting \& Clinical Psychology 42.2: 155-162.

- 1981. "Gender Schema Theory: A Cognitive Account of Sex Typing." Psychological Review 88.4: 354-364.

- 1983. "Gender Schema Theory and Its Implications for Child Development: Raising Gender-Aschematic Children in a Gender-Schematic Society." Signs: Journal of Women in Culture and Society 8.4: 598-616.

- 1993. The Lenses of Gender. New Haven: Yale University Press.

Bem, Sandra Lipsitz, \& Daryl J. Bem. 1970. "Case Study of a Nonconscious Ideology: Training the W0oman to Know Her Place." In Beliefs, Attitudes, and Human Affairs, edited by D. J. Bem. Belmont, CA: Brooks/Cole.

—. 1973. "Does Sex-biased Job Advertising 'Aid and Abet' Sex Discrimination?” Journal of Applied Social Psychology 3: 6-18.

Bendery, Jennifer. 2012. "Joe Biden: Transgender Discrimination Is 'The Civil Rights Issue of Our Time'." https://www.huffpost.com/entry/joe-biden-transgender-rights_n_20 47275

Bennett-Smith, Meredith. 2013. "Smith College Rejects Female Transgender Student Calliope Wong; Applicant Ruled 'Male' By Admissions.” Huffington Post (March 21). www. huffpost.com/entry/smith-college-transgender-calliope-wong_n_2920845

Berg, Stefan. 2009. "How Dora the Man Competed in the Woman's High Jump." Der Spiegel (September 15). www.spiegel.de/international/germany/1936-berlin-olympicshow-dora-the-man-competed-in-the-woman-s-high-jump-a-649104.html

Bertuzzi, Marco. 2015. I Femminielli: Il labile confine tra l'umano e il sacro. Firenze: Associazione Multimage.

Bérubé, Allan. 1990. Coming Out Under Fire: The History of Gay Men and Women in World War Two. New York: Penguin Group. 
Bessette, Joseph M. 1989. "Prisoners in 1988." Bureau of Justice Statistics Bulletin. www.bjs. gov/content/pub/pdf/p88.pdf

Bettcher, Talia Mae. 2007. "Evil Deceivers and Make-Believers: On Transphobic Violence and the Politics of Illusion." Hypatia 22.3: 43-65.

- 2009. "Trans Identities and First-person Authority." In "You've Changed": Sex Reassignment and Personal Identity, edited by Laurie J. Shrage (98-120). New York: Oxford University Press.

- 2013. "Trans Women and the Meaning of 'Woman'." In Philosophy of Sex: Contemporary Readings, 6th ed., edited by A. Soble, N. Power, \& R. Halwani (233-249). Lanham, MA: Rowan \& Littlefield.

- 2014, "Trapped in the Wrong Theory: Re-Thinking Trans Oppression and Resistance. " Signs: Journal of Women in Culture and Society 39.2: 43-65.

- 2020. "Feminist Perspectives on Trans Issues." In The Stanford Encyclopedia of Philosophy, edited by Edward N. Zalta. https://plato.stanford.edu/archives/fall2020/entries/ feminism-trans

2022. Personhood as Violence: An Essay in Trans Philosophy. Minneapolis: University of Minnesota Press.

Bianco, Marcie. 2015. "Statistics Show Exactly How Many Times Trans People Have Attacked You in Bathrooms." Mic. (April 2). www.mic.com/articles/114066/ statistics-show-exactly-how-many-times-trans-people-have-attacked-you-in-bathrooms

Biden, Joseph R. 2021a. "Executive Order on Enabling All Qualified Americans to Serve Their Country in Uniform." Whitehouse.gov (January 25). www.whitehouse.gov/brief ing-room/presidential-actions/2021/01/25/executive-order-on-enabling-all-qualifiedamericans-to-serve-their-country-in-uniform/

- 2021b. "Executive Order on Preventing and Combating Discrimination on the Basis of Gender Identity or Sexual Orientation." Whitehouse.gov (January 20). www.whitehouse. gov/briefing-room/presidential-actions/2021/01/20/executive-order-preventing-andcombating-discrimination-on-basis-of-gender-identity-or-sexual-orientation/

Big, Martina. 2020. "Martina Big/Malaika Kubwa." www.martina-big.com/

Billard, Thomas J. 2016. "Writing in the Margins: Mainstream News Media Representations of Transgenderism." International Journal of Communication 10: 4193-4219.

- 2018. "Attitudes Toward Transgender Men and Women: Development and Validation of a New Measure." Frontiers in Psychology 9 (April): 1-11. doi.org/10.3389/ fpsyg.2018.00387

- 2019. "Setting the Transgender Agenda: Intermedia Agenda-setting in the Digital News Environment.” Politics, Groups, E Identities 7.1: 165-176.

Biography.com Editors. 2020. "Molly Pitcher.” Biography.com (March 2). www.biography. com/military-figure/molly-pitcher

Bird, Chloe E., \& Patricia Rieker. 2008. Gender and Health: The Effects of Constrained Choices and Social Policies. Cambridge: Cambridge University Press.

Black, Connor. 2019. "Refuting Ignorance and Misinformation." The Hampden-Sydney Tiger XCIV.16 (November 14): 11-12.

Black, Michelle C., Kathleen C. Basile, Matthew J. Breiding, Sharon G. Smith, Mikel L. Walters, Melissa T. Merrick, Jieru Chen, \& Mark R. Stevens. 2011. The National Intimate Partner and Sexual Violence Survey (NISVS): 2010 Summary Report. Atlanta, GA: National Center for Injury Prevention and Control, Centers for Disease Control and Prevention.

Blackless. Melanie, Anthony Charuvastra, Amanda Derryck, Anne Fausto-Sterling, Karl Lauzanne, \& Ellen Lee. 2000. "How Sexually Dimorphic Are We? Review and Synthesis." American Journal of Human Biology 12.2: 151-166. 
Blake, Aaron. 2019. "Trump's Transgender Military Ban is Losing Support Even in his Own Party." Washington Post (June 11). www.washingtonpost.com/politics/2019/06/11/ trumps-transgender-military-ban-is-losing-even-his-own-party/

Blanchard, Timothy C. J. (2020). "Letter of Impending Enforcement Action." (May 15). U.S. Department of Education, Office for Civil Rights. www.adfmedia.org/files/Soule DOEImpendingEnforcementLetter.pdf

Bleiweis, Robin, Diana Boesch, \& Alexandra Cawthorne Gaines. 2020. "The Basic Facts About Women in Poverty." (August 3). Center for American Progress. www.american progress.org/issues/women/reports/2020/08/03/488536/basic-facts-women-poverty/

Blinken, Anthony J. 2021. "Proposing Changes to the Department's Policies on Gender on U.S. Passports and Consular Reports of Birth Abroad." Press Statement (June 30). www. state.gov/proposing-changes-to-the-departments-policies-on-gender-on-u-s-passportsand-consular-reports-of-birth-abroad/

Block, Julie. 2016. "Wabash Student Senate Votes against Resolution to Admit Transgender Students." The DePauw 164.35: 1-3. https://issuu.com/thedepauw/docs/e-edition031116

Blumell, Lindsey Erin, Jennifer Huemmer, \& Miglena Sternadori. 2019. "Protecting the Ladies: Benevolent Sexism, Heteronormativity, and Partisanship in Online Discussions of Gender-Neutral Bathrooms." Mass Communication \& Society 22.3: 365-388.

Bond, B. J., \& B. L. Compton. 2015. "Gay On-screen: The Relationship between Exposure to Gay Characters on Television and Heterosexual Audiences' Endorsement of Gay Equality." Journal of Broadcasting \& Electronic Media 59.4: 717-732.

Borrell, Carme, Laia Palència, Carles Muntaner, Marcelo Urquía, Davide Malmusi, \& Patricia O'Campo. 2014. "Influence of Macrosocial Policies on Women's Health and Gender Inequalities in Health." Epidemiologic Reviews 36.1: 31-48.

Botts, Tina Fernandes. 2018. "In Black and White: A Hermeneutic Argument Against 'Transracialism'.” Res Philosophica 95.2: 303-329.

Bourke, Joanna. 2011. What it Means to be Human. Berkeley: Counterpoint.

Brake, Deborah L. 2007. "Title IX as Pragmatic Feminism." Cleveland State Law Review 55.4: 513-546.

- 2010. Getting in the Game: Title IX and the Women's Sports Revolution. New York: New York University Press.

Brandeis, Louis. 1932. Dissenting Opinion, New State Ice Co. v. Liebmann, 285 U.S. 262, 280.

Brannon, Robert, \& Samuel Juni. 1984. "A Scale for Measuring Attitudes About Masculinity." Psychological Documents, 14: Doc. \#2612.

Brassel, Sheila T., \& Veanne N. Anderson. 2020. "Who Thinks Outside the Gender Box? Feminism, Gender Self-Esteem, and Attitudes toward Trans People." Sex Roles 82.7/8: 447-462.

Brayboy, Duane. 2018. "Two Spirits, One Heart, Five Genders." Indian Country Today (September 13). https://indiancountrytoday.com/archive/two-spirits-one-heart-fivegenders

Bredin, Wade. 2019. "Transgender Lies Become Tyrannical." The Hampden-Sydney Tiger XCIV.15 (October 28): 3, 9.

Breslin, Meg McSherry. 2001. "At Rare all-Male College, Gentlemen Prefer Bonds.” Chicago Tribune (January 16). www.chicagotribune.com/news/ct-xpm-2001-01-16-01011602 67-story.html

Bresser, Nina. 2016. "Book Review: Gender Hurts." European Journal of Women's Studies 23.2: $220-222$. 
Brewer, M. B., \& R. J. Brown. 1998. "Intergroup Relations." In The Handbook of Social Psychology, 4th ed., edited by D. T. Gilbert, S. T. Fiske, \& G. Lindzey (554-594). Boston: McGraw-Hill.

Brief for Amici Curiae Corpus-Linguistics Scholars Professors Brian Slocum, Stefan Th. Gries, and Lawrence Solan supporting employees, Bostock v. Clayton County, Altitude Express v. Zarda \& Moore, and Harris Funeral Homes v. EEOC. (2019).

Bromwich, Jonah Engel. 2017. "How U.S. Military Policy on Transgender Personnel Changed Under Obama." New York Times (July 26). www.nytimes.com/2017/07/26/ us/politics/trans-military-trump-timeline.html

Brookey, Robert Alan. 2002. Reinventing the Male Homosexual: The Rhetoric and Power of the Gay Gene. Bloomington: University of Indiana Press.

Brown, Capt. George R. 1988. "Transsexuals in the Military: Flight Into Hypermasculinity." Archives of Sexual Behavior 17.6: 527-537.

Brown, Taylor N. T., \& Jody L. Herman. 2015. Intimate Partner Violence and Sexual Abuse among LGBT People: A Review of Existing Literature. The Williams Institute. http://wil liamsinstitute.law.ucla.edu/wp-content/uploads/Intimate-Partner-Violence-andSexualAbuse-among-LGBT-People.pdf.

Browne, Ryan. 2018. "First Transgender Recruit Signs up to join US Military." CNN.com (February 26). www.cnn.com/2018/02/26/politics/first-transgender-recruit-join-usmilitary/index.html

Brubaker, Rogers. 2016 Trans: Gender and Race in an Age of Unsettled Identities. Princeton: Princeton University Press.

Bryant, Karl, \& Kristen Schilt. 2008. Transgender People in the U.S. Military: Summary and Analysis of the 2008 Transgender American Veterans Association Survey. Santa Barbara, CA: The Palm Center.

Brydum, Sunnivie. 2015. "Texas Doubles Down on Transphobic Legislation, Adding $\$ 2,000$ Fine for 'Wrong' Bathroom Use." The Advocate. www.advocate.com/politics/ transgender/2015/03/10/texas-doubles-down-transphobic-legislation-adding-2000fine-wrong-ba

Bryn Mawr. 2020. “Transgender Applicants.” www.brynmawr.edu/admissions/transgenderapplicants

Bucur, Maria. 2017. "Book Review: Gender Hurts. A Feminist Analysis of the Politics of Transgenderism, by Sheila Jeffreys." Women's History Review 26.4: 655-656.

Burgess, Alexis, Herman Cappelen, \& David Plunkett, eds. 2020. Conceptual Engineering and Conceptual Ethics. Oxford: Oxford University Press.

Burns, Katelyn. 2019. "The Internet Made Trans People More Visible. It also Left Them More Vulnerable.” Vox.com (December 27). www.vox.com/identities/2019/12/27/21028342/ trans-visibility-backlash-internet-2010

- 2020. "Why Police Often Single Out Trans People for Violence." Vox.com (June 23). www.vox.com/identities/2020/6/23/21295432/police-black-trans-people-violence

_. 2021. "Where LGBTQ Equality Legislation Goes to Die.” NewRepublic.com (June 30). https://newrepublic.com/article/162861/lgbtq-equality-act-joe-manchin-com promise-betrayal

Burt, Callie H. 2020. "Scrutinizing the U.S. Equality Act 2019: A Feminist Examination of Definitional Changes and Sociolegal Ramifications." Feminist Criminology 15.4: 363-409.

- 2021. "Discounting Females, Denying Sex, and Disregarding Dangers from SelfID: A Reply to Mezey, Upadhyay, and Sherrick." CrimRxiv (May 13). www.crimrxiv. $\mathrm{com} / \mathrm{pub} / \mathrm{gsp} 2 \mathrm{blxf} /$ release/1 
Butler, Judith. 1988. "Performative Acts and Gender Constitution: An Essay in Phenomenology and Feminist Theory." Theatre Journal 40.4: 519-531.

- 1993. Bodies that Matter: On the Discursive Limits of "Sex". London: Routledge. 1999. Gender Trouble: Feminism and the Subversion of Identity. London: Routledge.

Butler, Leslie. 2012. "From the History of Ideas to Ideas in History." Modern Intellectual History 9.1: 157-169.

Byrne, Alex. 2018. "Is Sex Socially Constructed?” Arc Digital (November 30). https://arc digital.media/is-sex-socially-constructed-81cf3ef79f07

- 2019. "What Is Gender Identity? The Elusive True Gender Self." Arc Digital (January 9). https://arcdigital.media/what-is-gender-identity-10ce0da71999

— 2020. “Are Women Adult Human Females?” Philosophical Studies 177: 3783-3803. . 2021. "Gender Muddle: Reply to Dembroff." Journal of Controversial Ideas 1.1: 5.

Byrne, Alex, \& Callie Burt. 2020. "Biological Sex and the Legal Protection of LGBT Individuals." Areo Magazine (August 20). https://areomagazine.com/2020/08/20/ biological-sex-and-the-legal-protection-of-lgbt-individuals/

Cain, Patricia A. 2001. "Women, Race, and Sports: Life before Title IX." Journal of Gender, Race and Justice 4.2: 337-352.

Callahan, Matthew P., \& Kyle T. Zukowski. 2019. "Reactions to Transgender Women and Men in Public Restrooms: Correlates and Gender Differences." Journal of Homosexuality 66.1: 117-138.

Campaign for Houston. 2015a. "Proposition 1, the Bathroom Ordinance, Resoundingly Defeated." Campaign for Houston. http://campaignforhouston.com/?page_id=24

- 2015b. "Campaign for Houston-TV Spot 1." YouTube. www.youtube.com/ watch? $\mathrm{v}=\mathrm{D} 7 \mathrm{thOvSvC} 4 \mathrm{E}$

Campbell, Beatrix. 2014. End of Equality (Manifestos for the 21st Century). Kolkata, India: Seagull Books.

Campbell, Colin, Jim Morrill, \& Steve Harrison. 2016. "Governor's Office: HB2 Repeal Possible if Charlotte drops LGBT Ordinance First.” The News \& Observer (September 16). www.newsobserver.com/news/politics-government/state-politics/article102251942. html

Campbell, Karlyn Kohrs. 1989. Man Cannot Speak For Her, Volume 1: A Critical Study of Early Feminist Rhetoric. New York: Greenwood Press.

Cappelen, Herman. 2018. Fixing Language: An Essay on Conceptual Engineering. New York: Oxford University Press.

Capranica, Laura, Maria F. Piacentini, Shona Halson, Kathryn H. Myburgh, Etsuko Ogasawara, \& Mindy Millard-Stafford. 2013. "The Gender Gap in Sport Performance: Equity Influences Equality.” International Journal of Sports Physiology and Performance 8.1: 99-103.

Carapezza, Kirk. 2018. "Transgender Success: From Ecuadorian Refugee To Wellesley Undergraduate.” WGBH.org (March 8). http://blogs.wgbh.org/on-campus/2018/3/8/ transgender-success-ecuadorian-refugee-wellesley-undergraduate/

Carlson, Tucker. 2021. “Biden Brings 'Equality' to Girls' Sports, and Who Knows What's Next?” FoxNews.com (January 22). www.foxnews.com/opinion/tucker-carlson-bidenequality-girls-sports

Carroll, Helen J. 2017. "Including Transgender Students in United States' School-based Athletics." In Transgender Athletes in Competitive Sports, edited by Eric Anderson and Ann Travers (143-155). London: Routledge.

Carroll, Helen J., Pat Griffin, \& Chris Mosier. 2018. "Creative Positive \& Inclusive Athletic Environments for Transgender Athletes.” www.ncaa.org/sites/default/files/2018INC_ Supporting_Transgender_And_Gender_Expansive_Student_Athletes_20180418.pdf 
Carter, W. Burlette. 2018. "Sexism in the 'Bathroom Debates': How Bathrooms Really Became Separated by Sex." Yale Law E Policy Review 37.1: 227-297.

Case, Mary Anne. 2017. "Heterosexuality as a Factor in the Long History of Women's Sports." Law \& Contemporary Problems 80: 25-46.

Caslen, Lt. Gen. (ret.) Robert L. 2020. Interview with the author (June 9).

Cavanagh, Sheila L. 2010. Queering Bathrooms: Gender, Sexuality, and the Hygienic Imagination. Toronto: University of Toronto Press.

Cedar Crest College. 2020. "Diversity and Inclusion." www.cedarcrest.edu/cdi/transgen der_resources.shtm

Chappell, Sophie Grace. 2019. “Glory, Beauty, Epiphany, Imagination: How To Do Moral Philosophy. Interview by Richard Marshall.” 3:16. https://316am.site123.me/articles/ glory-beauty-epiphany-imagination-how-to-do-moral-philosophy.

Charlotte, NC. 2016. Ordinance No. 7056. https://charlottenc.gov/NonDiscrimination/ Documents/NDO\%20Ordinance\%207056.pdf

Charlton, James I. 1998. Nothing About Us Without Us: Disability Oppression and Empowerment. Berkeley: University of California Press.

Chaudhry, V. Varun. 2018. Transforming Inclusion: An Organizational Guide. Philadelphia: Leeway Foundation.

Chemerinsky, Erwin. 2015. Constitutional Law: Principles and Policies, 5th ed. Frederick, MD: Wolters Kluwer.

Cheuvront, Samuel N., Robert Carter, III, Keith C. DeRuisseau, \& Robert J. Moffatt. 2005. "Running Performance Differences between Men and Women: An Update." Sports Medicine 35.12: 1017-1024.

City of Evanston. 2021. "Local Reparations: Restorative Housing Program." www.cityofe vanston.org/home/showpublisheddocument?id $=62777$

Clarke, Edward H. 1875. Sex In Education; or, A Fair Chance for Girls. Boston: James R. Osgood \& Company.

Claussen, Cathryn L. 2007. "Female Sport Participation in America: The Effectiveness of Title IX after 35 Years.” International Sports Law Journal 7.3-4: 79-83.

Cohen, Greta, ed. 2014. Women in Sport: Issues and Controversies, 2nd ed. Champaign, IL: Human Kinetics Publishers.

Cohen, Li. 2020. "Schools Must Allow Trans Students to Use Bathrooms that Match Gender." CBS News (August 8). www.cbsnews.com/news/federal-court-rules-that-transgen der-students-must-be-allowed-to-use-bathrooms-that-match-their-gender/

Coleman, Doriane Lambelet. 2017. "Sex in Sport." Law \& Contemporary Problems 80.4: 63-126.

- 2021. Email exchange with the author (July 28).

Coleman, Doriane Lambelet, Michael J. Joyner, \& Donna Lopiano. 2020. "Re-Affirming the Value of the Sports Exception to Title IX's General Non-Discrimination Rule." Duke Journal of Gender Law \& Policy 27.1: 69-134.

Collin, Lindsay, Sari L. Reisner, Vin Tangpricha, \& Michael Goodman. 2016. "Prevalence of Transgender Depends on the 'Case' Definition: A Systematic Review." Journal of Sexual Medicine 13.4: 613-626.

Combahee River Collective. 1977. "The Combahee River Collective Statement." www. blackpast.org/african-american-history/combahee-river-collective-statement-1977

Conkerton-Darby, Amy, et al. 2019. "Joint Statement in Response to the Aristotelian Society Talk on 3rd June 2019." Mapforthe Gap.org (June 4). www.mapforthegap.org.uk/post/ statement-in-response-to-the-aristotelian-society-talk-on-3rd-june-2019

Connell, R. W. 1995/2005. Masculinities, 2nd ed. Berkeley: University of California Press. 
Connell, Raewyn, \& Rebecca Pearse. 2015. Gender: In World Perspective, 3rd ed. Cambridge: Polity Press.

Connell, Will. 2018. "Transgender Athletes in the Olympics." Columbia Political Review. www.cpreview.org/blog/2018/4/transgender-athletes-in-the-olympics?rq=connell

Connerton, Kelly C. 1997. "The Resurgence of the Marital Rape Exemption: The Victimization of Teens by Their Statutory Rapists." Albany Law Review 61.1: 237-284.

Converse College. 2020. "Non-Discrimination Policy." www.converse.edu/about/ non-discrimination-policy/

Cooper, Helene. 2014. "Hagel 'Open' to Reviewing Military’s Ban on Transgender People." New York Times (May 11). www.nytimes.com/2014/05/12/us/hagel-open-to-reviewof-military-policy-on-transgender-people.html

Corrigan, David P., Jeremy D. Capps, M. Scott Fisher, \& George A. Somerville. 2019. Reply Brief of Appellant. Gavin Grimm v. Gloucester County School Board. U.S. Court of Appeals, Fourth District (December 9).

Costanza-Chock, Sasha. 2020. Design Justice: Community-Led Practices to Build the Worlds We Need. Cambridge, MA: M.I.T. Press.

Coubertin, Pierre de. 1912 [2000]. "The Women at the Olympic Games." In Olympism: Selected Writings, edited by Norbert Muller (711-713). Lausanne: International Olympic Committee.

Couric, Katie. 2017. Gender Revolution: A Journey with Katie Couric. Los Angeles: World of Wonder Productions.

Court of Arbitration for Sport. 2018. "Arbitral Award" [in the case of Mokgadi Caster Semenya v. International Association of Athletics Federations]. www.tas-cas.org/filead $\mathrm{min} /$ user_upload/CAS_Award_-_redacted_-_Semenya_ASA_IAAF.pdf

- 2019. "CAS Arbitration: Caster Semenya, Athletics South Africa (ASA) and International Association of Athletics Federations (IAAF): Decision." (May 1). www.tas-cas. org/fileadmin/user_upload/Media_Release_Semenya_ASA_IAAF_decision.pdf

Cowell, Roberta. 1954. Roberta Cowell's Story. London: William Heinemann Ltd.

Crary, David, \& Lindsay Whitehurst. 2021. "Lawmakers Can't Cite Local Examples of Trans Girls in Sports." APNews.com (March 3). https://apnews.com/article/ lawmakers-unable-to-cite-local-trans-girls-sports-914a982545e943ecc1e265e8c41042e 7

Cregan, Luke. 2018. "Trans Students, Barnard Admissions, and the Changing Meaning of the 'Women's College'." ColumbiaSpectator.com (October 25). www.columbiaspecta tor.com/the-eye/2018/10/25/trans-students-barnard-admissions-and-the-changingmeaning-of-the-womens-college/

Crenshaw, Kimberlé. 1989. "Demarginalizing the Intersection of Race and Sex: A Black Feminist Critique of Antidiscrimination Doctrine, Feminist Theory and Antiracist Politics." University of Chicago Legal Forum 1989.1: 139-167.

Crisler, Joan C., \& Maureen C. McHugh. 2011. "Waves of Feminist Psychology in the United States: Politics and Perspectives.” In Handbook of International Feminisms, edited by Alexandra Rutherford, et al. (37-58). New York: Springer.

Crissman, Halley P., Christina Czuhajewski, Michelle H. Moniz, Missy Plegue, \& Tammy Chang. 2019. "Youth Perspectives regarding the Regulating of Bathroom Use by Transgender Individuals." Journal of Homosexuality 67.14: 2034-2049.

CriticalPast. 2014. "Newly Recruited American Army Soldiers Undergo Medical Examination." YouTube.com (May 7). www.youtube.com/watch?v=p-7EsrIFgg0

Cull, Matthew John. 2020. Engineering Genders: Pluralism, Trans Identities, and Feminist Philosophy. PhD diss., University of Sheffield. 
Cullen, James. 2018. “The History of Mass Incarceration.” BrennanCenter.org ((July 20). www.brennancenter.org/our-work/analysis-opinion/history-mass-incarceration

Currah, Paisley. 2021. “The Work that Sex Does.” In The Intimate State: Gender, Sexuality, and Governance in Modern US History, edited by Margot Canaday, Nancy F. Cott, \& Robert O. Self. Chicago: University of Chicago Press.

- 2022. Sex is as Sex Does: Governing Transgender Identity. New York: New York University Press.

Currah, Paisley, \& Lisa Jean Moore. 2009. “'We Won't Know Who You Are': Contesting Sex Designations in New York City Birth Certificates." Hypatia 24.3: 113-135.

Currah, Paisley, \& Susan Stryker. 2015. "Introduction.” Transgender Studies Quarterly 2.1: $1-12$.

Dairity, Jr., William A., \& A. Kirsten Mullen. 2020. From Here to Equality: Reparations for Black Americans in the Twenty-First Century. Chapel Hill: University of North Carolina Press.

Daly, Mary. 1978. Gyn/Ecology: The Metaethics of Radical Feminism. Boston: Beacon Press.

Davies, Adam W. J., Evan Vipond, \& Ariana King. 2019. "Gender Binary Washrooms as a Means of Gender Policing in Schools: A Canadian Perspective." Gender and Education 31.7: 866-885.

Davis, Angela Y. 2003. Are Prisons Obsolete? New York: Seven Stories Press.

Davis, Georgiann. 2015. Contesting Intersex: The Dubious Diagnosis. New York: New York University Press.

Davis, Heath Fogg. 2017. Beyond Trans: Does Gender Matter? New York: New York University Press.

- 2018a. Building Gender-Inclusive Organizations: The Workbook. Philadelphia: Heath Fogg Davis.

—. 2018b. "Why the 'Transgender' Bathroom Controversy Should Make Us Rethink Sex-segregated Public Bathrooms.” Politics, Groups, \& Identities 6.2: 199-216.

Davis, Julie Hirschfeld, \& Helene Cooper. 2017. “Trump Says Transgender People Will Not Be Allowed in the Military." New York Times (July 26). www.nytimes.com/2017/07/26/ us/politics/trump-transgender-military.html

Defense Department. 1993. "Directive \#1304.26.” (December 21). https://biotech.law.lsu. edu/blaw/dodd/corres/html2/d130426x.htm

- 2010. "Department of Defense Instruction." (April 28). www.public.navy.mil/ netc/nstc/nrotc/pdfs/DoDI\%206130.03.pdf

Del Giudice, Marco. 2017. "Pink, Blue, and Gender: An Update." Archives of Sexual Behavior 46: $1555-1563$.

De Mars, Venus. 2017. "Performance by Venus de Mars." YouTube.com (November 8). www. youtube. $\mathrm{com} /$ watch?v=1HxVXEm09AI

Dembroff, Robin. 2021. "Escaping the Natural Attitude about Gender." Philosophical Studies 178.3: 983-1003.

Devor, Aaron, \& Ardel Haefele-Thomas. 2019. Transgender: A Reference Handbook. Santa Barbara, CA: ABC-CLIO.

Diamant, Lincoln, ed. 1998. Revolutionary Women in the War for American Independence: A One-Volume Revised Edition of Elizabeth Ellet's 1848 Landmark Series. Westport, CT: Praeger.

Diamond, Jeremy. 2016. "Donald Trump to LGBT Community: I'm a 'Real Friend'." CNN.com (June 13). www.cnn.com/2016/06/13/politics/donald-trump-lgbt-commu nity/index.html 
2017. "Trump to Reinstate US military Ban on Transgender People." CNN.com (July 26). www.cnn.com/2017/07/26/politics/trump-military-transgender/index.html Diaz, Jaclyn. 2021. "New Jersey Prisoners Will Be Placed Based on Gender Identity Under a New Policy.” NPR.org (June 29). www.npr.org/2021/06/29/1011181718/ new-jersey-prisoners-will-be-placed-based-on-gender-identity-under-a-new-policy

Díaz-León, Esa. 2016. “'Woman' as a Politically Significant Term: A Solution to the Puzzle." Hypatia 31.2: 245-258.

Disclosure. 2020. Directed by Sam Feder. Distributed by Netflix.

Doan, Petra L. 2010. "The Tyranny of Gendered Spaces-Reflections from beyond the Gender Dichotomy." Gender, Place, and Culture 17.5: 635-654.

Dodd, D. Aileen. 2019. "Morehouse College Reaffirms Dedication to Educate and Develop Men.” Press Release (April 13). www.morehouse.edu/newscenter/morehousecollegere affirmsdedicationtoeducateanddevelopmen.html

Dodge, L. M. 1999. “'One Female Prisoner Is of More Trouble Than Twenty Males': Women Convicts in Illinois Prisons, 1835-1896." Journal of Social History 32.4: 907-930.

Dolgoy, Reevan. 2000. The Search for Recognition and Social Movement Emergence: Towards an Understanding of the Transformation of the Fa'afafine of Samoa. Ph.D. diss., University of Alberta.

Dooley, Sean, Margaret Dawson, Lana Zak, Christina Ng, Lauren Effron, \& Meghan Keneally. 2015. "Bruce Jenner: 'I'm a Woman." 20/20 ABC News (April 24). https://abc news.go.com/Entertainment/bruce-jenner-im-woman/story?id=30570350

Dosh, Riley. 2019. "I was Discharged from the Military for Being Trans. I'm Losing Hope of Ever Serving Again.” Vox.com (January 25). www.vox.com/first-person/2019/1/24/ 18195975 /trump-trans-military-ban-supreme-court-decision

- 2020. Email exchange with the author, May 25.

Dow, Bonnie J. 2014. Watching Women's Liberation 1970: Feminism's Pivotal Year on the Network News. Urbana: University of Illinois Press.

Draz, Marie. 2019. "From Duration to Self-Identification?: The Temporal Politics of the California Gender Recognition Act.” Transgender Studies Quarterly 6.4: 593-607.

Dreger, Alice. 2015. Galileo's Middle Finger: Heretics, Activists, and the Search for Justice in Science. New York: Penguin Press.

Drescher, Jack. 2012. “The Removal of Homosexuality from the DSM: Its Impact on Today's Marriage Equality Debate." Journal of Gay E Lesbian Mental Health 16.2: 124-135.

- 2015. "Out of DSM: Depathologizing Homosexuality." Behavioral Sciences 5.4: $565-575$.

Duhem, Pierre. [1906] 1954. The Aim and Structure of Physical Theory. Translated by Philip P. Wiener. Princeton: Princeton University Press.

Dunkle, Margaret C. 1975. "Ten Myths that Limit Sports Opportunities for Girls." Sex Discrimination Regulations: Hearings Before the Subcommittee on Postsecondary Education of the Committee on Education and Labor, House of Representatives. Part 3 (June 17-26): 287-293. Washington, DC: Government Printing Office.

Dunlap, Shannon L., Ian W. Holloway, Chad E. Pickering, Michael Tzen, Jeremy T. Goldbach, \& Carl Andrew Castro. 2021. "Support for Transgender Military Service from Active Duty United States Military Personnel.” Sexuality Research and Social Policy 18: 137-143.

Dunning, Eric. 1986. "Sport as a Male Preserve: Notes on the Social Sources of Masculine Identity and its Transformations." Theory, Culture and Society 3.1: 79-90.

Durant, Henry Fowle. 1890. Notes of Mr. Durant's Sermon on "The Spirit of the College”. Boston: Frank Wood, Printer. https://repository.wellesley.edu/wellesleyhistories/5/ 
Dwyer, Devin. 2021. “'I'm Still here': Transgender Troops Begin New Era of Open Military Service.” ABCNews.com (February 23). https://abcnews.go.com/Politics/ im-transgender-troops-begin-era-open-military-service/story?id=76046328

Dyess, Amy. 2018. "TERF is Hate Speech and It's Time to Condemn It." Medium.com (October 25). https://medium.com/@amydyess83/terf-is-hate-speech-and-its-timeto-condemn-it-6efc897ce407

Eagly, Alice H., \& Valerie J. Steffen. 1984. "Gender Stereotypes Stem from the Distribution of Women and Men Into Social Roles." Journal of Personality and Social Psychology, 46.4: 735-754.

"Early Career Awards for 1976." 1977. American Psychologist 32.1: 88-91.

Eccleshare, Charlie. 2019. "Exclusive Interview: Meet Renee Richards-Sport's Accidental Transgender Pioneer." The Telegraph (March 26). www.telegraph.co.uk/tennis/2019/03/26/ meet-renee-richards-sports-accidental-transgender-pioneer/

Edgerton, Robert B. 1964. "Pokot Intersexuality: An East African Example of the Resolution of Sexual Incongruity." American Anthropologist 66: 1288-1299.

Eger, Isaac. 2017. "In the 1930s, Intersex Athletes Worried Olympic Officials about the Future of Women's Sports." Timeline.com (March 14). https://timeline.com/ intersex-athletes-olympic-test-5613d99f24dc

Eisenberg, Marla E., Amy L. Gower, Barbara J. McMorris, G. Nicole Rider, Glynis Shea, \& Eli Coleman. 2017. "Risk and Protective Factors in the Lives of Transgender/Gender Nonconforming Adolescents." Journal of Adolescent Health 61.4: 521-526.

Eitzen, Stanley, \& Maxine Baca Zinn. 1993. "The Sexist Naming of Collegiate Athletic Teams and Resistance to Change." Journal of Sport and Social Issues 17.1: 34-41.

Eliot, Lise. 2009. Pink Brain, Blue Brain: How Small Differences Grow Into Troublesome GapsAnd What We Can Do About It. Boston: Houghton Mifflin Harcourt.

Ellingson, Lyndall, \& Carol Odo. 2008. "HIV Risk Behaviors Among Mahuwahine (Native Hawaiian Transgender Women).” AIDS Education and Prevention 20.6: 558-569.

Ellis, Emma Grey. 2016. "Guess How Much That Anti-LGBTQ Law is Costing North Carolina.” Wired. (September 18). www.wired.com/2016/09/guess-much-anti-lgbtq-lawcosting-north-carolina/

Engdahl, Ulrica. 2014. "Wrong Body.” Transgender Studies Quarterly 1.1/2: 267-269.

Ephraim, Laura. 2017. Who Speaks for Nature? On the Politics of Science. Philadelphia: University of Pennsylvania Press.

Epple, Carolyn. 1998. "Coming to Terms with Navaho nádleehí: A Critique of berdache, 'Gay,' 'Alternate Gender,' and 'Two-spirit'.' American Ethnologist 25.2: 267-290.

Epstein, David. 2013. The Sports Gene: Inside the Science of Extraordinary Athletic Performance. New York: Penguin/Current.

Equality Act. 2010. UK Public General Acts. www.legislation.gov.uk/ukpga/2010/15/ pdfs/ukpga_20100015_en.pdf

Ermyas, Tinbete, \& Kira Wakeam. 2021. "Wave of Bills to Block Trans Athletes Has No Basis in Science, Researcher Says." NPR.org (March 18). www.npr.org/2021/ 03/18/978716732/wave-of-new-bills-say-trans-athletes-have-an-unfair-edge-whatdoes-the-science-s

Eskridge, William N., Brian G. Slocum, \& Stefan Th. Gries. 2021. "The Meaning of Sex: Dynamic Words, Novel Applications, and Original Public Meaning." Michigan Law Review 119.7: 1503-1580.

Fain, Mary Kate. 2020. "New Feminist Site, Ovarit, Fills the Gap Left by r/GenderCritical." 4W.pub (August 25) https://4w.pub/new-feminist-site-ovarit-fills-the-gapleft-by-r-gendercritical/ 
Fair Play For Women. 2017. "Half of all Transgender Prisoners are Sexual Offenders or Dangerous Category A Inmates.” Fair Play For Women (November 9). https://fairplayfor women.com/transgender-prisoners

Fanning, Eric. 2020. Phone interview with the author (June 15).

Fausset, Richard. 2017. "Bathroom Law Repeal Leaves Few Pleased in North Carolina." New York Times (March 30). www.nytimes.com/2017/03/30/us/north-carolina-senateacts-to-repeal-restrictive-bathroom-law.html

Fausto-Sterling, Anne. 1985. The Myths of Gender: Biological Theories about Women and Men. New York: Basic Books.

- 1993. "The Five Sexes: Why Male and Female are not Enough." The Sciences (March/April): 20-24.

- 2000. "The Five Sexes, Revisited." The Sciences (July/August): 19-23.

2012. Sex/Gender: Biology in a Social World. London: Routledge.

2016. "On the Critiques of the Concept of Sex." differences. 27.1: 189-205.

. 2018. "Why Sex is not Binary." The New York Times (October 25): A19.

. 2020a. "Science Won't Settle Trans Rights." Boston Review (February 10). https:// bostonreview.net/science-nature-gender-sexuality/anne-fausto-sterling-science-wontsettle-trans-rights

- 2020b. Sexing the Body: Gender Politics and the Construction of Sexuality (rev. ed.). New York: Basic Books.

Federal Bureau of Investigation. 2019. "Crime Data Explorer.” https://crime-data-explorer. fr.cloud.gov

Federal Bureau of Prisons. 2020. "Inmate Gender." www.bop.gov/about/statistics/statis tics_inmate_gender.jsp

Feldman, David M. 2015. "City of Houston Equal Rights Ordinance." www.houstontx. gov/council/committees/qol/20140430/ero.pdf

Ferber, Alona. 2020. "Judith Butler on the Culture Wars, JK Rowling and Living in 'Anti-Intellectual Times.”. New Statesman (September 22). www.newstatesman.com/ international/2020/09/judith-butler-culture-wars-jk-rowling-and-living-anti-intellec tual-times

Ferrannini, John. 2021. "Few Trans People Transferred under New CA Prisoner Law." Bay Area Reporter (May 12). www.ebar.com/news/news/304851

Firestone, Shulamith. 1970. The Dialectic of Sex: The case for Feminist Revolution. New York: Bantam Books.

Fischel, Joseph J. 2019. "Social Justice for Gender and Sexual Minorities: A Discussion with Paisley Currah and Aeyal Gross." Critical Analysis of Law 6.1: 82-101.

Fischer, Mia. 2019. Terrorizing Gender: Transgender Visibility and the Surveillance Practices of the U.S. Security State. Lincoln: University of Nebraska Press.

Fisher, Leslee A., Susannah K. Knust, \& Alicia J. Johnson. 2013. "Theories of Gender and Sport.” In Gender Relations in Sport, edited by Emily Rogers (21-38). Leiden: Brill.

Fleming, Little, Driever, \& Rhames v. U.S. 2017. Third Amended Verified Complaint (May 12). www.courtlistener.com/docket/6156954/59/rhames-v-united-states-of-america/

Flores, Andrew R. 2015. "Attitudes toward Transgender Rights: Perceived Knowledge and Secondary Interpersonal Contact.” Politics, Groups, E Identities 3.3: 398-416.

Flores, Andrew R., Donald P. Haider-Markel, Daniel C. Lewis, Patrick R. Miller, Barry L. Tadlock, \& Jami K. Taylor. 2018a. "Challenged Expectations: Mere Exposure Effects on Attitudes about Transgender People and Rights." Political Psychology 39.1: 197-216.

_ 2018b. "Transgender Prejudice Reduction and Opinions on Transgender Rights: Results from a Mediation Analysis on Experimental Data." Research \& Politics 5.1: 1-7. 
2020. "Public Attitudes about Transgender Participation in Sports: The Roles of Gender, Gender Identity Conformity, and Sports Fandom.” Sex Roles 83.5/6: 382-398.

Flores, Andrew R., Jody L. Herman, Gary J. Gates, \& Taylor N. T. Brown. 2016. How Many Adults Identify as Transgender in the United States? Los Angeles, CA: The Williams Institute.

Flores, Andrew R., \& Justin O’Neill. 2020. “Transgender-Specific Policy: Gender Identity Inclusion in Public Accommodations." In Oxford Encyclopedia of LGBT Politics and Policy, edited by Donald Haider-Markel. New York: Oxford University Press. doi: 10.1093/ acrefore/9780190228637.013.1223.

Flowers, Alison. 2014. "Dee Farmer Won a Landmark Supreme Court Case on Inmate Rights. But that's Not the Half of It." The Village Voice (January 29). www.villagevoice. com/2014/01/29/dee-farmer-won-a-landmark-supreme-court-case-on-inmate-rightsbut-thats-not-the-half-of-it/

Floyd, Henry F. 2020. Gavin Grimm v. Gloucester County School Board (slip opinion), U.S. Court of Appeals for the Fourth Circuit, No. 19-1952.

Fodor, Jerry A. 1998. Concepts: Where Cognitive Science Went Wrong. Oxford: Clarendon.

Frank, Nathaniel. 2009. Unfriendly Fire: How the Gay Ban Undermines the Military and Weakens America. New York: Thomas Dunne Books.

.2013. "The President's Pleasant Surprise: How LGBT Advocates Ended Don't Ask, Don't Tell." Journal of Homosexuality 60.2-3: 159-213.

Frankovic, Kathy. 2019. “American Views of Transgender People: The Impact of Politics, Personal Contact, and Religion." Economist/YouGov (October 11). https://today.yougov.com/ topics/politics/articles-reports/2019/10/11/american-views-transgender-people-poll

Freedman, Estelle. 1979. "Separatism as Strategy: Female Institution Building and American Feminism, 1870-1930.” Feminist Studies 5.3: 512-529.

Frow, John. 1995. Cultural Studies and Cultural Value. Oxford: Oxford University Press.

Frye, Phyllis Randolph. 1995. Proceedings from The Fourth International Conference on Transgender Law and Employment Policy. Houston, TX: ICTLE. www.digitaltransgenderarchive. net/files/hm50tr815

Gajanan, Mahita. 2020. "Report: Jail Officials Placed Layleen Polanco in Solitary Confinement Despite Health Concerns, Failed in Care of Duty." Time (June 24). https://time. com/5858514/layleen-polanco-rikers-island-solitary-confinement/

Gandía, Milagros Albert. 2016. On Word Definition in Children and Adults: Effects of Word Category and Level of Abstraction. Ph.D. diss., Universitat de Barcelona.

GAO [General Accounting Office]. 1992. Defense Force Management: DOD's Policy on Homosexuality. Washington, DC: GAO. www.gao.gov/assets/160/151963.pdf

Garfinkel, Harold. 1967. Studies in Ethnomethodology. New York: Prentice-Hall.

Garloch, Karen. 2016. "What it Means to be Transgender: Answers to 5 Key Questions." The Charlotte Observer (May 9). www.charlotteobserver.com/living/health-family/arti cle76580862.html

Gates, Gary J., \& Jody L. Herman. 2014. Transgender Military Service in the United States. Los Angeles, CA: Williams Institute.

Gates, Laura Daignault, \& H. Kim Bottomly. 2015. "Reaffirmation of Mission and Announcing Gender Policy." www.wellesley.edu/news/gender-policy/communityletter

Gathright, Jenny. 2018. "The Guidelines for Protection of Transgender Prisoners Just Got Rewritten." Alabama Public Radio (May 12). www.apr.org/post/guidelines-prot ection-transgender-prisoners-just-got-rewritten

Geertz, Clifford. 1975. "Common Sense as a Cultural System." The Antioch Review 33.1: $5-26$.

Geller, Mary. 2020. Email exchange with the author, May 4. 
Gender Issues Committee. 2019. "Gender Issues Committee and Intercultural Affairs Committee: Statement of Support for Trans and Non-Binary at H-SC." The Hampden-Sydney Tiger XCIV.16 (November 14): 8.

General Assembly of North Carolina. 2016. "House Bill 2: Public Facilities \& Security Act." www.ncleg.gov/Sessions/2015E2/Bills/House/PDF/H2v1.pdf

Gerber, Ellen W., Jan Felshin, Pearl Berlin, \& Waneen Wyrick, eds. 1974. The American Woman in Sport. Reading, MA: Addison-Wesley.

Germon, Jennifer. 2009. Gender: A Genealogy of an Idea. New York: Palgrave Macmillan.

Gilbert, Lucia Albino, \& Murray Scher. 1999. Gender and Sex in Counseling and Psychotherapy. Needham Heights, MA: Allyn \& Bacon.

Gillespie, B. L., \& R. M. Eisler. 1992. "Development of the Feminine Gender Role Stress Scale. A Cognitive-Behavioral Measure of Stress, Appraisal, and Coping for Women." Behavior Modification 16.3: 426-438.

Gillig, Traci K., Erica L. Rosenthal, Sheila T. Murphy, \& Kate Langrall Folb. 2018. "More than a Media Moment: The Influence of Televised Storylines on Viewers' Attitudes toward Transgender People and Policies." Sex Roles 78: 515-527.

Gill-Peterson, Julian. 2018. Histories of the Transgender Child. Minneapolis: University of Minnesota Press.

Gilmore-Cleveland, Sherie. 2020. Email exchange with the author, April 21.

GLAAD (Gay \& Lesbian Alliance Against Defamation). 2021. "Where We Are on TV: 2020-2021." glaad.org/whereweareontv20

Glascow, Joshua, Sally Haslanger, Chike Jeffers, \& Quayshawn Spencer. 2019. What is Race? Four Philosophical Views. New York: Oxford University Press.

GLSEN (Gay, Lesbian, \& Straight Education Network). 2017. "Separation and Stigma: Transgender Youth and School Facilities." www.glsen.org/sites/default/files/2019-11/ Separation_and_Stigma_2017.pdf

Glum, Julia. 2016. "The HB2, Anti-LGBT Laws Effect: List of Concerts, Events Canceled in North Carolina and Mississippi.” International Business Times (April 20). www.ibtimes. com/hb-2-anti-lgbt-laws-effect-list-concerts-events-canceled-north-carolina-missis sippi-2356695

Gold, Michael., \& Piccoli, Sean. 2019. “After a Transgender Woman's Death at Rikers, Calls for Justice and Answers.” The New York Times (June 11). www.nytimes.com/2019/06/11/ nyregion/layleen-polanco-xtravaganza-death-rikers-island.html

Goldberg, Abbie E., Genny Beemyn, \& JuliAnna Z. Smith. 2019. "What Is Needed, What Is Valued: Trans Students' Perspectives on Trans-Inclusive Policies and Practices in Higher Education." Journal of Educational and Psychological Consultation 29.1: 27-67.

Goldberg, Michelle. 2014. "What is a Woman? The Dispute between Radical Feminism and Transgenderism." The New Yorker (July 28). www.newyorker.com/magazine/ 2014/08/04/woman-2

Goldberg, Shoshana K. 2021. Fair Play: The Importance of Sports Participation for Transgender Youth. Washington, DC: Center for American Progress.

Goldin, Claudia, Lawrence F. Katz, \& Ilyana Kuziemko. 2006. "The Homecoming of American College Women: The Reversal of the College Gender Gap." Journal of Economic Perspectives 20.4: 133-156.

Gonzales, Oriana. 2021. "Exclusive Poll: The Deep Divide over Trans Athletes in Olympics." Axios.com (July 26). www.axios.com/poll-public-split-trans-athletes-tokyo-olym pics-d9b02e56-ad54-4525-8d41-d95676cdac49.html

Gordon,Demoya. 2015. “Anti-TransBathroomBillsProposedin Texas.'LambdaLegal(March5). www.lambdalegal.org/blog/20150305_anti-trans-bathroom-bills-proposed-in-tx 
Gordon, Lewis R. 2018. "Thinking through Rejections and Defenses of Transracialism." Philosophy Today 62.1: 11-19.

Gottschalk, Marie. 2006. The Prison and the Gallows: The Politics of Mass Incarceration in America. Cambridge: Cambridge University Press.

Government Equalities Office. 2018. "Trans People in the UK." https://assets.publishing. service.gov.uk/government/uploads/system/uploads/attachment_data/file/721642/ GEO-LGBT-factsheet.pdf

Gov.UK. 2020. “Apply for a Gender Recognition Certificate.” www.gov.uk/apply-genderrecognition-certificate

Graham, David A. 2017. "Trump Gives an Order Too Vague for His Generals to Obey." The Atlantic (July 27). www.theatlantic.com/politics/archive/2017/07/trump-the-generalsand-transgender-troops/535155/

Graham, Sharyn. 2007. "Sulawesi’s Fifth Gender." Inside Indonesia (July 30). www.insidein donesia.org/sulawesis-fifth-gender

Green, Erica L., Katie Brenner, \& Robert Pear. 2018. “ “Transgender' Could Be Defined Out of Existence Under Trump Administration.” New York Times (October 21). www.nytimes. com/2018/10/21/us/politics/transgender-trump-administration-sex-definition.html

Green, Howard J., I. G. Fraser, \& D. A. Ranney. 1984. "Male and Female Differences in Enzyme Activities of Energy Metabolism in Vastus Lateralis Muscle." Journal of the Neurological Sciences 65.3: 323-331

Green, Jamison. 1994. Investigation into Discrimination Against Transgendered People. San Francisco: Report by the Human Rights Commission. https://citeseerx.ist.psu.edu/ viewdoc/download?doi=10.1.1.586.7364\&rep=rep1\&type $=$ pdf

Green, Kristen. 2015. Something Must Be Done about Prince Edward County. New York: HarperCollins Publishers.

Green, Richard. 2010. "Robert Stoller's Sex and Gender: 40 Years On.” Archives of Sexual Behavior 39.6: 1457-1465.

Greenburg, Jordan E., \& Gaia, A. Celeste. 2019. "Interpersonal Contact, Stereotype Acceptance, Gender Role Beliefs, Causal Attribution, and Religiosity as Predictors of Attitudes Toward Transgender Individuals." Psi Chi Journal of Psychological Research 24.1: 18-32.

Greer, Germaine. 1970. The Female Eunuch. New York: McGraw Hill.

Griffin, Pat, \& Helen J. Carroll. 2010. "On the Team: Equal Opportunities for Transgender Student Athletes.” (October 4). www.ncaa.org/sites/default/files/NCLR_Trans StudentAthlete\%2B(2).pdf

Griffiths, Paul. 2020. "Sex is Real.” Aeon. https://aeon.co/essays/the-existence-of-biologicalsex-is-no-constraint-on-human-diversity

Grimm, Gavin. 2021. "I Fought for Years in Court for My Basic Rights as a Trans Kid. It Shouldn't Have Been this Hard.” The Washington Post (June 30). www.washingtonpost.com/ opinions/2021/06/30/gavin-grimm-transgender-bathroom-supreme-court-victory/

Grimshaw, Jean. 1986. Philosophy and Feminist Thinking. Minneapolis: University of Minnesota Press.

Grinberg, Emanuella. 2015. "Why Transgender Teen Jazz Jennings is Everywhere.” CNN.com (March 19). www.cnn.com/2015/03/16/living/feat-transgender-teen-jazz-jennings/

Guillamon, Antonio, Carme Junque, \& Esther Gómez-Gil. 2016. "A Review of the Status of Brain Structure Research in Transsexualizm." Archives of Sexual Behavior 45.7: 1615-1648.

Gunnarsson, Lena. 2011. “A Defence of the Category 'Woman'.” Feminist Theory 12.1: 23-37. Guo, Shenyang, \& Mark W. Fraser. 2015. Propensity Score Analysis (2nd ed.). Los Angeles: Sage. 
Guttmann, Allen. 1991. Women's Sports: A History. New York: Columbia University Press. Hacking, Ian. 1999. The Social Construction of What? Cambridge, MA: MIT Press.

Halberstam, Jack. 2018. Trans*: A Quick and Quirky Account of Gender Variability. Berkeley: University of California Press.

Hale, Jacob. 1996. “Are Lesbians Women?” Hypatia 11.2: 94-121.

Hancock, Ange-Marie. 2016. Intersectionality: An Intellectual History. New York: Oxford University Press.

Handelsman, David J. 2017. "Sex Differences in Athletic Performance Emerge Coinciding with the Onset of Male Puberty." Clinical Endocrinology 87.1: 68-72.

- 2020. "Performance Enhancing Hormone Doping in Sport." Endotext.org (February 29). www.ncbi.nlm.nih.gov/books/NBK305894/

Handelsman, David J., Angelica L. Hirschberg, \& Stephane Bermon. 2018. "Circulating Testosterone as the Hormonal Basis of Sex Differences in Athletic Performance." Endocrine Reviews 39.5: 803-829.

Hanes, Senior Master Sgt. Jerry. 2007. "Hello Girls Set Stage for Women in the Military." Malmstrom Air Force Base (March 2). https://web.archive.org/web/20110722181413/ www.malmstrom.af.mil/news/story.asp?id=123043247

Hanson, Norwood Russell. 1958. Patterns of Discovery. Cambridge: Cambridge University Press.

Hargreaves, Jennifer. 1994. Sporting Females: Critical Issues in the History and Sociology of Women's Sports. London: Routledge.

Harper, Joanna. 2015. "Race Times for Transgender Athletes.” Journal of Sporting Cultures \& Identities 6.1: 1-9.

- 2020. Sporting Gender: The History, Science, and Stories of Transgender and Intersex Athletes. New York: Rowman \& Littlefield.

- 2021. Interview with the author (July 15).

Harper, Joanna, Giscard Lima, Alexander Kolliari-Turner, Fernanda Rossell Malinsky, Guan Wang, Mari-Jose Martinez-Patino, Siddhartha Angadi, Theodora Papadopoulou, Fabio Pigozzi, Leighton Seal, James Barrett, \& Yannis P. Pitsiladis. 2018. "The Fluidity of Gender and Implications for the Biology of Inclusion for Transgender and Intersex Athletes." Current Sports Medicine Reports 17.12: 467-472.

Harper, Joanna, Maria-Jose Martinez-Patino, Fabio Pigozzi, \& Yannis Pitsiladis. 2018. "Implications of a Third Gender for Elite Sports." Current Sports Medicine Reports 17.2: $42-44$.

Harper, Joanna, Emma O'Donnell, Behzad Sorouri Khorahsad, Hilary McDermott, \& Gemma L. Witcomb. 2021. "How Does Hormone Transition in Transgender Women Change Body Composition, Muscle Strength and Haemoglobin? Systematic Review with a Focus on the Implications for Sport Participation." British Journal of Sports Medicine 55.15: 865-872.

Hasenbush, Amira, Andrew R. Flores, \& Jody L. Herman. 2019. “Gender Identity Nondiscrimination Laws in Public Accommodations: A Review of Evidence Regarding Safety and Privacy in Public Restrooms, Locker Rooms and Changing Rooms." Sexuality Research \& Social Policy 16.1: 70-83.

Haslanger, Sally. 2000. "Gender and Race: (What) Are They? (What) Do We Want Them To Be?” Noûs 34.1: 31-55.

—. 2003. "Future Genders? Future Races?” Philosophic Exchange 34.1: 4-27.

. 2006. "What Good are Our Intuitions?" Aristotelian Society Supplementary Volume 80.1: 89-118.

- 2012. Resisting Reality: Social Construction and Social Critique. New York: Oxford University Press. 
2016. "Theorizing with a Purpose: The Many Kinds of Sex." In Natural Kinds and Classification in Scientific Practice, edited by Catherine Kendig (129-144). London: Routledge.

- 2017. "The Sex/Gender Distinction and the Social Construction of Reality." In The Routledge Companion to Feminist Philosophy, edited by Ann Garry, Serene J. Khader, \& Alison Stone (157-167). London: Routledge.

Haslanger, Sally, \& Ásta. 2018. "Feminist Metaphysics. In The Stanford Encyclopedia of Philosophy, edited by Edward N. Zalta. https://plato.stanford.edu/archives/fall2018/entries/ feminism-metaphysics

Hattenstone, Simon. 2021. "Eddie Izzard: 'I'm Just Trying to Create a Space for Myself." The Guardian (March 12). www.theguardian.com/film/2021/mar/12/eddie-izzardive-had-boob-envy-since-my-teens

Haverluck, Michael F. 2018. "Women's College to Admit Male Students Posing as Women." OneNewsNow (December 27). https://onenewsnow.com/education/2018/12/27/ womens-college-to-admit-male-students-posing-as-women

Hayton, Debbie. 2018. "A Plea to Trans Activists: We Can Protect Trans Rights without Denying Biology." Quillette (March 30). https://quillette.com/2018/03/30/ plea-trans-activists-can-protect-trans-rights-without-denying-biology/

Heggie, Vanessa. 2017. "Subjective Sex: Science, Medicine, and Sex Tests in Sports." In Transgender Athletes in Competitive Sports, edited by Eric Anderson and Ann Travers (136142). London: Routledge.

Hellen, Nicholas. 2019. "Trans Woman Debbie Hayton Faces Ban for transphobia." The Times (December 22). www.thetimes.co.uk/article/trans-woman-debbie-hayton-facesban-for-transphobia-96tfkl5gc

Helm, Rebecca R. 2019. "Biologist Explains Biological Sex.” Tweets aggregated at geekxgirls.com/article.php?ID=12697.

- 2020. Email exchange with the author, March 4.

Herdt, Gilbert H., ed. 1994. Third Sex, Third Gender: Beyond Sexual Dimorphism in Culture and History. New York: Zone Books.

Herek, Gregory M., J. R. Gillis, \& J. C. Cogan. 2009. "Internalized Stigma among Sexual Minority Adults: Insights from a Social Psychological Perspective." Journal of Counseling Psychology 56.1: 32-43.

Hewstone, Miles, Mark Rubin, \& Hazel Willis. 2002. "Intergroup Bias." Annual Review of Psychology 53.1: 575-604.

Heyes, Cressida J. 2006. "Changing Race, Changing Sex: The Ethics of Self-Transformation." Journal of Social Philosophy 37.2: 266-282.

HHS Press Office. 2020. "HHS Finalizes Rule on Section 1557 Protecting Civil Rights in Healthcare, Restoring the Rule of Law, and Relieving Americans of Billions in Excessive Costs." Department of Health and Human Services (June 12). www.hhs.gov/about/ news/2020/06/12/hhs-finalizes-rule-section-1557-protecting-civil-rights-healthcare.html

Hill, Darryl B., \& Brian L. Willoughby. 2005. "The Development and Validation of the Genderism and Transphobia Scale." Sex Roles 53.7: 531-544.

Hill,Jessica. 2020. "FactCheck:PostDetailing9Things WomenCouldn'tdobefore1971 isMostly Right.”USA Today(October28).www.usatoday.com/story/news/factcheck/2020/10/28/ fact-check-9-things-women-couldnt-do-1971-mostly-right/3677101001/

Hill, Katie Rain \& Ariel Schrag. 2016. Rethinking Normal: A Memoir in Transition. New York: Simon \& Schuster.

Hilton, Emma N., \& Tommy R. Lundberg. 2021. "Transgender Women in the Female Category of Sport: Perspectives on Testosterone Suppression and Performance Advantage." Sports Medicine 51.2: 199-214. 
Hines, Sally. 2018. Is Gender Fluid? A Primer for the 21st Century. London: Thames \& Hudson. Hinton, Elizabeth. 2016. From the War on Poverty to the War on Crime. Cambridge, MA: Harvard University Press.

Hirschberg, Angelica Lindén. 2020. “Female Hyperandrogenism and Elite Sport.” Endocrine Connections 9.4: R81-R92.

Hobson, Will. 2021. "The Fight for the Future of Transgender Athletes." The Washington Post (April 15). www.washingtonpost.com/sports/2021/04/15/transgender-athleteswomens-sports-title-ix/

Holden, Dominic. 2019. "Trump Got What He Wanted-Transgender Soldiers Are Now Banned from the Military." BuzzFeedNews (April 12). www.buzzfeednews.com/article/ dominicholden/trump-trans-military-ban-takes-effect

Holland, Judith R., \& Carole Oglesby. 1979. "Women in Sport: The Synthesis Begins." The Annals of the American Academy of Political and Social Science 445.1: 80-90.

Hollingsworth, Julia. 2021. "A Transgender Weightlifter's Olympic Dream Has Sparked an Existential Debate about What it Means to be Female." CNN.com (July 4). www.cnn. com/2021/07/03/sport/transgender-athletes-tokyo-olympics-intl-hnk-dst

Hollins University. 2020. “Transgender Policy.” www.hollins.edu/on-campus/student-life/ new-student-info/policy-on-transgender-issues/

Holmes, Mary. 2007. What is Gender? Sociological Approaches. Los Angeles, CA: Sage Publications.

hooks, Bell. 2014 [1984]. Feminist Theory: From Margin to Center, 3rd ed. London: Routledge. Horak, Laura. 2014. “Trans on YouTube.” Transgender Studies Quarterly 1.4: 572-585.

Horowitz, Helen Lefkowitz. 1993. Alma Mater: Design and Experience in the Women's Colleges from Their Nineteenth-Century Beginnings to the 1930s, 2nd ed. Amherst: University of Massachusetts Press.

Hoston, William T. 2018. Toxic Silence: Race, Black Gender Identity, and Addressing the Violence against Black Transgender Women in Houston. New York: Peter Lang Publishing.

Howard, Adam. 2019. "Enduring Privilege: Schooling and Elite Formation in the United States." Zeitschrift für Pädagogik, Beiheft 65: 178-191.

. 2020. Email exchange with the author, April 28.

H.R.5. 2021. "Equality Act." www.congress.gov/bill/117th-congress/house-bill/5/text

Hughto, Jaclyn M. White, et al. 2018. "Creating, Reinforcing, and Resisting the Gender Binary: A Qualitative Study of Transgender Women's Healthcare Experiences in SexSegregated Jails and Prisons." International Journal of Prison Health 14.2: 69-88.

Hull, Carrie L. 2003. "Letter to the Editor." American Journal of Human Biology 15.1: 112-116.

Human Rights Campaign (HRC). 2016. "HRC National Survey of Likely Voters." www. hrc.org/resources/hrc-national-survey-of-likely-voters

- 2018. The Real Mike Pence: A Lifetime of Attacks on the LGBTQ Community. Washington, DC: Human Rights Campaign Foundation.

- 2020. An Epidemic of Violence: Fatal Violence Against Transgender and Gender NonConforming People in the United States in 2020. Washington, DC: Human Rights Campaign Foundation.

Human Rights Watch (HRW). 1996. "All Too Familiar: Sexual Abuse of Women in U.S. State Prisons.” www.hrw.org/reports/1996/Us1.htm

Hymas, Charles. 2019. "One In 50 Prisoners Identifies As Transgender Amid Concerns Inmates Are Attempting To Secure Prison Perks." The Telegraph (July 9). www.telegraph.co.uk/ news/2019/07/09/one-50-prisoners-identify-transsexual-first-figures-show-amid

IBSC (International Boys School Coalition). 2018. “Thoughts from IBSC on Transgender Conversations at Your School.” (February). Unpublished Memo. 
ICPR (Institute for Crime and Justice Policy Research). 2021. World Prison Brief. https:// www.prisonstudies.org/

Inch, Mark S. 2018. “Transgender Offender Manual: Change Notice.” (May 11). www.bop. gov/policy/progstat/5200-04-cn-1.pdf

Ingle, Sean. 2019. "IOC Delays New Transgender Guidelines after Scientists Fail to Agree." The Guardian (September 24). www.theguardian.com/sport/2019/sep/24/ ioc-delays-new-transgender-guidelines-2020-olympics

- 2021. "IOC Praises Weightlifter Laurel Hubbard before Transgender Athlete's Olympic Debut." The Guardian (July 29). www.theguardian.com/sport/2021/jul/29/ ioc-praises-weightlifter-laurel-hubbard-ahead-of-transgender-athletes-olympic-debut

Ingraham, Christopher. 2017. "The Military Spends Five Times as Much on Viagra as it would on Transgender Troops' Medical Care.” Washington Post (July 26). www.washing tonpost.com/news/wonk/wp/2017/07/26/the-military-spends-five-times-as-muchon-viagra-as-it-would-on-transgender-troops-medical-care/

Institute for Women's Policy Research. 2018. Status of Women in the States, Fact Sheet, IWPR \#R532. http://statusofwomendata.org/wp-content/uploads/2018/03/R532National-Fact-Sheet_Final.pdf

International Association of Athletics Federations (IAAF). 2018. "Eligibility Regulations for the Female Classification." (April 23). www.worldathletics.org/news/press-release/ eligibility-regulations-for-female-classifica

IOC. 2015. "IOC Consensus Meeting on Sex Reassignment and Hyperandrogenism." https://stillmed.olympic.org/Documents/Commissions_PDFfiles/Medical_commis sion/2015-11_ioc_consensus_meeting_on_sex_reassignment_and_hyperandrogenismen.pdf

Ivy, Veronica [formerly Rachel McKinnon] 2019. Veronicaivy.com.

- 2021. "Veronica Ivy on Why it is Right for Trans Olympians to Compete." The Economist (July 27). www.economist.com/by-invitation/2021/07/27/veronica-ivy-onwhy-it-is-right-for-trans-olympians-to-compete

Izzard, Eddie. 2002. Dress to Kill [DVD]. United States: Warner.

Jackson, Jr., John. 2001. Social Scientists for Social Justice: Making the Case against Desegregation. New York: New York University Press.

James, Sandy E., Jody L. Herman, Susan Rankin, Mara Keisling, Lisa Mottet, \& Ma'ayan Anafi. 2016. The Report of the 2015 U.S. Transgender Survey. Washington, DC: National Center for Transgender Equality.

James, William. 1981 [1890]. The Principles of Psychology. Cambridge: Harvard University Press.

Jamieson, Kathleen Hall. 1995. Beyond the Double Bind: Women and Leadership. New York: Oxford University Press.

Jaschik, Scott. 2017. "Women's Colleges Accept Trans Applicants. What About Men's Colleges?" Inside Higher Ed (September 9). www.insidehighered.com/admissions/article/ 2017/09/11/transgender-applicants-who-want-mens-college-appear-have-only-one

_. 2019. “Morehouse Will Start Admitting Transgender Men.” Inside Higher Ed (April 15) www.insidehighered.com/admissions/article/2019/04/15/morehouse-announcesnew-approach-transgender-applicants-and-students

Jay, Karla. 1999. Tales of the Lavender Menace: A Memoir of Liberation. New York: Basic Books. Jeffries, Sheila. 2014. Gender Hurts: A Feminist Analysis of the Politics of Transgenderism. London: Routledge.

Jenkins, Katharine. 2016. "Amelioration and Inclusion: Gender Identity and the Concept of Woman*." Ethics 126.2: 394-421. 
. 2018. "Toward an Account of Gender Identity." Ergo: An Open Access Journal of Philosophy 5.27: 713-744.

- 2020a. "Conferralism and Intersectionality: A Response to Ásta's Categories We Live By." Journal of Social Ontology 5.2: 261-272.

- 2020b. "Ontic Injustice." Journal of the American Philosophical Association 6.2: 188-205.

Jenness, Valerie. 2020. Phone \& Email Interview with the Author, September 14-16.

Jenness, Valerie, \& Sarah Fenstermaker. 2016. "Forty Years After Brownmiller: Prisons for Men, Transgender Inmates, and the Rape of the Feminine." Gender \& Society 30.1: 14-29.

Jenness, Valerie, Cheryl L. Maxson, Kristy N. Matsuda, \& Jennifer Macy Sumner. 2007. "Violence in California Correctional Facilities: An Empirical Examination of Sexual Assault." (May 16). https://ucicorrections.seweb.uci.edu/files/2013/06/ PREA_Presentation_PREA_Report_UCI_Jenness_et_al.pdf

Jenness, Valerie, Lori Sexton, \& Jennifer Sumner. 2019. "Sexual Victimization against Transgender Women in Prison: Consent and Coercion in Context." Criminology 57.4: 603-631.

Jennings, Jazz. 2016. Being Jazz: My Life as a (Transgender) Teen. New York: Crown Books.

Johns, Michelle M., Richard Lowry, Jack Andrzejewski, et al. 2019. “Transgender Identity and Experiences of Violence Victimization, Substance Use, Suicide Risk, and Sexual Risk Behaviors Among High School Students-19 States and Large Urban School Districts." Morbidity \& Mortality Weekly Report 68.3: 67-71.

Johnson, Lt. Gen. (ret.) Michelle D. 2020. Interview and correspondence with the author (June).

Johnson, Paula A. 2020. "Supporting Our Transgender Community Members." Email sent to Wellesley Community, April 19.

Johnson, Robert. 2019. "What No One is Telling You About Caster Semenya: She has XY Chromosomes." LetsRun.com (May 2). www.letsrun.com/news/2019/05/ what-no-one-is-telling-you-about-caster-semenya-she-has-xy-chromosomes/

Johnston, Tim R. 2014. "Review of Sheila Jeffreys, Gender Hurts: A Feminist Analysis of the Politics of Transgenderism." Hypatia Reviews Online. www.hypatiareviews.org/reviews/ content $/ 275$

Jones, Bethany Alice, Jon Arcelus, Walter Pierre Bouman, \& Emma Haycraft. 2017. "Sport and Transgender People: A Systematic Review of the Literature Relating to Sport Participation and Competitive Sport Policies." Sports Medicine 47.4: 701-716.

Jones, C. J. 2021. "Unfair Advantage Discourse in USA Powerlifting: Toward a Transfeminist Sports Studies." Transgender Studies Quarterly 8.1: 58-74.

Jones, Franklin D., Michael G. Deeken, \& Steven D. Eshelman. 1984. "Sexual Reassignment Surgery and the Military: Case Reports." Military Medicine 149: 271-275.

Jones, Philip Edward, \& Paul R. Brewer. 2020. "Elite Cues and Public Polarization on Transgender Rights.” Politics, Groups, and Identities 8.1: 71-85.

Jones, Philip Edward, Paul R. Brewer, Dannagal G. Young, Jennifer L. Lambe, \& Lindsay H. Hoffman. 2018. "Explaining Public Opinion Toward Transgender People, Rights, and Candidates." Public Opinion Quarterly 82.2: 252-278.

Jones, Robert P., \& Daniel Cox. 2011. "Most Americans Favor Rights and Legal Protections for Transgender People.” Public Religion Research Institute. www.prri.org/ research/american-attitudes-towards-transgender-people/.

Jorgensen, Christine. 1967. A Personal Autobiography. New York: Paul S. Erikson.

Kaestner, Robert, \& Xin Xu. 2010. "Title IX, Girls' Sports Participation, and Adult Female Physical Activity and Weight." Evaluation Review 34.1: 52-78.

Kapsidelis, Karin. 2016. "Hampden-Sydney Extends Professor's Contract Amid Transgender Uproar." Richmond Times-Dispatch (May 23). www.richmond.com/news/hamp 
den-sydney-extends-professor-s-contract-amid-transgender-uproar/article_6b5994 72-2b35-56bc-b27d-a7c6f3d566dc.html

Karkazis, Katrina A. 2008. Fixing Sex: Intersex, Medical Authority, and Lived Experience. Durham: Duke University Press.

Kaufman, Audie. 2016. "Defending Wabash's Nature.” The Bachelor 108.18: 7. www.wabash. edu/bachelor/issues/2016s/The\%20Bachelor\%202-26-2016.pdf

Kaufman, Pat. 2008. "Prison Rape: Research Explores Prevalence, Prevention.” National Institute of Justice (March 17). https://nij.ojp.gov/topics/articles/prison-rape-researchexplores-prevalence-prevention

Keenan, Kevin G., Jonathon W. Senefeld, \& Sandra K Hunter. 2018. "Girls in the Boat: Sex Differences in Rowing Performance and Participation.” PLoS ONE 13.1: 1-14.

Keith, Thomas. 2020. Email exchange with the author, April 23.

Kelly, Megyn. 2016. The Kelly File: NC Governor Responds to "Bathroom Bill" Backlash (video). https://video.foxnews.com/v/4869249318001\#sp=show-clips

Kergil, Skylar. 2017. Before I Had the Words: On Being a Transgender Young Adult. New York: Skyhorse.

Kessler, Suzanne J. 1998. Lessons from the Intersexed. New Brunswick: Rutgers University Press.

Kessler, Suzanne J., \& Wendy McKenna. 1978. Gender: An Ethnomethodological Approach. Chicago: University of Chicago Press.

Kessler-Harris, Alice. 1995. "The Paradox of Motherhood: Night Work Restrictions in the United States." In Protecting Women: Labor Legislation in Europe, the United States, and Australia, 1880-1920E, edited by Ulla Wikander, Alice Kessler-Harris, \& Jane Lewis (337-358). Champaign-Urbana: University of Illinois Press.

Kilty, Jennifer M. 2020. “I Just Wanted them to See Me': Intersectional Stigma and the Health Consequences of Segregating Black, HIV+ Transwomen in Prison in the US State of Georgia." Gender, Place, \& Culture 28.7: 1019-1039.

King, Mark E., Sam Wainter, \& Beverly Webster. 2009. “Contact Reduces Transprejudice: A Study on Attitudes towards Transgenderism and Transgender Civil Rights in Hong Kong." International Journal of Sexual Health 21.1: 17-34.

Knechtle, Beat, Athanasios. A. Dalamitros, Tiago. M. Barbosa, Caio Victor Sousa, Thomas Rosemann, \& Pantelis Theo Nikolaidis. 2020. "Sex Differences in Swimming Disciplines-Can Women Outperform Men in Swimming?” International Journal of Environmental Research and Public Health 17.10: E3651.

Knox, Taryn, Lynley C. Anderson, \& Alison Heather. 2019. "Transwomen in Elite Sport: Scientific and Ethical Considerations." Journal of Medical Ethics 45.6: 395-403.

Kogan, Terry S. 2007. "Sex-Separation in Public Restrooms: Law, Architecture, and Gender." Michigan Journal of Gender \& Law 14.1: 3-57.

- 2017. "Public Restrooms and the Distorting of Transgender Identity." North Carolina Law Review 95.4: 1205-1239.

Koller, Dionne L. 2010. "Not Just One of the Boys: A Post-Feminist Critique of Title IX's Vision for Gender Equity in Sports." Connecticut Law Review 43.2: 401-456.

Kosciw, Joseph G., Emily A. Greytak, Adrian D. Zongrone, Caitlin M. Clark, \& Nhan L. Truong. 2018. The 2017 National School Climate Survey: The Experiences of Lesbian, Gay, Bisexual, Transgender, and Queer Youth in Our Nation's Schools. New York: GLSEN. www. glsen.org/sites/default/files/2019-10/GLSEN-2017-National-School-Climate-SurveyNSCS-Full-Report.pdf

Kralik, Joellen. 2019. “'Bathroom Bill' Legislative Tracking.” National Conference of State Legislatures (October 24). www.ncsl.org/research/education/-bathroom-bill-legislativetracking635951130.aspx 
Krapfl, Zachary J. 2019. "Defining and Assessing Lethality." NCO Journal (February 20). www.armyupress.army.mil/Journals/NCO-Journal/Archives/2019/February/assess ing-lethality/

Kripke, Saul A. 1980. Naming and Necessity. Cambridge, MA: Harvard University Press.

Kuhn, Thomas S. 1970. The Structure of Scientific Revolutions, 2nd ed. Chicago: University of Chicago Press.

1989. "Possible Worlds in History of Science." In Possible Worlds in Humanities, Arts and Sciences, edited by Sture Allen (9-32). Berlin: de Gruyter.

. 1990. "Dubbing and Redubbing: The Vulnerability of Rigid Designation." Minnesota Studies in the Philosophy of Science 14: 298-318.

Kvetenadze, Tea. 2018. “Trans Students: A Test of Identity for U.S. Girls Schools.” Reuters (August 18). www.reuters.com/article/us-usa-education-transgender/trans-students-atest-of-identity-for-us-girls-schools-idUSKBN1L30B7

Lambert, Jonathan. 2019. "No 'Gay Gene': Massive Study Homes in on Genetic Basis of Human Sexuality.” Nature (September 5), 573: 14-15.

Lamothe, Dan. 2016. “The Pentagon's Ban on Transgender Service Just Fell—but the Details are Complicated." Washington Post (June 30). www.washingtonpost.com/news/ checkpoint/wp/2016/06/30/the-pentagons-ban-on-transgender-service-just-fellbut-the-details-are-complicated/

2017. "Mark Green withdraws as Trump's Army Secretary Nominee, Citing 'False and Misleading Attacks'." Washington Post (May 5). www.washingtonpost.com/news/ checkpoint/wp/2017/05/05/mark-green-withdraws-as-trumps-army-secretary-nomi nee-citing-false-and-misleading-attacks

Lance, Mark. 2019. “Taking Trans Lives Seriously." Inside Higher Ed (July 30). www. insidehighered.com/views/2019/07/30/philosophers-should-recognize-seriousrisks-trans-people-face-opinion

Lane, Sheila. 2016. "Local Single-Sex Schools Creating Transgender Policies." Los Feliz Ledger (March 3). www.losfelizledger.com/article/local-single-sex-schools-creatingtransgender-policies/

Langan, Patrick A., John V. Fundis, Lawrence A. Greenfeld, \& Victoria W. Schneider. 1988. Historical Statistics on Prisons in State and Federal Institutions, Yearend 1925-86. Washington, DC: U.S. Department of Justice.

Langdon, Emily A. 2001. "Women's Colleges then and Now: Access then, Equity Now." Peabody Journal of Education 76.1: 5-30.

Laskowski, Nicholas G. 2020. "Moral Constraints on Gender Concepts." Ethical Theory and Moral Practice 23.1: 39-51.

Laylor, Janet A. 2016. "The Battle over Bathrooms: A Solution without a Problem.” American Journal of Public Health 106.8: 1349.

Lee, Antonia. 2019. “The IOC's Transgender Guidelines are Unscientific and Pose a Serious Risk to the Health of Both Female and Transgender Athletes." Medium.com (January 30). https://medium.com/@Antonia_Lee/the-iocs-transgender-guidelines-are-unscientificand-pose-a-serious-risk-to-the-health-of-both-5f5f808748e 2

Lenzi, Michael J. 2018. "The Trans Athlete Dilemma: A Constitutional Analysis of High School Transgender Student-Athlete Policies.” American University Law Review 67.3: 841-889.

Lepley Adam S., Michael F. Joseph, Nathan R. Daigle, et al. 2018. "Sex Differences in Mechanical Properties of the Achilles Tendon: Longitudinal Response to Repetitive Loading Exercise." Journal of Strength \& Conditioning Research 32.11: 3070-3079.

Levant, Ronald F., Linda S. Hirsch, Elizabeth Celentano, Tracy M. Cozza, Susan Hill, Mary MacEachern, Nadine Marty, \& John Schnedeker. 1992. "The Male Role: An Investigation of Contemporary Norms." Journal of Mental Health Counseling 14: 325-337. 
Levant, Ronald F., \& Katherine Richmond. 2016. "The Gender Role Strain Paradigm and Masculinity Ideologies." In APA Handbook on Men and Masculinities, edited by Y. J. Wong \& S. R. Wester (23-49). Washington, DC: American Psychological Association.

Levenson, Michael. 2019. “Transgender Inmate Moved to Women's Prison." The Boston Globe (January 24). www.bostonglobe.com/metro/2019/01/24/transgender-inmatemoved-women-prison/Nf2k5Oqa3Ojnh1yH1IwWkL/story.html

Levin, Dan. 2019. "North Carolina Reaches Settlement on 'Bathroom Bill'." New York Times (July 23). www.nytimes.com/2019/07/23/us/north-carolina-transgender-bath rooms.html

Lhamon, Catherine E., \& Vanita Gupta. 2016. Dear Colleague Letter on Transgender Students (May 13). Archived at https://www2.ed.gov/about/offices/list/ocr/letters/colleague201605-title-ix-transgender.pdf

Li, Minjie. 2018. "Intermediate Attribute Agenda Setting in the Context of Issue-focused Media Events: Caitlyn Jenner and Transgender Reporting." Journalism Practice 12.1: $56-75$.

—. 2019a. "Mediated Vicarious Contact with Transgender People: How Narrative Perspective and Interaction Depiction Influence Intergroup Attitudes, Transportation, and Elevation." Journal of Public Interest Communications 3.1: 141-166.

—. 2019b. "(Mis)Matching: Journalistic Uses of Gender Pronouns and Names Can Influence Implicit Attitudes towards Transgender People, Perceived News Content Credibility, and Perceived Reporter Professionalism." Newspaper Research Journal. 40.4: $517-533$.

- 2021. "Transitioning Together: Negotiating Transgender Subjectivity with Family and Other Trans People on Reality Television." Journal of Homosexuality 68.3: 496-521.

Lindberg, Maya. 2017. "Nothing About Us Without Us is for Us." Learning for Justice, Issue 57, Fall. www.learningforjustice.org/magazine/fall-2017/nothing-about-us-withoutus-is-for-us

Lindesmith, Alfred R., Anselm Strauss, \& Norman Denzin. 1999. Social Psychology, 8th ed., Thousand Oaks, CA: Sage.

Liptak, Adam. (2021). "The Supreme Court Won't Hear a Case Challenging Transgender Bathroom Rights." The New York Times (June 28). www.nytimes.com/2021/06/28/us/ politics/supreme-court-transgender-bathroom-rights.html

Litowitz, Bonnie. 1977. "Learning to Make Definitions." Journal of Child Language 4.2: 289-304.

Loffman, Matt. 2021. "New Poll Shows Americans Overwhelmingly Oppose Antitransgender Laws.” PBS.org (April 16). www.pbs.org/newshour/politics/new-pollshows-americans-overwhelmingly-oppose-anti-transgender-laws

Longman, Jeré. 2020. “Track's Caster Semenya Loses Appeal to Defend 800-Meter Title." The New York Times (September 8). www.nytimes.com/2020/09/08/sports/olympics/ caster-semenya-court-ruling.html

Lothstein, Leslie Martin. 1983. Female-to-Male Transsexualism: Historical, Clinical, and Theoretical Issues. London: Routledge \& Kegan Paul.

Love, Ninotska. 2020. Interview with Gunjan Singh (October 15).

Lucas, J. A., \& R. A. Smith. 1982. "Women's Sport: A Trial of Equality.” In Her Story in Sport: A Historical Anthology of Women in Sports, edited by R. Howell (239-265). West Point, NY: Leisure Press.

Luhur, Winston, Taylor N. T. Brown, \& Andrew R. Flores. 2019. Public Opinion of Transgender Rights in the United States. Los Angeles: UCLA School of Law, Williams Institute.

Lumpkin, Lauren, \& Susan Svrluga. 2020. "White GWU Professor Admits She Falsely Claimed Black Identity." Washington Post (September 3). www.washingtonpost.com/ 
education/2020/09/03/white-gwu-professor-admits-she-falsely-claimed-black-iden tity/

Lundberg, Tove, Peter Hegarty, \& Katrina Roen. 2018. "Making Sense of 'Intersex' and 'DSD': How Laypeople Understand and Use Terminology." Psychology E Sexuality 9.2: 161-173.

Luthra, Shefali. 2020.'Boston Children's Hospital Will No Longer Perform Two Types of Intersex Surgery on Children." USA Today (October 22). www.usatoday.com/story/ news/health/2020/10/22/intersex-surgery-boston-childrens-hospitals-decision-water shed-moment-rights/3721096001/

Lynn, Mahdia. 2017. "Supporting Trans Resistance: Nothing About Us, Without Us." TheMedium.com (February 25). https://medium.com/@mahdialynn/supporting-transresistance-nothing-about-us-without-us-d51bc5b6ea54

Lytton, Hugh, \& David M. Romney. 1991. "Parents' Differential Socialization of Boys and Girls: A Meta-analysis.” Psychological Bulletin 109.2: 267-296.

Mahalik, James R., Benjamin Locke, Larry Ludlow, Matthew Diemer, R. P. J. Scott, M. Gottfried, \& G. Freitas. 2003. "Development of the Conformity to Masculine Norms Inventory." Psychology of Men and Masculinity 4.1: 3-25.

Mahalik, James R., E.B. Morray, A. Coonerty-Femiano, Larry Ludlow, S.M. Slattery, A. Smiler. 2005. "Development of the Conformity to Feminine Norms Inventory." Sex Roles 52.7: 417-435.

Mahowald, Lindsay, Sharita Gruberg, \& John Halpin. 2020. The State of the LGBTQ Community in 2020: A National Public Opinion Study. Center for American Progress (October 6). www.americanprogress.org/issues/lgbtq-rights/reports/2020/10/06/491052/ state-lgbtq-community-2020/

Mallon, Ron. 2016. The Construction of Human Kinds. Oxford: Oxford University Press.

Manandhar, Mary, Sarah Hawkes, Kent Buse, Elias Nosrati, \& Veronica Magar. 2018. "Gender, Health and the 2030 Agenda for Sustainable Development." Bulletin of the World Health Organization 96: 644-653.

Manion, Jen. 2020. Female Husbands: A Trans History. Cambridge: Cambridge University Press.

Marable, Manning. 2018 [1983]. How Capitalism Underdeveloped Black America: Problems in Race, Political Economy and Society, rev. ed. Chicago: Haymarket Books.

Margolin, Emma. 2016. "With Transgender Military Ban Lifted, Obama Cements Historic LGBT Rights Legacy." NBCNews.com (June 30). www.nbcnews.com/feature/nbc-out/ transgender-military-ban-lifted-obama-cements-historic-lgbt-rights-legacy-n600541

Marimow, Ann E. 2020. “Transgender Student Gavin Grimm's Battle over Bathroom Access Returns to Court." Washington Post (May 26). www.washingtonpost.com/local/legalissues/transgender-student-gavin-grimms-battle-over-bathroom-access-returns-to-cour t/2020/05/22/571073c8-9b8e-11ea-a2b3-5c3f2d1586df_story.html

Marshall, Zack, Vivian Welch, Alexa Minichiello, Michelle Swab, Fem Brunger, \& Chris Kaposy. 2019. "Documenting Research with Transgender, Nonbinary, and Other Gender Diverse (Trans) Individuals and Communities: Introducing the Global Trans Research Evidence Map." Transgender Health 4.1: 68-80.

Martin, Victoria. 2013. “Trans Student's Application Rejected from Smith College.” The Key (March 19). https://keystonestudentvoice.com/2013/03/trans-students-applicationrejected-from-smith-college/

MassGov. 2018. Mass. General Laws c.127 \$32A. www.mass.gov/info-details/mass-generallaws-c127-ss-32a\#section-32a-

Mathias, Christopher. 2014. "New York's Largest Jail to Open Housing Unit for Transgender Women." Huffington Post (November 18). www.huffpost.com/entry/rikers-transg ender-women_n_6181552 
Mattis, James N. 2018. “Military Service by Transgender Individuals.” (February 22). https:// media.defense.gov/2018/Mar/23/2001894037/-1/-1/0/MILITARY-SERVICE-BYTRANSGENDER-INDIVIDUALS.PDF

Mayo Clinic Laboratories. 2020. "Test ID: TTFB, Testosterone, Total, Bioavailable, and Free, Serum.” www.mayocliniclabs.com/test-catalog/Clinical+and+Interpretive/83686

Mays, Jay, \& Mel Reif Hill. 2014. The Gender Book. Houston: Marshall House Press.

Maza, Carlos. 2014. "Debunking the Big Myth about Transgender-Inclusive Bathrooms." Media Matters (March 20). www.mediamatters.org/fox-nation/debunking-big-mythabout-transgender-inclusive-bathrooms

Maza, Carlos, \& Luke Brinker. 2014. "15 Experts Debunk Right-Wing Transgender Bathroom Myth.” Media Matters (March 19). www.mediamatters.org/sexual-harassment-sex ual-assault/15-experts-debunk-right-wing-transgender-bathroom-myth

McBee, Thomas Page. 2021. "What I Saw in My First 10 Years on Testosterone." The New York Times (June 25). www.nytimes.com/2021/06/25/opinion/transgender-transitiontestosterone.html

McBride, Sarah. 2018. Tomorrow Will Be Different: Love, Loss, and the Fight for Trans Equality. New York: Crown Archetype.

McCarriston, Shanna. 2020. "Heaven Fitch becomes First Female Wrestler to Win Individual State Title in North Carolina." CBSsports (February 28). www.cbssports.com/general/news/ heaven-fitch-becomes-first-female-wrestler-to-win-individual-state-title-in-north-carolina/

McCarthy, Justin. 2021. "Mixed Views Among Americans on Transgender Issues." Gallup (May 26). https://news.gallup.com/poll/350174/mixed-views-among-americanstransgender-issues.aspx

McCarthy, Kelly. 2020. "New Bill Wants to Force Student-athletes in Tennessee to Play as Gender Identified at Birth." ABC News (January 7). https://abcnews.go.com/Politics/ bill-force-student-athletes-tennessee-play-gender-identified/story?id=68116109

McCloskey, Deirdre Nansen. 2007. "Free to be She-or He." The Globe and Mail (October 20), D23.

— 2019 [1999]. Crossing: A Transgender Memoir. With a new Afterword. Chicago: University of Chicago Press.

- 2020. "I'm a Transwoman Who Believes in Free Speech. Here's Why." Prospect (August 13). www.prospectmagazine.co.uk/magazine/im-a-transwoman-who-signedthe-harpers-letter-with-jk-rowling-heres-why

McCreide, Jane. 2012. Beyond X and Y: Inside the Science of Gender. New York: Rowman \& Littlefield.

McCrone, Kathleen E. 1988. Playing the Game: Sports and the Physical Emancipation of English Women, 1870-1914. Lexington: University of Kentucky Press.

McGaughy, Lauren. 2018. "After Transgender Inmate was Raped, Beaten, Texas Agrees to Clarify LGBTQ Prisoners Policies.” The Dallas Morning News (May 15). www.dallasnews. $\mathrm{com} /$ news/2018/03/15/after-transgender-inmate-was-raped-beaten-texas-agrees-toclarify-lgbt-prisoner-policies/.

McLeary, Paul. 2017. "Pence Working to Reverse Pentagon's Transgender Policies: The Vice President Has Long Been Viewed as an Opponent of LGBT Rights." Foreign Policy (July 25). https://foreignpolicy.com/2017/07/25/pence-working-to-reverse-pen tagons-transgender-policies/

Mc Manus, Siobhan Guerrero. 2019. "Transgeneridad y transracialidad: contrastes ontológicos entre género y raza." Diánoia 64.82: 3-30.

McNamara, Brittney. 2017. "Lady Gaga May Be the First to Say 'Transgender' at Super Bowl.” Teen Vogue (February 6). www.teenvogue.com/story/lady-gaga-may-be-first-tosay-transgender-at-super-bowl 
McQuade, Aaron. 2013. "Thousands Calling for Smith College to Stop Discriminating against Trans Women." GLAAD. www.glaad.org/blog/thousands-calling-smith-collegestop-discriminating-against-trans-women

McVeigh, Karen, \& Paul Harris. 2011. "US Military Lifts Ban on Openly Gay Troops." The Guardian (September 20). www.theguardian.com/world/2011/sep/20/us-militarylifts-ban-gay-troops

Meade, Elizabeth. 2020. Phone interview with the author, April 22.

Meadow, Tey. 2018. Trans Kids: Being Gendered in the Twenty-First Century. Berkeley: University of California Press.

Melvoin, Rick. 2020. Email and phone interview. April 24-28.

Memorandum in Support of Plaintiffs' Motion for Preliminary Injunction. 2020. Selina Soule, et al. v. Connecticut Association of Schools, Inc., et al. (February 12). U.S. District Court, District of Connecticut.

Mencher, Julie. 2017. "When the White Dress Doesn't Fit: What are Other Girls' Schools Doing about Transgender Students? A Research Project." www.ncgs.org/wp-content/ uploads/2018/03/When-the-White-Dress-Doesn\%E2\%80\%99t-Fit-What-Are-OtherGirls\%E2\%80\%99-Schools-Doing-about-Transgender-Students.pdf

Merriam-Webster Dictionary (online edition). Retrieved May 4, 2020 from www.mer riam-webster.com/dictionary/sex

Meyer, Leisa. 1996. Creating GI Jane: Sexuality and Power in the Women's Army Corps during World War II. New York: Columbia University Press.

Meyerowitz, Joanne. 2002. How Sex Changed: A History of Transsexuality in the United States. Cambridge, MA: Harvard University Press.

Michals, Debra. 2015a. "Deborah Sampson.” National Women's History Museum. www.wom enshistory.org/education-resources/biographies/deborah-sampson

_. 2015b. "Margaret Cochran Corbin." National Women's History Museum. www.wom enshistory.org/education-resources/biographies/margaret-cochran-corbin.

Michelson, Melissa R., \& Brian F. Harrison. 2020. Transforming Prejudice: Identity, Fear, and Transgender Rights. New York: Oxford University Press.

Mikkola, Mari. 2019. "Feminist Perspectives on Sex and Gender." In The Stanford Encyclopedia of Philosophy (Fall 2019 Edition), edited by Edward N. Zalta. https://plato.stanford. edu/archives/fall2019/entries/feminism-gender

Miller, Brandon. 2017. "YouTube as Educator: A Content Analysis of Issues, Themes, and the Educational Value of Transgender-Created Online Videos." Social Media + Society 3.2: 205630511771627.

Miller, Leila. 2021. "California Prisons Grapple with Hundreds of Transgender Inmates Requesting New Housing." Los Angeles Times (April 5). www.latimes.com/california/ story/2021-04-05/california-prisons-consider-gender-identity-housing-requests

Miller, Patrick R., Andrew R. Flores, Donald Haider-Markel, Daniel C. Lewis, Barry Tadlock, and Jami K. Taylor. 2019. "The Politics of Being 'Cait': Caitlyn Jenner, Transphobia, and Parasocial Contact Effects on Transgender-Related Political Attitudes.” Unpublished manuscript.

- 2020. "The Politics of Being 'Cait': Caitlyn Jenner, Transphobia, and Parasocial Contact Effects on Transgender-Related Political Attitudes." American Politics Research 48.5: 622-634.

Milloy, Courtland. 2018. "The Idea of Race May be a Fiction, but the Impact of Racism is Very Real." The Washington Post (November 27). www.washingtonpost.com/local/ the-idea-of-race-may-be-fiction-but-the-impact-of-racism-is-very-real/2018/11/27/ a5bbb298-f24e-11e8-80d0-f7e1948d55f4_story.html 
Mills College. 2020. "Transgender Admission Policy.” www.mills.edu/admission-aid/underg raduate-admissions/how-to-apply/transgender-admission-policy.php\#

Ministry of Justice. 2011. The Care and Management of Transsexual Prisoners. Prison Service Instructions: PSI 07/2011. www.antoniocasella.eu/salute/TRANSSEXUAL_2011.pdf

_. 2016. "The Care and Management of Transgender Offenders PSI 17/2016." www. insidetime.org/download/rules_\&_policies/psi_(prison_service_instructions)/2016/ PSI_2016-017_The-Care-and-Management-of-Transgender-Offenders.pdf

_. 2018. "Offender Management Statistics Bulletin, England and Wales." (April 26). https://assets.publishing.service.gov.uk/government/uploads/system/uploads/attach ment_data/file/702297/omsq-q4-2017.pdf.

_ 2019a. "The Care and Management of Individuals who are Transgender." https:// assets.publishing.service.gov.uk/government/uploads/system/uploads/attachment_ data/file/863610/transgender-pf.pdf

2019b. "Her Majesty's Prison and Probation Service Offender Equalities Annual Report, 2018/19.” https://assets.publishing.service.gov.uk/government/uploads/system/ uploads/attachment_data/file/848759/hmpps-offender-equalities-2018-19.pdf

Mitchell, Chelsea. 2021. "Chelsea Mitchell on the Unfairness of Trans Women at the Olympics." The Economist (July 27). www.economist.com/by-invitation/2021/07/27/ chelsea-mitchell-on-the-unfairness-of-trans-women-at-the-olympics

Mitchell, Deana. 2014. "Mills College Takes on the Nuances of Transgender Admits." Oakland North (October 2). https://oaklandnorth.net/2014/10/02/mills-college-takes-on-thenuances-of-transgender-admits/

Moi, Toril. 1999. What is a Woman? And Other Essays. Oxford: Oxford University Press.

Money, Joan G. Hampson, \& John Hampson. 1955. "An Examination of Some Basic Sexual Concepts: The Evidence of Human Hermaphroditism.” Bulletin of Johns Hopkins Hospital 97.4: 301-319.

- 1957. "Imprinting and the Establishment of Gender Role." Archives of Neurology and Psychiatry 77.3: 333-336.

Monson, Dori. 2021. "DOC Employee Reports Men are Claiming to be Women to Transfer Prisons." MyNorthwest.com (March 10). Mynorthwest.com/2666243/

Mordaunt, The Rt. Hon. Penny. 2018. Reform of the Gender Recognition Act-Government Consultation (July). London: Government Equalities Office.

Moreau, Julie. 2018a. "Bureau of Prisons Rolls Back Obama-era Transgender Inmate Protections." NBC News (May 14). www.nbcnews.com/feature/nbc-out/bureau-prisonsrolls-back-obama-era-transgender-inmate-protections-n873966

- 2018b. "Three Transgender-Rights Cases to Have Their Day in Court This Week.” NBCNews.com (May 22). https://www.nbcnews.com/feature/nbc-out/threetransgender-rights-cases-have-their-day-court-week-n876571

- 2021. "Advocates Brace for Anti-LGBTQ Backlash at the State Level after Biden Victory." NBCNews.com (January 26). www.nbcnews.com/feature/nbc-out/ advocates-brace-anti-lgbtq-backlash-state-level-after-biden-victory-n1255606

Morehouse College. 2019. "Gender Identity Policy.” www.morehouse.edu/genderidentity/ - 2021. "Our Mission." https://morehouse.edu/archive/mission/

Moreland, J., \& M. Van Tuinen. 1978. The Attitudes Toward Masculinity Transcendence Scale. Unpublished manuscript, Department of Psychology, Ohio State University.

Morgan, Robin. 1973. "Lesbianism and Feminism: Synonyms or Contradictions?" [Keynote Address, West Coast Lesbian Conference, April 14]. Lesbian Tide 2.10-11: 30-34.

-1977. Going Too Far: The Personal Chronicle of a Feminist. New York: Random House.

Morning, Ann. 2011. The Nature of Race: How Scientists Think and Teach about Human Difference. Berkeley: University of California Press. 
2014. "And You Thought We Had Moved beyond All That: Biological Race Returns to the Social Sciences." Ethnic \& Racial Studies 37.10: 1676-1685.

Morris, Jan. 1974. Conundrum: From James to Jan-An Extraordinary Personal Narrative of Transsexualism. New York: Harcourt Brace Jovanovich.

Morris, Mike. 2014. "Equal Rights Law Opponents Deliver Signatures Seeking Repeal." The Houston Chronicle (July 3). www.houstonchronicle.com/news/politics/ houston/article/Equal-rights-law-opponents-deliver-signatures-5599272.php?t= 63159f4ad9cf61987c\#/0

Morris, Rosalind C. 1994. "Three Sexes and Four Sexualities: Redressing the Discourses on Gender and Sexuality in Contemporary Thailand." Positions: Asia Critique 2.1: 15-43.

Morris, Steven. 2015. "Germaine Greer Gives University Lecture Despite Campaign to Silence Her.” The Guardian (November 18). www.theguardian.com/books/2015/nov/18/ transgender-activists-protest-germaine-greer-lecture-cardiff-university

Mount Holyoke. 2020. "Admission.” www.mtholyoke.edu/admission

Mull, Amanda. 2019. "What It Means for Health Care to Be a Human Right." The Atlantic (June 24). https://www.theatlantic.com/health/archive/2019/06/health-care-humanright/592357/

Mullen, A. Kirsten, \& William A. Darity, Jr. 2021. "Evanston, Ill., Approved 'Reparations.' Except it isn't Reparations." Washington Post (March 28). www. washingtonpost.com/opinions/2021/03/28/evanston-ill-approved-reparations-housing-programexcept-it-isnt-reparations/

Munro, Neil. 2018. “New York: Jailed Women Must Live With 'Transgender' Men.” Breitbart.com (April 17). www.breitbart.com/politics/2018/04/17/new-york-womenmust-share-jails-with-transgender-men

Nagoshi, Julie H., Adams, Katherine A., Terrell, Heather K., Hill, Eric D., Brzuzy, Stephanie, \& Craig T. Nagoshi. 2008. "Gender Differences in Correlates of Homophobia and Transphobia." Sex Roles 59: 521-531.

Nanda, Serena. 1994. "Hijras: An Alternative Sex and Gender Role in India." In Third Sex, Third Gender: Beyond Sexual Dimorphism in Culture and History, edited by Gilbert H. Herdt (373-418). New York: Zone Books.

National Center for Transgender Equality. 2016a. "Frequently Asked Questions about Transgender People." https://ransequality.org/sites/default/files/docs/resources/ Understanding-Trans-Full-July-2016_0.pdf

_. 2016b. "Understanding Transgender People: The Basics." https://transequality.org/ issues/resources/understanding-transgender-people-the-basics

- 2020. "ID Documents Center: Indiana." https://transequality.org/documents/ state/indiana

National Coalition for Women and Girls in Education (NCWGE). 2012. Title IX at 40: Working to Ensure Gender Equity in Education. Washington, DC: NCWGE. www.ncwge. org/TitleIX40/Athletics.pdf

- 2017. Title IX at 45: Advancing Opportunity through Equity in Education. Washington, DC: NCWGE, 2017. www.ncwge.org/TitleIX45/Title\%20IX\%20at\%2045-Advanc ing $\% 20$ Opportunity $\% 20$ through $\% 20$ Equity $\% 20$ in $\% 20$ Education.pdf

National Coalition of Girls' Schools (NCGS). 2018. "Comparison Chart of All-Girls Independent Schools' Policies on Transgender Students." www.ncgs.org/wp-content/ uploads/2018/01/PolicyComparisonTable.pdf

. 2020. "Database: Transgender \& Gender Identity." www.ncgs.org/research/database/ categories/transgender-gender-identity/ 
National Collegiate Athletic Association (NCAA). 2011. "NCAA Inclusion of Transgender Student-Athletes." www.ncaa.org/sites/default/files/Transgender_Handbook_2011_ Final.pdf

- 2018. "NCAA Sports Sponsorship and Participation Rates Report." https:// ncaaorg.s3.amazonaws.com/research/sportpart/Oct2018RES_2017-18SportsSponsorshipParticipationRatesReport.pdf.

National Federation of State High School Associations. 2011. "1971 Sports Participation Survey." NFHS.org. www.nfhs.org/media/1020206/hs_participation_survey_his tory_1969-2009.pdf

—. 2019. "2018-19 Participation Survey." (August 28). www.nfhs.org/media/ 1020412/2018-19_participation_survey.pdf.

National Institute of Justice Staff. 2006. "NIJ's Response to the Prison Rape Elimination Act.” Corrections Today (February). www.ncjrs.gov/pdffiles1/nij/213137.pdf

National PREA Resource Center. 2016. "Does a Policy that Houses Transgender or Intersex Inmates Based Exclusively on External Genital Anatomy Violate Standard 115.42(c) \& (e)?” (March 24). www.prearesourcecenter.org/node/3927

Newman, Tim. 2018 [revised in 2021]. "Sex and gender: What is the difference?" Medical News Today (February 7). https://www.medicalnewstoday.com/articles/232363

NikkieTutorials. 2020. "I'm Coming Out." YouTube (January 13). www.youtube.com/ watch?v=QOOw2E_qAsE

Nippold, Marilyn A. 1988. “The Literate Lexicon.” In Later Language Development: Ages 9 through 19, edited by Marilyn A. Nippold (29-47). Austin, TX: Pro-Ed.

Nix, Elizabeth. 2020. "Did Revolutionary War Herione Molly Pitcher Exist?” History.com (March17). www.history.com/news/who-was-molly-pitcher

Norquist, David L. 2019. "Directive-type Memorandum (DTM)-19-004-Military Service by Transgender Persons and Persons with Gender Dysphoria (March 12).” https://www. hsdl.org/?abstract\&did=823232

North, Anna. 2017. "Can Transgender Students go to Women's Colleges?” Vox.com (September 22). www.vox.com/identities/2017/9/21/16315072/spelman-college-transgenderstudents-womens-colleges

Norton, Aaron T., \& Gregory M. Herek. 2013. "Heterosexuals' Attitudes Toward Transgender People: Findings from a National Probability Sample of U.S. Adults." Sex Roles 68.11-12: 738-753.

Nownes, Anthony J. 2019. Organizing for Transgender Rights: Collective Action, Group Development, and the Rise of a New Social Movement. Albany: State University of New York Press.

Oakes, Penelope J., S. Alexander Haslam, \& Katherine J. Reynolds. 1999. "Social Categorization and Social Context: Is Stereotype Change a Matter of Information or of Meaning?" In Social Identity and Social Cognition, edited by Dominic Abrams \& Michael A. Hogg (55-79). Oxford: Blackwell.

Oakley, Anne. 1972. Sex, Gender, and Society. London: Maurice Temple Smith Ltd.

O'Dowd, Niall. 2018. Lincoln and the Irish. New York: Skyhorse Publishing.

- 2019. "Albert Cashier: The Irish Transgender Hero of the American Civil War." IrishCentral.com (June 15). www.irishcentral.com/opinion/niallodowd/albert-cashiercivil-war

OECD [Organisation for Economic Co-operation and Development]. 2019. "Parental Leave Systems." www.oecd.org/els/soc/PF2_1_Parental_leave_systems.pdf 
Olympics.com. 2021. "Gender Equality Through Time: At the Olympic Games." https://olympics.com/ioc/gender-equality/gender-equality-through-time/at-theolympic-games

O’Neil, James M. 2015. Men's Gender Role Conflict: Psychological Costs, Consequences, and an Agenda for Change. Washington, DC: American Psychological Association.

O'Neill, Aaron. 2019. "Population of the United States in 1860, by Race and Gender." Statista.com (based on U.S. Census of 1860). www.statista.com/statistics/1010196/ population-us-1860-race-and-gender/

OpJAGAF [Opinion of the Judge Advocate General Air Force]. 1984. Medical Service Digest. 1982/24, 35: 2.

Orellana, Ligia, Peter Totterdell, \& Aarti Iyer. 2020. "The Association between Transgender-Related Fiction and Transnegativity: Transportation and Intergroup Anxiety as Mediators." Psychology \& Sexuality. doi: 10.1080/19419899.2020.1759677

Osborne, Barbara. 2017. "Failing to Fund Fairly: Title IX Athletics Scholarships Compliance." Tennessee Journal of Race, Gender, E Social Justice 6.1: 83-104.

Overall, Christine. 2004. “Transsexualism and 'Transracialism'." Social Philosophy Today 20: 183-193.

Owen, Barbara, James Wells, \& Joycelyn Pollock. 2017. In Search of Safety: Confronting Inequality in Women's Imprisonment. Berkeley: University of California Press.

Page, Blair. 2019. "Letter to the Editor as Vice President, Minority Student Union." The Hampden-Sydney Tiger XCIV.16 (November 14): 10.

Paige, Caroline. 2017. True Colours: My Life as the First Openly Transgender Officer in the British Armed Forces. Hull, UK: Biteback Publishing.

Palm Center. 2019. "Substantial Majority of Americans Supports Transgender Military Service." (July 1, press release). www.palmcenter.org/wp-content/uploads/2019/06/ Substantial-Majority-Supports-Transgender-Military-Service.pdf

Paoletti, Jo B. 2012. Pink \& Blue: Telling the Boys from the Girls in America. Bloomington: University of Indiana Press.

Parliamentary Assembly. 1989. "Recommendation 1117: Condition of Transsexuals."https:// assembly.coe.int/nw/xml/XRef/Xref-XML2HTML-en.asp?fileid=15151\&lang=en

Parsa, Neeki, \& Sabra L. Katz-Wise. 2021. “Gender Expression.” In The Sage Encyclopedia of Trans Studies, edited by Abbie E. Goldberg \& Genny Beemyn (299-303). Los Angeles, CA: Sage.

Parsons, Vic. 2020. “The 'Gender Critical' Feminist Movement is a Cult that Grooms, Controls and Abuses, According to a Lesbian Who Managed to Escape.” PinkNews (May 17). www.pinknews.co.uk/2020/05/17/terf-gender-critical-feminism-movementlesbian-cult-amy-dyess-transphobia/

Parveen, Nazia. 2018a. "Karen White: How 'Manipulative' Transgender Inmate Attacked Again.” The Guardian (October 11). www.theguardian.com/society/2018/oct/11/karenwhite-how-manipulative-and-controlling-offender-attacked-again-transgender-prison.

—. 2018b. "Transgender Prisoner Who Sexually Assaulted Inmates Jailed for Life." The Guardian (October 11). www.theguardian.com/uk-news/2018/oct/11/ transgender-prisoner-who-sexually-assaulted-inmates-jailed-for-life

Patrick, Dan. 2015. "Vote NO on Houston's Proposition 1." YouTube (October 22). www. youtube.com/watch? $\mathrm{v}=8$ iwzgNz9Znw

Pavitt, Michael. 2020. "IOC Confirms Existing Guidelines on Transgender Athlete Eligibility to Remain for Tokyo 2020.” Inside the Games (March 3). www.insidethegames.biz/ articles/1091417/ioc-guidelines-transgender-tokyo-2020 
Peters, Jeremy W. 2017. "Trump Keeps His Conservative Movement Allies Closest." New York Times (August 2). www.nytimes.com/2017/08/02/us/politics/trump-conservativerepublicans.html

Pettigrew, Thomas F., \& Tropp, Linda R. 2006. “A Meta-analytic Test of Intergroup Contact Theory." Journal of Personality and Social Psychology 90.5: 751-783.

Philipps, Dave. 2017a. "Judge Blocks Trump's Ban on Transgender Troops in Military." New York Times (October 30). www.nytimes.com/2017/10/30/us/military-transgender-ban. html

— 2017b. "Second Judge Blocks Trump's Transgender Ban in the Military." New York Times (November 21). www.nytimes.com/2017/11/21/us/transgender-ban-military. html

Piatkowski, Peter. 2017. "On The Crying Game and That Scene." Bright Wall/Dark Room, issue 53. www.brightwalldarkroom.com/2017/11/24/crying-game-scene/

Pidd, Helen. 2017. "Transgender Woman at Male Prison Did Not Mean to Kill Herself, Jury Finds." The Guardian (May 19). www.theguardian.com/uk-news/2017/may/19/ jury-returns-verdict-on-transgender-woman-found-dead-in-male-prison

Pieper, Lindsay Parks. 2012. "Gender Regulation: Renée Richards Revisited.” International Journal of the History of Sport 29.5: 675-690.

- 2016. Sex Testing: Gender Policing in Women's Sports. Urbana: University of Illinois Press.

. 2017. “Advantage, Renée? Renée Richards and Women's Tennis.” In Transgender Athletes in Competitive Sports, edited by Eric Anderson and Ann Travers (13-22). London: Routledge.

Pilcher, Jane, \& Imelda Whelehan. 2004. Fifty Key Concepts in Gender Studies. Thousand Oaks, CA: Sage Publications.

Pitsiladis, Yannis, Joanna Harper, Jonathan Ospina Betancurt, Maria-Jose Martinez-Patino, Attilio Parisi, Guan Wang, \& Fabio Pigozzi. 2016. "Beyond Fairness: The Biology of Inclusion for Transgender and Intersex Athletes." Current Sports Medicine Reports 15.6: 386-388.

Plichta-Kellar, Jesse. 2019. "Cite It Before You Write It: A Response to Bredin's Citation-Deficient and Falsehood-Endorsing Editorial." The Hampden-Sydney Tiger XCIV.16 (November 14): 10-11.

Ponsford, Matthew. 2020. "Vivid Portraits Shine Light on Tahiti's 'Third Gender'." CNN (March 19). www.cnn.com/style/article/namsa-leuba-photographer

Powell, Tia, Sophia Shapiro, \& Edward Stein. 2016. "Transgender Rights as Human Rights." AMA Journal of Ethics 18.11: 1126-1131.

Prager, Sarah. 2020. "Meet all 21 Openly Gay Trans Candidates Running for Office this Fall.” Mic.com (October 29). www.mic.com/p/meet-all-21-openly-trans-candidatesrunning-for-office-this-fall-40830735

PREA Standards. 2012. "Prison Rape Elimination Act: Prisons and Jail Standards, United States Department of Justice Final Rule.” www.prearesourcecenter.org/sites/default/ files/content/prisonsandjailsfinalstandards_0.pdf

Presidential Memoranda. 2017. "Presidential Memorandum for the Secretary of Defense and the Secretary of Homeland Security." WhiteHouse.gov (August 25). www.white house.gov/presidential-actions/presidential-memorandum-secretary-defense-secretaryhomeland-security/

Prewitt, Kenneth. 2013. What is Your Race? The Census and Our Flawed Efforts to Classify Americans. Princeton: Princeton University Press. 
Quine. W. V. O. 1969. Ontological Relativity and Other Essays. New York: Columbia University Press.

Radicalesbians. 1970. “The Woman Identified Woman.” Archived at https://repository. duke.edu/dc/wlmpc/wlmms01011

Rafter, Nicole Hahn. 1985. Partial Justice: Women in State Prisons, 1800-1935. Boston: Northeastern University Press.

Ramsay, George, \& Jill Martin. 2020. "Caster Semenya Loses Appeal in Swiss Court over Restriction of Testosterone Levels." (September 9). www.cnn.com/2020/09/09/sport/ caster-semenya-ruling-athletics-spt-intl/index.html

Ransdell, Lynda B., \& Christine L. Wells. 1999. "Sex Differences in Athletic Performance." Women in Sport \& Physical Activity Journal 8.1: 55-81.

Ravitz, Jessica. 2015. "Women in the World: Where the U.S. Falters in Quest for Equality." CNN.com (April 16). www.cnn.com/2015/04/16/us/american-women-world-rank ings/index.html

Rawson, K. J., \& Cristan Williams. 2014. "Transgender*: The Rhetorical Landscape of a Term." Present Tense: A Journal of Rhetoric in Society 3.2: 1-10.

Raymond, Janice G. 1979. The Transsexual Empire: The Making of the She-Male. Boston: Beacon Press.

- 1994. The Transsexual Empire: The Making of the She-Male: Reissued with a New Introduction on Transgender. New York: Teachers College Press.

Reality Check Team. 2018. "How Many Transgender Inmates are There?" BBC News (August 13). www.bbc.com/news/uk-42221629.

Reft, Ryan. 2014. "Sporting Golden State: Women and Athletics in 20th Century California." KCET.org (March 20). www.kcet.org/history-society/sporting-golden-state-womenand-athletics-in-20th-century-california

Regina (FDJ) $v$ Secretary of State for Justice. 2021. EWHC 1746 (England and Wales High Court [Administrative Court] Decisions). www.bailii.org/ew/cases/EWHC/ Admin/2021/1746.html

Reilly, Katie. 2019. "What is the Role of an All-Boys School in 2019?" Time (October 14). https://time.com/5687978/all-boys-schools-me-too-movement/

Reuters. 2018. “Texas Governor says 'Bathroom Bill' is No Longer a Priority.” NBC News (October 1). www.nbcnews.com/feature/nbc-out/texas-governor-says-bathroom-billno-longer-priority-n915341

Rich, Adrienne. 1979. On Lies, Secrets, and Silence: Selected Prose 1966-1978. New York: W.W. Norton \& Company.

Richards, Renée. 1983. The Renée Richards Story: Second Serve. New York: Stein \& Day.

Richardson, Sarah S. 2013. Sex Itself: The Search for Male and Female in the Human Genome. Chicago: University of Chicago Press.

—. 2021. "Sex Contextualism." Philosophy, Theory, \& Practice in Biology 13.14.

Riley, John. 2018. "Connecticut Will Now House Transgender Inmates according to Gender Identity." Metro Weekly (May 28). www.metroweekly.com/2018/05/ connecticut-house-transgender-inmates-according-gender-identity/

Ring, Trudy. 2019. "Anti-Trans Feminists Appear at Panel of Right-Wing Heritage Foundation." The Advocate (January 30). www.advocate.com/transgender/2019/1/30/ anti-trans-feminists-appear-panel-right-wing-heritage-foundation

Rippon, Gina. 2019. Gender and Our Brains: The New Neuroscience that Shatters the Myth of the Male and Female Minds. New York: Pantheon.

Roberts, Timothy A., Joshua Smalley, \& Dale Ahrendt. 2021. "Effect of Gender Affirming Hormones on Athletic Performance in Transwomen and Transmen: Implications for Sporting Organisations and Legislators." British Journal of Sports Medicine 55: 577-583. 
Robertson, Carol E. 1989. "The Māhū of Hawai'i." Feminist Studies 15.2: 312-326.

Robertson, Ian. 1981. Sociology, 2nd ed. New York: Worth Publishers, Inc.

Robinson, Richard. 1950. Definition. Oxford: Clarendon.

Rorty, Richard. 1989. Contingency, Irony, and Solidarity. Cambridge: Cambridge University Press.

Rosay, André B. 2016. "Violence Against American Indian and Alaska Native Women and Men.” NIJ Journal 277: 38-45. www.ncjrs.gov/pdffiles1/nij/249822.pdf

Roscoe, Will. 1998. Changing Ones: Third and Fourth Genders in Native North America. New York: St. Martin's Press.

Rosen, Gideon. 2015. "Real Definition.” Analytic Philosophy 56.3: 189-209.

Rosenbaum, Paul R., \& Donald B. Rubin. 1983. "The Central Role of the Propensity Score in Observational Studies for Causal Effects." Biometrika 70.1: 41-55.

Rosenberg, Matthew. 2016. "Transgender People Will Be Allowed to Serve Openly in Military." New York Times (June 30). www.nytimes.com/2016/07/01/us/transgendermilitary.html

Roth, Amanda, \& Susan A. Basow. 2004. "Femininity, Sports, and Feminism: Developing a Theory of Physical Liberation." Journal of Sport and Social Issues 28.3: 245-265.

Rothblatt, Martine A. 1995. The Apartheid of Sex: A Manifesto on the Freedom of Gender. New York: Crown Publishers.

Rothman, David K. 2017. Conscience and Convenience: The Asylum and Its Alternatives in Progressive America, rev. ed. New York: de Gruyter.

Rotondi, Nooshin Khobzi, Greta R. Bauer, Kyle Scanlon, Matthias Kaay, Robb Travers, \& Anna Travers. 2013. "Nonprescribed Hormone Use and Self-Performed Surgeries: 'Doit-Yourself' Transitions in Transgender Communities in Ontario, Canada." American Journal of Public Health 103.10: 1830-1836.

Rowe, David. 2014. "Sport, Media, and the Gender-based Insult." In The Routledge Companion to Media and Gender, edited by Cynthia Carter, Linda Steiner, \& Lisa McLaughlin (395-405). London: Routledge.

- 2016. "Sports, Sexism and the Law: Some Contextual History." Institute for Culture and Society, Western Sydney University. www.westernsydney.edu.au/ics/news/ blog/sports,_sexism_and_the_law_some_contextual_history

Rubin, Gayle. 1975. "The Traffic in Women: Notes on the 'Political Economy' of Sex." In Toward an Anthropology of Women, edited by Rayna R. Reiter (157-210). New York: Monthly Review Press.

Ruby, Jennifer. 2016. "Eddie Izzard Gives Inspiring Speech on Being Transgender as $\mathrm{He}$ Takes a Break from Marathon to Get His Nails Done." Evening Standard (March 15). www.standard.co.uk/showbiz/celebrity-news/eddie-izzard-gives-inspiring-speech-onbeing-transgender-as-he-takes-a-break-from-marathon-to-get-a3204136.html

Rudolph, Frederick. 1962. The American College and University: A History. Athens: University of Georgia Press.

Russel, Frank. 2018. "Greatness, Hidden Beneath the Surface." The Bachelor 110.19: 7. www.wabash.edu/bachelor/issues/2018s/Final\%20Pages\%2003-16-2018.pdf.

Russell, Camisha. 2019. “'On Black Women, 'In Defense of Transracialism,' and Imperial Harm.” Hypatia 34.2: 176-194.

Rzegocki, Arkady. 2019. "Polish Constitutional Traditions." In The Concept of Constitution in the History of Political Thought, edited by Arkadiusz Górnisiewicz and Bogdan Szlachta (113-122). Warsaw/Berlin: De Gruyter.

Safer, Joshua D., Eli Coleman, Jamie Feldman, Robert Garofalo, Wylie Hembree, Asa Radiz, \& Jae Sevelius. 2016. "Barriers to Heath Care for Transgender Individuals." Current Opinions in Endocrinology, Diabetes, \& Obesity 23.2: 168-171. 
Sagal, Paul T. 1973. "Implicit Definition.” Monist 57.3: 443-450.

Samek, Alyssa A. 2015. "Pivoting Between Identity Politics and Coalitional Relationships: Lesbian-Feminist Resistance to Woman-Identified Woman." Women's Studies in Communication 38.4: 393-420.

Sandbakk, Øyvind, Guro Strøm Solli, \& Hans-Christer Holmberg. 2018. "Sex Differences in World-Record Performance: The Influence of Sport Discipline and Competition Duration." International Journal of Sports Physiology and Performance 13.1: 2-8.

San Francisco Human Rights Commission. 2003. "Compliance Guidelines to Prohibit Gender Identity Discrimination.” https://sf-hrc.org/compliance-guidelines-prohibitgender-identity-discrimination

Santora, Tara. 2020. "Ignored by Doctors, Transgender People Turn to DIY Treatments." (June 29). Undark.org. https://undark.org/2020/06/29/transgender-diy-treatments/

Saul, Jennifer Mather. 2012. "Politically Significant Terms and Philosophy of Language: Methodological Issues." In Out From the Shadows: Analytical Feminist Contributions to Traditional Philosophy, edited by Sharon L. Crasnow \& Anita M. Superson (195-216). New York: Oxford University Press.

Sawyer, Wendy. 2018. “The Gender Divide: Tracking Women's State Prison Growth.” PrisonPolicy.org (March 24). www.prisonpolicy.org/reports/women_overtime.html

Sawyer, Wendy, \& Peter Wagner. 2020. "Mass Incarceration: The Whole Pie 2020.” PrisonPolicy.org (March 24). www.prisonpolicy.org/reports/pie2020.html

Sax, Leonard. 2002. "How Common is Intersex? A Response to Anne Fausto-Sterling." Journal of Sex Research 39.3: 174-178.

SB-132. 2020. Senate Bill No. 132, Introduced by Senator Wiener. http://leginfo.legisla ture.ca.gov/faces/billTextClient.xhtml?bill_id=201920200SB132

Schaefer, Agnes Gereben, Radha Iyengar, Srikanth Kadiyala, Jennifer Kavanagh, Charles C. Engel, Kayla M. Williams, \& Amii M. Kress. 2016. Assessing the Implications of Allowing Transgender Personnel to Serve Openly. Santa Monica: Rand Corporation.

Scheim, Ayden I., Max Nicolai Appenroth, S. Wilson Beckham, Zil Goldstein, Mauro Cabral Grinspan, JoAnne G. Keatley, \& Asa Radix. 2019. "Transgender HIV Research: Nothing about Us Without Us.” The Lancet (August 19). www.thelancet.com/journals/ lanhiv/article/PIIS2352-3018(19)30269-3/fulltext

Scheman, Naomi. 1997. "Queering the Center by Centering the Queer: Reflections on Transsexuals and Secular Jews." In Feminists Rethink the Self, edited by Diana Tietjens Meyers (124-162). Boulder, CO: Westview Press.

—. 2016. "Looking Back on 'Queering the Center'." Transgender Studies Quarterly 3.1-2: 212-219.

- 2018. "Not in My Name: Jewishness, Womanhood, and the Ethics of Identification." Journal of Jewish Identities 11.1: 179-190.

Schiappa, Edward. 2003. Defining Reality: Definitions and the Politics of Meaning. Carbondale: Southern Illinois University Press.

- 2008. Beyond Representational Correctness: Rethinking Criticism of Popular Media. Albany: SUNY Press.

. 2012a. "Defining Marriage in California: An Analysis of Public \& Technical Argument." Argumentation \& Advocacy 48.4: 213-227.

.2012b. "Evolving Argument Strategies in the Debate over Same-Sex Marriage." In Proceedings of the 4th Tokyo Conference on Argumentation: The Role of Argumentation in Society (93-100). Tokyo: Japan Debate Association.

— 2019. "Will \& Grace." In The State of SIE: Mapping the Landscape of Social Impact Entertainment, edited by Peter Bisanz (96-99). Los Angeles, CA: UCLA. https://thestate ofsie.com/edward-schiappa-will-grace-contact-hypothesis-psychological-theory 
. 2021. "My Attempts at LGBT Advocacy \& Research: A Brief Retrospective." SchiappaSays (June 12). http://eschiappa.blogspot.com

Schiappa, Edward, Peter B. Gregg, \& Dean E. Hewes. 2005. "The Parasocial Contact Hypothesis." Communication Monographs 72.1: 95-118.

- 2006. "Can One TV Show Make a Difference? Will \& Grace and the Parasocial Contact Hypothesis." Journal of Homosexuality 51.4: 15-37.

Schmidt, Samantha, Emily Wax-Thibodeaux, \& Moriah Balingit. 2021. "Biden Calls for LGBTQ Protections in Day 1 Executive Order, Angering Conservatives." The Washington Post (January 21). www.washingtonpost.com/dc-md-va/2021/01/21/ biden-executive-order-transgender-lgbtq/

Schultz, Jaime. 2014. Qualifying Times: Points of Change in U.S. Women's Sport. Urbana: University of Illinois Press.

Schultz, Ken. 2021. "Girls are Caught in between Cis Athlete Advocates and Trans Inclusion Activists." Outsports.com (April 5). www.outsports.com/2021/4/5/22324504/cisgendergirls-women-athletes-trans-inclusion-activists-womens-sports-policy-working-group

Schwartzapfel, Beth. 2020. "What's In a Name?” The Marshall Project (January 27). https:// www.themarshallproject.org/2020/01/27/what-s-in-a-name

Scott, D. Travers. 2020. Gay Men and Feminist Women in the Fight for Equality: "What Did You Do During the Second Wave, Daddy?" Bern: Peter Lang.

Sealey, Kris. 2018. "Transracialism and White Allyship: A Response to Rebecca Tuvel." Philosophy Today 62.1: 21-29.

Searle, John R. 1995. The Construction of Social Reality. New York: Free Press.

Secretary of Defense. 2016. "Memorandum for Secretaries of the Military Departments. DTM 16-005.” (June 30).

Seelman, K. L. 2016. "Transgender Adults' Access to College Bathrooms and Housing and the Relationship to Suicidality." Journal of Homosexuality 63.10: 1378-1399.

Seelman, K. L., N. E. Walls, K. Costello, K. Steffens, K. Inselman, H. Montague-Asp, \& Colorado Trans on Campus Coalition. 2012. Invisibilities, Uncertainties, and Unexpected Surprises: The Experiences of Transgender and Gender Non-conforming Students, Staff, and Faculty at Colleges and Universities in Colorado. Denver, CO: Author. https://portfolio. du.edu/ewalls2

Serano, Julia. 2007. Whipping Girl: A Transsexual Woman on Sexism and the Scapegoating of Femininity. New York: Seal Press.

Shane, Leo. 2021. "VA to Offer Gender Surgery to Transgender Vets for the First Time." Military Times (June 19). www.militarytimes.com/veterans/2021/06/19/ va-to-offer-gender-surgery-to-transgender-vets-for-the-first-time/

Sharrow, Elizabeth A. 2020. "How High School Sports became the Latest Battleground over Transgender Rights." TheConversation.com (December 22). https://theconversation.com/ how-high-school-sports-became-the-latest-battleground-over-transgender-rights-151361

Sheer, Josselyn. 2020. "A Legal Analysis: The Transgender Bathroom Debate." Journal of Sociology \& Social Welfare 47.1: 53-72.

Shrier, Abigail. 2021. "Male Inmates in Women's Prisons." Wall Street Journal (May 31). www.wsj.com/articles/male-inmates-in-womens-prisons-11622474215

Simko-Bednarski, Evan. 2020. "New York City Reaches \$5.9 Million Settlement in Death of Transgender Woman Who Couldn't Pay $\$ 500$ Bail.” CNN.com (August 31). www. cnn.com/2020/08/31/us/transgender-woman-rikers-island-death-settlement-trnd/ index.html

Simmons-Duffin, Selena. 2020. "TransgenderHealthProtectionsReversedBy TrumpAdministration.”NPR.org(June12).www.npr.org/sections/health-shots/2020/06/12/868073068/ transgender-health-protections-reversed-by-trump-administration 
SJU. 2020. "Mission, Vision, Strategic Directions and Values." www.csbsju.edu/about/ saint-johns-university/sju-mission

SJU Trustees. 2016. “Transgender Students” (Human Rights Policy). www.csbsju.edu/ human-rights/policies-violations-forms/transgender-students

Skelly, Shawn. 2020. “Transphobia and NationalSecurity."CenterforStrategic and International Studies (October 29). https://defense360.csis.org/transphobia-and-national-security/

Skirstad, Berit. 2000. "Gender Verification in Competitive Sport." In Values in Sport: Elitism, Nationalism, Gender Equality, and the Scientific Manufacturing of Winners, edited by Claudio M. Tamburrini and Torbjörn Tännsjö (116-122). New York: Taylor \& Francis.

Sloop, John M. 2004. Disciplining Gender: Rhetorics of Sex Identity in Contemporary U.S. Culture. Amherst: University of Massachusetts Press.

Smith, Adam. 2019. "Opposing Ban on Transgender Members of Armed Forces." Congressional Record (March 28). H2891-H2899.

Smith, Reiss. 2019. "Nine Out of 10 Trans Inmates are in the Wrong Prison for their Gender.” PinkNews (November 29). www.pinknews.co.uk/2019/11/29/transgendertrans-prison-england-wales/

Smith, Sharon G., Xinjian Zhang, Kathleen C. Basile, Melissa T. Merrick, Jing Wang, Marcie-Jo Kresnow, \& Jieru Chen. 2018. The National Intimate Partner and Sexual Violence Survey (NISVS): 2015 Data Brief-Updated Release. Atlanta, GA: National Center for Injury Prevention and Control, Centers for Disease Control and Prevention.

Smith College. 2020. "Gender Identity \& Expression." www.smith.edu/about-smith/ equity-inclusion/gender-identity-expression

Smythe, Viv. 2018. "I'm Credited with Having Coined the Word 'Terf.' Here's How it Happened." The Guardian (November 28). www.theguardian.com/commentisfree/2018/ nov/29/im-credited-with-having-coined-the-acronym-terf-heres-how-it-happened

Solnit, Rebecca. 2020. "Trans Women Pose No Threat to Cis Women, But We Pose a Threat to Them if We Make Them Outcasts." The Guardian (August 10). www.theguard ian.com/commentisfree/2020/aug/10/trans-rights-feminist-letter-rebecca-solnit

Sosin, Kate. 2020. "Transgender Women are Nearly Always Incarcerated with Men. That's Putting Many in Danger." NBCNews.com (February 26). www.nbcnews.com/feature/nbc-out/ transgender-women-are-nearly-always-incarcerated-men-s-putting-many-n1141681

Southern Baptist Convention. 2014. “On Transgender Identity.” www.sbc.net/resolutions/ 2250/on-transgender-identity

Spade, Dean. 2014. "Why Do Trans Men + GNC People Belong at Women's Colleges?" YouTube.com (May 13). www.youtube.com/watch? $=\mathrm{m} 4$ oxH6WEmfQ

- 2015. Normal Life: Administrative Violence, Critical Trans Politics, and the Limits of Law, rev. ed. Durham, NC: Duke University Press.

Stack, Liam. 2017. "Boy Scouts apologize over President Trump's remarks at Jamboree." The New York Times (July 27). https://www.nytimes.com/2017/07/27/us/boy-scoutstrump-apology.html

Stahl, Aviva. 2018. "Christian Group that Pushed 'Bathroom Bills' is Taking Anti-Transgender Fight to Prisons." The Intercept (January 18). https://theintercept.com/2018/01/18/ transgender-woman-prison-prea/.

Stanford 125. 2016. "Women's Intercollegiate Basketball Debuted in 1896 with a Fierce Stanford vs. Cal Contest." https://125.stanford.edu/the-first-game/

Stanley, Eric A. 2014. "Gender Self-Determination." Transgender Studies Quarterly 1.1-2: 89-91.

Stanley, Eric A., Johanna Burton, \& Reinna Gossett, eds. 2017. Trap Door: Trans Cultural Production and the Politics of Visibility. Cambridge: MIT Press. 
Stanton, Elizabeth Cady. 1848. "Declaration of Sentiments." https://sourcebooks.fordham. $\mathrm{edu} / \mathrm{mod} / \mathrm{senecafalls.asp}$

Starr, Barbara, \& Caroline Kelly. 2020. "US Navy Grants First Waiver for Transgender Service Member to Serve UNDER their Preferred Gender." CNN.com. (May 15). www. cnn.com/2020/05/14/politics/navy-first-waiver-transgender/index.html

Statement. 2003. "Statement of the Stockholm Consensus on Sex Reassignment in Sports." https://stillmed.olympic.org/Documents/Reports/EN/en_report_905.pdf

Stein, Daisy, \& Natalie Green. 2019. “Twenty-Five Terrible Ways Trump Has Undermined Reproductive Health." www.plannedparenthoodaction.org/blog/twenty-five-terriblethings-trump-has-done-on-reproductive-health

Stein, Edward. 1999. The Mismeasure of Desire: The Science, Theory, and Ethics of Sexual Orientation. Oxford: Oxford University Press.

Stephen, Lynn. 2002. "Sexualities and Genders in Zapotec Oaxaca." Latin American Perspectives 29.2: 41-59.

Stephens College. 2018. "Frequently Asked Questions: Stephens College Admissions and Enrollment Policy." http://komu.s3.amazonaws.com/files/faq_admissions_policy_(1). pdf

Sterling, Joe, Eliot C. McLaughlin, \& Joshua Berlinger. 2016. "North Carolina, U.S., Square Off over Transgender Rights." CNN.com (May 10). www.cnn.com/2016/05/09/poli tics/north-carolina-hb2-justice-department-deadline/index.html

Stevenson, Betsey. 2010. "Beyond the Classroom: Using Title IX to Measure the Return to High School Sports." Review of Economics and Statistics 92.2: 284-301.

Stimpert, Larry. 2019. [Statement of the President] The Hampden-Sydney Tiger XCIV.16 (November 14): 6.

2020. Phone interview with the author. May 12.

Stock, Kathleen. 2018. "Changing the Concept of 'Woman' Will Cause Unintended Harms." The Economist (July 6). www.economist.com/open-future/2018/07/06/ changing-the-concept-of-woman-will-cause-unintended-harms

Stoff, Laurie. 2006. They Fought for the Motherland: Russia's Women Soldiers in World War I and the Revolution. Lawrence: University Press of Kansas.

Stolberg, Sheryl Gay. 2017. "Loophole in Rules on Transgender Troops Denies 2 Their Commissions." New York Times (May 26). www.nytimes.com/2017/05/26/us/loopholein-rules-on-transgender-troops-denies-2-their-commissions.html

Stoljar, Natalie. 1995. "Essence, Identity, and the Concept of Woman." Philosophical Topics 23: 261-293.

. 2011. "Different Women. Gender and the Realism-Nominalism Debate." In Feminist Metaphysics: Explorations in the Ontology of Sex, Gender and the Self, edited by Charlotte Witt (27-46). New York: Springer.

Stoller, Robert J. 1964. "A Contribution to the Study of Gender Identity." International Journal of Psychoanalysis 45: 220-226.

Stones, Rebecca J. 2017. "Which Gender is More Concerned About Transgender Women in Female Bathrooms?" Gender Issues 34: 275-291.

Strangio, Chase. 2014. "Dee's Triumph: One of the Most Important Trans Victories You Never Heard Of." American Civil Liberties Union (June 6). www.aclu.org/blog/smart-justice/ mass-incarceration/dees-triumph-one-most-important-trans-victories-you-never

2018. "The Biological Sex Dog-Whistle and Another Unconstitutional Assault on Trans Existence." Into (May 16). www.intomore.com/impact/the-biological-sexdogwhistle-and-another-unconstitutional-assault-on-trans-existence/ 
Strangio, Chase, \& Amy Fettig. 2018. "The Trump Administration is Attacking Trans People in Federal Prison." ACLU (May 25). www.aclu.org/blog/lgbt-rights/ criminal-justice-reform-lgbt-people/trump-administration-attacking-trans-people

Stroumsa, Daphna, Elizabeth F. S. Roberts, Hadrian Kinnear, \& Lisa H. Harris. 2019. "The Power and Limits of Classification: 32-year-old Man with Abdominal Pain." New England Journal of Medicine 380.20: 1885-1888.

Stryker, Susan. 2017. Transgender History: The Roots of Today's Revolution, rev. ed. New York: Seal Press.

Stryker, Susan, \& Talia M. Bettcher. 2016. "Introduction: Trans/Feminisms.” Transgender Studies Quarterly 3.2: 5-14.

Sufrin, Carolyn. 2017. Jailcare: Finding the Safety Net for Women Behind Bars. Berkeley: University of California Press.

Sumner, Jennifer, \& Valerie Jenness. 2014. "Gender Integration in Sex-Segregated U.S. Prisons: The Paradox of Transgender Correctional Policy.” In Handbook of LGBT Communities, Crime, and Justice, edited by Dana Peterson \& Vanessa R. Panfil (229-259). New York: Springer.

Sutherland, Michelle A. B., Richard J. Wassersug, \& Karen R. Rosenberg. 2017. "From Transsexuals to Transhumans in Elite Athletics: The Implications of Osteology (and other issues) in Leveling the Playing Field." In Transgender Athletes in Competitive Sports, edited by Eric Anderson and Ann Travers (173-193). London: Routledge.

Swartz, Anna K. 2018. “'Are You Really Trans?': The Problem with Trans Brain Science.” IJFAB Blog (July 9). www.ijfab.org/blog/2018/07/3694/

Swartz, Natalie. 2017. "Coming Out While Staying In.” Harvard Political Review (May 26). https://harvardpolitics.com/united-states/coming-out-while-staying-in-how-transgen der-students-are-pushing-girls-schools-to-examine-gender-policies/

Tadlock, Barry L. 2014. "Issue Framing and Transgender Politics." In Transgender Rights and Politics: Groups, Issue Framing, \& Policy Adoption, edited by Jami K. Taylor \& Donald P. Haider-Markel (25-48). Ann Arbor: University of Michigan Press.

Tadlock, Barry L., Andrew R. Flores, Donald Haider-Markel, Daniel C. Lewis, Patrick R. Miller, \& Jami K. Taylor. 2017. "Testing Contact Theory and Attitudes on Transgender Rights.” Public Opinion Quarterly 81.4: 956-972.

Taylor, Jami K. 2021. Interview via videochat and email, June 14-15.

Taylor, Jami K., Daniel C. Lewis, \& Donald Haider-Markel. 2018. The Remarkable Rise of Transgender Rights. Ann Arbor: University of Michigan Press.

Taylor, Jami K., Daniel C. Lewis, Donald Haider-Markel, Andrew R. Flores, Patrick R. Miller, and Barry L. Tadlock. 2018a. "The Factors Underlying Public Opinion about Transgender Rights." In The Remarkable Rise of Transgender Rights, edited by Jami K. Taylor, Daniel C. Lewis, and Donald Haider-Markel (87-103). Ann Arbor, MI: University of Michigan Press.

- 2018b. "Public Opinion about Transgender People and Policies." In The Remarkable Rise of Transgender Rights, edited by Jami K. Taylor, Daniel C. Lewis, and Donald HaiderMarkel (61-86). Ann Arbor: University of Michigan Press.

Taylor, Margaret E., \& Jean Glasscock. 1975. "The Founders and the Early Presidents." In Wellesley College 1875-1975: A Century of Women, edited by Jean Glasscock (1-59). Wellesley, MA: Wellesley College.

Thibault, Valérie, Marion Guillaume, Geoffroy Berthelot, Nour El Helou, Karine Schaal, Laurent Quinquis, Hala Nassif, Muriel Tafflet, Sylvie Escolano, Olivier Hermine, \& Jean Francois Toussaint. 2010. "Women and Men in Sport Performance: The Gender Gap has not Evolved since 1983." Journal of Sports Science and Medicine 9.2: 214-223. 
Thomas, Rachel, et al. 2019. "Women in the Workplace, 2019." https://womeninthework place.com/

Thompson, Edward H., \& Joseph H. Pleck. 1986. "The Structure of Male Norms.” American Behavioral Scientist 29.5: 531-543.

Thompson, Myron H. 2021. Opinion, Corbitt v. Taylor. Civil Action NO. 2:18cv91-MHT (WO) (M.D. Ala. January 15).

Tobin, Harper Jean. 2016. "Pentagon Lifts Transgender Military Service Ban." National Center for Transgender Equality (June 30). https://transequality.org/blog/pentagon-liftstransgender-military-service-ban

Tolman, Deborah L., \& Michelle V. Porche. 2000. "The Adolescent Femininity Ideology Scale: Development and Validation of a New Measure for Girls." Psychology of Women Quarterly 24.4: 365-376.

Torres, Jada Benn. 2020. "Anthropological Perspectives on Genomic Data, Genetic Ancestry, and Race." Yearbook of Physical Anthropology 171.S70: 74-86.

Totman, Richard. 2003. The Third Sex: Kathoey: Thailand's Ladyboys. London: Souvenir Press.

t philosopher. 2019. "I am Leaving Academic Philosophy because of its Transphobia Problem.” Medium.com (May 30). https://medium.com/@transphilosopher33/i-am-leavingacademic-philosophy-because-of-its-transphobia-problem-bc618aa55712

Travers, Ann. 2018. The Trans Generation: How Trans Kids (And Their Parents) Are Creating a Gender Revolution. New York: New York University Press.

Travison, Thomas G., et al. 2017. "Harmonized Reference Ranges for Circulating Testosterone Levels in Men of Four Cohort Studies in the United States and Europe." Journal of Clinical Endocrinology \& Metabolism 102.4: 1161-1173.

Treadwell, Mattie E. 1954. The Women's Army Corps. Washington, DC: Center of Military History. https://history.army.mil/books/wwii/Wac/index.htm

Trumbach, Randolph. 1994. "London's Sapphists: From Three Sexes to Four Genders in the Making of Modern Culture.” In Third Sex, Third Gender: Beyond Sexual Dimorphism in Culture and History, edited by Gilbert H. Herdt (111-136). New York: Zone.

Trump, Donald J. (@realDonaldTrump) 2017. Series of Three Tweets Beginning “After Consultation with My Generals.” Twitter. (July 26, 2017 8:55-9:08 AM). www.thetrump archive.com

Truss, The Rt. Hon. Elizabeth. 2020. "Written Ministerial Statement: Response to Gender Recognition Act (2004) Consultation.” (September 22). www.gov.uk/government/ speeches/response-to-gender-recognition-act-2004-consultation

Tuvel, Rebecca. 2017. "In Defense of Transraciliam.” Hypatia 32.2: 263-278.

- 2018. "Racial Transitions and Controversual Positions: Reply to Taylor, Gordon, Sealey, Hom, and Botts." Philosophy Today 62.1: 73-88.

- 2021. "Changing Identities: Are Race and Gender Analogous?” Blog of the APA (July 6). https://blog.apaonline.org/2021/07/06/changing-identities-are-race-and-genderanalogous/

Unger, Rhonda Kessler. 1975. Sex-Role Stereotypes Revisited: Psychological Approaches to Women's Studies. New York: Harper \& Row.

UNODC [United Nations Office on Drugs and Crime]. 2018. Global Report on Trafficking in Persons. New York: United Nations.

Ura, Alexa. 2017. “After Months of Controversy, Texas Bathroom Bill Dies Quietly.” The Texas Tribune (August 16). www.texastribune.org/2017/08/16/after-months-controversytexas-bathroom-bill-dies-quiet-death/

U.S. Commission on Civil Rights. 2020. Women in Prison: Seeking Justice Behind Bars. Briefing Report. Washington, DC: U.S. Commission on Civil Rights. 
U.S. Department of Education. 2021. "U.S. Department of Education Confirms Title IX Protects Students from Discrimination Based on Sexual Orientation and Gender Identity." Press Release (June 16). www.ed.gov/news/press-releases/us-departmenteducation-confirms-title-ix-protects-students-discrimination-based-sexual-orientationand-gender-identity

U.S. Justice Department. 2015. "PREA Data Collection Activities, 2015.” https://www.bjs. gov/content/pub/pdf/pdca15.pdf

U.S. National Library of Medicine. 2020. MedlinePlus: Androgen Insensitivity Syndrome. https://medlineplus.gov/genetics/condition/androgen-insensitivity-syndrome/

Utzinger, Mike. 2019. "An Open Letter." The Hampden-Sydney Tiger XCIV.16 (November 14): 7.

Van Dyke, Nella, \& Bryan Amos. 2017. "Social Movement Coalitions: Formation, Longevity, and Success." Sociology Compass 11.7: e12489.

Van Dyke, Nella, \& Holly J. McCammon, eds. 2010. Strategic Alliances: Coalition Building and Social Movements. Minneapolis: University of Minnesota Press

"Vee, See" (pseudonym). 2020. "A First Step.” Medium.com (September 6). https://medium. com/@cvvitolo/a-first-step-da38275071e1 [original post deleted but available on the Internet Archive via the Wayback Machine]

Vescio, Theresa K., \& Nathaniel E. C. Schermerhorn. 2021. "Hegemony Masculinity Predicts 2016 and 2020 Voting and Candidate Evaluations." PNAS [Proceedings of the National Academy of Sciences] 118.2: 1-10.

Vezzali, Loris, Sofia Stathi, Dino Giovannini, Dora Capozza, \& Elena Trifiletti. 2015. "The Greatest Magic of Harry Potter: Reducing Prejudice." Journal of Applied Social Psychology 45.2: 105-121.

Vilain, Eric, John C. Achermann, Erica A. Eugster, Vincent R. Harley, Jean D. Wilson, \& Olaf Hiort. 2007. "We Used to Call Them Hermaphrodites." Genetics in Medicine 9.2: 65-66.

Vilain, Eric, Jonathan Ospina Betancurt, Nereida Bueno-Guerra, \& Maria Jose MartinezPatiño. 2017. "Transgender Athletes in Elite Sport Competitions." In Transgender Athletes in Competitive Sports, edited by Eric Anderson and Ann Travers (156-170). London: Routledge.

Vilain, Eric, \& Maria Jose Martinez-Patiño. 2019. “Science's Place in Shaping Gender-based Policies in Athletics." The Lancet 393: 1504.

Villemez, W., \& J. Touhey. 1977. "A Measure of Individual Differences in Sex Stereotyping and Sex Discrimination: The 'Macho' Scale." Psychological Reports 41: 414-415.

Vincent, Ben, Sonja Erikainen, \& Ruth Pearce, eds. 2020. "TERF Wars: Feminism and the Fight for Transgender futures." Special issue of The Sociological Review 68.4.

Vogel, Lisa. 2013. "Letter to the Community." (April 11). Archived at https://web.archive. org/web/20150330195141/http://michfest.com/letter-to-the-community-4_11_13/

Wabash College. 2020. “Mission and Core Values.”http://bulletin.wabash.edu/about-wabash/ mission-core-values/

Walch, Susan E., Kimberly A. Sinkkanen, Elisabeth M. Swain, Jacquelyn Francisco, Cassi A. Breaux, \& Marie D. Sjoberg. 2012. "Using Intergroup Contact Theory to Reduce Stigma Against Transgender Individuals: Impact of a Transgender Speaker Panel Presentation.” Journal of Applied Social Psychology 42.10: 1559-1816.

Wamsley, Laurel. 2020. "GWU Investigating Whether White Professor Invented Her Black Identity." NPR.org (September 4). www.npr.org/sections/live-updates-protests-forracial-justice/2020/09/04/909617385/gwu-investigating-whether-white-professorinvented-her-black-identity 
Wang, Francis Kai-Hwa. 2015. “Adoptees to Rachel Dolezal: You're Not Transracial.” NBCNews.com (June 17). www.nbcnews.com/news/asian-america/adoptees-rachel-dolezalyoure-not-transracial-n377121

Wang, Timothy, Danielle Solomon, Laura E. Durso, Sarah McBride, \& Sean Cahill. 2016. State Anti-transgender Bathroom Bills Threaten Transgender People's Health and Participation in Public Life. Boston: The Fenway Institute. https://fenwayhealth.org/wp-content/ uploads/2015/12/COM-2485-Transgender-Bathroom-Bill-Brief_v8-pages.pdf

Ward, L. Monique, \& Petal Grower. 2020. "Media and the Development of Gender Role Stereotypes." Annual Review of Developmental Psychology 2: 177-199.

Watson, Ryan J., Christopher W. Wheldon, \& Rebecca M. Puhl. 2020. "Evidence of Diverse Identities in a Large National Sample of Sexual and Gender Minority Adolescents." Journal of Research on Adolescence 30 (supplement 2): 431-442.

Weinberg, Justin. 2015. “Philosophers on Rachel Dolezal.” DailyNous.com (June 15). http:// dailynous.com/2015/06/15/philosophers-on-rachel-dolezal/

Wellesley College. 2020. "Mission and Gender Policy FAQ." www.wellesley.edu/news/ gender-policy/faq

Werner, David. 1998. Nothing About Us Without Us: Developing Innovative Technologies For, By, and With Disabled Persons. Lakeport, CA: Healthwrights.

Wesleyan College. 2020. "Undergraduate Admission.” www.wesleyancollege.edu/registrar/ catalog/Undergraduate-Admission.cfm

West, Isaac. 2014. Transforming Citizenship: Transgender Articulations of the Law. New York: New York University Press.

Westbrook, Laurel, \& Kristen Schilt. 2014. "Doing Gender, Determining Gender: Transgender People, Gender Panics, and the Maintenance pf the Sex/Gender/Sexuality System." Gender \& Society 28.1: 32-57.

Whipp, Brian J., \& Susan A. Ward. 1992. “Will Women Soon Outrun Men?” Nature (January 2), 355: 25 .

Whisnant, Rebecca. 2007. “'A Woman's Body is Like a Foreign Country': Thinking about National and Bodily Sovereignty." In Global Feminist Ethics, edited by DesAutels \& R. Whisnant (155-176). Lanham, MD: Rowman \& Littlefield.

White, John Henry. 1973 [1932]. The History of Phlogiston Theory. New York: AMS Press. Originally published in London by E. Arnold.

Williams, Rachel Anne. 2019. "Being Nonbinary Has Nothing to Do with Looking Nonbinary." Medium (July 20). https://medium.com/@transphilosophr/beingnonbinary-has-nothing-to-do-with-looking-nonbinary-bef864483a43

Wilson, Lt. Col. Anna W. 1944. “The WAC.” Archived at www.lonesentry.com/gi_stories_ booklets/wac/wac.html

Winter, Michael. 2012. "Va. College Punished 4 in Racial Protest over Obama Win." USA Today (December 13). www.usatoday.com/story/news/nation/2012/12/13/ obama-election-virginia-students-racial-slurs/1767429/

Witt, Charlotte. 2011. The Metaphysics of Gender. New York: Oxford University Press.

Wittgenstein, Ludwig. 1958. Philosophical Investigations, 3rd ed. Translated by G. E. M. Anscombe. New York: Palgrave Macmillan.

Wittig, Monique. 1992. The Straight Mind and Other Essays. Boston: Beacon Press.

WoLF (Women's Liberation Front). 2019. "California Legislature Poised to put Men in Women's Prisons under SB 132.” (May 22). http://womensliberationfront.org/ california-legislature-poised-to-put-men-in-womens-prisons-under-sb-132/

Wolff, Michael. 2018. Fire and Fury: Inside the Trump White House. New York: Henry Holt. 
Women's Sports Policy Working Group. 2021a. “About Us.” (April 16). https://womenss portspolicy.org/about-us/\#mission

. 2021b. "The Resolution." https://womenssportspolicy.org/the-resolution/

World Economic Forum. 2021. Global Gender Gap Report 2021. Cologny/Geneva: WEF. http://www3.weforum.org/docs/WEF_GGGR_2021.pdf

World Population Review. 2020. "Incarceration Rates by Country 2020.” https://world populationreview.com/country-rankings/incarceration-rates-by-country

Wu, Katherine J. 2016. "Between the (Gender) Lines: The Science of Transgender Identity." Science in the News (October 25). https://sitn.hms.harvard.edu/flash/2016/genderlines-science-transgender-identity/

Wuest, Joanna W. 2022. Born This Way: Science, Citizenship, and Inequality in the American LGBTQ+ Movement. Chicago: University of Chicago Press.

Yerke, Adam F., \& Valory Mitchell. 2013. “Transgender People in the Military: Don't Ask? Don't Tell? Don't Enlist!” Journal of Homosexuality 60.2: 436-457.

Young, Iris Marion. 1994. "Gender as Seriality: Thinking about Women as a Social Collective." Signs: Journal of Women in Culture and Society 19.3: 713-738.

Yudell, Michael. 2014. Race Unmasked: Biology and Race in the Twentieth Century. New York: Columbia University Press.

Yurcaba, Jo. 2021. "Senate Confirms Shawn Skelly and Gina Ortiz Jones in Historic LGBTQ Firsts." NBCNews.com (July 23). www.nbcnews.com/nbc-out/out-politics-and-policy/ senate-confirms-shawn-skelly-gina-ortiz-jones-historic-lgbtq-firsts-rcna1200

Zaveri, Mihir. 2018. "Oregon Judge Rules in Favor of Transgender Students in Bathroom Case.” New York Times (July 26). www.nytimes.com/2018/07/26/us/transgender-stu dents-restrooms-oregon.html

Zdanowicz, Christina. 2020. "Oxford Dictionaries Change 'Sexist' and Outdated Definitions of the Word 'Woman'." CNN.com (November 10). www.cnn.com/2020/11/09/ world/woman-definition-revised-oxford-dictionary-trnd/index.html

Zeman, Dan. 2020. "Subject-Contextualism and the Meaning of Gender Terms." Journal of Social Ontology 6.1: 69-83. 


\section{INDEX}

academic feminists $15-19,26,43,47$, 51-52, 56, 60, 70, 73, 112, 127, 131, 141, 150-169, 177-178, 189

Alcoff, Linda Martin xii, 156-157

American Medical Association 5, 38

American Psychiatric Association 16, 27

American Psychological Association 20,29

androcentrism 107-109, 126, 132, 134, 153-154, 189

androgen insensitivity 22, 31, 113, 127

Aristotelian definitions 9, 53

bathrooms 3, 47, 72-85, 100, 102-103, 141, 181, 184

Beauvoir, Simone de 154-155, 168

Bem, Sandra L. 17-19, 29-31, 52, 107-109, 154, 189

Bettcher, Talia Mae xiii, 161-164

Biden, Joseph (and Biden administration) 1, 38-39, 47-48, 83, 93, 101, 104, $125-126$

biological determinism/essentialism 1-2,

5, 15-17, 19-20, 22-29, 32, 36-37, 48, 63, 65-66, 70, 77-85, 87-89, 100-103, 107-109, 123-125, 137-138, 141, 148, 154, 156, 158, 160, 162-163, 173-174, 184, 189

birth certificates $59,63,71,79,85$, 122-123, 141-142, 144, 182, 185-186

Bono, Chaz 2, 42, 51

Bostock v. Clayton County 45, 83, 126, 188

Brown v. Topeka Board of Education 49,62

Butler, Judith 26, 160, 160, 167-168, 178 chromosomes $20,22,25,28,31-32,53$, $81,100,116,118,121-122,129,182$, 187

Connell, Raewyn 20, 27

contact theory 39-41, 45-46, 49

Couric, Katie 43, 52

Cox, Laverne 39, 43

cult of domesticity/true womanhood 73 , 84, 156

Currah, Paisley xiii, 13, 49, 150, 185, 188, 190

Davis, Heath Fogg xiii, 84, 126, 128, 180, 185

Defining Reality (Schiappa) 5, 13, 65, 159, 166, 168, 175

definitional gap or rupture $1-2,10,35,53$, $70,83,122-123,141,174,187$

denotative conformity 11, 69, 102, 175, 187

Diagnostic and Statistical Manual of Mental Disorders (DSM) 16, 27, 32, 90-91

Differences in Sex Development (DSD) $16,22-23,31-32,43,48,75,80,106$, 117-121, 137, 146

Dolezal, Rachel 177-178, 189

Don't Ask, Don't Tell policy 89-90, 93, 95, 98, 102

driver's licenses $12,71,182,185-186$

durational criteria 52, 58, 62, 70, 94-95, 118-119, 122-123, 145, 181, 184, 189

Equality Act (UK) 180-181

Equality Act (US) 181, 189

essentialism see biological determinism/ essentialism 
Fausto-Sterling, Anne 19, 23, 28, 31-32, 128

femininity \& feminine norms $15-19,21$, 29-31, 36, 52, 68, 84, 109, 126, 154, 162,177

feminism(s) 15-17, 19, 26, 43, 47, 51-52, 56, 59-60, 70, 73, 112, 127, 131, 141, 150-169, 177-178, 189

first-person authority see self-identification

Geertz, Clifford 80

gender-critical feminists xii, 60, 164-166, 168

gender dysphoria 3, 15-16, 28, 91, 94, 96, 99-100, 116, 122, 139, 142, 144, 165, 181,184

gender polarization 107, 109, 154, 189

Gender Recognition Certificate (GRC) 142, 144, 165, 167, 169

gender variance xiii, $3,21,51$

GLAAD 40, 43

Halberstam, Jack xiii, 39

Haslanger, Sally 155, 158, 161, 168, 189

Helm, Rebecca R. 25, 65, 158

homosexuality xii-iii, 27-28, 30, 32, $36-37,40-42,45-48,69,71,78$, 89-90, 93, 102-104, 134, 155-156, 168 hormones 2, 14, 22, 25, 28, 32, 38, 51, 91, $98,101,108,116-124,127,130,144$, 164-165, 182

Human Rights Campaign 38, 44, 80, 95, 103

intersectionality 156, 160

intersex see Differences in Sex Development (DSD)

Izzard, Eddie 3, 40

James, William 12, 65, 71, 158, 179

Jenner, Caitlyn 2, 39, 41-42, 49, 51, 135, 178

Jennings, Jazz 34, 42-43

Justice Department, U.S. 77, 81, 83, 103, 125-126, 133, 136, 140

Kuhn, Thomas S. 24

levels of Scrutiny 2, 181-186, 188

Mahalik, James R. 19, 29-30, 109

Manning, Chelsea 42

masculinity \& masculine norms 1 , 14-21, 29-31, 36-37, 52, 64, 66-70,
84, 89-91, 104, 109, 126, 162, 172,

176-177, 189

McCloskey, Deirdre Nansen xii, 14, 172

medical care $2-5,10-12,23,26-28,38$, 45, 51, 76, 90, 92-98, 100-103, 116, 122, 137, 143, 174-175, 184, 190

metaphysical accounts 65, 155, 179

Money, John 16, 31

natural attitude 16, 36, 80, 175

NCAA 81, 111, 122-124, 161

neuroscience and gender 28, 32

nominalism 52, 157, 174, 184

nonbinary $3,21,38,47,51-53,57,60$, $123,174,184$

"nothing about us without us" xii, 187

Oakley, Ann 17

Obama, Barack (and Obama administration) xiii, $38,46,62,82-83$, 93, 95-104, 137

Parasocial Contact Hypothesis 40-44, 49 prototypical exemplar 2-3, 9, 23, 51, 175 public/private spheres $20,47,55-56$, 73-82, 84, 164-165, 179

Richards, Renée 2, 52, 91, 115-117, 124, 128

Rorty, Richard 85, 166, 176

Scheman, Naomi 163, 166-167, 177

science/scientific definitions 22-30, 32, 65, 74, 119-121, 126, 153, 178, 189

self-identification $1-3,32,48,52,57-59$, 61-62, 66-67, 69, 77, 83, 84, 119, 123, 125-126, 138, 140-141, 148, 156, 159, 163, 166-167, 172, 174, 177-181, 184-185, 187, 189

Spade, Dean xiii, 59, 187

$S R Y$ (sex determining region $\mathrm{Y}$ ) gene 22, 25

Stoller, Robert 16, 31

Stryker, Susan xiii, 1, 31, 49, 164

suicide 37, 76-77, 147

Supreme Court, U.S. 27, 38, 45, 62-63, $83,85,100,126,136,182-184$, 188-189

surgery $2-3,14,27,38,51,59,85,90-91$, 94, 99, 101, 104, 116-118, 123-124, 127, 143-145, 162-165, 175, 182, 185-186

TERF (Trans-exclusionary radical feminists) see gender-critical feminists 
third gender 20-21, 31

Title IX 60, 77, 81-83, 103, 110-115, 125-128

transgender umbrella $3-5$

transgender voices $14,34,54,72,86,106$, 130, 150, 172, 188

transracialism 177-180, 189

Trump, Donald (and Trump administration) xii-xiii, 1, 23, 38, 46-47, 79, 83, 86, 93, 95-103, 125, 138-139, 182,189
United Kingdom 92, 141-148, 164-168, 180-181

Vilain, Eric 23, 28, 31, 118, 127, 129

World Health Organization 20, 29

$\mathrm{X}$ counts as $\mathrm{Y}$ in context $\mathrm{C} 11-12,24$, $57-59,66,69,75,77,79,87-88,94$, 102, 138-140, 143, 145, 147, 159, 166, 173-176, 181-182, 186 


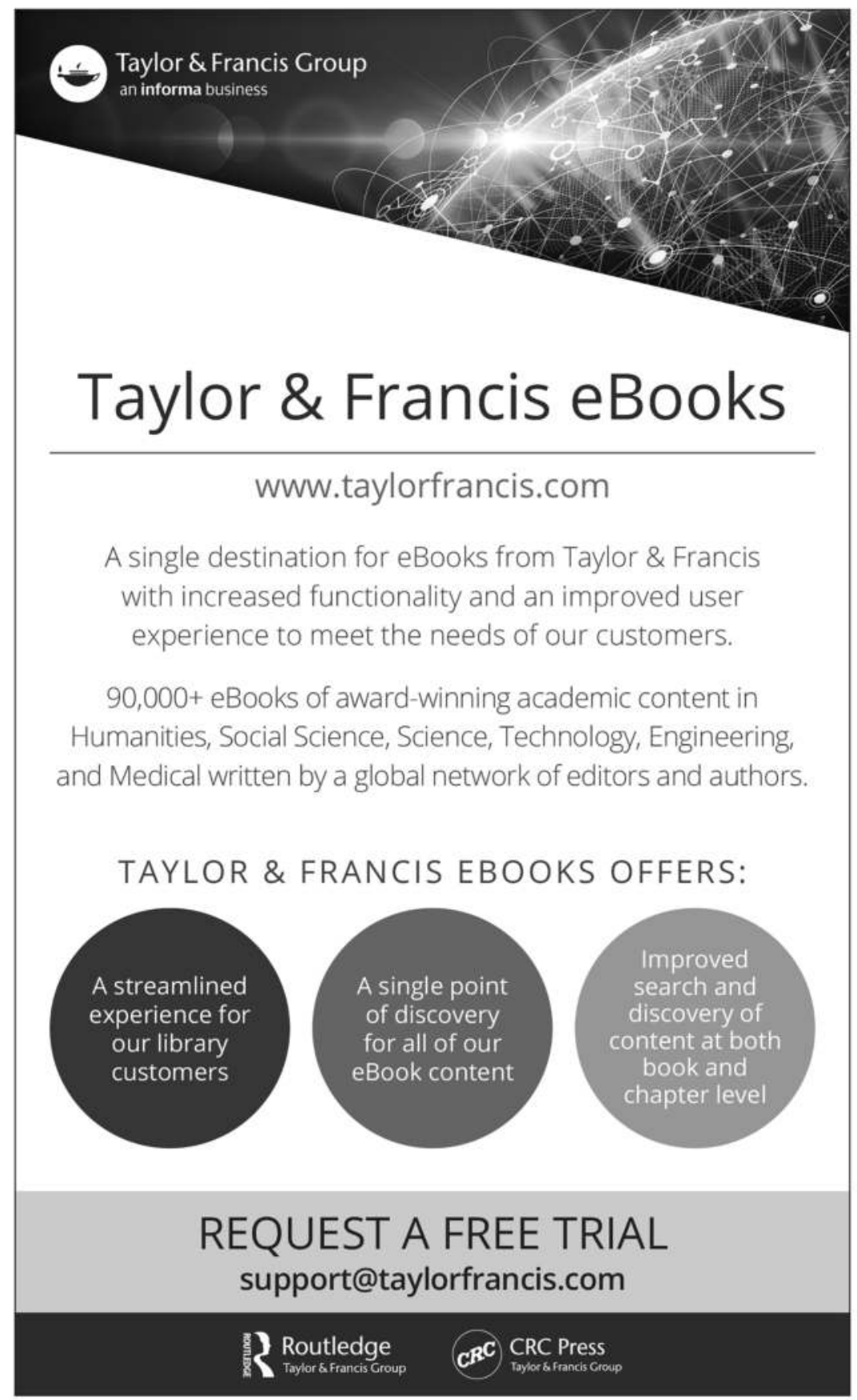

